Eduardo Rodrigues Capocchi

Avaliações em larga escala e políticas de responsabilização na educação: evidências de implicações indesejadas no Brasil

São Paulo 

Eduardo Rodrigues Capocchi

\title{
Avaliações em larga escala e políticas de responsabilização na educação: evidências de implicações indesejadas no Brasil
}

\author{
Dissertação apresentada à Banca Examina- \\ dora da Faculdade de Educação da Universi- \\ dade de São Paulo (FE-USP), como exigência \\ parcial para obtenção do título de mestre na \\ área de Educação.
}

\author{
Universidade do São Paulo - USP \\ Faculdade de Educação \\ Programa de Pós-Graduação
}

Orientadora: $\operatorname{Prof}^{\mathrm{a}}$. Dr ${ }^{\mathrm{a}}$. Adriana Bauer

São Paulo 
AUTORIZO A REPRODUÇÃO E DIVULGAÇÃO TOTAL OU PARCIAL DESTE TRABALHO, POR QUALQUER MEIO CONVENCIONAL OU ELETRÔNICO, PARA FINS DE ESTUDO E PESQUISA, DESDE QUE CITADA A FONTE.

Catalogação na Publicação

Serviço de Biblioteca e Documentação

Faculdade de Educação da Universidade de São Paulo

Capocchi, Eduardo Rodrigues
C245a
Avaliações em larga escala e políticas de responsabilização na educação:
evidências de implicações indesejadas no Brasil / Eduardo Rodrigues
Capocchi; orientação Adriana Bauer. São Paulo: s.n., 2017.
214 p. ils.; grafs.; tabs.; anexos; apêndice
Dissertação (Mestrado - Programa de Pós-Graduação em
Educação. Área de Concentração: Estado, Sociedade e Educação) -
Faculdade de Educação da Universidade de São Paulo.
1. Prova Brasil 2. Gaming 3. Avaliações Externas
4. Responsabilização 5. Fraudes 6. Exclusão I. Capocchi, Eduardo
Rodrigues, orient.




\title{
Eduardo Rodrigues Capocchi
}

\section{Avaliações em larga escala e políticas de responsabilização na educação: evidências de implicações indesejadas no Brasil}

\begin{abstract}
Dissertação apresentada à Banca Examinadora da Faculdade de Educação da Universidade de São Paulo (FE-USP), como exigência parcial para obtenção do título de mestre na área de Educação.
\end{abstract}

Versão corrigida.

São Paulo, 30 de agosto de 2017

Banca Examinadora
Instituição: FE-USP
Instituição: FEARP-USP

Prof. Dr. Reynaldo Fernandes

Prof $^{\text {a }}$. Dr ${ }^{\text {a }}$. Maria Paula Ferreira Instituição: Fundação SEADE

\begin{tabular}{|c|c|c|c|}
\hline Nome dos Participantes da Banca & Função & Sigla da CPG & Resultado \\
\hline Adriana Bauer & Presidente & FE - USP & APROIADA \\
\hline Reynaldo Fernandes & Titular & FEARP - USP & APROA ADO \\
\hline Maria Paula Ferreira & Titular & Externo & Arrevar \\
\hline
\end{tabular}

Resultado Final: APROVAD

Parecer da Comissão Julgadora *

Eu, Marcelo de Souza Ribeiro___ lavrei a presente ata, que assino juntamente com os(as) Senthores(as) São pauto, aos 30 dias do mês de agosto de 2017.

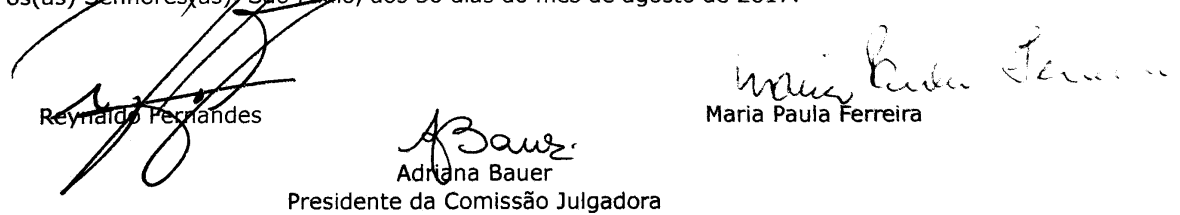

São Paulo 

À Roxana, ao André e à Chiara;

à memória de Raymond Joseph Wilson (1955-2016),

"Keep imagining, keep inventing, stay ingenious!";

à memória de George F. Madaus (1934-2016),

Professor emérito na Lynch School of Education, Boston College. 



\section{Agradecimentos}

À minha esposa, amiga e cúmplice, Roxana, pelo suporte incondicional sem fim. Aos meus filhos, André e Chiara, pelo sentido que dão à curiosidade e à tolerância a ela ligada. À Prof ${ }^{\mathrm{a}}$. Silvia Helena Assumpção Rodrigues (in memoriam) e ao Prof. Dr. José Deodoro Trani Capocchi, pelo sereno incentivo e perene exemplo.

À Prof ${ }^{\mathrm{a}}$. Dra ${ }^{\mathrm{a}}$. Maria Paula Ferreira e ao Prof. Dr. Romualdo Luiz Portela de Oliveira, membros da banca de qualificação, pela fundamental contribuição à formatação deste trabalho.

À Prof ${ }^{\mathrm{a}}$. Dr ${ }^{\mathrm{a}}$. Sandra Maria Zákia Liam de Sousa, uma bússola nos primeiros passos para o entendimento da Avaliação Educacional e seus múltiplos papéis.

À Prof ${ }^{\text {a }}$. Dr ${ }^{\text {a }}$. Maria da Graça Jacintho Setton, pela expansão de horizontes e pela preciosa experiência de trabalhar em grupo.

Ao Prof. Dr. Ocimar Munhoz Alavarse, pelas páginas e portas abertas ao compartilhar sua enciclopédica bibliografia, interpretada sempre com fino humor.

À Prof ${ }^{\mathrm{a}}$. Dr ${ }^{\mathrm{a}}$. Lorena Guadalupe Barberia e ao Prof. Dr. Glauco Peres da Silva, pelo excelente curso de métodos quantitativos em Ciências Sociais, que em muito ajudou na construção deste trabalho.

Aos talentosos e dedicados amigos do Inep, Prof. Dr. Adolfo Samuel de Oliveira, Prof. Dr. João Luiz Horta Neto e Prof. Dr. Alessandro Tatagiba, por sugestões de leitura, insights oportunos e ouvidos interessados.

Aos colegas Ilona Maria Lustosa Becskeházy Ferrão, Erika Souza, Jarbas Belos, Lígia Sanchez, Bruno Pegorari e Renata Mendes Bezerra, pelo generoso compartilhamento de ideias, moeda fortíssima.

Aos amigos André Matsushima Teixeira, Antonio Luís Chinelatto, Diego Ferreira de Almeida, Marcelo Moraes, Roberto Henrique de Souza Marchiori, Roberto Marques Bekman e Wellington Nunes Moraes, cuja paciência em ouvir e críticas ajudaram a dar forma a perguntas interessantes. À Ana Cristina Barral Mariani Passos, pela revisão cuidadosa dos originais.

E, especial e finalmente, à $\operatorname{Prof}^{\mathrm{a}}$. Dr ${ }^{\mathrm{a}}$. Adriana Bauer, orientadora presente, guia dedicada e debatedora firme. Muito obrigado. 

It would be nice if all of the data which sociologists require could be enumerated because then we could run them through IBM machines and draw charts as the economists do. However, not everything that can be counted counts, and not everything that counts can be counted.

William Bruce Cameron (1963, p. 13), grifos nossos. 



\section{Resumo}

Capocchi, E. R. Avaliações em larga escala e políticas de responsabilização na educação: evidências de implicações indesejadas no Brasil. 2017. 214 p.

Dissertação (Mestrado), Faculdade de Educação, Universidade de São Paulo, São Paulo, 2017.

Este estudo analisa os efeitos colaterais indesejados de avaliações externas quando combinadas a políticas de responsabilização (accountability) escolar no Brasil. Estes efeitos colaterais, denominados "peiragênicos" por Madaus e Russell, são previsíveis, indesejados e decorrem da manipulação (gaming) das regras do sistema pelos agentes envolvidos, levando à inflação de escores, vieses nos resultados reportados e interferências indevidas nos processos escolares que se pretendiam monitorar. Este estudo completa uma lacuna na literatura nacional, visando a medir a extensão de dois destes efeitos: a exclusão não aleatória de alunos de baixa proficiência de avaliações e a incidência de fraudes ingênuas, em desacordo aos protocolos de aplicação das avaliações. Duas abordagens são apresentadas. Para estimar as exclusões de alunos de baixa proficiência é proposta uma análise baseada na assimetria de distribuições de proficiência, usando distribuições normais truncadas. Para avaliar a extensão de fraudes ingênuas, definidas como a divulgação de respostas aos alunos testados sem levar em conta a existência de cadernos de itens ou permissividade com "colas" entre alunos, é introduzida uma abordagem baseada na contagem de blocos impróprios maximizadores. Ambos os algoritmos são aplicados à Prova Brasil, de 2013 e 2015. As medições obtidas são confrontadas com variáveis explicativas associadas às pressões da responsabilização, mediante modelos hierárquicos lineares. As pressões consideradas neste trabalho resultam de programas estaduais de bonificação docente e de acompanhamento do Indicador de Desenvolvimento da Educação Básica (Ideb), assim como variações em rankings do Ideb nos municípios. Os resultados indicam que tanto a exclusão de alunos de baixo desempenho quanto fraudes ingênuas ocorrem em associação a estas pressões. O gaming parece mais intenso em unidades da federação com políticas high-stakes, assim como em escolas com Ideb baixo verificado na avaliação anterior. Tendências de variação do Ideb, distâncias deste indicador às metas, ou mudanças em posições no ranking resultam não correlacionados significativamente às pressões. Exclusões medidas são menores em UFs com avaliações próprias para cálculo de bonificação. Um substancial aumento nas indicações de fraudes em 2015, versus 2013, pode estar associado às mudanças na participação mínima de alunos exigida nestas avaliações. Conclui-se que há necessidade dos formuladores de avaliações tomarem cuidados para controlar os dois efeitos estudados.

Palavras-chave: Prova Brasil. Gaming. Avaliações Externas. Responsabilização. Fraudes. Exclusão. 



\section{Abstract}

Capocchi, E. R. Large scale assessments and school accountability: evidence of undesired consequences in Brazil. 2017. 214 p. Dissertação (Mestrado), Faculdade de Educação, Universidade de São Paulo, São Paulo, 2017.

This survey analyzes the undesired side effects of standardized assessments when combined with accountability policies, in public schools in Brazil. These effects, identified as "peiragenics" by Madaus and Russell, are predictable, undesired and unplanned for, and arise from agents engaging in "gaming the system", leading to score inflation, biased reported results and undue interference in the schooling processes under assessment. This survey attempts to fill a void in Brazilian literature regarding the measurement of two side effects: exclusion of low performing students from assessments and undue interference of teachers or testers in the assessment protocols (cheating). To this effect, two analytic approaches are presented. To estimate non-random exclusions of low performing students from testing, a model based on the observed asymmetry of proficiency results, using truncated normal distributions, is proposed. A second model, to assess the extension of naive teacher cheating, defined as attempts to share common answers regardless of differences in test booklets or turning a blind eye to students' copying answers from classmates, counts unexpected appearances of improper score-maximizing blocks, introduced in this study. Both algorithms are applied to Prova Brasil's 2013 and 2015 data sets, a federal assessment of mathematics and reading skills. Measurements are confronted with explanatory variables to test for accountability pressures and gaming-inducing drivers, using two-level hierarchical linear models. The pressures considered in this survey arise from teacher bonus programs adopted by several Brazilian states, performance tracking and rankings of the $I d e b$ indicator (a nationwide metric of the development of elementary and middle-school public education). Results indicate that both selective exclusions of low performing students and naive teacher cheating occur, in patterns associated with pressures. Gaming behavior appears to be more intense in states with high-stakes linked to the assessment, in schools with lower $I d e b$ ratings. Past trends and gaps versus targets in $I d e b$ and changes in local rankings result not significantly correlated with gaming behavior. Lowest exclusion measurements occur in states where alternative assessments are used for bonus payments. A substantial increase in cheating indications in 2015 over 2013 was measured, possibly reflecting increased minimum participation requirements stressing schools to maintain performance through cheating attempts. In conclusion, the need for care in design of assessment policies to control for the two effects measured is made evident.

Keywords: Prova Brasil. Gaming. Student Assessments. Accountability. Cheating. Exclusion. 



\section{Lista de figuras}

Figura 1 - Placa Ideb em Goiás . . . . . . . . . . . . . . . . . . . . 29

Figura 2 - Placa Ideb em Minas Gerais . . . . . . . . . . . . . . . . . 29

Figura 3 - Fac-símile de placa Ideb adotada em Minas Gerais . . . . . . . . . . 29

Figura 4 - Estreitamento curricular verificado no estado de Washington . . . . . . 56

Figura 5 - Mudanças de tempo de instrução - elementary school . . . . . . . . . 58

Figura 6 - Respostas suspeitas em Chicago . . . . . . . . . . . . . 65

Figura 7 - Descontinuidades nas pontuações - Regents Exam - Nova York . . . 66

Figura 8 - Mapa sintético dos efeitos listados em literatura . . . . . . . . . 69

Figura 9 - Taxas de participação na Prova Brasil 2013 e 2015 para $5^{\circ}$ e $9^{\circ}$ ano . . 74

Figura 10 - Distribuições da variável FLAG associada à variação do Ideb . . . . . . 76

Figura 11 - Distribuições da variável FLAG associada à distância à meta Ideb . . . 77

Figura 12 - Distribuições da variável FLAG associada a ranking . . . . . . . . . . . 78

Figura 13 - Taxas de abandono para $5^{\circ}$ e $9^{\circ}$ anos por UF - 2013 . . . . . . . . . 84

Figura 14 - Taxas de mortalidade, Brasil 2013, nas idades do $5^{\circ}$ e $9^{\circ}$ anos EF . . . 85

Figura 15 - Movimentos e ausências na Prova Brasil - conceitual . . . . . . . . . 87

Figura 16 - Ausências aleatórias e não aleatórias na distribuição de proficiências . . 88

Figura 17 - Simulações de truncamentos à esquerda . . . . . . . . . . . . . . . . . 90

Figura 18 - Exemplo de gráfico diagnóstico de normalidade . . . . . . . . . . . . 92

Figura 19 - Exemplo de histograma de proficiências com baixa exclusão . . . . . . 93

Figura 20 - Exemplo de histograma de proficiências com alta exclusão . . . . . . . 93

Figura 21 - Decomposição de ausências na Prova Brasil - conceitual . . . . . . . . 97

Figura 22 - Exemplos de regressões para estimar ausências aleatórias . . . . . . . . 98

Figura 23 - Exemplo de fraude docente "ingênua" em The Simpsons . . . . . . . . 102

Figura 24 - Correlações na proficiência com uso de blocos próprios ou impróprios . 105

Figura 25 - Exemplo de blocos maximizadores . . . . . . . . . . . . 106

Figura 26 - Blocos maximizadores por blocos próprios - Língua Portuguesa . . . . 107

Figura 27 - Blocos maximizadores por blocos próprios - Matemática . . . . . . . 108

Figura 28 - Exemplo distribuição de p-valores indicativos de fraudes . . . . . . . . 109

Figura 29 - Exemplo distribuição acumulada de p-valores indicativos de fraudes . . 110

Figura 30 - Indicações de fraudes e níveis de confiança - 2013 . . . . . . . . . . . 111

Figura 31 - p-valores acumulados do $\chi^{2}$ Língua Portuguesa . . . . . . . . . . . . . 112

Figura 32 - p-valores acumulados do $\chi^{2}$ Matemática . . . . . . . . . . . . . . 113

Figura 33 - Mapa de alunos considerados nas análises . . . . . . . . . . . 120

Figura 34 - Distribuições de proficiência por Inse, Matemática $5^{\circ}$ ano . . . . . . . . 121

Figura 35 - Indicação de fraudes em função dos níveis de confiança 2013-2015 . . 125 
Figura 36 - Taxas de exclusão por Unidade da Federação . . . . . . . . . . . . . . . 127

Figura 37 - Indicadores de fraudes por UF . . . . . . . . . . . . . . . 128

Figura 38 - Taxas de exclusão por tipo de bonificação estadual . . . . . . . . . . . 130

Figura 39 - Indicadores de fraudes por tipo de bonificação na UF . . . . . . . . . . 131

Figura 40 - Taxas de exclusão por Ideb absoluto anterior . . . . . . . . . . . . . . . 133

Figura 41 - Indicadores de fraudes por Ideb absoluto . . . . . . . . . . . . . . . . 134

Figura 42 - Diretores conhecem seus resultados anteriores? . . . . . . . . . . . . 135

Figura 43 - Taxas de exclusão por NSE . . . . . . . . . . . . . . . . . . 137

Figura 44 - Indicadores de fraudes por NSE . . . . . . . . . . . . . . . . . 138

Figura 45 - Fatores do Ideb - anos iniciais - 2005-2015 . . . . . . . . . . . . . . 140

Figura 46 - Taxas de exclusão por variação do Ideb . . . . . . . . . . . . . . . . . . 141

Figura 47 - Indicadores de fraudes por variação do Ideb . . . . . . . . . . . . . . . 142

Figura 48 - Taxas de exclusão por distância à meta . . . . . . . . . . . . . . . . . . 144

Figura 49 - Indicadores de fraudes por distância à meta Ideb . . . . . . . . . . . 145

Figura 50 - Taxas de exclusão por variação no ranking na rede e município . . . . . 147

Figura 51 - Indicadores de fraudes por variação no ranking na rede e município . . 148

Figura 52 - Taxas de exclusão por reporte ou não do Ideb . . . . . . . . . . . . . . 150

Figura 53 - Indicadores de fraudes por reporte ou não do Ideb . . . . . . . . . . . . 151

Figura 54 - Indicadores de fraudes por rede e localização . . . . . . . . . . . . . . . 152

Figura 55 - Variação dos efeitos indesejados por UF 2013-2015 . . . . . . . . . . . 161

Figura 56 - Inflação de escores causada pela exclusão . . . . . . . . . . . . . . . 165

Figura 57 - Polinômio interpolador e sua capacidade preditiva . . . . . . . . . . . . 204

Figura 58 - Fluxograma da abordagem para análise de exclusões . . . . . . . . . . 206

Figura 59 - Fluxograma da abordagem para análise de fraudes . . . . . . . . . . . 207

Figura 60 - Fontes de dados e organização analítica . . . . . . . . . . . . . . . . 208 


\section{Lista de quadros}

Quadro 1 - Efeitos positivos e negativos . . . . . . . . . . . . . . . . . . . . . .

Quadro 2 - Os princípios de Madaus . . . . . . . . . . . . . 48

Quadro 3 - Consequências indesejadas de avaliações em larga escala atreladas às políticas de responsabilização . . . . . . . . . . . . . . . 50 . . . . . 50

Quadro 4 - A classificação de Koretz de reações à accountability . . . . . . . . . . 52

Quadro 5 - Bonificações docentes por UF . . . . . . . . . . . . . . . 80

Quadro 6 - Objetivos declarados de sistemas de avaliação nas Américas . . . . . 190 



\section{Lista de tabelas}

Tabela 1 - Ausência de dados de Ideb e metas associadas para escolas . . . . . . 79

Tabela 2 - Variáveis associadas à bonificação docente para 2013 . . . . . . . . . 82

Tabela 3 - Inconsistências de registro entre Censos e Provas Brasil . . . . . . . . . 86

Tabela 4 - Composição Cadernos por Blocos no Saeb 2013 . . . . . . . . . . . 103

Tabela 5 - Coincidências de respostas em gabaritos - Prova Brasil 2013 . . . . . 115

Tabela 6 - Entropia dos gabaritos da Prova Brasil . . . . . . . . . . . . . 116

Tabela 7 - Resultados resumidos da exclusão 2013-2015 . . . . . . . . . . . . 123

Tabela 8 - Modelagem hierárquica para exclusão de alunos - $5^{\circ}$ ano . . . . . . 153

Tabela 9 - Modelagem hierárquica para exclusão de alunos - 9 ano . . . . . . 155

Tabela 10 - Modelagem hierárquica de fraudes pelo indicador FRACO - $5^{\circ}$ ano . . 156

Tabela 11 - Modelagem hierárquica de fraudes pelo indicador FRACO - $9^{\circ}$ ano . . 158

Tabela 12 - Oferta de ensino fundamental por rede administrativa em 2015 . . . 158

Tabela 13 - Modelagem hierárquica de fraudes pelo indicador FORTE - $5^{\circ}$ ano . . . 159

Tabela 14 - Modelagem hierárquica de fraudes pelo indicador FORTE - 9ªno . . . 160

Tabela 15 - Pontuação por posse de itens e serviços - Critério Brasil 2013 . . . . . 197

Tabela 16 - Pontuação por instrução do chefe de família - Critério Brasil 2013 . . . 197

Tabela 17 - Nível socioeconômico por pontuação - Critério Brasil 2013 . . . . . . . 198

Tabela 18 - Resumo de variáveis de modelagem para a exclusão . . . . . . . . . . . 213

Tabela 19 - Resumo de variáveis de modelagem para a fraudes . . . . . . . . . . 214 



\section{Lista de abreviaturas e siglas}

\begin{tabular}{|c|c|}
\hline $\mathrm{AIC}$ & Akaike information criterion \\
\hline $\mathrm{BIC}$ & Bayesian information criterion \\
\hline Ana & Avaliação Nacional da Alfabetização \\
\hline ABEP & Associação Brasileira de Empresas de Pesquisa \\
\hline Aneb & Avaliação Nacional do Ensino Básico \\
\hline Anova & Analysis of Variance (análise de variância) \\
\hline Anresc & Avaliação Nacional do Rendimento Escolar \\
\hline BIB & Blocos Incompletos Balanceados \\
\hline DE & Diretoria de Ensino \\
\hline DP & Desvio Padrão \\
\hline $\mathrm{EF}$ & Ensino Fundamental \\
\hline EM & Ensino Médio \\
\hline Enem & Exame Nacional do Ensino Médio \\
\hline ESSA & Every Student Succeeds Act \\
\hline FDP & Função densidade de probabilidade \\
\hline FLAG & Fator ligado ao gaming \\
\hline IBGE & Instituto Brasileiro de Geografia e Estatística \\
\hline ICC & Intra-class correlation (correlação intraclasse) \\
\hline Ideb & Indicador de Desenvolvimento da Educação Básica \\
\hline Inep & Instituto Nacional de Estudos e Pesquisas Educacionais Anísio Teixeira \\
\hline IPCA & Índice Nacional de Preços ao Consumidor Amplo \\
\hline LP & Língua Portuguesa ou Leitura, disciplina avaliada pelo Saeb \\
\hline $\mathrm{MT}$ & Matemática, disciplina avaliada pelo Saeb \\
\hline MEC & Ministério da Educação \\
\hline MHL & Modelo hierárquico linear \\
\hline NCLB & No Child Left Behind \\
\hline NSE & Nível Socioeconômico \\
\hline PAR & Plano de Ações Articuladas \\
\hline PIP & Programa de Intervenção Pedagógica \\
\hline PDF & Portable Document Format \\
\hline PNG & Portable Network Graphics \\
\hline PNE & Plano Nacional de Educação \\
\hline $\mathrm{Q}-\mathrm{Q}$ & Gráfico Quantil-Quantil \\
\hline SASS & Schools and Staffing Survey \\
\hline Saeb & Sistema de Avaliação da Educação Básica \\
\hline Saresp & Sistema de Avaliação de Rendimento Escolar do Estado de São Paulo \\
\hline $\mathrm{SEE} / \mathrm{SP}$ & Secretaria Estadual de Educação de São Paulo \\
\hline SEDUC/GO & Secretaria de Estado de Educação de Goiás \\
\hline $\mathrm{TCT}$ & Teoria Clássica de Testes \\
\hline TRI & Teoria de Resposta ao Item \\
\hline UF & Unidade da Federação \\
\hline URL & Uniform Resource Location \\
\hline
\end{tabular}





\section{Lista de símbolos}

$\alpha$

$\alpha_{\text {crit }}$

$\infty$

Área sob a curva normal proporcional ao número de alunos de baixa proficiência excluídos p-valor crítico associado ao nível de confiança escolhido Número de alunos ausentes na Prova Brasil Área sob a curva normal proporcional ao número de alunos avaliados Coeficientes de regressão auxiliar para estimar $t_{R_{x}}$ Estatística Chi-quadrado para frequência observada de blocos maximizadores impróprios

Número de alunos contados no Censo Escolar

Fração dos alunos em abandono $D$ verificados entre Censo Escolar e Prova Brasil

Número de alunos em abandono no ano letivo sem obter status de aprovado ou reprovado

Número de alunos de baixa proficiência excluídos pelo abandono antes da Prova Brasil

Número de alunos de baixa proficiência excluídos da Prova Brasil

Contagem esperada de cadernos próprios

Número de Euler (2.718...), base dos logaritmos naturais

Limite de erro usado na construção do polinômio interpolador

Número de alunos de baixa proficiência excluídos no dia da Prova Brasil

Número de alunos que teriam feito a Prova Brasil, caso não houvesse exclusão de baixa proficiência

Coeficientes de regressão auxiliar para estimar $t_{R_{D}}+t_{E_{D}}$ Infinito

Integral de uma função $\cdot$ na variável $z$ 
Mediana de uma distribuição de proficiências $p$

Média de uma distribuição de proficiências $p$

Obs

$\Phi$

$\pi$

$P$

$p$

$R_{D}$

$R$

$R_{x}$

$\sigma$

$t_{A}$

$t_{E_{D}}$

$t_{E}$

$t_{E_{x}}$

$t_{R_{D}}$

$t_{R}$

$t_{R_{x}}$

$W^{\prime}$

$W_{p}$

$z_{c}$

Constante pi $(3.1415 \ldots)$

Número de alunos avaliados na Prova Brasil

Número de alunos aleatoriamente ausentes

Taxa de ausências $=\frac{A}{C}$ escolar $=\frac{E_{D}}{C}$ $=\frac{E_{x}}{C}$

Taxa de faltas aleatórias $=\frac{R}{C}$ dade
Número de alunos incluídos por agrupamento de análise de exclusão

Número de tipos de blocos em estruturas BIB do Saeb

Contagem observada de gabaritos maximizadores

Função densidade de distribuição de probabilidade

Proficiência aferida de um aluno na Prova Brasil

Número de alunos aleatoriamente em abandono antes da Prova Brasil

Número de alunos aleatoriamente ausentes no dia da Prova Brasil

Desvio padrão de uma distribuição de proficiências $p$

Taxa de exclusão de alunos de baixa proficiência devido ao abandono

Taxa de exclusão de alunos de baixa proficiência $=\frac{E}{C}$

Taxa de exclusão de alunos de baixa proficiência no dia da Prova Brasil

Taxa de faltas aleatórias devido ao abandono escolar $=\frac{R_{D}}{C}$

Taxa de faltas aleatórias no dia da Prova Brasil $=\frac{R_{x}}{C}$

Estatística de Shapiro-Francia para teste de normalidade

p-valor associado à estatística de Shapiro-Francia para teste de normali-

Abscissa indicativa de onde ocorre o truncamento à esquerda nas distribuições normais de proficiência 


\section{Sumário}

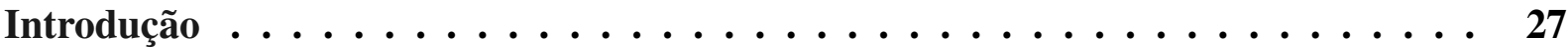

1 A literatura sobre efeitos indesejados . . . . . . . . . . . . . . 39

1.1 A responsabilização educacional . . . . . . . . . . . . . . . . . . . 40

1.2 Os efeitos peiragênicos . . . . . . . . . . . . . . . . . 44

1.3 Os princípios de Madaus . . . . . . . . . . . . . . . . . . . . . 48

1.4 A classificação de Koretz, McCaffrey e Hamilton . . . . . . . . . . . . . . . 52

1.5 Exemplos de reações positivas . . . . . . . . . . . . . . . . 53

1.6 Estudos sobre realocação e alinhamento de recursos . . . . . . . . . . . . . 54

1.6.1 O "ensinar para o teste" e o estreitamento curricular . . . . . . . . . . . 55

1.7 Estudos sobre comportamentos fraudulentos . . . . . . . . . . . . . 60

1.7.1 Estudos sobre manipulações da base de alunos testados . . . . . . . . . 61

1.7.2 Estudos sobre fraudes docentes . . . . . . . . . . . . . . . 64

1.8 Um mapa sintético dos efeitos reportados . . . . . . . . . . . . . . . 68

2 Métodos e abordagens propostos . . . . . . . . . . . . . . 71

2.1 Um histórico recente . . . . . . . . . . . . . . . . . . . . 71

2.2 FLAGs - os Fatores Ligados Ao Gaming . . . . . . . . . . . . . . . . . 74

2.2.1 Fatores FLAG derivados do Ideb . . . . . . . . . . . . . . . . . 75

2.2.2 Fatores FLAG associados à bonificação docente . . . . . . . . . . . . . 79

2.3 A manipulação da base de alunos avaliados . . . . . . . . . . . . . . . . . . 83

2.3.1 Tipos de ausências na Prova Brasil e suas explicações . . . . . . . . . . 83

2.3 .2 Identificação das ausências não aleatórias . . . . . . . . . . . . . . . 87

2.3.3 Limitações da abordagem na identificação de ausências não aleatórias 100

2.4 A análise das fraudes ou colas na Prova Brasil . . . . . . . . . . . . . . . . 100

2.4.1 Descrição da abordagem para fraudes . . . . . . . . . . . . . . . . . . . 102

2.4.2 Limitações da abordagem na identificação de fraudes . . . . . . . . . . 111

2.5 Modelos hierárquicos . . . . . . . . . . . . . . . . 116

2.6 Fontes de dados . . . . . . . . . . . . . . . . . . . . . . . . . . . . . . 118

3 Resultados e suas interpretações . . . . . . . . . . . . . . . 123

3.1 Efeitos medidos por Unidade da Federação . . . . . . . . . . . . . . . . . 126

3.2 Efeitos medidos por tipo de bonificação . . . . . . . . . . . . . . . . 129

3.3 Efeitos medidos por Ideb absoluto . . . . . . . . . . . . . . . . . 132

3.4 Efeitos medidos por nível socioeconômico . . . . . . . . . . . . . . 136

3.5 Efeitos medidos por variação do Ideb . . . . . . . . . . . . . . . . . . . . 139

3.6 Efeitos medidos por distância à meta Ideb . . . . . . . . . . . . . . . . . . 143

3.7 Efeitos medidos pela variação no ranking na rede e município . . . . . . . . 146 
3.8 Efeitos medidos por reporte ou não do Ideb . . . . . . . . . . . . . . . . . . 149

3.9 Indicadores de fraudes por rede e localização . . . . . . . . . . . . . . . 152

3.10 Resultados das modelagens de regressão . . . . . . . . . . . . . . . . 153

3.11 Resultados combinados por Unidade da Federação . . . . . . . . . . . . . . 161

4 Conclusões: implicações para políticas públicas . . . . . . . . . . . 163

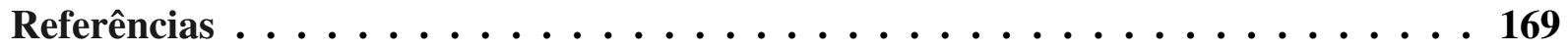

$\begin{array}{ll}\text { Anexos } & 187\end{array}$

ANEXO A Usos de avaliações em países da América . . . . . . . . . . . . 189

ANEXO B Protocolo da aplicação da Prova Brasil . . . . . . . . . . . . . . . . 191

ANEXO C Edital de convocação de aplicadores da Prova Brasil 2015 . . . . . . 195

ANEXO D O Critério Brasil de nível socioeconômico f . . . . . . . . . . 197

Apêndices 199

APÊNDICE A Descrição da abordagem de Jacob e Levitt para análise de fraudes 201

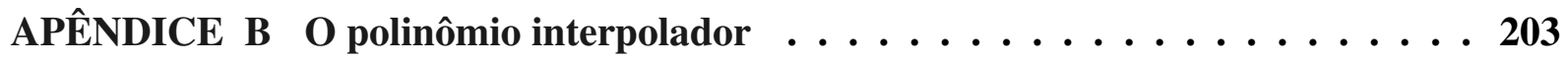

APÊNDICE C Fluxogramas descritivos . . . . . . . . . . . . . 205

APÊNDICE D As tecnologias utilizadas neste estudo . . . . . . . . . . . 209

APÊNDICE E Síntese das variáveis de modelagem linear . . . . . . . . . . 213 


\section{Introdução}

"Avaliações são meios eficazes e eficientes de indicar se um dólar destinado à educação foi bem e adequadamente gasto."

Gary Fenstermacher (1991), tradução nossa.

Avaliações externas em larga escala, usadas para julgar a qualidade do ensino em sistemas de educação, podem ter associados a elas efeitos colaterais que comprometem os processos que pretendem avaliar. Estes efeitos não são decorrentes das avaliações per se, mas resultam da combinação destas avaliações com políticas públicas de incentivos que as usam como subsídio para sanções e premiações. Políticas de responsabilização criadas para promover a melhoria na educação tendem a criar problemas não previstos na sua concepção original. Este trabalho tem como objeto de estudo estas avaliações nas escolas públicas brasileiras e os efeitos colaterais delas decorrentes, quando combinadas com os incentivos de políticas de responsabilização "high-stakes".

Nigel Brooke, no contexto brasileiro, define uma política de responsabilização como

[...] uma tentativa de melhorar os resultados das escolas mediante a criação de consequências para a escola ou para professores individuais, sejam elas materiais ou simbólicas, de acordo com o desempenho dos alunos medido por procedimentos avaliativos estaduais ou municipais (2008, p. 94).

Segundo Rustique-Forrester, as políticas de responsabilização educacional esperam que "quando escolas, redes, professores e alunos são enquadrados como responsáveis por resultados e atingimento de metas, o ensino melhore e alunos tenham expectativas aumentadas" ${ }^{\prime 1}$ (2005, p. 2, tradução nossa).

A responsabilização pode ser atribuída de forma agregada à escola ou à rede, ou, ainda, aplicada de maneira mais granular ao professor, como se vê em alguns estados do Brasil $^{2}$ e em outros países que adotam incentivos docentes, ou mesmo ao aluno. Ela pode ter consequências mais ou menos relevantes aos envolvidos e pode contar com variados modos de medir resultados.

Como exemplos de políticas de responsabilização educacional estão a bonificação docente, em função do atingimento de metas, verificado por meio de avaliações externas, a premiação de alunos ou escolas com destacado desempenho positivo nas avaliações

1 The central assumption of many contemporary accountability schemes is that by holding schools, districts, teachers, and students responsible for results on a range of achievement and performance measures, teaching will improve and expectations for students will rise.

2 Ver Quadro 5 à página 80. 
padronizadas, ou a aplicação de sanções e intervenções em escolas que não tenham atingido metas determinadas, como é o caso em alguns sistemas educacionais norte-americanos. Estas consequências materiais e substantivas caracterizam a política de responsabilização como "sólida" ou de "high-stakes", em contrapartida aos resultados "brandos" ou de "low-stakes". Brooke e Cunha explicam a etimologia do high/low-stakes:

[...] accountability no contexto educacional significa acima de tudo a associação entre resultados de aprendizagem e consequências para o distrito educacional, a escola, os professores ou os alunos. O grau de pressão que a autoridade educacional deseja aplicar ao processo de indução pode ser calibrado de acordo com o tipo ou a seriedade das consequências. Nesse contexto, é comum rotular os níveis de pressão/indução mais altos de high-stakes e os mais baixos de low-stakes, usando a palavra inglesa stakes, que significa "o valor colocado em jogo pelo apostador" (BROOKE; CUNHA, 2011, p. 22).

O pagamento "por desempenho docente", uma política "high-stakes" característica, não é ideia nova. Já fora empregada como política educacional na Inglaterra vitoriana, por 35 anos, como explica Brendan Rapple (1990). Este autor conclui que a experiência foi um fracasso, posto que ganhos educacionais de longo prazo foram preteridos em troca de ganhos financeiros de curto prazo.

Em tempos modernos, modelos diferentes começaram a ser considerados e implantados nos anos 1980-90, nos Estados Unidos e Reino Unido, seguidos por países como Chile, México, Israel, Índia, Quênia, Eslováquia, República Checa, Romênia e Austrália (BAUER, 2010; BROOKE; CUNHA; FALEIROS, 2011; BRUNS et al., 2011; ELLIOTT; HOUT, 2011; FIGLIO; LOEB, 2011; MINARECHOVÁ, 2012).

No caso norte-americano, sistemas estaduais e alguns distritais têm associados a eles high-stakes com consequências negativas fortes. Neste contexto, escolas inteiras podem ter suas atividades encerradas em função do não atingimento de metas estabelecidas. Professores podem ter de se mudar a outras escolas ou cidades. Alunos podem ter suas oportunidades de progressão acadêmica afetadas por seus resultados nas avaliações.

Outros exemplos mais brandos ou com "low-stakes", porém discutivelmente não inócuos, são a publicação de rankings de resultados por escola e a divulgação oficial de resultados e boletins por escola, rede ou município. São exemplos brasileiros de responsabilização branda o Boletim da Escola, do Paraná, o Relatório Pedagógico do Distrito Federal, o Programa de Intervenção Pedagógica (PIP) e Escola Referência em Minas Gerais (BROOKE; CUNHA; FALEIROS, 2011, p. 61-62).

A expectativa presente nas políticas de responsabilização low-stakes ligadas a estas divulgações é a de mobilizar as comunidades, agentes e stakeholders na educação e assim fomentar a melhoria nos resultados, por meio de incentivos não pecuniários e competição e com o menor investimento incremental possível. Com este intuito, por exemplo, a marcação 
de escolas com placas portadoras dos resultados do Indicador de Desenvolvimento da Educação Básica (Ideb) foi adotada em Goiás em 2011 (Figura 1) e Minas Gerais em 2012 (Figura 2).

Figura 1 - Placa Ideb em Goiás

Figura 2 - Placa Ideb em Minas Gerais
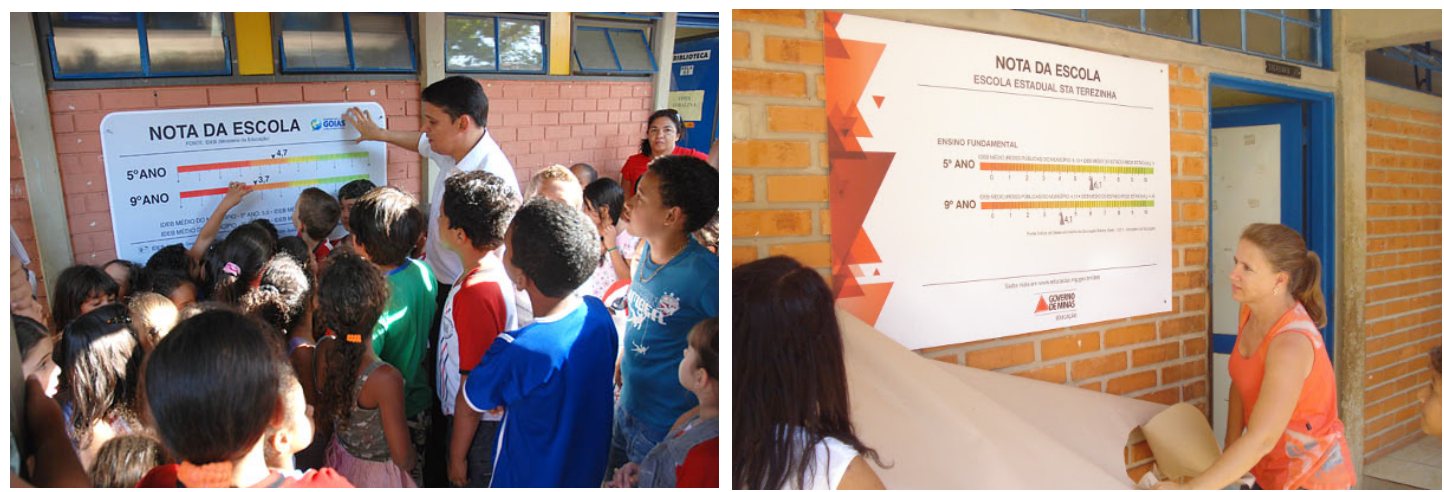

Fonte: GOIÁS. SEDUC (2011).

Fonte: EE SANTA TEREZINHA (2013).

A Figura 3 detalha a informação presente numa placa de Minas Gerais. Nela são apresentados os resultados do Ideb da escola e o Ideb médio do município e do estado, dos $5^{\circ}$ e $9^{\circ}$ anos do Ensino Fundamental (EF). A graduação de cores nas escalas vai de um acusatório vermelho até um distante verde. Solene, a placa recebe os alunos, pais e professores, na escola, por dois anos, até ser atualizada.

Figura 3 - Fac-símile de placa Ideb adotada em Minas Gerais

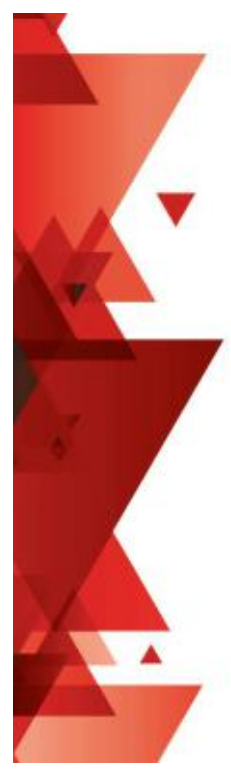

NOTA DA ESCOLA ESCOLA ESTADUAL FREDERICO ZACARIAS

\section{ENSINO FUNDAMENTAL}

$5 \circ$ ANO IDEB MEOIO (FEDES PÚBLICAS) DO MUNICIPIO: 6.10 • IDEB MEDIO DO ESTADO (REDE ESTADUAL): 6

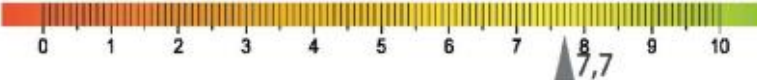

$9 \circ$ ANO IDEB MEDIO (REDES PÜBUCAS) DO MUNICIPIO: 4.20 • IDEB MEDIO DO ESTADO (REDE ESTADUAL): 4.40 ${ }_{0}^{|||||||||||||||||||||||||||||||||||||||||||||||||||||||||||||||||||||||||||||||||||||||||||||||||||||| ~}$

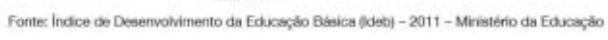

Fonte: MINAS GERAIS. Secretaria de Estado de Educação (2013). 
Nigel Brooke (2006) e Eduardo Andrade (2008) comparam o modelo de responsabilização norte-americano com o brasileiro, qualificando as iniciativas brasileiras federais como brandas quando comparadas às americanas. Nas palavras de Andrade:

\begin{abstract}
Espera-se contar com a pressão da sociedade para que os professores/ diretores das escolas, cujos alunos tenham tido desempenhos insatisfatórios, adotem políticas adequadas para reverter os resultados[...] [...]a política adotada no Brasil corresponderia àquela "sem consequência", a vigente nos report card states ${ }^{3}$ (ANDRADE, 2008, p. 446-447).
\end{abstract}

No Brasil, os sistemas de avaliação federais do ensino básico, assim como nos EUA, não se focam no desempenho individual de alunos, mas sim em componentes do sistema como escolas e redes, de municípios e UFs. Há estados e municípios brasileiros que oferecem bônus que, quando concedidos, variam de um a três salários adicionais por ano ${ }^{4}$ aos agentes premiados (professores, funcionários ou diretores). Escolas não são fechadas em função dos resultados, como ocorre em sistemas estaduais nos EUA. Para os alunos brasileiros, há esporádicos casos de premiações por desempenho, adotados pela liberalidade de secretarias municipais e estaduais.

Brooke lista, como exemplos high-stakes no Brasil, os casos dos municípios de Sobral, no Ceará, Rio de Janeiro e São Paulo (BROOKE, 2008, p. 96). Desde então, Acre, Goiás, Roraima, Espírito Santo, Minas Gerais, Pernambuco, Amazonas, Tocantins, Sergipe e Paraíba incluíram alguma forma de bonificação docente, ainda que nem todas vinculadas à aferição de proficiência dos alunos (SCORZAFAVE; FERREIRA; DORIGAN, 2014).

No contexto brasileiro, as avaliações em larga escala cobrem toda a vida escolar do aluno, do ensino infantil ao ensino superior. Estas avaliações, quando federais, são coordenadas pelo Instituto Nacional de Estudos e Pesquisas Educacionais Anísio Teixeira (Inep), uma autarquia ligada ao Ministério da Educação e Cultura (MEC), e aplicadas por consórcios ou fundações com a capacidade logística de cobrir o território nacional e testar milhões de alunos por evento.

Há um crescente número de UFs e municípios com avaliações próprias, sob controle de suas secretarias de educação ${ }^{5}$. Horta Neto (2014, p. 175-176) relatava que em 2013, 19 das 27 UFs já tinham seus sistemas próprios. Este número chega a 21 em 2016 (HORTA NETO; JUNQUEIRA; OLIVEIRA, 2016, p. 24).

3 Estados norte-americanos que simplesmente divulgam os resultados dos testes de proficiência dos alunos, sem atrelar um sistema de bonificações / penalidades.

4 Exemplos: Rio de Janeiro oferece $14^{\circ}$ salário (CERDEIRA; ALMEIDA; COSTA, 2014), Amazonas oferece $14^{\circ}$ e $15^{\circ}$ salários (SCORZAFAVE; FERREIRA; DORIGAN, 2014) e São Paulo até 2,9 salários adicionais (CASTRO, 2009).

5 Exemplos: Saresp (SP), Spaece (CE), Saepe (PE), Paebes (PB), Simave (MG), Salto (TO) e Saerj (RJ). 
Neste trabalho é abordado o Sistema de Avaliação da Educação Básica (Saeb) ${ }^{6}$, que realiza a Avaliação Nacional do Rendimento Escolar (Anresc) ou Prova Brasil, avaliação bianual censitária para alunos dos $5^{\circ}$ e $9^{\circ}$ anos do ensino fundamental das escolas públicas ${ }^{7}$.

As primeiras avaliações federais da educação básica foram amostrais e usavam a Teoria Clássica de Testes (TCT). Depois de 1995, a Teoria de Resposta ao Item (TRI) passou a ser usada, possibilitando a divulgação de resultados por município, estado e região, em escores passíveis de comparação ao longo do tempo. A partir de 2005, uma importante mudança ocorreu com a Prova Brasil: ela permitiu desdobrar os resultados de desempenho por escola e com este passo, abriu a possibilidade de aplicar políticas de responsabilização, como ressalta Eduardo Andrade (2008).

Com o aporte de proficiências de uma Prova Brasil censitária, em 2007 é criado o Indicador de Desenvolvimento da Educação Básica, o Ideb (FERNANDES, 2007). O Ideb é a medida da qualidade da educação básica, atendendo a preocupação natural que se seguiu à conquista da quase universalização de alunos matriculados (OLIVEIRA; ARAÚJO, 2005, p. 16). O índice teve uma projeção de metas até o ano 2021, por meio de um esforço colegiado do Conselho Nacional da Educação e do programa Todos pela Educação (2010), sendo essas metas desdobradas para cada escola do sistema público.

Seria o Ideb um fator de pressão demasiada? Se o Ideb de uma escola estiver abaixo da meta, que ações concretas decorrem? E se o Ideb cair de um ciclo para outro? Como reagem os agentes para minimizar os prejuízos ou rapidamente mostrar resultados melhores?

Com a instauração de uma política de accountability, é esperada uma reação dos agentes envolvidos, para que a política surta efeito. Caso não haja resposta, não haverá resultado associável à política e esta se torna inócua. As questões que emergem são: quais são as reações estratégicas decorrentes e são todas elas as pretendidas?

Estratagemas podem ser adotados pelos agentes para maximizar o retorno individual quanto a incentivos. Estes, antecipam as consequências percebidas da responsabilização, podendo levar a efeitos colaterais não antecipados, não planejados. Estes efeitos podem vir a prejudicar tanto a validade das avaliações como ferramenta de política pública, quanto a qualidade da educação que se pretendia melhorar.

6 O Saeb inclui também a Avaliação Nacional do Ensino Básico (Aneb), que é amostral, para os mesmos anos da Prova Brasil acrescidos de alunos do $3^{\circ}$ ano do ensino médio (EM), além de escolas privadas. O sistema engloba também a Avaliação Anual de Alfabetização (Ana), aplicada desde 2013 para os alunos do $3^{\circ}$ ano do ensino fundamental.

7 Uma perspectiva histórica das avaliações brasileiras e seus enlaces com as políticas podem ser encontradas nas publiações de Bonamino e Sousa (2012), Horta Neto (2014) Alavarse, Bravo e Machado (2012). No contexto internacional, referências relevantes para a história destas avaliações são os trabalhos de Amrein e Berliner (2002), Ryan e Shepard (2008) e Madaus, Russell e Higgins (2009). Esta perspectiva histórica não será abordada neste trabalho. 


\section{A pressão de incentivos}

Incentivos, definidos como recompensas e penalidades que motivam comportamentos, tal como contemplado nas políticas de responsabilização, podem ou não funcionar como desenhados. Podem ter consequências inesperadas e surpreender seus idealizadores.

Um exemplo se deu na Inglaterra dos anos finais do século XVIII. Em 1787, o governo britânico contratou capitães da marinha mercante para transportar criminosos para a Austrália, recém "descoberta" pelo capitão James Cook. Parecia uma solução oportuna, para livrar o país de um incômodo e ao mesmo tempo colonizar o desconhecido com levas de degredados. Os registros da época atestam as péssimas condições da viagem nos navios: muitos dos prisioneiros morriam durante o trajeto, de fome, sede, escorbuto ou outras doenças. Há registro de viagens em que um terço dos condenados morreu no transporte.

O degredo era uma roleta russa, cujas consequências, assim que conhecidas em Londres, logo incomodaram clero, imprensa e legisladores. Condições melhores de transporte foram exigidas, sem lograr efeito. É importante apontar que os capitães das naves, eram, até então, remunerados por prisioneiro embarcado.

Em 1793, uma mudança de regras fez com que o pagamento fosse feito por passageiro desembarcado em terras australianas. A taxa de mortalidade prontamente caiu para 1\%, com as mesmas naves, a mesma medicina e a mesma tecnologia de viagem, apenas com a mudança no critério de remuneração dos agentes. Este episódio, narrado por Cowen e Tabarrok (2014), ilustra como o desenho dos mecanismos de incentivo pode substantivamente influenciar os resultados obtidos, por moldar o comportamento dos agentes.

Um sombrio exemplo de efeitos colaterais inesperados se deu no Congo Belga, sob o governo de Leopoldo II, rei da Bélgica, nos anos finais do século XIX. Interessado nos lucros da extração da borracha, recém industrializada, o governo iniciou um sistemático processo de exploração da população local nos seringais.

Para conter as rebeliões decorrentes do trabalho forçado, as milícias a serviço do rei estavam autorizadas a atirar para matar e manter a ordem com execuções públicas. Como as munições eram caras e rotineiramente desviadas para a caça de animais, uma política foi instituída para controlar o uso de munições pelas milícias. Para cada projétil usado numa execução, uma mão direita, amputada e defumada, deveria ser entregue à autoridade como comprovação do uso regular da munição. Isto não impediu o uso irregular das munições na caça de animais, mas criou um incentivo perverso. Mãos direitas de homens, mulheres e crianças inocentes, ainda vivos mas agora desfigurados, passaram a ser coletadas para justificar as munições usadas irregularmente (DOYLE, 1909). 
Além da óbvia e brutal violação da população, o interesse de Leopoldo II também não foi atingido por conta da medida, que encontrou na manipulação da sua milícia um conflito de interesses inesperado, aumentando a revolta e diminuindo a força de trabalho.

Os dois exemplos acima ilustram um par importante de pontos: se adequadamente desenhados, incentivos podem ser eficazes. Caso contrário, podem levar a efeitos inesperados e indesejados em detrimento do objetivo final. No contexto da educação, estes pontos também são encontrados.

Em 1985, nos Estados Unidos, um médico de nome John Jacob Cannell leu, com ceticismo, matérias publicadas em jornais de West Virginia, relatando que todos os distritos daquele estado tinham obtido resultados acima da média nacional nas avaliações educacionais padronizadas comerciais em uso. Cannell, que conhecia o público desses distritos, estranhou os resultados reportados terem sido tão elevados.

Com ajuda de uma equipe pequena do seu consultório, Cannell coletou e analisou resultados das avaliações comerciais usadas no país, concluindo que absolutamente todos os estados reportavam resultados acima da média nacional. Cannell publicou um relatório preliminar em 1987, depois editado em livro, How Public Educators Cheat on Standardized Achievement Tests: The Lake Wobegon Report (1989), denunciando fraudes sistêmicas e inflação dos escores nos sistemas comerciais de avaliação contratados pelos estados ${ }^{8}$.

O relatório de Cannell chamou a atenção de acadêmicos: George Madaus, pesquisador de Boston, fez referência (1988a) ao trabalho de Cannell e associou-o ao de Donald Campbell, o qual postulava que "quanto mais um indicador social quantitativo for usado para a tomada de decisões, mais sujeito ele estará a pressões corrompedoras e mais apto

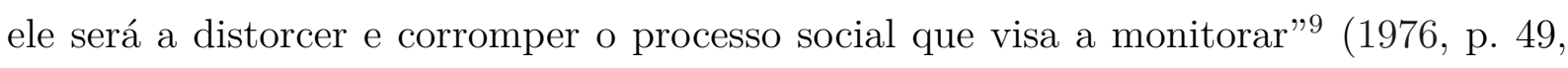
tradução nossa). De maneira independente, no mesmo ano, o então pesquisador da RAND Corporation, Daniel Koretz publicou Arriving in Lake Wobegon: Are Standardized Tests Exaggerating Achievement and Distorting Instruction? (1988).

Estes autores, em seus trabalhos subsequentes, analisaram as respostas dos agentes quando confrontados com avaliações para a responsabilização, contribuindo fundamentalmente à literatura estudada neste trabalho.

8 No título do seu relatório e livro, Cannell fazia alusão à cidade rural fictícia Lake Wobegon, popularizada pelo programa de rádio Praire Home Companion. Este programa de fiç̧ão narrava as crônicas locais e repetia que "em Lake Wobegon, todas as mulheres são fortes, todos os homens são bonitos e todas as crianças são acima da média". O Efeito Lake Wobegon se consolidou como um bordão popular e foi adotado por áreas como a psicologia e, graças a Cannell, às análises de avaliações em educação.

9 The more any quantitative social indicator is used for social decision-making, the more subject it will be to corruption pressures and the more apt it will be to distort and corrupt the social processes it is intended to monitor. 


\section{De quais efeitos colaterais se falam?}

A exclusão planejada de alunos de baixa proficiência das avaliações é uma resposta estratégica registrada na literatura com o objetivo de elevar a média de proficiência da unidade avaliada, convenientemente expurgando "maus alunos" da amostra. Esta manipulação pode incluir a reclassificação indevida de alunos para programas não avaliados ou a retenção indevida de alunos em anos anteriores aos avaliados. Alunos de baixa proficiência ou de minorias desprivilegiadas podem vir a sofrer suspensões mais extensas e estar ausentes no dia da aplicação da avaliação.

Fraudes docentes, nas quais se verificam desvios nas regras de aplicação das provas, incluem o compartilhamento indevido de respostas ou adulteração de registros nos cadernos de respostas. Há fraudes administrativas, nas quais as organizações incumbidas de divulgar os resultados das avaliações omitem, manipulam ou adulteram pontuações obtidas.

Outra reação é o "ensinar para o teste", no qual professores passam a concentrar a maior parte do tempo de aula ou tarefas de casa nos tópicos estritamente cobertos nas avaliações, com a consequente redução de carga horária nas disciplinas não avaliadas. O ensino se concentra em torno de tópicos ou formatos e linguagens frequentemente abordados nas avaliações.

Professores podem reagir, ainda, dedicando seus esforços exclusivamente aos alunos ligeiramente abaixo da média, pois nestes o retorno marginal do tempo investido seria maior. Os alunos de baixa proficiência estariam muito abaixo para reagirem em tempo para a prova e os acima da média já teriam aprendido o necessário para assegurar o resultado estes alunos ligeiramente abaixo da média em foco são conhecidos por "bubble kids" na literatura norte-americana ${ }^{10}$.

A prática de ranqueamento de escolas, em geral não incentivada pelo estado avaliador, é propagada pela mídia e oferece alguma pressão pela mobilização da opinião pública local, sendo apropriada sua designação como consequência branda (BROOKE, 2008). Este autor afirma que o município de Belo Horizonte e o estado do Paraná adotam desta abordagem. O resultado do ranqueamento divulgado tem reflexo na prática. Um estudo sobre a premiação da Secretaria Municipal da Educação do Rio de Janeiro, com base em análises dos questionários contextuais dos diretores da Prova Brasil 2009 e 2011 e dados da Secretaria Municipal de Educação / RJ de premiação em 2010 e 2011, aponta a redução de procura por vagas oferecidas nas escolas não premiadas e um aumento na procura por vagas nas premiadas. Suas autoras comentam que o efeito medido foi brando, mesmo depois de dois anos de implementadas as políticas de premiação e divulgação de rankings (CARVALHO; OLIVEIRA; LIMA, 2014, p. 68-69).

${ }_{10}$ Hannaway (1996) e Booher-Jennings (2005) descrevem este fenômeno, abordado no próximo capítulo. 
Edna Martins Borges, da Universidade Federal de Minas Gerais, vê o uso de rankings como uma prestação de contas à opinião pública:

No caso brasileiro, os rankings entre as escolas públicas, organizados em especial pela mídia, mas às vezes também por gestores das redes de ensino, não parece ter como pano de fundo uma política educacional orientada para o mercado, [...] mas sim de uma prestação de contas perante a opinião pública, ainda que isto possa causar constrangimentos (BORGES, 2016, p. 51-52).

Esses estratagemas resultam na inflação artificial das proficiências medidas nas avaliações, o que poderia prejudicar os formuladores de políticas públicas, que passariam a contar com resultados enviesados ou inválidos para a tomada de decisões. Isso levaria à alocação inadequada de recursos.

Outras reações têm impacto direto nos alunos, como o estreitamento curricular decorrente do "ensinar para o teste", uma vez que estes deixariam de ter exposição adequada a disciplinas e a conteúdos importantes para suas formações. A equidade na escola também é posta em risco quando exclusões deliberadas de alunos de baixa proficiência ou atenção focada em "bubble kids" acentuam preconceitos e desmotivam alunos (MADAUS, 1988a).

No Brasil, alguns autores levantaram a questão dos efeitos colaterais quando as políticas de responsabilização começaram a surgir como opção de política educacional. Sousa e Oliveira anteviram efeitos colaterais para as políticas de responsabilização recém implantadas. Estes autores também associaram o Exame Nacional do Ensino Médio (Enem) ao estreitamento do currículo:

Comparando-se com o Saeb, é possível afirmar que o Enem apresenta-se com um potencial maior de condicionar os currículos escolares, ou seja, ensina-se para a obtenção de bons resultados no exame. Aliás, já há até "cursinhos" preparatórios para o Enem! (SOUSA; OLIVEIRA, 2003, p. 884).

Com o passar do tempo e a importância expandida adquirida pelo Enem, em evolução de uso antevista por Heraldo Vianna (2003, p. 20), para as escolas que dele dependem para propaganda e, principalmente, para os alunos avaliados e sujeitos a consequências tangíveis (ingresso em universidades públicas e acesso a financiamento para universidades privadas), a existência de cursinhos preparatórios não parece tão absurda. 


\section{Relevância crescente}

Nas últimas décadas, as políticas de responsabilização tiveram o amplo suporte de governos de partidos antagonistas. Nos Estados Unidos, tiveram forte impulso com o programa No Child Left Behind (NCLB), iniciado em 2002 no governo republicano de George W. Bush, com forte suporte bipartidário. O NCLB, apesar de continuadas críticas, foi mantido pelo seu sucessor democrata, Barack Obama. Em 2015, o NCLB foi substituído pelo Every Student Succeeds Act (ESSA), mantendo as mesmas rotinas avaliativas e sanções. Um fenômeno parecido se deu no Brasil: políticas de avaliação iniciadas sob o PSDB nos anos 1990 foram mantidas e fortalecidas sob o governo do PT, no século XXI.

Gary Fenstermacher (1991) explica a popularidade da accountability escolar com os governos de todos os lados do espectro. Este autor afirma que a accountability é um modo cômodo de qualquer governo justificar seus gastos com a educação, sendo as avaliações externas o meio mais econômico de fazê-lo:

\footnotetext{
Quanto mais longe um dólar gasto com educação tiver que viajar, entre a fonte e o destino, e quanto mais níveis burocráticos tiver que transpassar, maiores serão as demandas da fonte para demonstrar que este dólar foi bem e adequadamente gasto (BERLINER; BIDDLE, 1995 apud FENSTERMACHER, 1991, p. 200, tradução nossa).
}

Na medida em que estes testes se tornaram rotineiros, passaram a ter reflexo na cultura popular. Em 2009, os roteiristas ${ }^{11}$ do seriado animado The Simpsons criam o episódio "How the Test was Won", no qual descrevem a resposta estratégica da escola pública de Springfield sob pressão de uma avaliação externa com consequências fortes (KRAMER, 2009). Às vésperas da prova, um "seleto" grupo de alunos indisciplinados e com conhecido baixo desempenho é "premiado" com uma viagem de helicóptero para uma festa de pizza na capital do estado. Extasiados, os alunos são ovacionados pelos colegas ao entrarem no ônibus escolar disfarçado de aeronave. Seu diretor, Seymour Skinner, os acompanha, enquanto o superintendente Chalmers, arquiteto da ideia, fica para trás, para supervisionar a preparação dos alunos "bons" a serem avaliados. A estratégia empregada consiste em remover da base testada os alunos "problema", assim aumentando a proficiência média aferida pela prova, melhorando as chances da escola receber recursos e não ser sancionada com alguma penalização.

Enquanto isso, os alunos que ficaram na escola são sujeitados a um desgastante preparo, que inclui a memorização de sequências de letras, na esperança de serem as mesmas dos gabaritos. O roteiro prossegue, contando o estresse e desencanto dos alunos que ficaram para trás, para serem avaliados, enquanto os alunos "problema" tem sua aventura longe das aulas. Felizmente, estes últimos têm uma rica experiência de campo,

11 Vários deles com doutorados, como apontado em Singh (2016). 
junto com o diretor, que aproveita a proximidade para contar histórias de Mark Twain e explicar, com acrobacias emergenciais, o princípio físico da conservação do momento angular. Um dos garotos mais desinteressados com os estudos exclama: "Isso é legal! Deveriam ensinar isso na escola!".

Um segundo exemplo de como a polêmica sobre o uso de avaliações ganha força na mídia é a videorreportagem do comentarista e humorista John Oliver (2015), divulgando uma ácida crítica aos excessos das avaliações, em seu programa Last Week Tonight. A versão disponível no seu canal no Youtube contava com mais de nove milhões de views, após dois anos no $\operatorname{ar}^{12}$.

O excesso de testes do contexto americano fica evidente no relatório do Council of the Great City Schools, que reporta o alarmante número médio de oito avaliações por aluno, por ano (HART et al., 2015, p. 25). Este inventário mapeou distritos das maiores cidades norte-americanas ao longo do ano letivo 2014-2015. Um aluno passaria por 112 avaliações, ao longo de sua vida escolar equivalente ao Ensino Básico. Como reação, um forte movimento "anti-testing" se estabeleceu e cresceu nos EUA, com o ativismo de organizações como a FairTest de Robert Schaeffer, ou com a militância de Diane Ravitch (2010, 2013). Outra voz em ascensão deste movimento é o jovem educador Jesse Hagopian (2014, 2016b, 2016a) que, ao contrário de Ravitch, ainda é pouco referenciado no Brasil. O impulso deste movimento se verifica quando a temática permeia mídias de consumo, indo além das arenas acadêmicas e fóruns políticos, ganhando tração com a população.

Escândalos envolvendo fraudes em exames estaduais tiveram ampla cobertura na mídia norte-americana. Em abril de 2015, sentenças de prisão de um a sete anos foram distribuídas a diretores e professores do sistema de ensino de Atlanta, Geórgia, declarados culpados por fraudes ocorridas em 2009 (KAMENETZ, 2014; CALAMUR, 2015; FAUSSET; BLINDER, 2015). Diane Ravitch conta (2010) que o ocorrido se deveu à ameaça de substituição dos diretores que não conseguissem melhorias substanciais depois de três anos, induzindo ao comportamento fraudulento. O que se viu ocorrer em Atlanta parece não ser um caso isolado: $80 \%$ dos estados norte-americanos reportaram alegações de fraudes nos seus sistemas estaduais de avaliação, ligadas às pressões do programa NCLB, com confirmação de casos em 33 estados, de acordo com uma investigação federal do US Government Accountability Office (2013).

O Brasil não tem um movimento contra avaliações ligadas à responsabilização tão forte quanto o que se vê nos EUA. O Movimento Contra Testes de Alto Impacto em Educação, criado em 2010 não compartilha da repercussão pública alcançada lá ${ }^{13}$. Nos últimos dez anos, são poucas as pesquisas que abordam o sentimento dos professores brasileiros

12 https://www.youtube.com/watch?v=J6lyURyVz7k

13 O sítio na internet não é atualizado desde junho de 2013, mas o blog mantido por Luiz Carlos de Freitas em https://www.avaliacaoeducacional.com é bastante ativo. 
quanto às avaliações externas, especialmente com o uso de amostras representativas.

Em consulta a 500 professores, em 2007, o Instituto Paulo Montenegro (2010) registrou que $55 \%$ dos professores desconheciam o Ideb (recém introduzido) e 14\% desconheciam qualquer mecanismo de avaliação externa. Esta pesquisa não abordou explicitamente a questão da satisfação docente com as avaliações externas, mas apontou que os professores se consideravam em grande parte responsáveis positivos pelos resultados obtidos pelos alunos. Mais recentemente, com amostra de mil professores da rede pública brasileira, a pesquisa Conselho de Classe, levada a cabo pela Fundação Lemann e pelo Instituto Paulo Montenegro (2015) identificou que só $12 \%$ dos professores veem positivamente a extinção de avaliações externas. É neste contexto de polarização que se conduz o presente trabalho, com foco no Brasil.

\section{A questão de pesquisa}

Na literatura acadêmica nacional, o emprego de estratagemas em resposta a políticas de avaliação high-stakes e seus efeitos colaterais tem sido estudado, de forma pontual, por meio de estudos de casos em pequena escala, depoimentos de professores e administradores, em amostras de pequena extensão e quase sempre sem suporte quantificador.

O objetivo deste trabalho é identificar e analisar, de maneira exploratória, com dados observacionais, efeitos colaterais das avaliações educacionais em larga escala, no Brasil, quando associadas a políticas educacionais de responsabilização. A questão que se aborda é: Há evidência empírica do emprego de estratagemas indesejados e seus efeitos colaterais no Brasil?

Em particular, há exclusão seletiva de alunos de baixa proficiência na Prova Brasil? Há padrões suspeitos nos cadernos de resposta da Prova Brasil que indiquem fraudes? Estes efeitos podem ser mensurados? Se constatados, seriam estes fenômenos mais intensos em casos em que a pressão da responsabilização é maior?

A relevância deste trabalho está em medir a extensão de dois efeitos colaterais, que de maneira geral, não têm suas grandezas estudadas ou divulgadas, apesar de serem citados na literatura acadêmica como presentes na realidade escolar. Esta abordagem recorre a uma expressiva massa de dados: a avaliação de mais de oito milhões de alunos participantes, em duas instâncias da Prova Brasil, cobrindo dezenas de milhares de escolas em milhares de municípios, em todas as Unidades da Federação.

Este trabalho, portanto, visa a preencher, ainda que de modo exploratório, esta lacuna na literatura brasileira. Para tanto, revê-se a literatura relevante sobre os efeitos colaterais indesejados e propõe-se duas abordagens para medir efeitos notáveis e correlacioná-los a fatores de pressão usualmente associados à responsabilização. 


\title{
1 A literatura sobre efeitos indesejados
}

\author{
"'Inda garoto deixei de ir à escola \\ Cassaram meu boletim
}

Não sou ladrão, eu não sou bom de bola

Nem posso ouvir clarim

Um bom futuro é o que jamais me esperou

Mas vou até o fim"

Até o fim, Chico Buarque (1978).

A pesquisa bibliográfica se deu por meio da consulta a repositórios de periódicos nacionais e estrangeiros, produção de dissertações e teses na Biblioteca Digital Brasileira de Teses e Dissertações ${ }^{1}$ e buscadores, como o $\mathrm{ERIC}^{2}$, do Institute of Educational Sciences e os sistemas Scielo e Google Scholar. Também foi consultada literatura impressa na Biblioteca da Faculdade de Educação da USP e na Fundação Carlos Chagas, em São Paulo.

Os tópicos e palavras-chave usados cobriram tanto o campo das avaliações e seus efeitos, quanto o ferramental estatístico e programático aplicado, expostos no capítulo Abordagem e Métodos. Um corpo de textos de referência foi compilado, com ajuda de ferramentas informatizadas também descritas em apêndice à página 209. Foram levantadas 248 referências estrangeiras sobre os efeitos da accountability, 181 brasileiras sobre o mesmo tema, 281 sobre avaliações externas em geral.

Este processo se deu de maneira iterativa, partindo de referências indicadas em Nigel Brooke (2006, 2008, 2011, 2013a, 2013b, 2013c), Brooke e Cunha (2011), Brooke et al. (2011), Madaus e Russell (2010), Nichols e Berliner (2007), Freitas (2013a) e Amrein e Berliner (2002). Destas referências, expandiu-se para buscas por palavras-chave fraude, cheating, gaming, efeitos colaterais, exclusão, manipulação, accountability, responsabilização, teaching to the test, curriculum narrowing, estreitamento e suas variantes.

A literatura sobre os efeitos colaterais das políticas de accountability na educação é rica e extensa. A estrangeira, contudo, apresenta dois desafios ao entendimento. O primeiro deles é a abundante referência a expressões ancoradas em contexto cultural norte-americano, para nomear e explicar fenômenos, nem sempre facilmente assimiláveis por leitores de outras culturas, como "red-shirting" e "Lake Wobegon". O segundo desafio é a variação de nomenclaturas, às vezes sutil, requerendo cuidados ao realizar buscas por expressões-chave: "teach to the test" e "teaching to the test" são exemplos.

$1<$ http://bdtd.ibict.br/vufind/>

$2<$ http://eric.ed.gov/> 
A literatura estrangeira é particularmente rica em estudos que visam a medir a extensão dos efeitos, ocorrendo o oposto no corpo da literatura nacional sobre o tema. Como apresentado na introdução, na literatura nacional, o estudo de estratagemas e outros efeitos colaterais, quando ocorre, baseia-se em abordagens qualitativas de pesquisa.

Este capítulo introduz princípios generalizadores que contextualizam os efeitos colaterais indesejados. Em seguida, apresenta-se uma revisão dos efeitos indesejados, tanto na literatura brasileira quanto estrangeira.

\subsection{A responsabilização educacional}

Neste trabalho, responsabilização e accountability são empregados como sinônimos. O embate sobre o significado preciso do termo e a pertinência de traduções persiste ${ }^{3}$. Alguns autores preferem o termo em inglês, como pragmaticamente notam Fernandes e Gremaud: "o termo accountability tem sido traduzido como transparência, responsabilização, rendição de contas e outros. Na falta de concordância sobre a melhor tradução, manteremos o termo em inglês." (2009, p. 214). Brooke e Cunha propõem "responsabilização", ressalvando que a tradução é imperfeita:

\footnotetext{
[...] a palavra accountability expressa dois conceitos, um relacionado com a prestação de contas e o outro com a ideia da responsabilização. Quando aplicada especificamente à escola, a noção de prestação de contas significa a cobrança legítima de um serviço público de qualidade em troca da manutenção da escola com recursos públicos oriundos dos impostos pagos pela população. O segundo significado da palavra é inseparável e consequência do outro, mas expressa a ideia que o público tem o direito de demandar que a escola assuma sua responsabilidade direta pelos resultados de seus alunos. Accountability, portanto, significa uma cobrança por bons resultados e a demanda de que cada um dos atores envolvidos assuma a sua responsabilidade na produção desses resultados (BROOKE; CUNHA, 2011, p. 21).
}

David Figlio e Susanna Loeb apresentam a responsabilização ou "accountability" escolar como "o processo de avaliar o desempenho de uma escola com base em medidas de desempenho de seus alunos" (2011, p. 384-421). Ressaltam que esta abordagem cria respostas tanto positivas quanto negativas e que se não for bem projetada e monitorada, corre-se o risco de ser contraproducente. Estes autores, acertadamente, resgatam o modelo teórico do "Problema Agente-Principal" ou Teoria da Agência, em sua apreciação de sistemas de accountability. Este modelo tem suas origens nos anos 1970, com o trabalho de Jensen e Meckling (1976) e versa sobre as dificuldades de conciliar os interesses de um "principal" e seu "agente", à sombra de informações assimétricas, para selecionar uma remuneração ou incentivo que induzam o agente a se comportar de acordo com as

3 Ver Campos (1990) e Afonso (2012). 
preferências do principal. Por ter suas origens em círculos econômicos e da teoria dos jogos, este modelo teórico não tem grande penetração na produção acadêmica da educação (LADD; ZELLI, 2002), mas é uma abordagem eficaz para entender incentivos tais como os que se apresentam. No Brasil, Alexandre, Lima e Waltenberg tratam da responsabilização à luz da Teoria de Agência, de maneira conceitual, indicando que há suporte para embasar tanto defensores quanto críticos dos programas de responsabilização "high-stakes".

[...U $] \mathrm{m}$ programa de responsabilização, mesmo que extremamente bem concebido e implementado, será capaz de recompensar apenas inadequada ou grosseiramente o esforço de professores. Nada impede que, apesar disso, a nota média dos alunos aumente como consequência da implementação do programa - de modo que um dos objetivos será alcançado. Porém, ao custo de efeitos colaterais ainda não integralmente conhecidos, de disseminação de ressentimentos variados e de resistências que poderiam minar a legitimidade da reforma no médio prazo (ALEXANDRE; LIMA; WALTENBERG, 2014, p. 59).

As políticas de responsabilização têm as componentes comuns indicadas por Helen Ladd e Arnaldo Zelli (2002), descritas a seguir. Fundamentalmente, há um currículo e um padrão de conteúdos conhecido e aceito como pano de fundo ao aprendizado. Também há consenso em torno de quais disciplinas e conteúdos desse currículo serão incluídos no sistema de responsabilização, ou seja, quais componentes curriculares serão amostradas na forma de itens de provas. Há ferramentas, tecnologias e processos de medição, confiáveis e válidos, para aferir o domínio dos alunos sobre o currículo avaliado, e por consequência, há métodos para medir quanto as escolas estejam aumentando os aprendizados dos seus alunos ou melhorando outras variáveis de interesse da política. Finalmente, há tanto recompensas e incentivos positivos críveis para as escolas e agentes que progridam quanto ameaças de sanções e intervenções para escolas e agentes de baixo desempenho.

Linda Darling-Hammond (2004) lembra que a responsabilização pode se dar ao longo de vários eixos. No eixo político, legisladores e conselheiros de escolas têm que prestar contas por suas decisões, periodicamente enfrentando eleições. No eixo legal, escolas têm que operar dentro da lei e cidadãos e contribuintes podem acioná-las em tribunais, caso venham a achar ilegalidades. No eixo burocrático, procedimentos e regras promulgados nos níveis federal, estadual ou municipal devem ser seguidos pelas escolas. No eixo profissional, professores e outros agentes educativos têm que seguir determinados padrões de conduta, obter conhecimento técnico específico ou certificações, pelos quais prestam contas. No eixo mercadológico, pais e alunos podem vir a escolher cursos ou escolas que acreditem sejam mais apropriados, à luz dos resultados aferidos e transparentemente divulgados.

O atingimento dos resultados pretendidos pelas políticas de responsabilização, no sentido estrito de causalidade entre política adotada e impacto verificado nas proficiências medidas, é complexo e não faz parte do escopo do presente trabalho. Contudo, a eficácia das políticas de accountability na educação precisa ser abordada, ainda que resumidamente. 
Nos EUA, uma meta-análise abrangente pode ser encontrada em Elliot e Hout (2011), representando os esforços de uma comissão multidisciplinar do National Research Council, associado à National Academy of Sciences dos Estados Unidos. Esta comissão chegou a duas conclusões nada promissoras sobre a eficácia das políticas do programa NCLB:

Conclusão 1: incentivos baseados em avaliações não aumentaram a proficiência o suficiente para trazer os EUA à paridade versus outros países de alto desempenho. Quando medido por avaliações de "low-stakes", portanto sem a pressão inflacionária de escores, ganhos de proficiência tendem a ser pequenos. Programas em outros países que mostram resultados maiores não são aplicáveis no contexto dos EUA. Incentivos no nível de escolas, tais como implementados pelo NCLB, produzem estimativas maiores de ganhos, da magnitude de 0,08 desvios padrão, concentrados em matemática dos anos iniciais, efeitos pequenos comparados aos almejados;

Conclusão 2: a evidência sugere que os exames de fim de curso do ensino médio norte-americano diminuem os níveis de conclusão, sem melhorar a proficiência. Em contraste, incentivos para a graduação, na forma de prêmios, enquanto mantêm as taxas de graduação constantes, sugerem que possam ser usados para melhorar estes níveis (ELLIOTT; HOUT, 2011, p. 4.26, tradução nossa) $)^{4}$.

No Brasil, estudos investigaram os efeitos e eficácia da accountability com bonificação docente na qualidade da educação de três estados pioneiros na sua adoção, Pernambuco, São Paulo e Ceará ${ }^{5}$.

Em Pernambuco, Bruns et al. (2011) registram alguma melhora nas proficiências em Língua Portuguesa e Matemática para o $9^{\circ}$ ano e nas taxas de aprovação desse ano e pouco ou nenhum resultado no $5^{\circ}$ ano do ensino fundamental. Estes autores citam, brevemente, que não foi verificado gaming relacionado à exclusão de alunos de baixa proficiência.

4 Conclusion 1: Test-based incentive programs, as designed and implemented in the programs that have been carefully studied, have not increased student achievement enough to bring the United States close to the levels of the highest achieving countries. When evaluated using relevant low-stakes tests, which are less likely to be inflated by the incentives themselves, the overall effects on achievement tend to be small and are effectively zero for a number of programs. Even when evaluated using the tests attached to the incentives, a number of programs show only small effects. Programs in foreign countries that show larger effects are not clearly applicable in the U.S. context. School-level incentives like those of NCLB produce some of the larger estimates of achievement effects, with effect sizes around 0.08 standard deviations, but the measured effects to date tend to be concentrated in elementary grade mathematics and the effects are small compared to the improvements the nation hopes to achieve.

Conclusion 2: The evidence we have reviewed suggests that high school exit exam programs, as currently implemented in the United States, decrease the rate of high school graduation without increasing achievement. The best available estimate suggests a decrease of 2 percentage points when averaged over the population. In contrast, several experiments with providing incentives for graduation in the form of rewards, while keeping graduation standards constant, suggest that such incentives might be used to increase high school completion.

5 Em Rodrigues (2007) há um estudo pioneiro sobre estes efeitos no estado do Rio de Janeiro, mas sem suporte estatístico comparável aos demais citados. 
A dissertação de mestrado de Cláudia Oshiro (2012) abordou os ganhos de proficiência dos alunos do estado de São Paulo com a implementação da bonificação estadual. A pesquisadora encontrou uma pequena melhoria na proficiência de alunos do $5^{\circ}$ ano e nenhuma melhoria para os alunos do $9^{\circ}$ ano do ensino fundamental.

O Prêmio Escola Nota 10, criado em 2009 no Ceará, foi estudado por Calderón, Raquel e Cabral, que concluíram que é uma política indutora de cooperação, ainda que sem quantificar os benefícios:

[...] uma política pública que não somente incentiva a transparência de informações e das estruturas educativas, por meio da utilização de indicadores de referência de qualidade, amplamente divulgados na opinião pública e na comunidade escolar, mas também valoriza o trabalho realizado pelas escolas, estimulando-as para que trabalhem de forma interdependente, por meio da socialização de boas práticas escolares e de incentivos para o estabelecimento de relações colaborativas e de cooperação entre os atores das unidades escolares (CALDERÓN; RAQUEL; CABRAL, 2015, p. 535).

Em trabalho decorrente da dissertação de Marcia Maria Vieira Maia (2013), Sousa, Maia e Hass (2014) estudaram os efeitos da bonificação docente com base nos resultados do Idesp, o Índice de Desenvolvimento da Educação do Estado de São Paulo, para os anos de 2008 a 2012. Com foco no $3^{\circ}$ ano do ensino médio, as autoras encontraram inconsistências entre o desempenho aferido pelos alunos e a bonificação paga.

\footnotetext{
A interpretação dos dados aponta oscilação de desempenho das escolas no decorrer dos anos analisados, não apoiando conclusões que indiquem melhorias gradativas e sustentáveis e identificando, inclusive, premiação de escolas que atingiram patamares inferiores aos de anos anteriores (SOUSA; MAIA; HAAS, 2014, p. 188).
}

As autoras concluem que "não se verifica uma relação entre cumprimento de metas e evidências de melhoria de qualidade das escolas, assim como não se pode afirmar que a premiação anual incida em escolas que evidenciam real aprimoramento" (2014, p. 205), ressaltando que o foco no curto prazo compromete os objetivos de desenvolvimento de longo prazo, tal qual reportado por Rapple (1990) para a Inglaterra do século XIX. Apesar de ter se baseado em apenas 41 escolas de uma rede da Grande São Paulo, a abordagem das autoras é acessível e direta, merecendo ser expandida para uma conjunto maior de casos.

Como se vê pela variedade de conclusões encontradas, falta ao Brasil um estudo na linha da meta-análise de Hout e Elliot (2011), que permita atestar de maneira mais compreensiva a real extensão dos impactos da bonificação na qualidade da educação. 


\title{
1.2 Os efeitos peiragênicos
}

Aos efeitos negativos indesejados e não intencionais, George Madaus e Michael Russell atribuíram o termo "peiragenics" (2010, p. 28). O termo tem paralelo com o efeito iatrogênico, no qual o médico, apesar de imbuído de boas intenções, causa dano ao paciente, pela aplicação de um tratamento que resulta prejudicial. A raiz "peira" tem origem protoindo-europeia, e significa "experiência" ou "risco". É a origem de "empírico" e "perigo". Madaus (1988b) caracteriza a influência do medir (componente importante da avaliação) sobre o medido como uma manifestação social do Princípio da Incerteza, postulado pelo físico Werner Heisenberg em 1927. Este princípio afirma que o simples ato de medir uma partícula subatômica é suficiente para alterar a realidade medida fundamental e inexoravelmente. A paráfrase é clara: o ato de avaliar influencia diretamente a aprendizagem que visa aferir. Madaus e Russell sumarizam os efeitos peiragênicos:

\begin{abstract}
Os efeitos negativos são muitos. Incluem o estreitamento do currículo, redução da atenção dada a assuntos não cobertos nos testes, alterações no currículo infantil, foco demasiado na preparação para os testes, corrompimento dos resultados dos testes, fraudes, triagem de "bubble students", retenção em séries não avaliadas, aumento do abandono escolar, aumento da ansiedade e estresse dos alunos. Todas estas consequências paradoxais das avaliações associadas a high-stakes são crônicas, previsíveis e bem documentadas ao longo dos séculos, em todos os continentes ${ }^{6}$. (MADAUS; RUSSELL, 2010, p. 28)
\end{abstract}

Entretanto, estes autores frisam que não é a avaliação per se que leva a estes efeitos negativos. São as consequências materiais associadas aos escores medidos que induzem comportamento indesejado dos agentes. O paradoxo emergente é que as políticas de responsabilização têm como mola mestra estas mesmas consequências materiais, que podem levar a efeitos tanto desejados quanto indesejados, sendo estes últimos, às vezes, mais danosos que os males que se intencionava corrigir. Freitas, opositor das políticas high-stakes no Brasil, pondera:

[...] temos feito críticas à accountability, não à avaliação - vamos separar bem. Uma coisa é a cultura de avaliação que defendemos, outra coisa é a cultura de auditoria que a accountability traz. São duas coisas diferentes. Sou favorável à cultura da avaliação, mas não sou favorável à cultura da auditoria - auditoria pesada em cima da escola, dos profissionais, das redes (FREITAS, 2013b, p. 350).

Diversos trabalhos criticam as políticas públicas de responsabilização, adotadas sem os devidos cuidados. Os argumentos apresentados, ideológicos ou técnicos, são repetidos

$6 \quad$ The negative effects are many. They include narrowing the curriculum, decreasing attention on nontested subjects, changing preschool and kindergarten curricula, narrow test preparation, corruption of test results, cheating, triaging "bubble" students, retaining students in grade, increased dropout rates, and increasing student stress and anxiety. All of these paradoxical negative consequences of high-stakes testing are chronic, predictable, and well documented over centuries and across continents. 
em quase trinta anos de estudos. Uma simples contestação, que não é referenciada com frequência, mas que tem lógica e simplicidade notáveis, é apresentada por Berliner e Biddle (1995). Estes autores, ao investigar a razão por trás da popularidade de políticas de responsabilização denunciam que a accountability educacional se apresenta com pesos e medidas diferentes, quando confrontada com outras manifestações de responsabilização. Propõem que, em teoria, não há nada de errado com a responsabilização, recaindo o problema na sua execução. Sugerem que educadores devam ser responsabilizados pelas suas ações e condutas, algo difícil e custoso de acompanhar e documentar, e não pelo resultado de uma avaliação de resultados. Acusam a existência de pesos e medidas diferentes para julgar docentes comparados a outros servidores:

[...] nenhuma sociedade deve tolerar políticos corruptos, policiais violentos, bombeiros incompetentes ou clero predador de jovens vulneráveis. Analogamente, a sociedade não deve tolerar docentes que não consigam ensinar e diretores que não saibam administrar escolas.

[...] para que sejam sancionados, políticos têm que ser formalmente julgados por corrupção e policiais têm que ter suas ações violentas registradas. Segue, se comparações forem feitas com justiça, que educadores teriam que ter sua competência avaliada pela coleta completa de dados sobre sua conduta profissional. O problema é que esta coleta de dados sobre condutas individuais é onerosa, em desalinhamento com o interesse imediato dos proponentes das políticas. Estes, portanto, promovem propostas baseadas na medição de resultados, tais como a proficiência aferida em avaliações padronizadas. (BERLINER; BIDDLE, 1995, p. 200-202, tradução e grifos nossos)

Sugerem a proximidade de legisladores a conceitos de mercado. Explicam que a responsabilização atende também à necessidade do legislador aparentar resolver problemas na educação com o menor investimento possível, ainda que deixando reais empecilhos sem solução. A responsabilização educacional por meio de avaliações de proficiência seria, portanto, uma saída cômoda para os legisladores. Estes autores salientam que as políticas de responsabilização, tais quais sugeridas, não exonerariam os agentes educacionais de responsabilidades por suas condutas.

Os efeitos, intencionais ou não, das políticas de accountability, quando vinculadas às avaliações externas, podem ser tanto positivos (se alinhados aos objetivos das políticas públicas que as definiram) quanto negativos (como efeitos colaterais não intencionais e prejudiciais). O julgamento de valor embutido na terminologia "positivo/negativo" pode ser de complexa interpretação. As políticas educacionais em foco neste trabalho têm, em geral, objetivos declarados que são considerados positivos, no sentido de avançar a qualidade da educação, melhorar a informação sobre os sistemas educacionais e suportar decisões e seus controles.

Um levantamento feito por Adriana Bauer (2010) sobre os objetivos e usos de sistemas de avaliação em vinte países do continente americano elenca estes objetivos 
declarados. Nenhum dos objetivos inventariados e resumidos em anexo à página 189, pode ser frontalmente considerado "negativo".

[N]um momento inicial de consolidação dos sistemas de avaliação educacional, os objetivos declarados voltavam-se mais para gerenciamento e tomada de decisões políticas e prestação de contas e responsabilização (accountability), sendo possível observar características semelhantes entre os países (BAUER, 2010, p. 329).

Especificamente para o Brasil, Brooke e Cunha listam sete objetivos para o uso de avaliações externas para fins de gestão (2011, p. 24). São eles: avaliar e orientar a política educacional, informar escolas sobre a aprendizagem dos alunos e definir as estratégias de formação continuada, informar o público, alocar recursos, suportar políticas de incentivos salariais, compor política de avaliação docente e certificar escolas e alunos.

Nesta dissertação é assumido que as políticas propostas são "positivas" enquanto busquem avanços na educação, levando a resultados "positivos" quando atingem seus objetivos e a resultados "negativos" quando criam efeitos colaterais não intencionais que conflitam com os objetivos originais.

Exemplos providos por Brian Stecher (2002) ilustram os efeitos, para os principais envolvidos, conforme Quadro 1 a seguir. Stecher lembra ainda que há estudos que indicam um efeito nulo, elencando os trabalhos de Firestone, Mayrowetz, e Fairman (1998) e de Jones et al. (1999), como exemplos ${ }^{7}$.

Os efeitos podem ser percebidos além dos círculos escolares. Por exemplo, o mercado imobiliário pode ser impactado pelas conceitos atribuídos pelos processos de accountability às escolas. Sandra Black identificou (1999) que pais estariam dispostos a pagar 2,5\% a mais pelo metro quadrado imobiliário para ter acesso a escolas com pontuações $5 \%$ maiores, em Massachusetts, Estados Unidos. Na mesma linha de raciocínio, David Figlio e Maurice Lucas (2004) identificam a correlação positiva das pontuações das escolas na Flórida, Estados Unidos, no final dos anos 1990, com o valor de mercado de imóveis residenciais ${ }^{8}$.

7 O primeiro, com entrevistas com 82 professores e diretores dos estados norte-americanos de Maine e de Maryland, concluiu que políticas estaduais têm efeitos menores que os alegados, tanto por opositores quanto proponentes. O segundo, abordou a bonificação docente na Carolina do Norte iniciada em 1998. Estes autores identificaram, por meio de questionários respondidos por 236 professores do ensino básico, que dois terços destes mudaram suas práticas de instrução em função das políticas, mas com porcentagens similares reportando aumentos e diminuições em práticas investigadas.

8 Não se conhecem estudos similares no Brasil. 


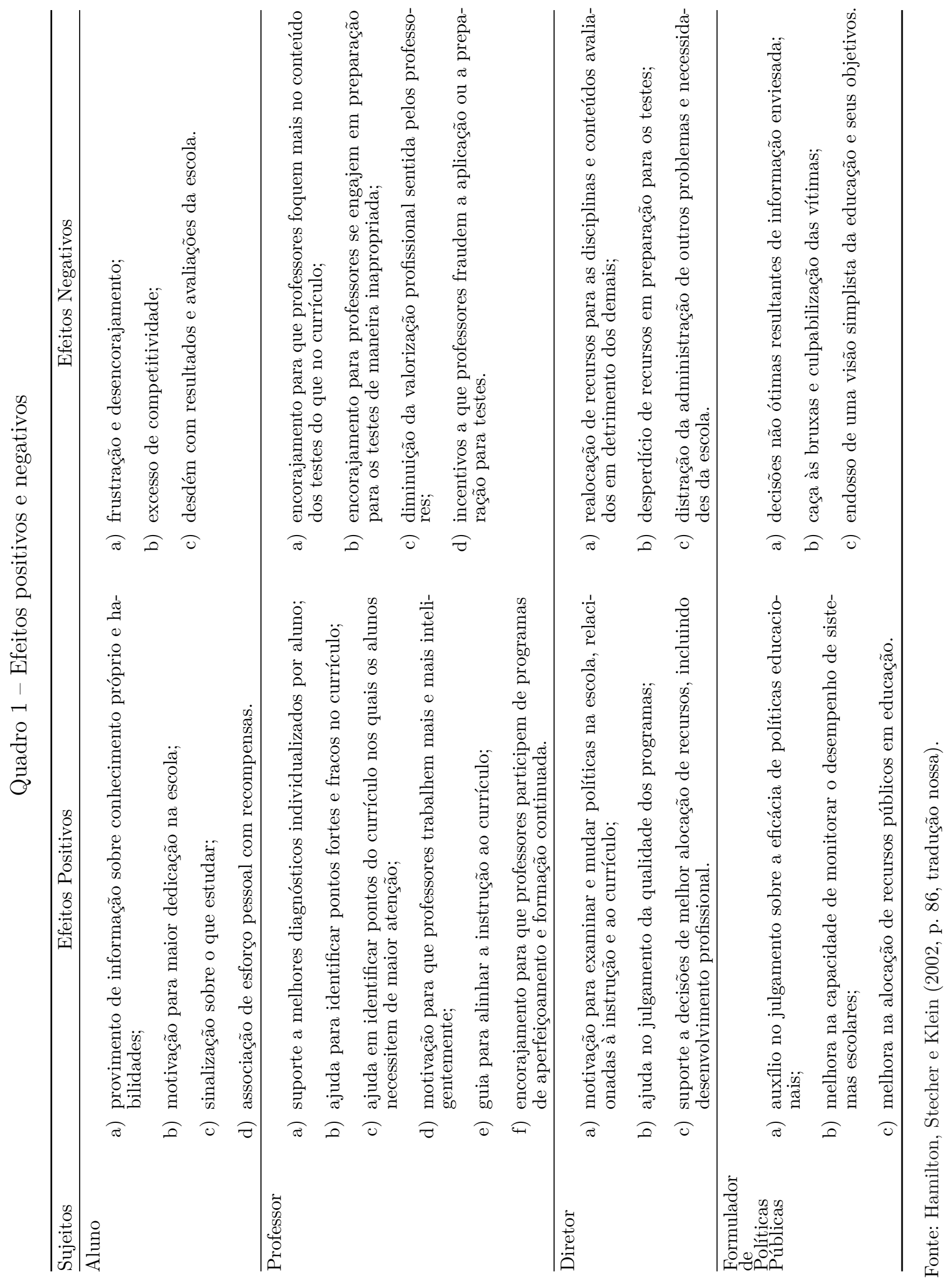




\subsection{Os princípios de Madaus}

Madaus (1988a) enuncia seis princípios que permitem entender as motivações e respostas estratégicas dos agentes às avaliações atreladas a políticas de accountability. $\mathrm{O}$ Quadro 2 apresenta os enunciados em tradução livre ${ }^{9}$ destes princípios ${ }^{10}$.

Quadro 2 - Os princípios de Madaus

\begin{tabular}{cl}
\hline Princípio & Enunciado \\
\hline 1 & $\begin{array}{l}\text { a percepção da importância de uma avaliação induz reações estratégicas nos } \\
\text { agentes envolvidos com as mesmas; }\end{array}$ \\
\hline 2 & $\begin{array}{l}\text { há um inexorável corrompimento de qualquer indicador social usado como base } \\
\text { de políticas e incentivos; }\end{array}$ \\
\hline 3 & $\begin{array}{l}\text { se há a expectativa de que decisões relevantes serão tomadas com base em } \\
\text { resultados de avaliações, professores ensinarão para o teste; }\end{array}$ \\
\hline 5 & $\begin{array}{l}\text { uma cultura de "testes passados" passa a existir em ambientes fortemente } \\
\text { marcados por avaliações com consequências fortes; }\end{array}$ \\
\hline 6 & $\begin{array}{l}\text { professores ajustam seu ensinar aos modos e formatos de cobrança presentes } \\
\text { indicador (falível) de desempenho, especialmente quando as avaliações têm } \\
\text { efeitos determinantes na vida dos avaliados. }\end{array}$ \\
\hline
\end{tabular}

Fonte: Madaus (1988a, p. 35-43, tradução nossa).

O primeiro e terceiro princípios, coordenados, explicam as respostas estratégicas dos agentes frente aos incentivos e regras apresentados pelas políticas com consequências materiais high-stakes e avaliações associadas.

Este não é um fenômeno restrito ao contexto educacional. Em contextos empresariais, se gerentes tiverem benefícios tangíveis ou intangíveis associados ao atingimento de

9 Os princípios de Madaus são apresentados em português no trabalho de Sousa e Oliveira (2010, p. 798-799).

10 1-The power of tests and examinations to affect individuals, institutions, curriculum, or instruction is a perceptual phenomenon; if students, teachers, or administrators believe that the results of an examination are important, it matters very little whether this is really true or false-the effect is produced by what individuals perceive to be the case.

2-The more any quantitative social indicator is used for social decision-making, the more likely it will be to distort and corrupt the social processes it is intended to monitor.

3-If important decisions are presumed to be related to test results, then teachers will teach to the test. 4-In every setting where a high-stakes test operates, a tradition of past tests develops, which eventually de facto defines the curriculum.

5-Teachers pay particular attention to the form and format of the questions on a high-stakes test (e.g., short answer, essay, multiple-choice) and adjust their instruction accordingly.

6 -When test results are the sole or even partial arbiter of future educational or life choices, society tends to treat test results as the major goal of schooling rather than as a useful but fallible indicator of achievement. 
metas de vendas, o processo de planejamento antecipado das mesmas será enviesado por contar com projeções tímidas e conservadoras. De forma análoga, se um bônus financeiro "por atingimento de resultados" para funcionários for determinado pelo cumprimento de um limite superior de orçamento, é esperado que a previsão orçamentária feita previamente com participação dos stakeholders seja inflada, levando a uma má alocação de recursos e um atingimento facilitado de metas (JENSEN, 2003).

O segundo princípio faz referência à Lei de [Donald] Campbell, que propõe que "quanto mais um indicador social quantitativo for usado para a tomada de decisões, mais sujeito ele estará a pressões corrompedoras e mais apto ele será a distorcer e corromper o processo social que visa monitorar" (CAMPBELL, 1976, p. 49).

Os princípios quatro e cinco compreendem o "ensinar para o teste". O principal problema com o "ensinar para o teste" é a inflação de resultados: escores mais altos podem não significar habilidades maiores, havendo práticas que causam inflação em indicadores de proficiência sem que haja real e substantiva melhoria na aprendizagem. Madaus vê a inversão de papéis, em que o conteúdo do teste passa a determinar o currículo abordado em aula, além do empobrecimento na forma de abordar estes conteúdos, de maneira a mimetizar a forma das provas.

O sexto princípio exemplifica o que se dá com o Exame Nacional do Ensino Médio (Enem) no Brasil, com sua crescente projeção na mídia e nas agendas dos educadores.

Uma introdução aos efeitos indesejados das políticas de responsabilização na literatura nacional pode ser encontrada nas contribuições de Luiz Carlos de Freitas e de Nigel Brooke (BAUER; GATTI, 2013). O Quadro 3 resume tanto a opinião dos autores dos textos, quanto a dos autores por eles referenciados.

Para autores diferentes, os efeitos colaterais têm pesos e seriedades diferentes. Em geral, parece ser consenso que o gaming, tal qual introduzido em 1975 pelo American Institute of Industrial Engineers, ocorre dentro das regras propostas enquanto que as fraudes se dão em desacordo às regras (CIZEK, 2001a). Contudo, nem sempre a classificação é clara. 


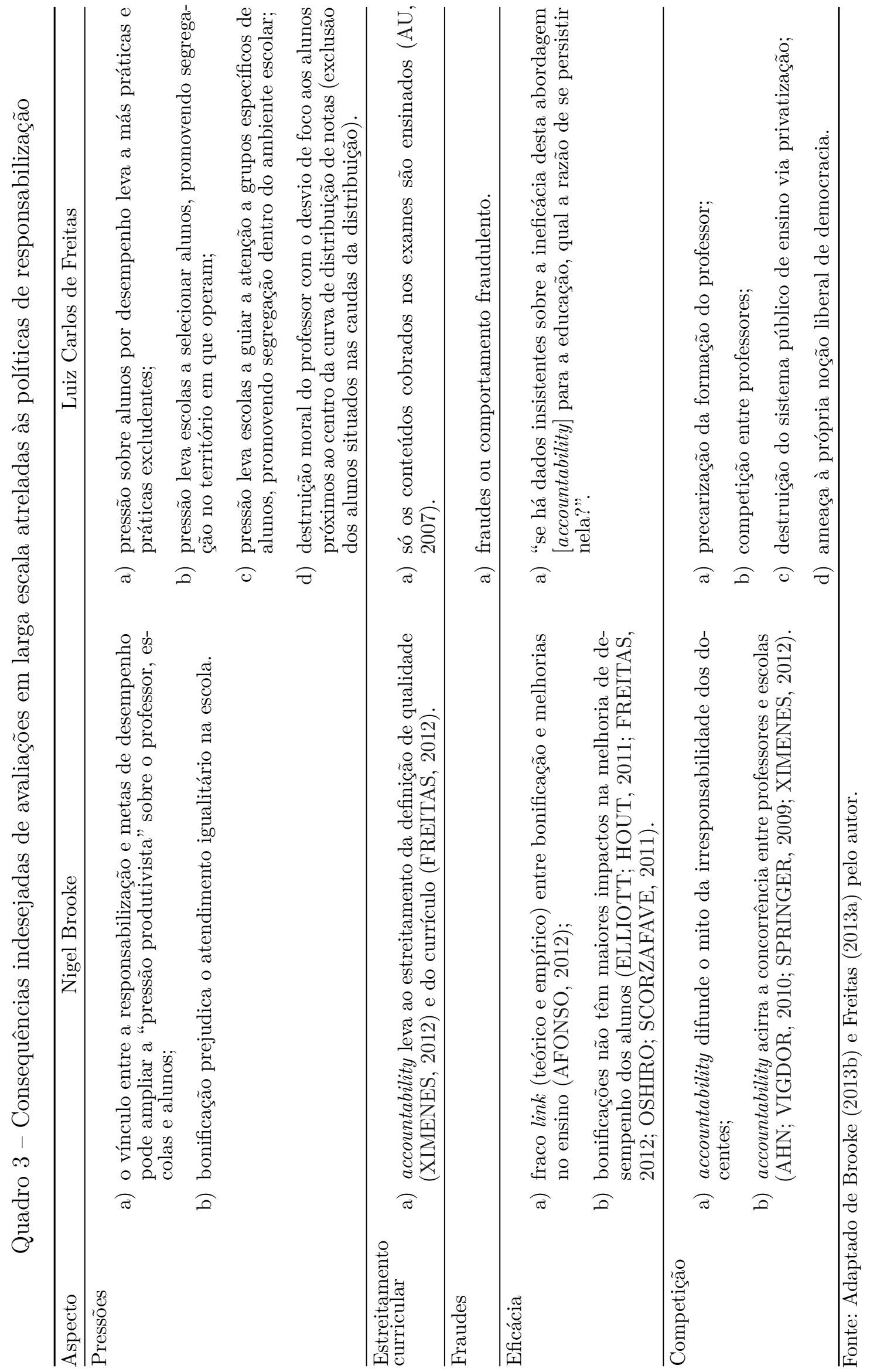


Para ilustrar a gama de valores atribuídos aos efeitos colaterais e suas conflitantes classificações, há o trabalho de Amrein-Beardsley, Berliner e Rideau (2010), que trata todos os efeitos negativos como fraudes, com graus maiores ou menores de seriedade. Estes autores, radicais na categorização, afirmam que é importante ter definições claras para entender, medir e inibir "fraudes".

Para Fernandes e Gremaud, o estreitamento curricular e a manipulação da base de alunos são exemplos de "distorção de incentivos" e fraudes são uma inevitabilidade do gaming:

Dois potenciais riscos têm sido destacados na literatura: distorção de incentivos e gaming. No primeiro, o destaque tem sido dado para o "estreitamento" do currículo e para a exclusão de alunos de baixa proficiência. Se os objetivos dos programas são adequados, o estreitamento do currículo não vem a ser um problema. Por outro lado, pode, de fato, haver um incentivo para a exclusão de alunos com baixa proficiência. Por exemplo, programas cuja medida é a parcela de estudantes acima de determinado nível estimulam as escolas a se concentrarem nos estudantes cujo desempenho está próximo a esse nível de proficiência e a abandonar os alunos de pior desempenho, com baixa probabilidade de alcançar o nível exigido. Assim, os programas devem procurar incluir formas de penalizar a exclusão de alunos com baixa proficiência.

O segundo risco (gaming) decorre do fato que as escolas podem adotar estratégias para alterar os resultados, mas que não mudam a qualidade do ensino ministrado como, por exemplo, treinar e motivar os estudantes para os testes ou excluir dos exames alunos de baixa proficiência. Parte desses problemas não se pode evitar como, por exemplo, o treinamento e motivação dos estudantes para os exames, mas não tendem a ser grave. O problema maior é quando o gaming se confunde com fraude. Nesses casos, só a fiscalização pode resolver (FERNANDES; GREMAUD, 2009, p. 223-224).

Para Koretz (2008, p. 777), ao abordar os efeitos colaterais por uma ótica psicométrica, uma gravidade maior se verifica quando fraudes ou coaching distorcem o escore do aluno. Em contrapartida, é menos grave a inflação do escore agregado da turma, escola ou estado, por meio da exclusão de alunos de baixa proficiência, sem enviesar resultados individuais.

Como modelo de estudo, apresenta-se a classificação a seguir, que permite uma ordenação das reações possíveis às políticas de accountability na educação. A vantagem desta classificação é situar reações e seus efeitos em escala de gravidade, com partições razoavelmente bem definidas, permitindo ao pesquisador, educador ou gestor entender os fenômenos de maneira comparativa e decidir por si o que é aceitável ou não. 


\subsection{A classificação de Koretz, McCaffrey e Hamilton}

Em 2001, Daniel Koretz, Daniel McCaffrey e Laura Hamilton publicaram um estudo sobre a validade de melhorias aferidas em avaliações, vinculadas a políticas de responsabilização. Sob esta ótica, apresentaram uma classificação (2001, p. 16) que descreve os tipos de respostas e reações estratégicas às avaliações externas, referindo-se às ações que educadores tomam, tanto desejáveis quanto indesejáveis. Koretz retoma esta classificação, com exemplos, em seu livro Measuring up: what educational testing really tells us (2009).

Esta classificação é útil pela abrangência e pragmatismo na organização de pesquisas e relatos, por ordenar os efeitos como decorrência de (re)ações dos agentes. O Quadro 4 traduz os termos originais empregados e suas descrições, para os sete tipos de respostas de professores às políticas. Uma importante característica desta classificação é sua ordenação, refletindo o julgamento dos autores quanto ao mérito ou gravidade comparativos de cada categoria, conforme explicado adiante.

Quadro 4 - A classificação de Koretz de reações à accountability

\begin{tabular}{|c|c|}
\hline Reação & Descrição \\
\hline $\begin{array}{l}1 \text { Working more ef- } \\
\text { fectively }\end{array}$ & $\begin{array}{l}\text { trabalhar com mais eficácia (por exemplo, desenvolver e aplicar } \\
\text { melhores métodos de ensino, melhores currículos); }\end{array}$ \\
\hline 2 Teaching more & $\begin{array}{l}\text { ensinar mais (por exemplo, passar mais tempo ensinando, aumentar } \\
\text { número de horas de aula ou dias letivos por ano, instituir aulas de } \\
\text { reforço e suplementares); }\end{array}$ \\
\hline 3 Working harder & $\begin{array}{l}\text { aumentar esforço envolvido no aprendizado (aplicando lição de casa } \\
\text { em volumes maiores ou tarefas mais difíceis, cobrindo conteúdo mais } \\
\text { extenso, desde que não haja comprometimento de profundidade); }\end{array}$ \\
\hline 4 Reallocation & $\begin{array}{l}\text { realocar recursos (incluindo tempo dedicado a grupos de alunos } \\
\text { com necessidades específicas ou dando ênfase a tópicos ou tipos de } \\
\text { questões cobradas nos exames, à custa de outros, desprestigiados); }\end{array}$ \\
\hline 5 Alignment & $\begin{array}{l}\text { alinhar o currículo ensinado ao currículo cobrado nos exames, redu- } \\
\text { zindo cobertura de conteúdos não avaliados; }\end{array}$ \\
\hline 6 Coaching & $\begin{array}{l}\text { preparar os alunos (com base em testes anteriores, simulados, dedi- } \\
\text { cação excessivamente focada em formatos ou questões de testes). }\end{array}$ \\
\hline 7 Cheating & $\begin{array}{l}\text { praticar fraudes (exclusão de alunos das avaliações, reclassificações } \\
\text { fraudulentas, adulteração de respostas individuais ou resultados } \\
\text { agregados, "colas" e auxílio marginal às regras das avaliações). }\end{array}$ \\
\hline
\end{tabular}

Fonte: Koretz, McCaffrey e Hamilton (2001, p. 16, tradução nossa). 


\subsection{Exemplos de reações positivas}

Os itens 1, 2 e 3 do Quadro 4 são, nas palavras de Koretz, "aquilo que alguns proponentes de políticas sólidas querem ver"11 (KORETZ, 2009, p. 251, tradução nossa). Em geral, as respostas associadas aos três primeiros itens têm efeito sustentável e duradouro em ganhos na aprendizagem e "podem produzir melhores desempenhos em elementos substantivos das avaliações"12 (KORETZ; MCCAFFREY; HAMILTON, 2001, p. 17. tradução nossa).

Nessas respostas, cabem para o Brasil os exemplos de escolas de ensino integral, aulas de reforço ou esforços de recuperação antecipada ou o Programa Novo Mais Educação do MEC, relançado em 2016, com a adesão voluntária de escolas para aumentar a carga horária em cinco a quinze horas por semana. Não se trata de ingenuidade destes autores imaginar que há simplesmente espaço para ensinar mais. A classificação de Koretz et al. visa a enquadrar as respostas dos agentes, sem fazer julgamento de valor sobre a exequibilidade das políticas. Se faltam materiais didáticos, preparo ou capacitação docente, infraestrutura básica nas escolas ou há um clima disciplinar adverso, todos problemas frontais ao "ensinar mais", a preocupação dos autores é com a reação dos agentes e é neste sentido que propõem a classificação.

Na dimensão da eficácia, tome-se o exemplo dos resultados sobre comportamento de alunos em sala de aula, com base na pesquisa Talis 2013. Gabriela Moriconi e Julie Bélanger (2015) reportam um Brasil em que 20\% do tempo de aula dos anos finais do ensino fundamental são gastos com esforços dos professores para manter a ordem em sala equivalente a um dia inteiro por semana, um claro exemplo de espaço para ensinar com mais eficácia.

Como exemplos do ensinar material mais "difícil", vale lembrar iniciativas como a Olimpíada Brasileira de Matemática para Escolas Públicas (OBMEP), a Olimpíada Nacional de História do Brasil (ONHB) e a Olimpíada Brasileira de Astronomia (OBA). No caso da primeira, Roberta Biondi (2009) encontrou efeito positivo da participação das escolas na OBMEP sobre a proficiência Saeb em Matemática do $9^{\circ}$ ano do EF.

Contra-intuitivamente, mas com suporte de evidências, os resultados não são sempre os esperados: Aquino (2011), ao estudar o efeito da ampliação do horário de aulas com escolas integrais no estado de São Paulo, não encontrou efeito na proficiência dos alunos avaliados pelo Saresp, levando a crer que há mais complexidades em jogo, não bastando dar "mais do mesmo".

O "ensinar mais" nem sempre é uma solução. Em excesso, pode levar a estresse, desânimo e degradação da aprendizagem. Um aumento na carga de trabalho com resultante

11 The first three are what proponents of high-stakes testing want to see.

$12[\ldots]$ they can produce higher levels of performance on substantive elements of the test. 
redução nos horários de recreio é criticado por Koretz (2009) e citado por ele como um problema potencial associado ao "ensinar mais". Outros exemplos de excessos são elencados por David Nichols e Sharon Berliner (2005), que apresentam inúmeros relatos de uso de horários de recreio para reforçar a preparação para exames em escolas americanas ${ }^{13}$.

A saúde dos avaliados pode estar em jogo: Liang Choon Wang (2013) verifica o aumento de tendências suicidas em jovens sul-coreanos em razão das pressões por resultados nas avaliações e do esforço preparatório a eles associados. A recente Pesquisa Nacional de Saúde Escolar (IBGE, 2016), apesar de mencionar que mais de $12 \%$ dos jovens do $9^{\circ}$ ano do EF têm perda de sono por preocupações, não faz nenhuma associação destes sintomas com pressão de estudos ou responsabilização escolar.

\subsection{Estudos sobre realocação e alinhamento de recursos}

Os itens 4, 5 e 6 do Quadro 4 têm natureza ambígua: "todos os três podem levar a ganhos reais [de aprendizagem], levar à inflação de escores, ou a ambos" segundo Koretz. Este autor lembra, que de modo geral, estes três itens recebem, ainda que ambiguamente, a designação de "ensinar para o teste", com interpretações positivas ou negativas, dependendo de "como" se ensina para o teste, podendo até se dar a melhoria da validade dos resultados medidos (KORETZ, 2009, p. 255).

A realocação (item 4) envolve a mudança de foco de recursos empregados na instrução para melhor atender o conteúdo de uma dada avaliação. São eles: tempo de aula, lições de casa, atenção dos pais, professores mais hábeis, entre outros. A realocação se dá no contexto de recursos finitos: faz-se necessário tirar de um para dar a outro. O efeito prejudicial da realocação depende da importância daquilo que recebe menos atenção ou simplesmente deixa de receber. Uma avaliação é sempre uma amostragem dos conteúdos relevantes de uma disciplina, portanto, há sempre tópicos não cobertos pela amostragem. Se a realocação desprestigiar estes aspectos não amostrados, porém ainda importantes, os escores medidos serão inflados artificialmente.

O ensinar para o teste é um exemplo de realocação: nesse caso, do tempo e talento usado para ensinar aspectos importantes do currículo, quando se passa a focar somente em conteúdos ou formatos que "caem na prova". O estreitamento curricular é um efeito resultante desta realocação. Madaus preconiza que o conteúdo das avaliações passa a ser efetivamente o currículo e, neste sentido, Sousa e Oliveira lembram que "os testes transferem controle do currículo para a agência que controla o exame" (2010, p. 799).

Quanto ao item 5, "o alinhamento é apenas um sinônimo de realocação", Koretz admite, em seu livro (2009, p. 254). O autor ilustra, para o alinhamento, os mesmos

13 Não se encontrou registro na literatura brasileira sobre uso similar dos horários de recreio no Brasil. 
exemplos de prejuízos por inflação associados à realocação. Ao leitor, mesmo que cuidadoso, não há real distinção entre estas duas categorias.

Jane Hannaway (1996, p. 104), cita Gramlich e Koshel 1975 e Rappel (1990), apontando o fenômeno de concentração dos esforços docentes sobre os alunos de desempenho mediano, ignorando os demais, nas extremidades da distribuição de proficiência. O termo "bubble kids"14 se popularizou com o artigo de Jennifer Booher-Jennings (2005). Este estudo focou uma única escola do Texas, identificando três efeitos, designados pela expressão "educational triage":

a) a realocação de tempo docente para focar prioritariamente alunos percebidos como ligeiramente abaixo da nota de corte da avaliação, os "bubble kids". Com isso, a escola acumularia um resultado agregado marginalmente maior na pontuação, às custas do tratamento inequitativo aos alunos;

b) a concentração dos esforços docentes somente no subconjunto de alunos avaliados, de séries específicas, relegando a segundo plano os alunos de séries não avaliadas externamente;

c) a alteração da base de alunos avaliados, por meio de reclassificações fraudulentas quanto às necessidades especiais de alunos de baixa proficiência ${ }^{15}$.

O fenômeno dos "bubble kids" recebeu crescente atenção em pesquisas, à luz do NCLB, como indicado em Hamilton (2007), Springer (2007; 2008), McCarty (2009), Dee e Jacob (2010; 2011), Neal e Schazenbach (2010), Lauen e Gaddis (2012), Reid (2012), Zane (2012), DeMatthews (2014) e Jennings e Sohn (2014). Andrew Ho (2008, p. 357) associa esta triagem e foco em alunos fronteiriços como uma resposta estratégica associada à escassez de recursos, um "zero-sum game" (jogo de soma zero), simplesmente por não haver recursos suficientes para atender a todos. O foco nos medianos asseguraria maior retorno para a escola, no que diz respeito ao atingimento de metas sob o NCLB. Este tipo de "triagem" ou fenômeno dos "bubble-kids" não encontra paralelo, por enquanto, na literatura nacional ${ }^{16}$.

\subsubsection{O "ensinar para o teste" e o estreitamento curricular}

Brian Stecher (2002, p. 1) resgata a história da origem do termo "estreitamento curricular", atribuindo-o a Shepard e Dougherty (1991), ressaltando que o trabalho de Corbett e Wilson do mesmo ano (1991) foi pioneiro na vinculação do estreitamento às

14 Ver também Linda McNeil (2000, p. 254) e Walt Haney (2000, p. 2).

15 A alteração da base de alunos testados e a reclassificação por necessidades especiais de maneira irregular são classificáveis como fraudes, cabendo no sétimo item de Koretz.

16 A expressão "triagem", no Brasil, habitualmente aparece associada à questão da seleção e admissão de alunos e a medição do efeito escola. 
políticas high-stakes. Stecher estudou o fenômeno do estreitamento, no Kentucky e no estado de Washington, nos EUA, com base em questionários respondidos por professores, indicando o aumento ou diminuição do tempo dedicado a disciplinas (STECHER et al., 2000). Os resultados ilustrados na Figura 4 indicam que as disciplinas cobertas pelas avaliações registraram aumentos no tempo de aula, enquanto que as disciplinas não avaliadas tiverem um decréscimo, em Washington.

Figura 4 - Estreitamento curricular verificado no estado de Washington

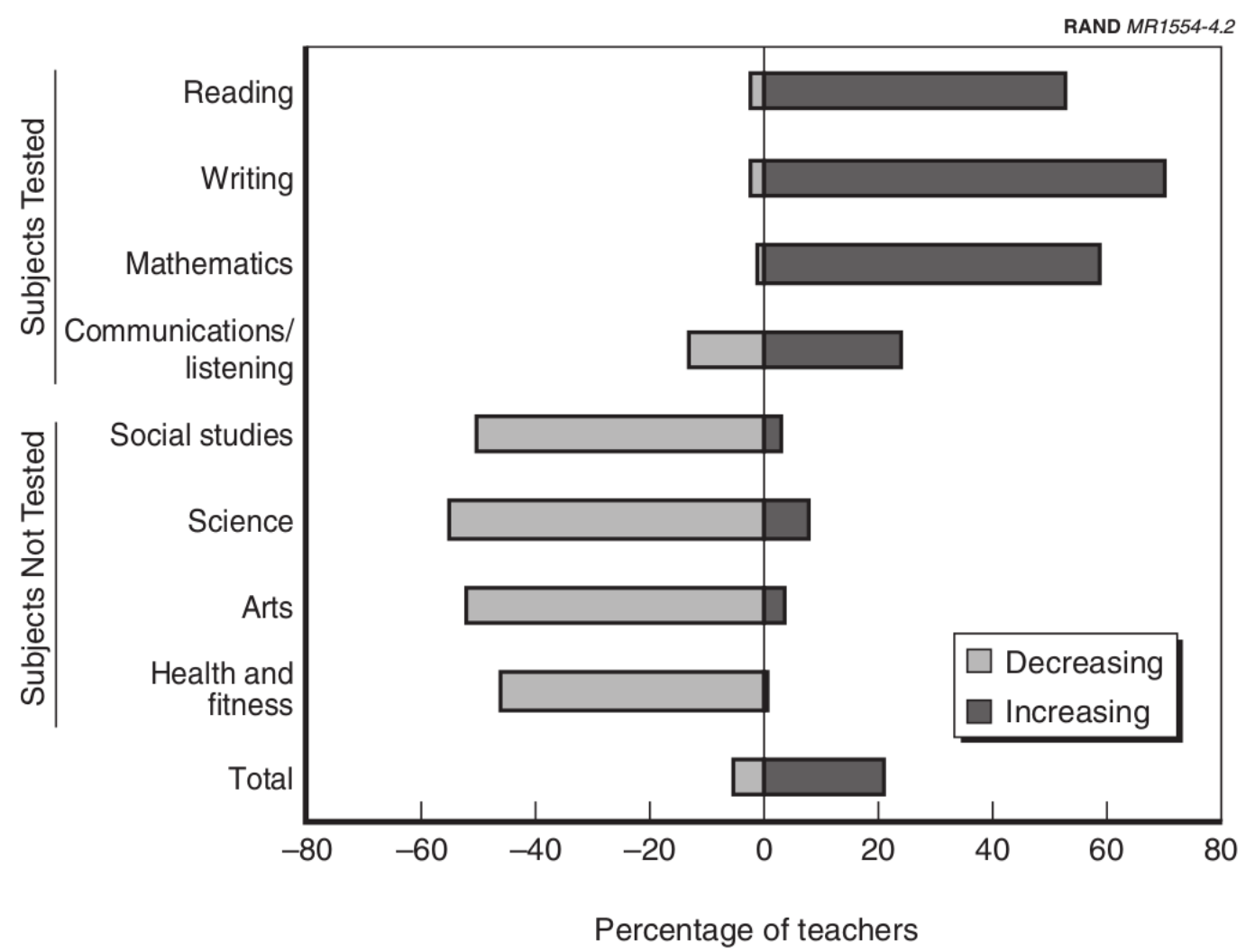

Fonte: Hamilton, Stecher e Klein (2002, p. 92).

Um estudo preparado por Pedulla et al (2003) baseou-se em questionários preenchidos por 12 mil professores, em 2001, cobrindo todos os Estados Unidos com atenção especial ao estado de Massachusetts, para a National Board on Educational Testing and Public Policy. Fortemente embasado nos princípios postulados por Madaus, um dos coautores do estudo e seu colega no Boston College, os questionários tinham 80 questões cobrindo a influência de políticas de accountability sobre clima escolar, pressão sobre os docentes, alinhamento de práticas em classe, percepção de valor das avaliações, influências no conteúdo e modos de instrução, esforços na preparação para avaliações, consequências não intencionais e usos declarados das avaliações. O estudo usou análise fatorial e análises de variância (Anova) para organizar as respostas em grupos de escolas classificadas de acordo com a intensidade de consequências para docentes e alunos. Ainda sem estar sensibilizada pelos efeitos do programa NCLB, que só entrou em vigor em janeiro de 2002, 
mas refletindo as políticas estaduais de accountability adotadas desde os anos 1990, os resultados apresentados suportaram empiricamente os princípios de Madaus. Ao longo de todos os programas analisados, professores relataram aumento do tempo dedicado a disciplinas testadas e decréscimo naquelas não avaliadas, por meio de reportes nos questionários. Os efeitos foram mais fortes nos anos iniciais e intermediários e mais fracos nos anos finais do high school.

No Brasil, uma recente abordagem que trata do tema do "ensinar para o teste", com análises quantitativas foi desenvolvida por Botelho e colaboradores (2014, p. 59-80). Estes autores usaram dados da pesquisa BNDES 2012, que abordou 300 escolas públicas do Brasil, avaliando cerca de 35 mil alunos do $4^{\circ}, 6^{\circ}$ e $8^{\circ}$ ano do ensino fundamental, em Leitura e Matemática, com escala compatível com o Saeb (FERNANDES et al., 2014, p. xii). Adicionalmente, a pesquisa contou com trabalho de campo, suportando a aplicação de questionários a alunos, professores e gestores das escolas amostradas. Este estudo pioneiro, no sentido de quantificar incidências, associou as proficiências aferidas a respostas dos questionários, algumas destas endereçando o "ensinar para o teste". Para a pergunta "Alguns dias antes da Prova Brasil a escola ou algum professor ensinou 'macetes' ou 'truques' para ir bem na prova?", 38\% dos alunos do $4^{\circ}$ ano responderam "Sim", contra 31\% do $6^{\circ}$ ano e $21 \%$ do $8^{\circ}$ ano. As respostas "Não" foram, respectivamente, $37 \%, 40 \%$ e $50 \%{ }^{17}$. O estudo foi inconclusivo quanto à associação dos "macetes" à existência de premiações formais, mas concluiu que "existe evidência de que as escolas com pior desempenho são as que mais se utilizam de 'truques' e 'macetes' para melhorar o desempenho dos piores alunos" (BOTELHO et al., 2014, p. 78).

Laura Hamilton, em Standards-based Accountability Under No Child Left Behind (2007), estuda o efeito do estreitamento curricular a partir de questionários preenchidos por professores dos estados da Califórnia, Pensilvânia e Geórgia, no período de 2003 a 2004, já sob efeitos de accountability forte do programa NCLB. Os questionários apresentados a professores e diretores do "elementary school" (educação infantil até o quinto ano) e "middle school" (do sexto ano ao oitavo ano), por disciplina, indagavam qual fora a variação da carga semanal de aula. A pesquisadora contou com respostas de 2731 professores, distribuídos em 267 escolas nos três estados, tendo obtido uma taxa média de participação de 83\%. As disciplinas cobertas em avaliações high-stakes tiveram aumento na carga horária. Nos anos iniciais (elementary) o estreitamento curricular resultou mais acentuado do que nos anos finais (middle), contudo, o efeito se verificou em ambas as etapas.

A Figura 5 aponta as variações de tempo alocado por disciplina identificados pela pesquisadora para alunos do Elementary School dos três estados estudados. Este estudo revela que o estreitamento se manifesta também em anos escolares mais avançados, em que mais de um professor se envolve com as turmas afetadas.

$\overline{17}$ As diferenças para acomodar um total de $100 \%$ por ano foram apresentadas como "Não sei o que é". 
Figura 5 - Mudanças de tempo de instrução - elementary school

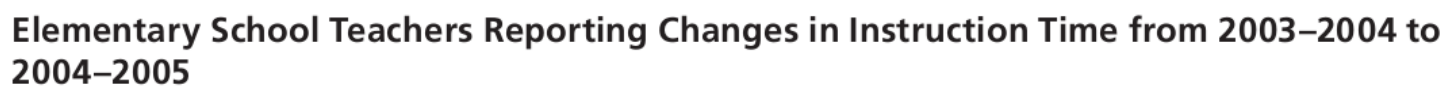

\begin{tabular}{|c|c|c|c|c|c|c|c|c|c|c|c|c|c|c|c|c|c|c|}
\hline \multirow{3}{*}{$\begin{array}{l}\text { Subject } \\
\text { Changed }\end{array}$} & \multicolumn{6}{|c|}{ California } & \multicolumn{6}{|c|}{ Georgia } & \multicolumn{6}{|c|}{ Pennsylvania } \\
\hline & \multicolumn{2}{|c|}{-} & \multicolumn{2}{|c|}{$=$} & \multicolumn{2}{|c|}{+} & \multicolumn{2}{|c|}{ - } & \multicolumn{2}{|c|}{$=$} & \multicolumn{2}{|c|}{+} & \multicolumn{2}{|c|}{ - } & \multicolumn{2}{|c|}{$=$} & \multicolumn{2}{|c|}{+} \\
\hline & $\%$ & SE & $\%$ & SE & $\%$ & SE & $\%$ & SE & $\%$ & SE & $\%$ & SE & $\%$ & SE & $\%$ & SE & $\%$ & SE \\
\hline Math & 5 & 2 & 62 & 3 & 28 & 3 & 6 & 1 & 60 & 3 & 22 & 2 & 3 & 1 & 55 & 5 & 38 & 5 \\
\hline Science & 19 & 3 & 54 & 4 & 21 & 3 & 10 & 1 & 63 & 3 & 11 & 2 & 22 & 4 & 62 & 4 & 8 & 2 \\
\hline $\begin{array}{l}\text { Reading } \\
\text { or ELA }\end{array}$ & 3 & 1 & 59 & 4 & 32 & 4 & 4 & 1 & 62 & 3 & 21 & 2 & 7 & 3 & 63 & 4 & 24 & 3 \\
\hline $\begin{array}{l}\text { Social } \\
\text { studies }\end{array}$ & 28 & 5 & 55 & 4 & 10 & 2 & 11 & 1 & 65 & 3 & 9 & 2 & 25 & 4 & 60 & 4 & 6 & 1 \\
\hline $\begin{array}{l}\text { Arts or } \\
\text { music }\end{array}$ & 23 & 4 & 60 & 4 & 9 & 2 & 9 & 2 & 69 & 3 & 4 & 1 & 2 & 1 & 88 & 2 & 3 & 1 \\
\hline $\begin{array}{l}\text { Physical } \\
\text { education }\end{array}$ & 23 & 4 & 58 & 5 & 11 & 3 & 5 & 1 & 74 & 3 & 5 & 1 & 3 & 1 & 88 & 2 & 3 & 1 \\
\hline
\end{tabular}

NOTE: Response options included decreased by $>45$ minutes per week, decreased by 1-45 minutes per week, stayed the same, increased by $>45$ minutes per week, increased by 1-45 minutes per week, and don't know. Percentages for - columns represent the sums of decreased by $>45$ minutes per week and decreased by 1-45 minutes per week responses. Percentages for + columns represent the sums of increased by $>45$ minutes per week and increased by 1-45 minutes per week responses. Percentages for $=$ columns represent stayed the same responses.

Fonte: Adaptado da Tabela B.52 em Hamilton (2007, p. 175) pelo autor.

Margareth Crocco e Arthur Costigan, em The Narrowing of Curriculum and Pedagogy in the Age of Accountability (2007), usam uma abordagem diferente, inteiramente embasada em entrevistas feitas entre 2000 e 2005, para pontuar a influência de políticas de accountability, em escolas da cidade de Nova York.

Martin West lamenta a ausência de evidências além das anedotais para entender o estreitamento curricular, nos EUA pós-NCLB (2007, p. 52). Para "fechar esta lacuna", o autor compilou dados do Schools and Staffing Survey (SASS) do U.S. Department of Education sobre o tempo de aula reportado para alunos do primeiro a sexto anos, por semana, nos anos letivos de 1987/88 a 2003/04, para as disciplinas de Leitura, Matemática, Ciências e História/Estudos Sociais. A tabulação ${ }^{18}$ identificou que Leitura teve um aumento de 36,6 minutos por semana, Matemática teve 28,8 minutos semanais adicionais, ambas avaliadas em modo high-stakes, enquanto Ciências e História/Estudos Sociais, não cobertas pelas avaliações high-stakes, tiveram reduções de 17,4 e 21,6 minutos semanais, respectivamente. Cruzando os dados do SASS com dados da pesquisa Quality Counts 2004 da Education Week, West identificou que as reduções eram maiores para as

18 Suas amostras tinham 6,9 mil a 9,3 mil escolas. 
disciplinas não cobertas nas avaliações externas. Adicionalmente, o autor verificou que os movimentos de estreitamento foram maiores em escolas com maior número de alunos representantes de minorias raciais.

No Brasil, Luiz Carlos Gesqui (2015a, 2015b) apontou estreitamento curricular, aplicação excessiva de simulados e promoções discentes baseadas em frequência como respostas à responsabilização em escolas da rede paulista:

As escolas, com base no Idesp, definem as práticas escolares a serem efetivadas das quais se destacam a excessiva aplicação de exames simulados e a promoção - pautada basicamente nos registros de frequência - dos alunos para a série seguinte. Tal afirmação é possível a partir de participações em reuniões pedagógicas em quatro destas escolas, no período de 2008 a 2011 (GESQUI, 2015b, p. 465).

Em Cerdeira, Almeida e Costa (2014), são contrastadas as redes da cidade do Rio de Janeiro e de Duque de Caxias, a primeira com política de alto impacto (bonificação) e a segunda, com low-stakes ("Não houve divulgação pública dos objetivos, da metodologia e dos resultados da avaliação" (p. 204). Os autores registraram qualitativamente depoimentos que sugerem o estreitamento curricular:

Podemos perceber também que entre os profissionais do Rio de Janeiro, onde a política de responsabilização é de altas consequências, há mais relatos sobre a redução ou abolição da utilização do livro didático, em função do uso exclusivo da apostila elaborada pela Secretaria de Educação e de alguns professores estarem deixando de produzir provas internas, contando apenas com o desempenho nas provas bimestrais externas. Esses relatos podem sugerir que esse tipo de política de responsabilização favorece maior estreitamento do currículo escolar (CERDEIRA; ALMEIDA; COSTA, 2014, p. 220).

A dissertação de Caio Augusto Carvalho Alves (2011) analisou a influência do Saresp no cotidiano de duas escolas de Guarulhos, no estado de São Paulo, com desempenhos bem distintos na avaliação estadual. Em entrevistas registradas no seu trabalho, destacam-se os trechos abaixo, indicativos de estratagemas maximizadores de resultados, por meio do ensinar para o teste, a supressão de alunos de baixa proficiência e fraudes com gabaritos. Sobre o ensinar para o teste, Alves registrou:

Eu conheço um caso de escola, que no dia que foi aplicada a prova do Saresp, pegou um professor específico daquela matéria pra resolver o exercício pros alunos. Pra quê? Pra colocar o índice lá em cima. Então você desvirtua todo o trabalho do governo. Então virou um caos, por quê? Qual é o objetivo afinal? É atingir o índice? Você colocar um professor ali daquela matéria pra preparar o aluno praquilo. Pra ele dar uma dica "ó, é assim que faz, ó[...] mais ou menos é por aqui[...]" (ALVES, 2011, p. 87).

Outro exemplo de tática que objetiva as dificuldades de interpretação que os alunos têm da prova é o uso recorrente, nas duas escolas, das 
questões de avaliações de anos anteriores para a composição das aulas. Muitos professores postergam ou substituem atividades de seus planos de ensino para trabalhar estas questões. Alguns chegaram a denunciar que a "Proposta São Paulo faz Escola" não atende às competências e habilidades cobradas no Saresp, o que os leva a buscar outras práticas de ensino[...] [...] Alguns professores, para treinar questões que exigem a interpretação de texto dos alunos, simplesmente planejam suas aulas incluindo um maior ou menor número de questões do Saresp nas suas atividades diárias com os alunos. (ALVES, 2011, p. 118)

O coaching, classificado no item 6 de Koretz (conforme Quadro 4), é uma ajuda de natureza operacional dada pelos instrutores aos testados. Suas consequências, como a realocação/alinhamento, são de natureza ambígua. Se proporcionado em demasia, subtrai tempo útil de aula de conteúdo mais geral e importante. Como ilustração, o foco exagerado em "macetes" e "dicas" para optar entre respostas a questões de múltipla escolha pode inflar os escores e sobrecarregar os alunos com uma habilidade de difícil reaplicação no mundo externo, um "ensinar para o aspecto operacional do teste".

Koretz lembra, porém, que na medida certa, o coaching pode até melhorar a validade de uma avaliação, se abordar aspectos práticos de como preencher folhas de respostas adequadamente sem incorrer em erros de transcrição ou de marcações incompatíveis com a leitura ótica automatizada.

\subsection{Estudos sobre comportamentos fraudulentos}

O item 7 do Quadro 4 inclui todos os comportamentos francamente fraudulentos com reações descritas por Koretz como "unambiguously bad" (claramente indesejáveis) (2008, p. 3). Gregory Cizek, estudioso das fraudes em ambientes educacionais, as definiu como "qualquer tentativa, por engodo ou meios fraudulentos, de se fazer representar como possuidor de conhecimentos que não se tem"19 (1999, p. 3, tradução nossa). Dois anos depois, expandiu sua definição para permitir maior generalização: "fraude é qualquer ação que viole as regras de aplicação de uma avaliação"20 (CIZEK, 2001a, tradução nossa).

Como suporte ao entendimento das metodologias de análises de fraudes em avaliações, há dois trabalhos estrangeiros de interesse, como introdução ao assunto. O primeiro é a dissertação de mestrado de Bradley Thiessen (2006), da Universidade de Iowa, com grande mérito de decompor métodos e abordagens existentes à época em parcelas mais simples de entender, caracterizando-se como uma introdução bastante acessível ao assunto. O segundo é a tese de T.J Bliss (2012), da Brigham Young University, que consiste de uma

19 Cheating can be seen as an attempt, by deceptive or fraudulent means, to represent oneself as possessing knowledge.

20 Cheating can be defined as any action that violates the rules for administering a test. 
extensa revisão da literatura, descrevendo e comparando treze abordagens para identificar fraudes mediante índices e estatísticas ${ }^{21}$.

Esta dissertação aborda o aspecto da fraude docente. Sugere-se uma partição destas fraudes verificadas em dois subgrupos, "tampering with the test-taking pool" (a manipulação da base de alunos avaliados) e "teacher cheating" (a fraude docente), pois tratam de mecanismos diferentes de gaming, com abordagens de análise distintas.

\subsubsection{Estudos sobre manipulações da base de alunos testados}

Uma primeira forma de fraude, conhecida na literatura estrangeira como "tampering with the test-taking pool", trata da manipulação fraudulenta do grupo de alunos que são efetivamente testados. Aqui, também, as ações identificadas são variadas, mas dependem fundamentalmente do conhecimento prévio que os docentes têm sobre o potencial desempenho futuro do aluno numa avaliação. Alunos tidos como "liabilities" ("passivos", no sentido literal contábil), que potencialmente prejudicariam o resultado da escola, numa avaliação, são guiados a se ausentarem no dia da prova. Múltiplas opções se apresentam aos agentes, com dezenas de incidências registradas, como descrevem Amrein e Berliner (2002), Nichols e Berliner (2005; 2007), Amrein-Beardsley, Berliner e Rideau (2010) e Ahn (2013). Bill Zlatos, um dos primeiros a estudar a manipulação de alunos nas avaliações, explica o fenômeno:

Como qualquer bom veneno, a exclusão é de difícil detecção. O público desavisado e a mídia raramente perguntam quem foi testado. Editores dificilmente atrapalharão os rankings de escolas com ainda mais números. A exclusão se apresenta com álibis plausíveis: a escola não quer constranger determinados alunos ou torná-los mais ansiosos; a prova não foi feita para crianças como estas; as normas das avaliações permitem e acomodam ausências; além do mais, educadores e reguladores não têm, ainda, consenso sobre a ética da exclusão ${ }^{22}$ (ZLATOS, 1994, p. 25, tradução nossa).

Há múltiplos estratagemas descritos para excluir os alunos dos testes. Alunos podem receber dispensa prévia, como relatado por Amrein-Beardsley, Berliner e Rideau (2010, p. 6). Alunos podem ser redirecionados a atividades alternativas, em horários concorrentes às provas, como explanado por Rustique-Forrester (2005, p. 22). Alunos

21 Uma abordagem promissora que possivelmente terá frutos é proposta por Zhan Shu, da Universidade da Carolina do Norte (2010). Este autor introduz em sua tese uma abordagem descrita como "Deterministic, Gated Item Response Theory Model" (DGIRTM), com potencial para identificar múltiplos tipos de fraudes e corrigir pontuações TRI para acomodar estes efeitos.

22 Like any good poison, exclusion is difficult to trace. The unsuspecting public and news media rarely ask questions about who is tested, end newspaper editors are unlikely to confuse the rankings of local schools with more numbers. Exclusion also provides a host of reasonable alibis: The school does not want to embarrass specific groups of children or make them anxious, The test was not normed for children like them. And besides, educators and policymakers haven't reached consensus on whether exclusion is appropriate - even ethical in the first place. State regulations and local policies usually allow it. 
podem ser suspensos para que estejam ausentes durante a avaliação, fenômeno descrito por Figlio (2005, p. 3), que reporta evidências de alunos de desempenho mais fraco serem sujeitados a suspensões mais longas que alunos que não sejam "liabilities". Alunos podem ser reclassificados, proposital e incorretamente, em grupos com necessidades especiais (de língua nativa, com dificuldades cognitivas, com necessidades especiais), para que sejam avaliados por exames alternativos ou não tenham resultados consolidados nos grupos passíveis de responsabilização, como reportado por Cullen e Reback (2006), Figlio e Getzler (2002) e, mais recentemente, por Richardson (2015).

Ao analisar as experiências inovadoras em Sobral, Ceará, pesquisadores do Inep descreveram estratagemas para a obtenção do Prêmio Escola Alfabetizadora, em consonância com o observado nos EUA:

\begin{abstract}
Visando ao prêmio, algumas unidades tentaram transferir alunos com baixo desempenho para outros estabelecimentos ou impedir a participação das crianças na avaliação externa. A Secretaria de Educação precisou se valer de alguns mecanismos de inibição de condutas impróprias: se um aluno for transferido após o mês de setembro, seu resultado será contabilizado na escola de origem. Além disso, estabeleceu como critério de premiação que, no mínimo, 98\% dos alunos de cada unidade escolar passem pela avaliação externa. Garantiu ainda o diálogo com as escolas sempre que se percebia a existência de alguma prática fora dos padrões éticos em função da busca de resultados (BRASIL. Ministério da Educação. Instituto Nacional de Estudos e Pesquisas Educacionais Anísio Teixeira, 2005, p. 57, grifos nossos).
\end{abstract}

Rosistolato, Prado e Fernández trazem relatos de grupos focais, para a rede municipal do Rio de Janeiro, indicando o uso de "jeitinhos" e "atalhos" para responder à responsabilização (2014, p. 103). Entre os depoimentos relatados, sobressaem os que indicam a manipulação da base de alunos testados ("Ó, hoje é a avaliação externa, quem tem conceito I[nsuficiente] fica em casa"), a realocação de recursos mais eficazes nos anos avaliados e até a seleção ilegal de alunos transferidos.

Koslinski, Cunha e Andrade apontam a manipulação de alunos testados, no contexto de escolas premiadas pelo programa de bonificação da rede municipal do Rio de Janeiro. Ressaltam que, em particular nas de pequeno porte, este fenômeno teve importância plausível nas premiações de 2011:

\footnotetext{
Outra recente modificação foi o estabelecimento de uma nova condição para o recebimento do prêmio: as escolas precisam garantir uma taxa de participação dos alunos igual ou superior a $85 \%$ na Prova Brasil e/ou Prova Rio. Tal medida pode coibir estratégias de seleção de alunos para a realização das avaliações externas de referência do Prêmio Anual de Desempenho (KOSLINSKI; CUNHA; ANDRADE, 2014, p. 131).
}

Rubens Camargo, José Marcelino de Rezende Pinto e José Luiz Guimarães, em 
trabalho que trata do financiamento escolar, sugerem existir exclusão de alunos para melhorar o Ideb:

\begin{abstract}
Da maneira como o índice [Ideb] está montado, ao invés de investir em medidas de longo prazo que sabidamente melhoram a qualidade do ensino, os municípios, para não verem minguar o repasse de recursos do governo federal, tendem a adotar medidas cosméticas, ou mesmo a valer-se de fraude. A imprensa noticiou casos de escolas que diziam a determinados alunos, aqueles que tinham as maiores dificuldades, que não precisariam vir à escola no dia da Prova Brasil, por exemplo (CAMARGO; PINTO; GUIMARÃES, 2008, p. 832, grifo nosso).
\end{abstract}

Alves (2011) registra a manipulação da base de alunos testados pelo Saresp:

Entre as práticas que puderam ser ouvidas durante a observação inicial e
que não visam mudanças no comportamento dos alunos, estão os estímulos
para que alunos com desempenho escolar insatisfatório faltem no dia da
avaliação; revisão e correção de algumas provas antes de sua entrega; e
a distribuição de gabaritos para os avaliados antes do horário previsto
para o encerramento do teste [...] [...] Alguns professores disseram que
há escolas que suspendem alunos dias antes das datas previstas para
as aplicações, outros disseram que alguns gestores dispensam os "maus
alunos" antes de entregarem a prova (ALVES, 2011, p. 115, grifos nossos).

Ainda no contexto do Saresp, a exclusão de alunos de baixo desempenho aparece com o eufemismo de "Dia de Hopi Hari", fazendo alusão ao parque de diversões paulista, que recebe excursões regulares de aluno.

Avaliações de determinada série podem afetar alunos de séries anteriores, no fenômeno conhecido por "red shirting", expressão emprestada dos esportes universitários americanos. Crianças do ensino infantil são retidas, desnecessariamente, em séries anteriores às avaliadas por testes high-stakes, para assegurar que tenham maiores habilidades quando forem testadas, ainda que só por uma questão de idade (KATZ, 2000; MADAUS; RUSSELL; HIGGINS, 2009).

Alunos podem ser realocados para escolas diferentes, como descrevem Rajashri Chakrabarti e Noah Schwartz (2013), em arranjos de conveniência entre diretores, para acomodação de interesses mútuos. Curiosamente, estas transferências afetam tanto alunos de baixa proficiência quanto os de alta proficiência. Estes últimos são reclassificados de escolas para alunos "gifted" (superdotados), de alto desempenho em avaliações, para as escolas "normais", para assegurar, via reciprocidade, que as escolas "normais" continuem a indicar alunos para as escolas para "superdotados" (NICHOLS; BERLINER, 2007, p. 68-69).

A manipulação da base de alunos avaliados, neste trabalho, está associada à exclusão de alunos de baixa proficiência das avaliações. No artigo $A$ internalização da exclusão, 
Freitas (2002), diferencia entre a exclusão objetiva e a subjetiva, refletindo processos formais e informais de exclusão, respectivamente:

\begin{abstract}
Professores e alunos defrontam-se na sala de aula construindo representações uns dos outros. Tais representações e juízos orientam novas percepções, traçam possibilidades, estimam desenlaces, abrem ou fecham portas e, do lado do professor, afetam o próprio envolvimento deste com os alunos, terminando por interferir positiva ou negativamente com as próprias estratégias de ensino postas em marcha na sala de aula. É aqui que se joga o sucesso ou o fracasso do aluno - nesse plano informal e não no plano formal. De fato, quando o aluno é reprovado pela nota, no plano formal, ele já tinha sido, antes, reprovado no plano informal, no nível dos juízos de valor e das representações do professor - durante o próprio processo. (FREITAS, 2002, p. 313)
\end{abstract}

O conceito de exclusão subjetiva de Freitas é o que melhor define a exclusão nesta dissertação, pois é uma escolha informal e subjetiva que segrega alunos de baixa proficiência. Aqui, a exclusão é precisa e observa-se, especificamente, a remoção do aluno de conhecido baixo desempenho cognitivo da avaliação externa, no dia de sua realização, como artifício para inflar os escores agregados.

\title{
1.7.2 Estudos sobre fraudes docentes
}

Num segundo subgrupo de fraudes, conhecido na literatura como "teacher cheating" (fraudes docentes), ocorrem desvios com variados graus de intensidade: desde sutis "dicas" durante a realização da prova ("Será que você pensou bem ao marcar esta resposta?"), passando por divulgação de gabaritos durante as avaliações, retificação de folhas de resposta (durante e após as avaliações serem aplicadas) e até adulterações nos resultados finais reportados por autoridades responsáveis pelas avaliações ou pela "prestação de contas".

O relatório de Nichols e Berliner (2005) lista dezenas de casos de fraudes de professores e diretores. Contudo, trazem a perspectiva sensata de questionar o sistema antes de questionar o profissional:

A questão a ser respondida é por que estes profissionais pensam que
o sistema no qual se inserem é tão injusto para suas escolas que se
justifiquem fraudes, preparação direta para exames e violações aos pro-
cedimentos padronizados? Que sistema educacional acua professores e
diretores a ponto de cometerem fraudes para assegurar seus empregos
no futuro? Estas são as questões a serem debatidas, em vez das que
se ouvem mais frequentemente, como "por que não se demitem estes
patifes?". (NICHOLS; BERLINER, 2005, p. 23, tradução nossa)

As fraudes docentes, taxadas por Koretz como francamente indesejáveis, são tópico difícil de submeter à análise. A literatura especializada foca principalmente a identificação de fraudes de alunos, nas avaliações. Além do livro de Gregory Cizek (1999), poucos são 
os artigos sobre o assunto e os existentes usualmente são propostos por empresas privadas envolvidas com os testes em larga escala nos EUA, além de algumas peças de opinião de estudiosos. Cizek trata a fraude docente simplesmente como um apêndice marginal do "ensinar para o teste" (2001a, 2001b).

Há exemplos elencados na literatura estrangeira cobrindo fraudes, enquanto o tema é fracamente coberto no Brasil. Em trabalho analítico brilhante e de referência, Brian Jacob e Steven Levitt (2003a, 2003b) identificaram fraudes levadas a cabo no sistema público de Chicago nos anos 1990. Os autores acompanharam longitudinalmente classes que apresentavam flutuações inexplicáveis de proficiência. Estes autores inferiram que de $4 \%$ a $5 \%$ dos professores envolvidos com a aplicação das avaliações externas tinham cometido fraude ao interferir nas respostas dos alunos.

A metodologia desenvolvida pelos autores observava flutuações ascendentes "suspeitas", por turmas, na proficiência verificada de uma primeira avaliação para a segunda, seguida de uma flutuação "suspeita" descendente para os mesmos alunos, da segunda para a terceira avaliação. Observando os padrões de resposta dos itens para os alunos que apresentaram as flutuações suspeitas, encontraram sequências com repetições improváveis, como indicado na Figura 6. Uma descrição da abordagem quantitativa destes autores está no apêndice à página 201.

Figura 6 - Respostas suspeitas em Chicago

\begin{tabular}{|c|c|c|c|}
\hline \multirow[b]{2}{*}{$\begin{array}{l}\text { Student Answer Strings } \\
\text { (each row represents one student's answers) }\end{array}$} & \multicolumn{3}{|c|}{ Student Test Scores } \\
\hline & Year $\mathrm{t}-1$ & Year $\mathbf{t}$ & Year $\mathbf{t}+1$ \\
\hline \multicolumn{4}{|l|}{ Suspected Cheating Classroom } \\
\hline 112A4A342CB214D000/ & 1.9 & 5.3 & 4.4 \\
\hline 1B2A34D4AC42D23B14 IACD24A3A.12DADBCB4A2134141 & 4.3 & 5.6 & 4.3 \\
\hline DB2ABADIACBDDA212B ACD24A3A12DADBCE $\$ 00000000$ & 3.0 & 6.5 & 5.1 \\
\hline $1142340 C 2 \mathrm{CBDDADB} 4 \mathrm{~B} / \mathrm{ACD} 24 \mathrm{~A} 3 \mathrm{~A} 12 \mathrm{DADBCB}+3 \mathrm{D} 133 \mathrm{BC} 4$ & 3.6 & 6.3 & 4.9 \\
\hline D43A3A24ACB1D32B412ACD24A3A12DADBCB $22143 \mathrm{BCO}$ & 5.2 & 5.9 & 4.9 \\
\hline D4 3AB4D1AC3DD43421240D24A3F12DADBCB400000000 & 4.8 & 5.3 & 3.6 \\
\hline DBA2BA2 1AC3D2AD3 C4C4CDA OA3A2 2DFDBCB 400000000 & 1.9 & 6.1 & 3.6 \\
\hline DBAA4 ADC4 CBD2 4DBCB2A1110A3A12DADBCB 400000000 & 3.3 & 6.3 & 6.2 \\
\hline 144A3ADC4 CBDDADBCBC2C2CC43A 2DADBCB $4211 \mathrm{AB} 343$ & 3.0 & 6.8 & 4.9 \\
\hline D43ABA3CACEDDADBCBCA 42C2A.32/2DADBCB $42344 \mathrm{~B} 3 \mathrm{CB}$ & 4.8 & 7.1 & 6.6 \\
\hline 214AB4DC4CBDD3131B2213C4ADA2DADBCB4ADB00000 & 3.6 & 6.1 & 4.3 \\
\hline 313A3ADIAC3D2A234312.23C0000/2DADBCB4 00000000 & 3.8 & 4.7 & 5.1 \\
\hline D4AAB 2124 CBDDADBCB 1A4 2CCA34/2DADBCB $423134 \mathrm{BC}$ & 5.5 & 6.6 & 7.7 \\
\hline 3B3AB 4D 14C3D2AD4 CBCAC1C003A42DADBCB 4ADB40000 & 3.0 & 6.5 & 6.6 \\
\hline DBAAB3DCACB1DADBC42AC2CC310 2DADBCB4ADB40000 & 3.8 & 7.1 & 5.6 \\
\hline DB223A2 4ACB1 1A.3B24 CACD12A24 1CDADBCB 4ADB4B300 & 4.9 & 6.5 & 5.8 \\
\hline D122BA2CACBD1A13211A2D02A2412DODBCB4ADB4 B3CO & 3.6 & 6.1 & 6.2 \\
\hline
\end{tabular}

Fonte: Jacob e Levitt (2003b, p. 848).

Apesar de robusto e relativamente acessível do ponto de vista da abordagem empregada, o processo seguido por Jacob e Levitt não pode ser aplicado aos dados públicos da Prova Brasil por necessitar de identificação de alunos por turma, ao longo do tempo. 
Uma replicação no Brasil seria de muito valor ${ }^{23}$.

Um exemplo da manipulação dos resultados reportados de maneira fraudulenta pode ser encontrado no estudo de Dee, Jacob e McCrary (2011). Estes autores concluem que de $3 \%$ a $5 \%$ dos resultados obtidos no tradicional Regents Exam de Nova York foram fraudados, por conta das pressões high-stakes, inclusive com consequências fortes para os alunos avaliados.

Os autores estudaram as curvas de distribuição de escores por disciplina avaliada e verificaram descontinuidades suspeitas em torno de pontos de corte relevantes, indicando a manipulação das folhas de resposta. A Figura 7 ilustra uma dessas distribuições, com as descontinuidades suspeitas nas proximidades das retas verticais demarcatórias dos "pontos de corte" instituídos pela política high-stakes de Nova York. A contagem de alunos imediatamente à direita ou sobre os pontos de corte é suspeitamente alta, enquanto as frequências de alunos imediatamente à esquerda dos pontos de corte são anormalmente baixas, indicando uma manipulação para "empurrar" estes alunos para além dos limiares de corte. Uma abordagem similar, com observação dos padrões de distribuição de escores, será útil adiante, ao ser endereçada a questão de alunos excluídos na Prova Brasil.

Figura 7 - Descontinuidades nas pontuações - Regents Exam - Nova York

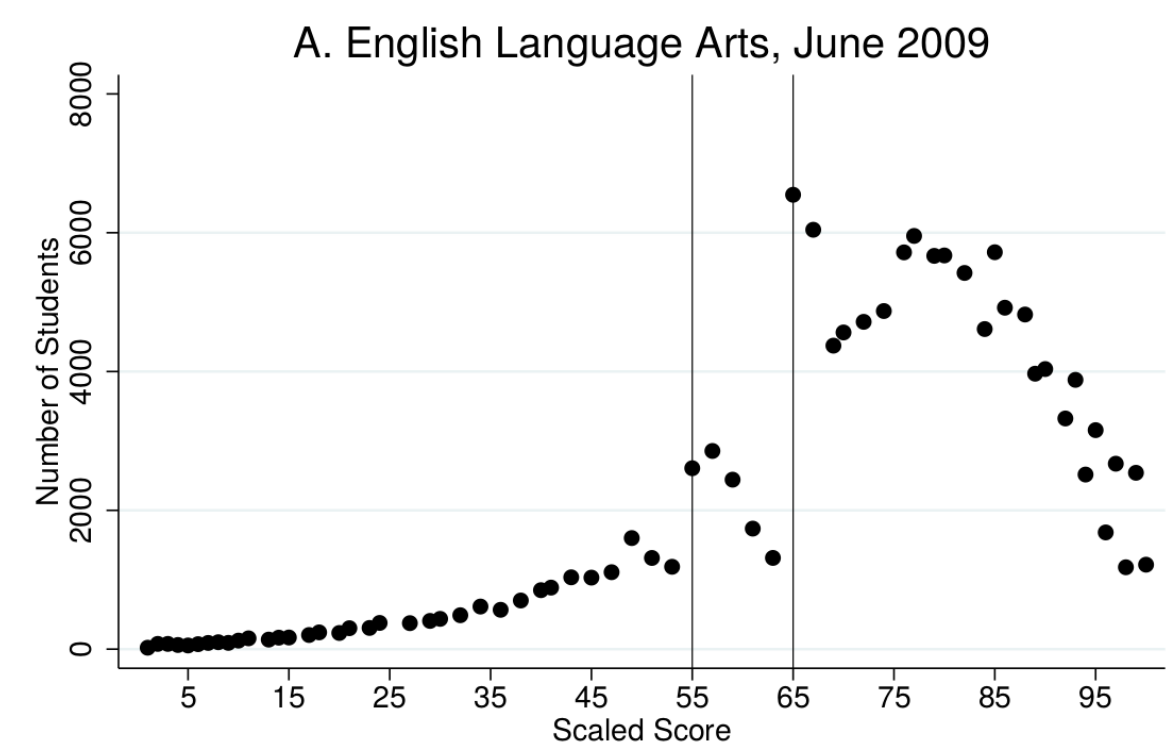

Fonte: Dee, Jacob e McCrary (2011, p. 18).

Outro resultado interessante foi obtido por Dale Ballou e Matthew Springer, que testaram os efeitos de ter aplicadores não independentes em avaliações high-stakes. Reportam que "a cada série avaliada, o número de questões respondidas corretamente era

23 Nesta dissertação é apresentada uma abordagem alternativa, não tão elegante quanto a de Jacob e Levitt, mas adequada a avaliações que usem múltiplos cadernos de questões. 
mais alto quando os alunos foram monitorados por aplicador que era, também, o professor regular da turma" (2015, p. 82, tradução nossa) ${ }^{24}$. Este efeito colateral previsível reflete um defeito intrínseco nos protocolos de aplicação dos exames estudados pelos autores: o teste aplicado pelo próprio professor da turma, num estado não divulgado do Sul dos EUA, em 2009-2010.

O desenho da Prova Brasil, em princípio, evitaria tal conflito de interesses, pelas exigências de independência na contratação de aplicadores ${ }^{25}$, contudo, é possível que o mesmo efeito se manifeste no Brasil, em avaliações de menor porte ou quando restrições logísticas ou orçamentárias se façam presentes.

No Brasil, Alves registra a ocorrência de fraudes docentes no Saresp, ocorridas antes de aperfeiçoamentos logísticos na aplicação da prova:

\begin{abstract}
As outras duas táticas destacadas ocorriam durante as primeiras aplicações do Saresp, quando a correção e aplicação da prova dependiam muito dos funcionários da rede de ensino. A distribuição prévia de gabaritos para os alunos, enquanto esses ainda faziam a prova, ocorreu quando a SEE, equivocadamente, enviou os gabaritos para a correção da prova antes do horário previsto para o seu término em todo o estado, visto que deveria haver sincronia nessas operações.

Durante esses eventos, muitas escolas foram investigadas e muitos funcionários punidos, já que muitas dessas atitudes foram julgadas como atos de "má fé". A tática que envolve a revisão e a correção das provas antes da sua entrega às DEs também ocorria com frequência somente no período inicial do Saresp, visto que atualmente não há mais possibilidade de sua ocorrência por conta do lacre que os fiscais enviados às escolas pela entidade responsável pela logística da prova devem colocar no encerramento da aplicação (ALVES, 2011, p. 116, grifos nossos).
\end{abstract}

Foram também encontradas registros sobre fraudes na imprensa do Brasil. Com ajuda de buscadores de notícias online durante a realização da pesquisa bibliográfica, foram encontrados poucos casos de fraudes associados a avaliações no Brasil, parecendo ser todos eles casos isolados, a saber:

a) exclusão de alunos do Saresp em Osasco (TOLEDO, 2015);

b) adulteração de notas no Saresp em Sorocaba, SP (AGÊNCIA ESTADO, 2012);

c) adulteração de folhas de respostas da Prova Brasil de 2015 em escola de Cabaceiras, PB (O GLOBO, 2013);

d) indicação de respostas pelos professores na Prova Brasil de 2013, em Foz do Iguaçu, PR (RÁDIO CULTURA FOZ DO IGUAÇU, 2013).

$\overline{24}$ The results are striking. At every grade level, the number of questions answered correctly is higher when students are monitored by their own teacher.

25 Ver anexo à página 195, com as condições de independência do aplicador descritas no edital de convocação para o Saeb. 
Dadas as magnitudes e abrangências da Prova Brasil, das avaliações estaduais e municipais, são surpreendentemente escassas as notícias de fraudes a elas associadas.

\subsection{Um mapa sintético dos efeitos reportados}

A Figura 8 apresenta um mapeamento dos efeitos registrados em literatura, localizados ao longo do espectro de respostas da classificação de Koretz. Apesar de não exaustivo, o mapa resultante permite agrupar os comportamentos registrados, para facilitar seu entendimento, à guisa de resumo deste capítulo.

Os efeitos indicados na região $A$ da Figura 8 são associados às três primeiras categorias de Koretz. Exceto em casos de exagero, não são reputados como prejudiciais.

Os efeitos indicados por $B$ são exemplos de realocação de recursos, mas não são estritamente "ensinar para o teste", pois a decisão de incrementar calorias de merenda ou reduzir duração de recreio são, discutivelmente, decisões administrativas e não pedagógicas. O "ensinar para o teste" está compreendido em $C$, sendo o estreitamento curricular um aspecto particular do "ensinar para o teste".

Na categoria de fraudes, há dois grupos. O primeiro, $D$, caracteriza as fraudes dos agentes (professores, diretores, administradores). As fraudes podem ocorrer antes, durante ou após as realizações das provas, com a divulgação prévia de respostas, comunicação de "colas" durante a prova ou manipulações de folhas de resposta, por parte dos docentes ou aplicadores. Os administradores do sistema de avaliação também podem ser fraudadores, adulterando os resultados reportados.

Finalmente, o grupo $E$ resume as manipulações da base de alunos avaliados, visando, por exemplo, excluir da pontuação os alunos de baixa proficiência e com isso inflar os escores.

No próximo capítulo, são descritas as abordagens para identificar e analisar a extensão de dois tipos de comportamentos fraudulentos: exclusão não aleatória e proposital de alunos de baixa proficiência e as fraudes docentes. 


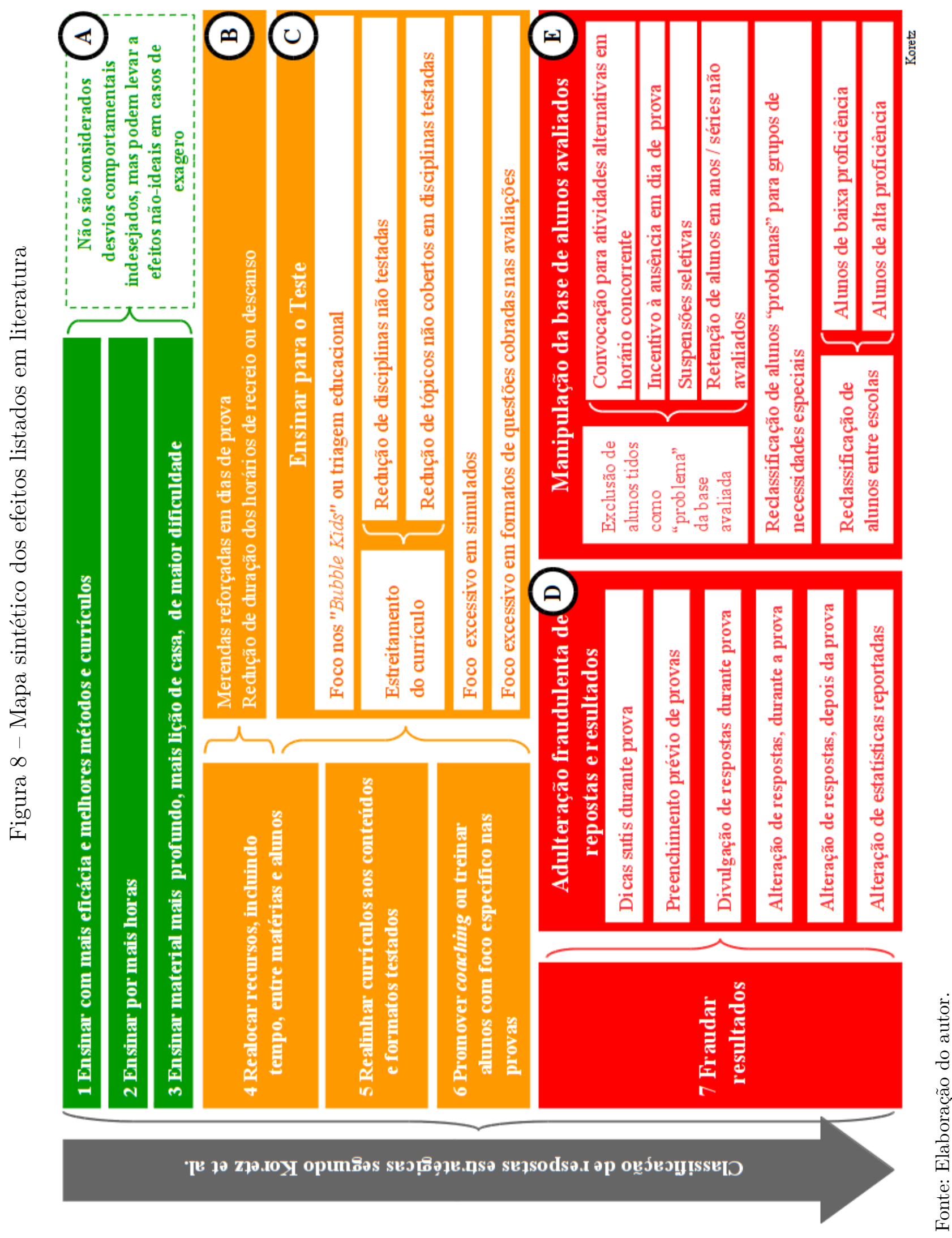





\section{Métodos e abordagens propostos}

"Quando alguma coisa desaparece, você pode sempre recriá-la pelo vazio que deixou", disse The Doctor, para Clara Oswald.

Hell Bent, roteiro de Steven Moffat, direção de Rachel Talalay (2015), tradução nossa.

Neste capítulo são descritas as abordagens propostas, introduzidas pelo autor, para quantificar os efeitos colaterais estudados e suas associações às pressões decorrentes das políticas de responsabilização. Para o caso da manipulação da base de alunos testados, são caracterizadas as ausências não aleatórias de alunos na Prova Brasil 2013 e 2015 com base em distorções nas distribuições de proficiência medidas.

Para o caso de "colas" ou fraudes, uma análise a partir da maximização de escores com base em gabaritos diferentes dos designados para cada aluno é explicada adiante, também para as provas de 2013 e 2015.

Como variáveis de controle exógenas para ambos os efeitos acima, são usados os FLAGs - Fatores Ligados Ao Gaming - baseados no Ideb e nas características de políticas de bonificação docente estaduais. Finalmente, são propostos dois modelos lineares para analisar a correlação entre os resultados do gaming e os FLAGs.

\subsection{Um histórico recente}

O documento Resumo Técnico: Resultados do Índice de desenvolvimento da Educação Básica 2005-2015, do Inep, apresenta um contexto importante para este estudo:

Desde a quarta edição do Ideb (2011), o Inep estabeleceu uma nova sistemática do Sistema de Avaliação da Educação Básica - Saeb e instituiu que o público-alvo para aplicação das provas seria obtido a partir dos dados fornecidos ao Censo Escolar. Este procedimento permitiu que as provas passassem a ser identificadas com nome e dados pessoais dos estudantes ainda no processo de impressão e, no momento de sua aplicação, a distribuição do material passou a ser nominal. Tal medida configura-se em um procedimento valioso para o controle de qualidade da aplicação e da representatividade dos resultados obtidos, pois possibilita a identificação dos alunos que fizeram a prova e, naturalmente, aqueles que não a fizeram (BRASIL. Ministério da Educação. Instituto Nacional de Estudos e Pesquisas Educacionais Anísio Teixeira, 2016b, p. 8, grifo nosso). 
Como reportado acima, a vinculação das proficiências medidas na Prova Brasil com os dados do Censo Escolar é fundamental, pois permite caracterizar as ausências no dia da avaliação. Este mesmo Resumo Técnico segue com outro parâmetro importante nestas avaliações: o critério de participação mínima dos alunos de uma escola. Como introduzido pela documentação oficial:

\begin{abstract}
Outra ação importante foi o critério de participação mínima na aplicação, que foi estabelecido como sendo $50 \%$ do número de estudantes declarados ao Censo Escolar. Tiveram divulgados os seus resultados de desempenho na Prova Brasil e, consequentemente, no Ideb, tão somente as unidades escolares públicas e os municípios que cumpriram este critério, buscando, dessa forma, garantir um número mínimo de participação e a maior precisão do resultado (BRASIL. Ministério da Educação. Instituto Nacional de Estudos e Pesquisas Educacionais Anísio Teixeira, 2016b, p. 8, grifos nossos).
\end{abstract}

Fica patente no documento a necessidade de ter participação mínima para assegurar a validade e minimizar o gaming. A Portaria $N^{\circ} 304$, de 21 de junho de 2013, do Inep, no parágrafo $1^{\circ}$ do artigo 11 , capítulo II, definiu a taxa de participação mínima de $50 \%$ :

Para a divulgação dos resultados de desempenho na ANRESC (Prova Brasil) de cada unidade escolar pública e de cada município será estabelecido critério de participação mínima de $50 \%$ de participantes nas provas de Leitura ${ }^{1}$ e Matemática, em relação ao número de matrículas declaradas ao Censo Escolar de 2013 (BRASIL. Ministério da Educação. Instituto Nacional de Estudos e Pesquisas Educacionais Anísio Teixeira, 2013b, p. 33, grifo nosso).

Portanto, a Prova Brasil de 2013 permitiu uma margem de manobra de 50 pontos percentuais na participação para acomodar exclusões e faltas. A Figura 9 indica a distribuição de escolas quanto às suas taxas de participação na prova de 2013, com massiva aderência aos limites mínimos.

Dois anos depois, a Portaria $N^{\circ} 174$, de 13 de maio de 2015, do Inep, no seu artigo $9^{\circ}$, parágrafo único, alterou o patamar mínimo de participação para $80 \%$ :

Para a divulgação dos resultados de desempenho na ANRESC (Prova Brasil) de cada unidade escolar pública e de cada município será estabelecido critério de participação mínima de $80 \%$ de participantes nas provas de Leitura e Matemática, em relação ao número de matrículas declaradas ao Censo Escolar de 2015 (BRASIL. Ministério da Educação. Instituto Nacional de Estudos e Pesquisas Educacionais Anísio Teixeira, 2015d, p. 16, grifo nosso).

1 Leitura e Língua Portuguesa aparecem de maneira alternada como sinônimos na documentação do Inep. 
Esta alteração alinha-se ao artigo 11 do Plano Nacional da Educação (PNE) de 2014, que já havia redefinido o patamar mínimo de participação para 80\%, ante os 50\% vigentes por ocasião do Saeb 2013, como apresentado a seguir:2.

Art. 11. O Sistema Nacional de Avaliação da Educação Básica, coordenado pela União, em colaboração com os Estados, o Distrito Federal e os Municípios, constituirá fonte de informação para a avaliação da qualidade da educação básica e para a orientação das políticas públicas desse nível de ensino.

$\S 1^{\circ} \mathrm{O}$ sistema de avaliação a que se refere o caput produzirá, no máximo a cada 2 (dois) anos:

I - indicadores de rendimento escolar, referentes ao desempenho dos (as) estudantes apurado em exames nacionais de avaliação, com participação de pelo menos $80 \%$ (oitenta por cento) dos (as) alunos (as) de cada ano escolar periodicamente avaliado em cada escola, e aos dados pertinentes apurados pelo censo escolar da educação básica (BRASIL. Presidência da República, 2014, grifo nosso).

Este novo patamar, conhecido ou não, respeitado ou não pelas escolas, era a norma durante a aplicação 2015 da Prova Brasil. A realidade é que este limite mínimo de participação teve dificuldade em ser atingido por muitas escolas, conforme ilustra a Figura 9: a participação média para o $5^{\circ}$ ano foi de $84 \%$ e apenas $78 \%$ para o $9^{\circ}$ ano em 2015 .

Uma discreta retificação publicada pelo Inep (2016c) após a aplicação da Prova Brasil de 2015, à página 19 do Diário Oficial da União de 29 de julho de 2016, alterou o percentual de $80 \%$ de volta para os $50 \%$ anteriores, afetando apenas a divulgação dos resultados mas não o incentivo estratégico que existira por ocasião da aplicação da avaliação. Nesta retificação não há menção clara sobre a razão da alteração, mas a análise dos microdados revela alta incidência de escolas com baixas taxas de participação, fato que inviabilizaria os cálculos do Ideb para muitas escolas, como indicado na Figura 9. Maria Inês Fini, presidente do Inep à época da elaboração deste relatório, informou à imprensa que o novo critério só valeria na edição seguinte da Prova Brasil - 2017: "vamos considerar este ano [2015] como uma edição de transição", concluindo que a nova regra não havia sido divulgada suficientemente nas redes participantes (JORNAL DO COMÉRCIO, 2016) ${ }^{3}$.

A ampla faixa de 50\%-100\% de participação com reporte de resultados abre, potencialmente, o espaço para o jogo estratégico por parte de professores e gestores escolares, pela indução à ausência de alunos com potencial para serem avaliados com proficiência baixa. A alteração desta faixa para 80\%-100\% reduziria este espaço, possivelmente suscitando uma maior "necessidade" de fraudar resultados, para compensar a inclusão de alunos de baixa proficiência. Ao que indicam as taxas de participação da Figura 9, a norma não foi

2 Não há no PNE uma justificativa para o aumento do patamar mínimo de participação.

3 Em entrevista à Folhapress, de acesso fechado. Notícia sindicada no Jornal do Comércio de acesso livre para consulta. 
respeitada, com padrões interessantes de gaming emergindo. As análises que seguem visam a medir a extensão do gaming associado às supostas pressões de responsabilização, à luz das políticas vigentes distintas de 2013 e 2015.

Figura 9 - Taxas de participação na Prova Brasil 2013 e 2015 para $5^{\circ}$ e $9^{\circ}$ ano
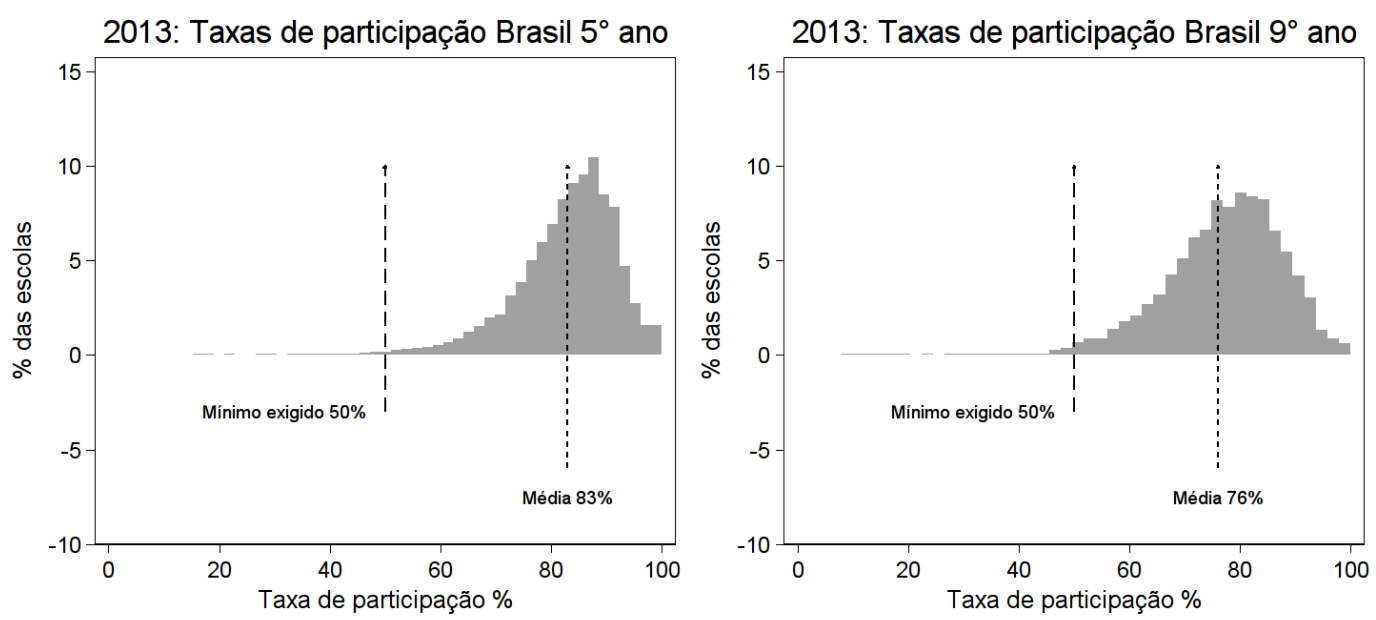

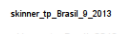
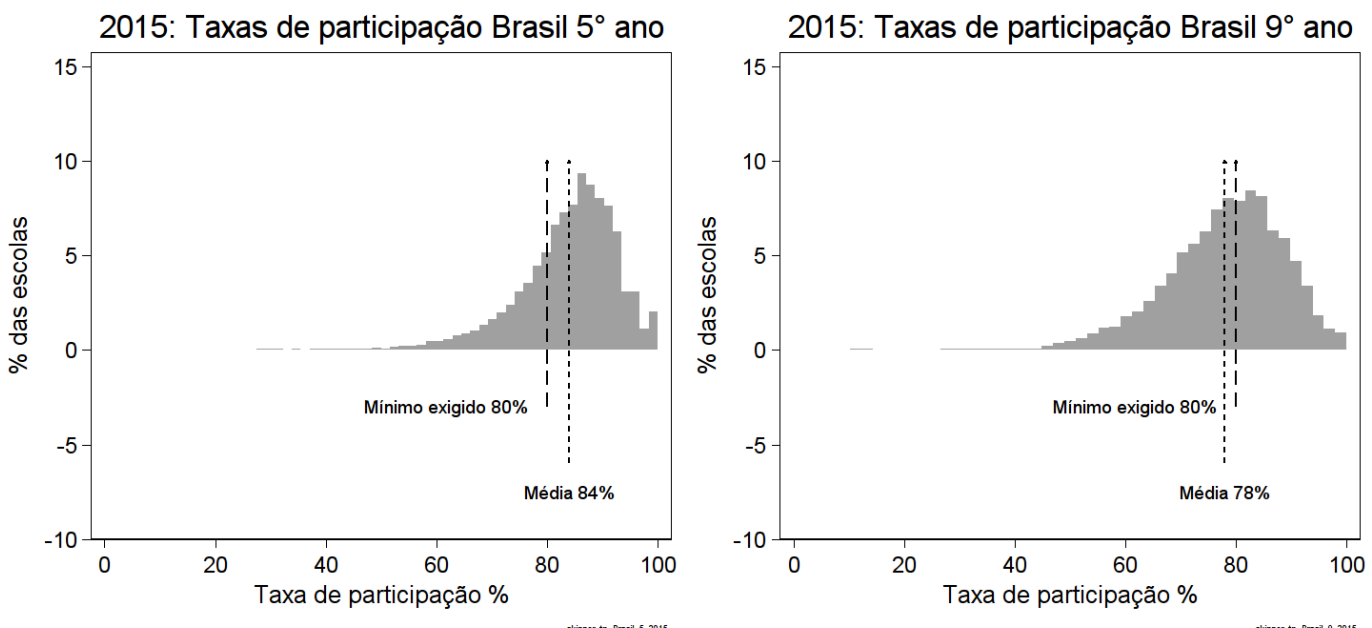

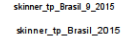

Fonte: Elaboração do autor.

\subsection{FLAGs - os Fatores Ligados Ao Gaming}

Os fatores ligados ao gaming (FLAGs) são os indicadores das pressões resultantes das avaliações high-stakes sobre os participantes no processo avaliativo. Em particular, este trabalho se concentra nos fatores que pressionam, alegadamente, professores ou diretores de escolas avaliadas, refletindo indicações da literatura apresentada no capítulo anterior. Há FLAGs propostos que derivam diretamente dos dados do Ideb. Outros FLAGs têm sua origem na existência de programas estaduais de bonificação docente. 
Os FLAGs têm duas funções nas análises propostas. A primeira é a de servir como fatores explicativos independentes, sendo associados aos efeitos indesejados medidos. O segundo papel dos FLAGs é de servirem de critério de agrupamento nas análises da manipulação da base de alunos testados. Os FLAGs podem ser binários (dummies), por exemplo, indicando se uma UF tem ou não uma política de bonificação docente vigente na data da Prova Brasil ou se uma dada escola está acima ou abaixo da meta de Ideb. Também podem ser variáveis contínuas, indicando, por exemplo, há quantos anos uma UF tem uma política de bonificação docente na data de realização da prova ou qual a magnitude do crescimento ou queda do Ideb nos anos anteriores aos da Prova Brasil estudada.

\subsubsection{Fatores FLAG derivados do Ideb}

Parte-se da hipótese de que o Ideb cria pressões que induzem comportamentos. Além do valor absoluto do Ideb, procurou-se apreender outros aspectos relacionados ao indicador que poderiam pressionar os agentes a engajarem no gaming: a variação do Ideb no tempo, a distância do Ideb obtido à sua respectiva meta projetada e a variação no tempo da posição da escola no ranking em relação ao seu município e rede.

Foi calculada a variação do Ideb no tempo, por escola e série avaliada. Neste trabalho, supões-se que um valor negativo (indicando queda no Ideb aferido de 2011 versus 2009, por exemplo), indicará, potencialmente, uma maior pressão sobre os agentes para o gaming na realização da Prova Brasil de 2013. A Figura 10 ilustra as distribuições das escolas por ciclo inicial e final do EF e por ano de avaliação em função da variação do Ideb de uma avaliação à seguinte ${ }^{4}$.

A Figura 10 permite um diagnóstico da construção da variável DELTA_IDEBt. Os valores modais, ou os mais frequentes, em todas as distribuições são próximos de zero, indicando que o caso mais comum é ter escolas com pequenas variações no Ideb. Contudo, as distribuições são mais densas à direita do zero, indicando que há mais escolas com crescimento do que com decaimento do Ideb, nos períodos analisados.

Esta variável $D E L T A \_I D E B_{t}$ será empregada nas modelagens, com rótulo de DELT A, estimada por escola para as análises de fraudes, e consolidada por agrupamento nas análises de exclusões, como explicado adiante, neste capítulo. Os valores para os "anos iniciais" são usados nas análises do $5^{\circ}$ ano e os "anos finais" para o $9^{\circ}$ ano do EF. Esta lógica se repete para as demais variáveis apresentadas a seguir.

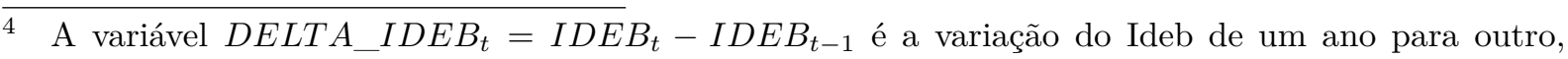
calculada por escola. 
Figura 10 - Distribuições da variável FLAG associada à variação do Ideb

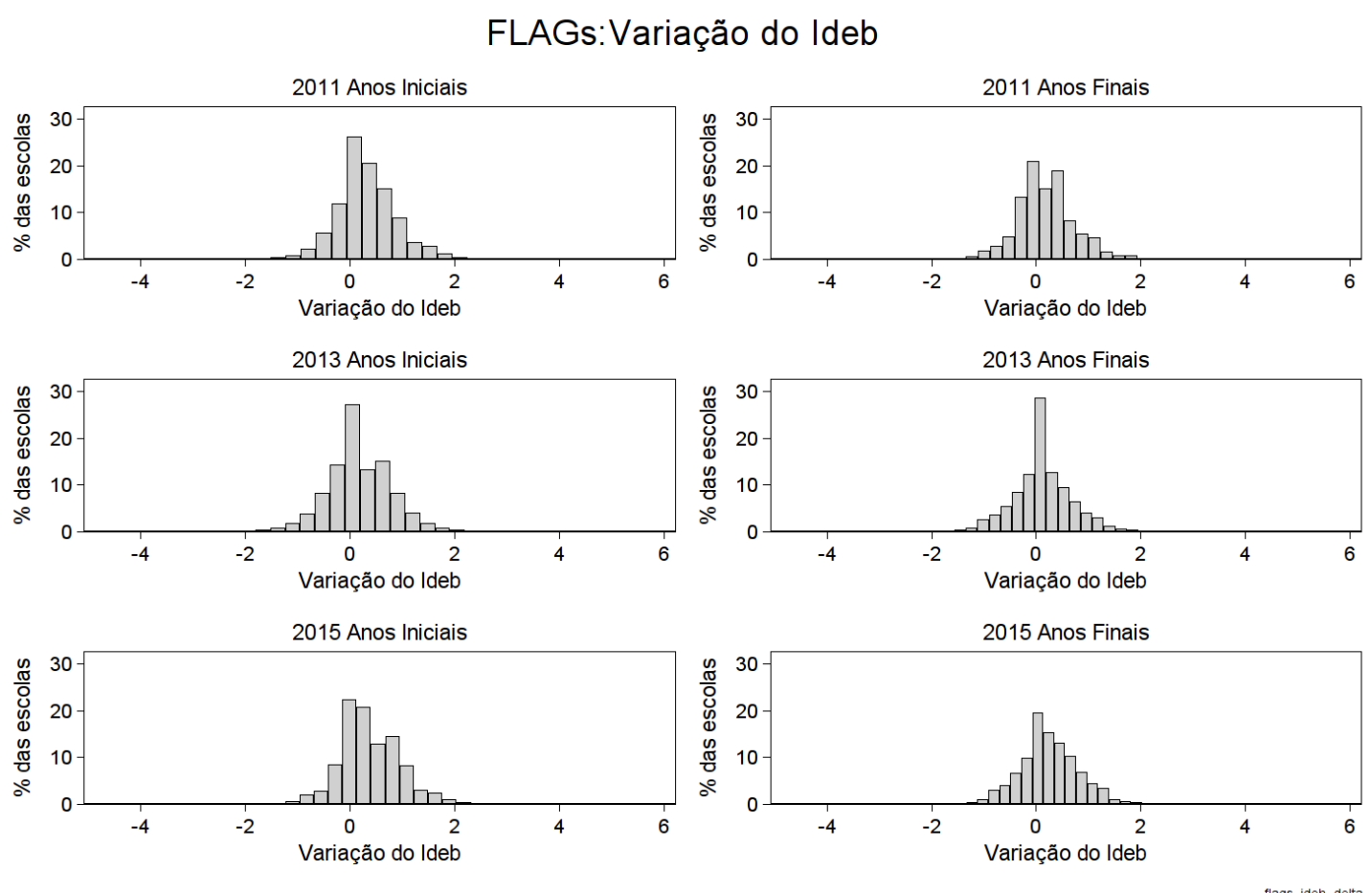

Fonte: Elaboração do autor.

Para apreender a pressão nos agentes por conta de metas não atingidas, calculou-se a distância entre o Ideb aferido e sua respectiva meta projetada, para um dado ano ${ }^{5}$. Esta distância entre o Ideb medido e sua meta projetada é chamado de gap neste trabalho. Supõe-se que quanto mais negativa for a distância, ou melhor, quanto mais abaixo da meta for o Ideb, num dado ano, maior será a pressão de gaming presente na avaliação seguinte.

A Figura 11 ilustra as distribuições das escolas por ciclo inicial e final do EF e por ano de avaliação em função da distância à meta Ideb. Usa-se o gap referente a 2011 como indicador de pressão sobre o resultado de 2013 e o gap de 2013, para 2015.

As distribuições da Figura 11 indicam que para os anos iniciais, em geral, as escolas vêm superando suas metas, posto que as densidades à direita do zero são maiores que à esquerda. O contrário se verifica para os anos finais, já a partir de 2013, quando a simetria nas distribuições deste gap se perde, havendo mais escolas abaixo de suas metas que acima delas.

5 A variável DELTA_GAP $=I D E B_{t}-M E T A_{t}$ é a distância entre o Ideb aferido num dado ano de aplicação da Prova Brasil para uma dada escola e a sua respectiva meta predeterminada, por ocasião da criação do Ideb. 
Figura 11 - Distribuições da variável FLAG associada à distância à meta Ideb

\section{FLAGs:Distâncias entre Ideb e Meta}
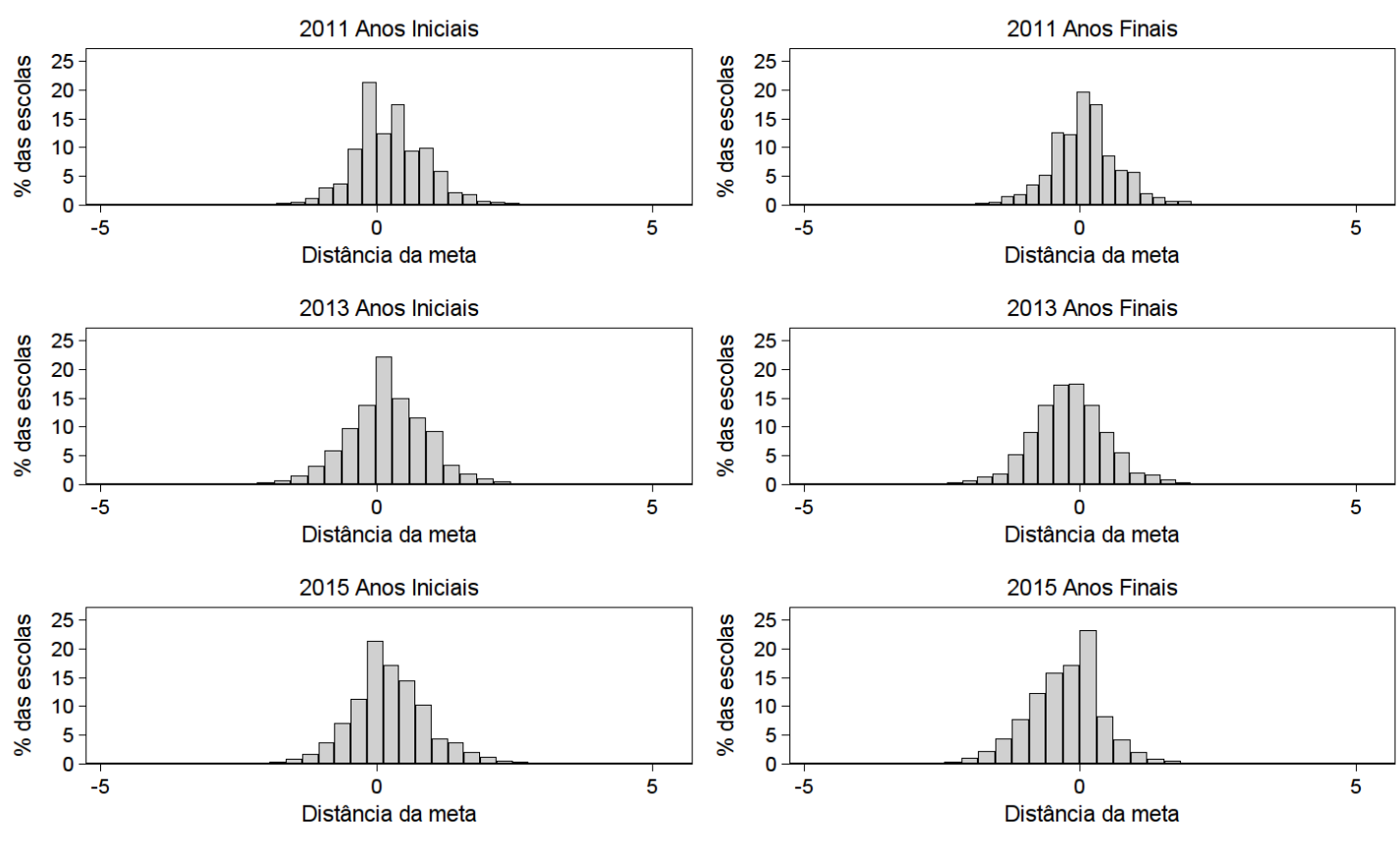

Fonte: Elaboração do autor.

Para apreender a pressão do ranqueamento, citado como um mecanismo de pressão, é proposta uma variável que indica a mudança de posição no ranking de uma dada escola, num dado ano, dentro do conjunto de escolas do mesmo município e rede administrativa ${ }^{6}$. Uma escola que tenha mantido sua posição de um ano para outro terá valor zero para esta variável. Quanto menor for esta variável (mais negativa) para uma determinada escola, supõe-se que maior será a pressão para que os agentes se envolvam com o gaming na avaliação seguinte.

A Figura 12 ilustra as distribuições das escolas por ciclo inicial e final do EF e por ano de avaliação em função de suas mudanças de posição no ranking no município e rede. Vê-se que entre um quarto e um terço das escolas não mudam de posição no ranking, o que enfraquece o poder de influência da variável construída, como será exposto adiante. Os resultados desta variável aferidos em 2011, na modelagem são empregados para explicar os efeitos colaterais em 2013, enquanto os de 2013 explicam os efeitos colaterais medidos em 2015 .

$\overline{6}$ Este FLAG é definido por DELTA_RAN $K_{t}=R A N K_{t}-R A N K_{t-1}$ onde $R A N K_{t}$ indica a posição em percentis da escola dentro da rede e município. São valores ajustados entre -100 e 100 indicando em percentis, a variação no ranking na rede e município. 
Figura 12 - Distribuições da variável FLAG associada a ranking

FLAGs:Mudanças em posições de ranking de Ideb
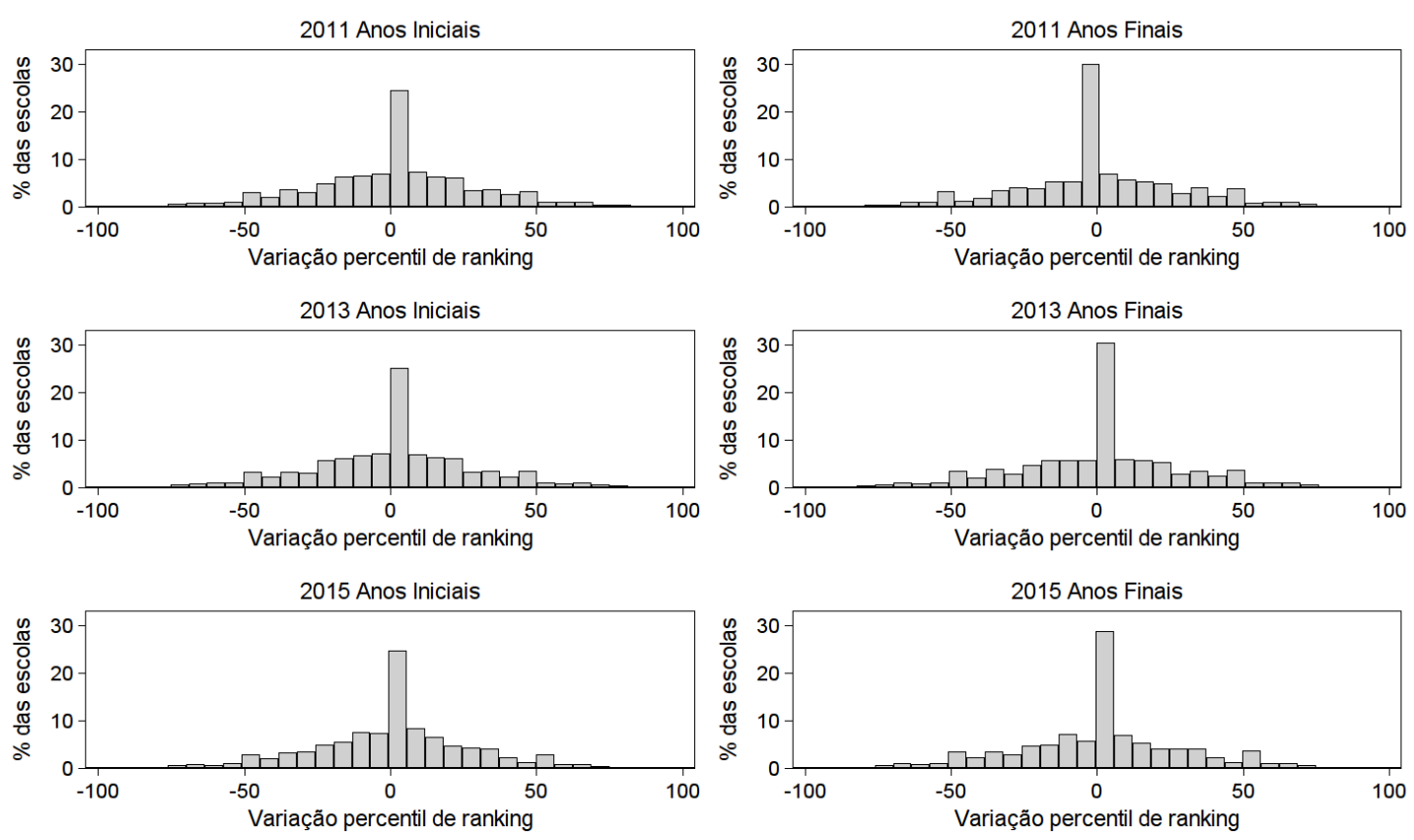

flags_ideb_ranking

Fonte: Elaboração do autor.

Para as três variáveis acima, foram criadas variáveis binárias associadas, a fim de facilitar agrupamentos. Por exemplo, uma variável $A B A I X O \_M E T A$ é zero se o Ideb do ano anterior esteve acima ou igual à meta e 1 se esteve abaixo dela. Analogamente, são construídas variáveis $Q U E D A \_I D E B$ e $Q U E D A \_R A N K I N G$, autoexplicativas. Estas variáveis dummy, por construção, assumem valor 1 sempre na condição que indica maior pressão sobre os agentes, conforme suposto pela literatura. Estas variáveis estão sumarizadas nas Tabelas 18 e 19, em apêndice à página 213.

O Ideb absoluto aferido em dada avaliação também é usado como FLAG de pressão para a avaliação seguinte. Esta variável tem o benefício de apresentar menos lacunas de dados faltantes, quando comparada às demais, por não exigir metas ou valores históricos associados. Como variável explicativa adicional, usa-se o nível socioeconômico, fortemente correlacionado com o Ideb absoluto.

Uma variável auxiliar, binária, baseada na não-divulgação dos resultados Ideb de uma dada escola, também foi analisada, com base no pedido de bloqueio permitido pela governança da Prova Brasil e da divulgação do Ideb por escola ou município. Esta variável não tem poder de "previsão" quanto à indução de comportamentos indesejados, pois não é conhecida por ocasião da avaliação. Ela só se faz conhecida depois de encaminhados os resultados preliminares às secretarias competentes, contudo ilustra padrões interessantes a posteriori discutidos adiante, indicando que o "não reporte" pode estar associado a 
incidências maiores de gaming.

A fonte para as variáveis FLAG sugeridas acima foram os reportes disponibilizados pelo Inep ${ }^{7}$ sobre o Ideb histórico e suas metas projetadas, por escola. A base de dados tem alguns valores de Ideb e de metas associadas faltantes, num dado ano, por razões variadas: não atingimento de patamar mínimo de participação, pedidos de veto de reporte atendidos pelo Inep ou mudança no status de atividade da escola. Uma meta pode estar ausente num dado ano pelo encerramento da oferta de cursos num ciclo específico (EF I ou EF II) da escola ou por ela ter sido fechada ou, ainda, pela fusão com outra escola. A dimensão destes dados faltantes está quantificada na Tabela 1.

Tabela 1 - Ausência de dados de Ideb e metas associadas para escolas

\begin{tabular}{llccc}
\hline \multicolumn{2}{c}{ Porcentagem de escolas sem dados de Ideb nos anos... } & $\ldots 2011$ & $\ldots 2013$ & $\ldots 2015$ \\
\hline \multirow{2}{*}{ Anos iniciais } & Sem Ideb & $27,0 \%$ & $29,9 \%$ & $30,9 \%$ \\
& Sem meta & $12,4 \%$ & $6,6 \%$ & $2,7 \%$ \\
\hline \multirow{2}{*}{ Anos finais } & Sem Ideb & $21,8 \%$ & $21,5 \%$ & $26,5 \%$ \\
& Sem meta & $12,3 \%$ & $6,4 \%$ & $1,9 \%$ \\
\hline
\end{tabular}

Fonte: Elaboração do autor.

A falta destes dados deixa lacunas também nos FLAGs derivados. Nestes casos faltantes, deixam de ser usados como covariantes explicativos nas análises de associação e classificação, sendo expurgados pelo pacote estatístico.

\subsubsection{Fatores FLAG associados à bonificação docente}

Ao classificar os tipos de bonificação docente implantados no Brasil, Nathalia Cassettari reconhece três tipologias:

O primeiro, o pagamento por mérito individual, é o modelo mais criticado, por depender de avaliações subjetivas do desempenho dos professores e por incentivar a competição entre eles.

Já a bonificação com base no resultado das escolas, apesar de receber diversas críticas ao relacionar diretamente o desempenho dos professores ao resultado dos alunos nos sistemas de avaliação, tem se expandido com bastante rapidez.

Por fim, a bonificação com base nos conhecimentos e habilidades dos professores é o modelo mais recente e consiste em avaliações objetivas dos professores que podem ser das mais complexas (envolvendo múltiplos instrumentos) às mais simples (resumidas a um único instrumento, como provas, em geral), sendo essas últimas as mais utilizadas no Brasil. (CASSETTARI, 2012, p. 14)

$\overline{7}$ http://portal.inep.gov.br/web/portal-ideb/planilhas-para-download 
Esta autora lista efeitos colaterais associados: "a criação de uma rivalidade entre os professores; o aumento da desigualdade entre as escolas; o incentivo a fraudes; a exclusão de alunos que não apresentem bons desempenhos, dentre outros" (CASSETTARI, 2012, p. 3).

Os dados para a construção dos FLAGs associados às políticas de bonificação, no nível das UFs, foram embasados nos trabalhos de Scorzafave, Ferreira e Dorigan (2014, 2015). Estes autores indicam cinco tipos de bonificação docente, resumidas no Quadro 5.

As características destes sistemas de bonificação são detalhadas por Nogueira et al. (2013), incluindo datas de início, legislação aplicável e abrangência. As datas de início das políticas foram empregadas para determinar a "dosagem" da exposição à política no momento de realização das provas estudadas.

Quadro 5 - Bonificações docentes por UF

\begin{tabular}{|c|c|c|c|c|}
\hline \multicolumn{3}{|c|}{ Tipologia de Bonificação Docente } & $\mathrm{UF}$ & Tipo para agrupamento \\
\hline \multicolumn{3}{|c|}{ Sem bonificação } & $\begin{array}{l}\mathrm{AL}, \mathrm{AP}, \mathrm{BA}, \\
\mathrm{DF}, \mathrm{MA}, \mathrm{MT}, \\
\mathrm{MS}, \mathrm{PA}, \mathrm{PR}, \\
\mathrm{PI}, \mathrm{RN}, \mathrm{RS}, \\
\mathrm{RO}, \mathrm{SC}\end{array}$ & 1 \\
\hline \multirow{4}{*}{$\begin{array}{l}\text { Com } \\
\text { bonificação }\end{array}$} & \multicolumn{2}{|c|}{$\begin{array}{l}\text { Não vinculada a } \\
\text { proficiência discente }\end{array}$} & $\mathrm{AC}, \mathrm{GO}, \mathrm{RR}$ & 2 \\
\hline & \multirow{3}{*}{$\begin{array}{l}\text { Vinculada a } \\
\text { proficiência } \\
\text { discente }\end{array}$} & $\begin{array}{l}\text { Base em avaliação } \\
\text { estadual própria }\end{array}$ & $\begin{array}{l}\mathrm{CE}, \mathrm{ES}, \mathrm{MG}, \\
\mathrm{PE}, \mathrm{RJ}, \mathrm{SP}\end{array}$ & 3 \\
\hline & & $\begin{array}{l}\text { Base mista } \\
\text { (avaliação própria e } \\
\text { Prova Brasil) }\end{array}$ & AM, TO & 4 \\
\hline & & $\begin{array}{l}\text { Base no Ideb e } \\
\text { Prova Brasil }\end{array}$ & SE, PB & 5 \\
\hline
\end{tabular}

Fonte: Elaboração do autor, com base em Scorzafave et al. (2014).

O Tipo 1 indica a ausência de políticas de bonificação estadual, à época de realização da Prova Brasil 2013 e 2015. São 14 UFs representadas nesta categoria.

O Tipo 2 abrange as três UFs que têm políticas de bonificação, sendo estas não embasadas na medida da proficiência dos alunos. Nelas, são usados critérios de assiduidade docente, formação continuada, projetos desenvolvidos nas escolas, entre outros. Estas políticas têm paralelo com o apresentado por Berliner e Biddle (1995) como uma alternativa interessante ao uso da proficiência docente como insumo da responsabilização. 
O Tipo 3 cobre as seis UFs que têm bonificação docente embasada na proficiência aferida dos alunos, entre outros fatores, mas que contam unicamente com avaliações estaduais próprias para suportar os resultados. Por não usar a Prova Brasil como insumo, não são esperados, a priori, resultados de gaming para UFs classificadas como de Tipo 3.

O Tipo 4 conta com duas UFs que bonificam seus docentes com base na proficiência discente medida tanto por avaliações estaduais próprias quanto pela Prova Brasil e Ideb resultante. Para este tipo, é plausível a associação com evidências de gaming.

O Tipo 5, também com duas UFs, bonificam os docentes com base em atingimento de metas de proficiência discente aferida exclusivamente com base na Prova Brasil. É esperada maior pressão de gaming, na Prova Brasil, nestes contextos.

A Tabela 2 ilustra as variáveis FLAGs para as UFs, conforme a tipificação do Quadro 5. A variável DOSE indica o tempo decorrido, em anos, desde a implantação da política de bonificação e a data da Prova Brasil em estudo (2013 e 2015) ${ }^{8}$.

A classificação por tipo de bonificação estadual, apesar de ser apenas uma das tantas alavancas indutoras de gaming possíveis, se mostra suficiente para evidenciar padrões de interesse, revelados adiante. Por exemplo, os Tipos 4 e 5 (bonificações associadas diretamente ou indiretamente ao Ideb) tendem a apresentar maiores indicadores de fraudes e exclusões de baixa proficiência que os Tipos 2 e 3.

Há vários outros mecanismos potencialmente indutores de gaming que vão além da bonificação estadual. Por não serem disponíveis com a extensão e granularidade compatível com a Prova Brasil, não foram tabulados nem empregados como fatores explicativos. Por exemplo, é crescente a adoção de sistemas municipais de avaliação, alguns deles associados a políticas de responsabilização.

Um levantamento destas avaliações (BAUER et al., 2015), em parceria do Inep com a Fundação Carlos Chagas, com expressiva cobertura municipal, revela que 37\% dos municípios respondentes já tinham, em 2014, suas avaliações próprias e $21 \%$ dos que ainda não tinham, planejavam ter. As razões alegadas para ter suas próprias avaliações municipais, estão majoritariamente relacionadas à "melhoria de qualidade".

Apenas 6,3\% dos municípios respondentes usam os resultados para bonificar docentes e 9,5\% usam as avaliações para premiar escolas. $6 \%$ dos municípios indicam usar os resultados para demitir diretores e 22,6\% contam colocar resultados em placa visível à frente das escolas, como ilustrado na Introdução.

8 Consultas aos sítios das secretarias de educação estaduais não indicaram alteração nas tipificações entre 2013 e 2015. Portanto, UFs têm mesmo TIPO de um ano Saeb para outro, com a variável DOSE de 2015 incrementada em exatos 2 anos versus seus valores de 2013. 
Tabela 2 - Variáveis associadas à bonificação docente para 2013

\begin{tabular}{|c|c|c|c|c|c|c|}
\hline \multirow[t]{2}{*}{ Unidade da Federação } & $\begin{array}{l}\text { Bonificação } \\
\text { Docente }\end{array}$ & $\begin{array}{l}\text { Vinculada a } \\
\text { proficiência }\end{array}$ & $\begin{array}{l}\text { Avaliação } \\
\text { Própria }\end{array}$ & $\begin{array}{c}\text { Ideb e } \\
\text { Prova Brasil }\end{array}$ & $\begin{array}{l}\text { Anos desde } \\
\text { Implantação }\end{array}$ & \multirow[t]{2}{*}{ Tipo } \\
\hline & BONIF_DOC & BASE_PROF & $\begin{array}{c}\text { BASE_- } \\
\text { AVAL_PROP }\end{array}$ & $\begin{array}{l}\text { BASE_- } \\
\text { IDEB }\end{array}$ & DOSE & \\
\hline $\mathrm{AL}$ & 0 & 0 & 0 & 0 & 0.00 & 1 \\
\hline $\mathrm{AP}$ & 0 & 0 & 0 & 0 & 0.00 & 1 \\
\hline $\mathrm{BA}$ & 0 & 0 & 0 & 0 & 0.00 & 1 \\
\hline $\mathrm{DF}$ & 0 & 0 & 0 & 0 & 0.00 & 1 \\
\hline MA & 0 & 0 & 0 & 0 & 0.00 & 1 \\
\hline MS & 0 & 0 & 0 & 0 & 0.00 & 1 \\
\hline MT & 0 & 0 & 0 & 0 & 0.00 & 1 \\
\hline $\mathrm{PA}$ & 0 & 0 & 0 & 0 & 0.00 & 1 \\
\hline PI & 0 & 0 & 0 & 0 & 0.00 & 1 \\
\hline PR & 0 & 0 & 0 & 0 & 0.00 & 1 \\
\hline $\mathrm{RN}$ & 0 & 0 & 0 & 0 & 0.00 & 1 \\
\hline $\mathrm{RO}$ & 0 & 0 & 0 & 0 & 0.00 & 1 \\
\hline $\mathrm{RS}$ & 0 & 0 & 0 & 0 & 0.00 & 1 \\
\hline $\mathrm{SC}$ & 0 & 0 & 0 & 0 & 0.00 & 1 \\
\hline $\mathrm{AC}$ & 1 & 0 & 0 & 0 & 3.27 & 2 \\
\hline GO & 1 & 0 & 0 & 0 & 4.69 & 2 \\
\hline $\mathrm{RR}$ & 1 & 0 & 0 & 0 & 4.93 & 2 \\
\hline ES & 1 & 1 & 1 & 0 & 2.52 & 3 \\
\hline RJ & 1 & 1 & 1 & 0 & 2.85 & 3 \\
\hline $\mathrm{CE}$ & 1 & 1 & 1 & 0 & 4.10 & 3 \\
\hline SP & 1 & 1 & 1 & 0 & 4.93 & 3 \\
\hline $\mathrm{MG}$ & 1 & 1 & 1 & 0 & 5.35 & 3 \\
\hline $\mathrm{PE}$ & 1 & 1 & 1 & 0 & 5.35 & 3 \\
\hline TO & 1 & 1 & 1 & 1 & 2.10 & 4 \\
\hline $\mathrm{AM}$ & 1 & 1 & 1 & 1 & 5.94 & 4 \\
\hline $\mathrm{SE}$ & 1 & 1 & 0 & 1 & 2.18 & 5 \\
\hline $\mathrm{PB}$ & 1 & 1 & 0 & 1 & 2.27 & 5 \\
\hline
\end{tabular}

Fonte: Elaboração do autor.

Planos de Ações Articuladas (PAR) também poderiam representar alguma forma de pressão, pelos potenciais fluxos de financiamentos a eles associados. Os PAR constituem o "planejamento multidimensional e plurianual (4 anos) que os municípios, os estados e o Distrito Federal devem fazer para a obtenção de apoio técnico e financeiro do MEC com a adesão ao Plano de Metas Compromisso Todos pela Educação do PDE" (LIBÂNEO; OLIVEIRA; TOSCHI, 2012, p. 402). Estes autores consideram o PAR fundamental para a melhoria do Ideb, mas Bartolomeu Sousa (2011) ao analisar os PAR, discorda:

[Há p]roblemas e limites estruturais na proposta e execução do PAR que não lhe permite ser um instrumento de planejamento da educação, seja para estados ou municípios, mas apenas um instrumento de planejamento da rede de ensino, e instrumento de controle do MEC, com forte viés gerencial e regulatório. (SOUSA, 2011, p. 1) 
Sousa segue evidenciando os problemas operacionais que seguiram a implementação dos PAR. De importância para este presente trabalho, é a explicação dada para a alocação de recursos: os programas começaram pelos municípios de Ideb mais baixo, para só depois se expandirem aos demais. Esta construção leva a crer que os PAR não levariam a gaming envolvido com táticas de aumentar o Ideb reportado, pois isto potencialmente diminuiria o acesso aos recursos aportados. Os dados públicos dos PAR, no sítio do MEC, não permitem uma pronta confrontação com os valores de Ideb e não foram considerados neste estudo. Também não são públicos os microdados do survey municipal da FCC e Inep citado anteriormente, por isso não foram incluídas estas informações como covariantes úteis na modelagem.

\subsection{A manipulação da base de alunos avaliados}

A literatura registra o estratagema de excluir alunos de baixa proficiência das avaliações externas, visando a aumentar o escore obtido pela escola. Esta exclusão, aqui representada por ausências "não aleatórias" no dia da prova, tem por objetivo levar a um desempenho agregado mais alto do que resultaria caso fossem incluídos estes alunos de baixo desempenho, caracterizando assim uma inflação de escores. No contexto deste trabalho, a ausência não aleatória é aquela dependente do nível proficiência do ausente. Uma ausência aleatória é aquela que é independente do nível de proficiência do ausente.

O objetivo da abordagem proposta é medir a incidência e a extensão destas exclusões não aleatórias de alunos de baixa proficiência, na Prova Brasil, com a exploração de dados observacionais da Prova Brasil. A análise da manipulação da base de alunos avaliados se baseia em decompor em suas componentes a lacuna entre alunos contados no Censo Escolar e os que de fato foram avaliados na Prova Brasil ${ }^{9}$. A análise se faz para duas aplicações da Prova Brasil (2013 e 2015) para avaliar a influência de mudanças na legislação pertinente ocorridas entre as duas aplicações, contextualizadas a seguir.

\subsubsection{Tipos de ausências na Prova Brasil e suas explicações}

Para medir exclusões potencialmente intencionais de alunos da base avaliada, é necessário entender as componentes das ausências na Prova Brasil. Para tanto, parte-se do conceito de "movimento", descrito pelo Inep ao apresentar o Censo da Educação (BRASIL. Ministério da Educação. Instituto Nacional de Estudos e Pesquisas Educacionais Anísio Teixeira, 2016a), que aborda (1) o abandono, (2) o óbito e (3) a transferência de alunos. Estas componentes do movimento explicam uma parte da ausência. O restante é explicado

9 Esta lacuna entre os alunos mapeados no Censo e os avaliados é observada por meio da taxa de participação para cada escola incluída na avaliação. 
por dois tipos de faltas: (4) aleatórias e (5) não aleatórias,estas últimas são as de interesse maior nesta análise.

Abandonos (1): identificam os alunos que terminam o ano escolar sem serem aprovados ou reprovados, conforme definição de Ruben Klein (2003, p. 110) e replicada na documentação do Inep. O abandono tem sentido dentro da vigência do ano escolar em curso. A situação de abandono carregada para o ano escolar seguinte, caso o aluno em abandono não se reintegre ao sistema escolar, caracteriza a evasão. A contagem dos alunos nesta condição de abandono, portanto dentro do ano escolar, cursando o $5^{\circ}$ e $9^{\circ}$ anos, é usada para explicar uma parte significativa da ausência na Prova Brasil, nas abordagens descritas adiante.

Figura 13 - Taxas de abandono para $5^{\circ}$ e $9^{\circ}$ anos por UF - 2013

Taxas de abandono nas escolas públicas por UF, 2013
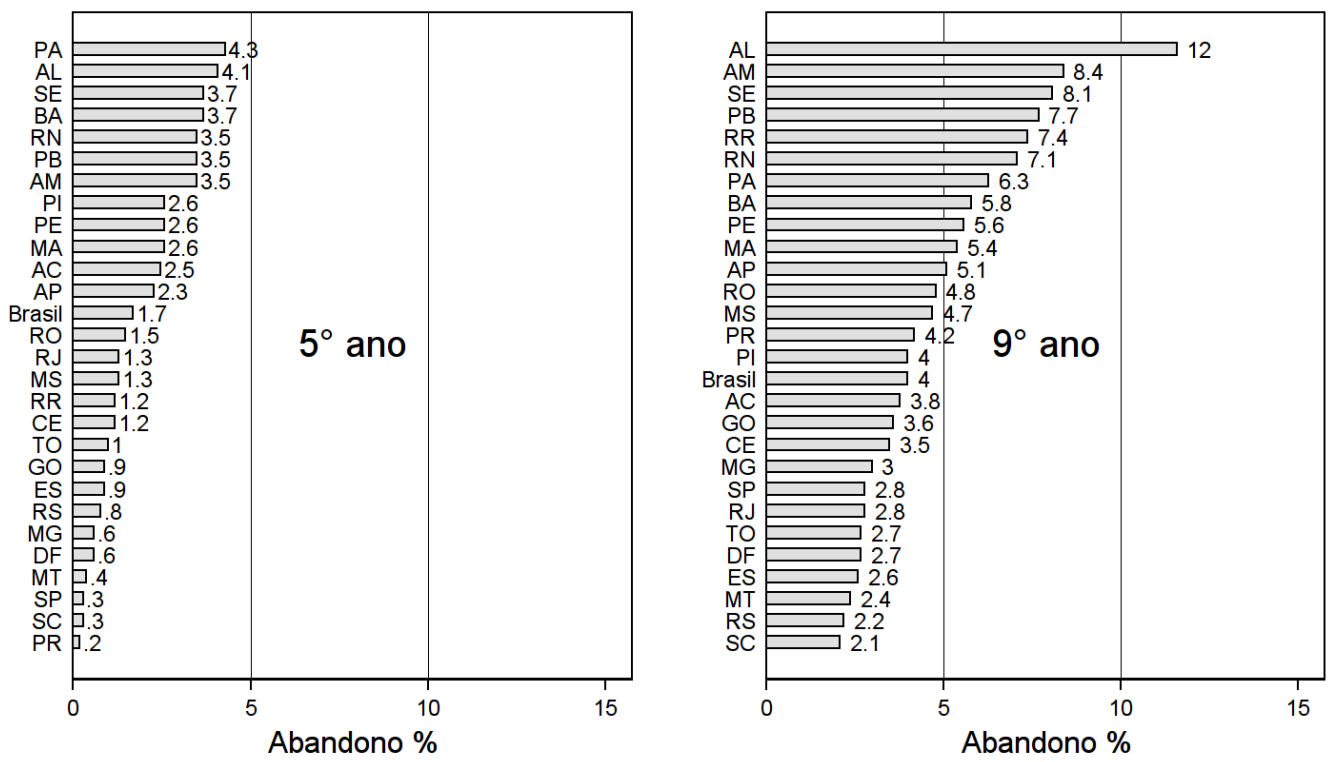

Fonte: Elaboração do autor, com dados do Inep.

A Figura 13, produzida com dados do Inep, exemplifica as ordens de grandeza das taxas percentuais de abandono por UF e o agregado para o Brasil, para 2013. As taxas de abandono são em geral maiores para o $9^{\circ}$ ano, comparadas às do $5^{\circ}$ ano.

Óbitos (2): se o aluno falece entre a data de realização do Censo e a da Prova Brasil, não há o que fazer: ele de fato não será avaliado. Para estimar a participação de óbitos nas ausências da Prova Brasil, usou-se a tábua de mortalidade do ano de 2013, para ambos os sexos, produzida pelo Instituto Brasileiro de Geografia e Estatística (IBGE, 2013). Nela, apresenta-se a taxa de mortalidade entre idades, em óbitos por mil habitantes. Aqui se ajusta para óbitos para cada 100 habitantes,para ter comparabilidade com as 
demais componentes explicativas de ausência, medidas em percentagens, e se reduz número esperado de óbitos, usando um fator proporcional ao tempo entre o Censo Escolar e a Prova Brasil: seis meses no ano, resultando em fator de ajuste de 0,5.

Como se vê pela Figura 14, as taxas de mortalidade para as idades normalmente associadas ao $5^{\circ}$ e $9^{\circ}$ anos são três ordens de grandeza menores que as percentagens referentes às taxas de abandono ${ }^{10}$. Não há registro nas bases do Inep consultadas da indicação de óbitos (bases Saeb e Censo Escolar), assim sendo, aliada à magnitude relativa pequena, o efeito dos óbitos não será computado.

Figura 14 - Taxas de mortalidade, Brasil 2013, nas idades do $5^{\circ}$ e $9^{\circ}$ anos EF
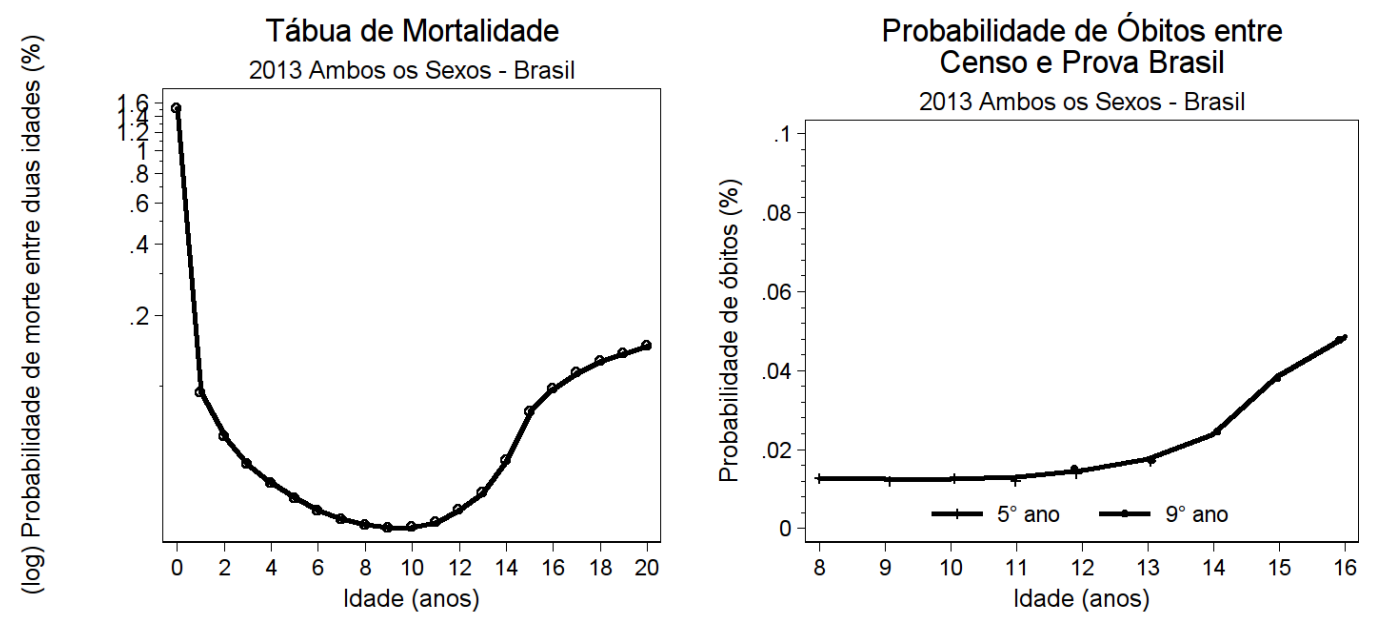

Fonte: Elaboração do autor, com base em dados do IBGE (2013).

Transferências de alunos (3): o aluno incluído na escola $i$ por ocasião do Censo, mas que se transfere para a escola $j \neq i$ antes da Prova Brasil, seria contado como uma ausência na escola $i$ e uma participação não recenseada na escola $j$.

Infelizmente, os microdados públicos da Prova Brasil não permitem reconstruir os fluxos de transferência. Contudo, apresentam uma variável indicativa ${ }^{11}$ da consistência do aluno com o Censo. Com base na contagem dos casos de inconsistência, é possível mensurar a magnitude destes casos versus os alunos que fizeram as provas, conforme a Tabela 3. Dadas as magnitudes encontradas, este efeito será desprezado nas análises.

\footnotetext{
$\overline{10}$ Por mais impactante que seja o óbito do aluno no contexto de sua família e de sua comunidade escolar, no agregado dos fatores explicativos das ausências da Prova Brasil, o impacto numérico destes é negligenciável e será desconsiderado.

11 Variável IN_SITUACAO_CENSO assume valor 0 caso haja inconsistência.
} 
Tabela 3 - Inconsistências de registro entre Censos e Provas Brasil

\begin{tabular}{clc}
\hline Alunos avaliados mas inconsistentes com o & \multicolumn{2}{l}{ Prova Brasil realizada em... } \\
Censo Escolar por série/ano & $\ldots 2013$ & $\ldots 2015$ \\
\hline $5^{\circ}$ ano & $0,28 \%$ & $0,53 \%$ \\
$9^{\circ}$ ano & $0,40 \%$ & $0,24 \%$ \\
\hline
\end{tabular}

Fonte: Elaboração do autor, com base em dados da Prova Brasil 2013 e 2015.

Ausências aleatórias (4): são as ausências verificadas nos dias de realização da Prova Brasil, mas que sejam independentes das características do aluno faltante, em particular, sua proficiência provável nas disciplinas avaliadas. Estas faltas não alteram a forma da distribuição de proficiências. Um exemplo seria a quebra do ônibus usado para levar os alunos à escola no dia da avaliação, o qual transporta tanto alunos mais proficientes quanto menos proficientes. Todos os passageiros faltariam à avaliação, independentemente de suas proficiências. Um segundo exemplo seria uma virose que acometesse múltiplos alunos, às vésperas da prova, incapacitando temporariamente um grupo de alunos em amplo espectro de proficiências. A real natureza aleatória é questionável, assumidamente: o aluno com maior nível socioeconômico talvez tivesse meios de conseguir transporte alternativo ao ônibus quebrado ou tivesse uma resistência maior à virose, infringindo a condição de independência.

Ausências não aleatórias (5): são as faltas que se associam com algum tipo específico de característica discente. Estas são as ausências associadas aos estratagemas que se visam a analisar: se os alunos tidos como "problema" e de baixa proficiência forem excluídos da avaliação, por qualquer meio, a curva de distribuição de proficiências terá sua forma alterada, ainda que sutilmente.

A Figura 15 resume as componentes (1) a (5) descritas acima. Este trabalho desconsidera óbitos e transferências e apresenta a seguir as etapas para decompor as ausências levando em conta o abandono e a aleatoriedade das faltas no dia da avaliação. 
Figura 15 - Movimentos e ausências na Prova Brasil - conceitual

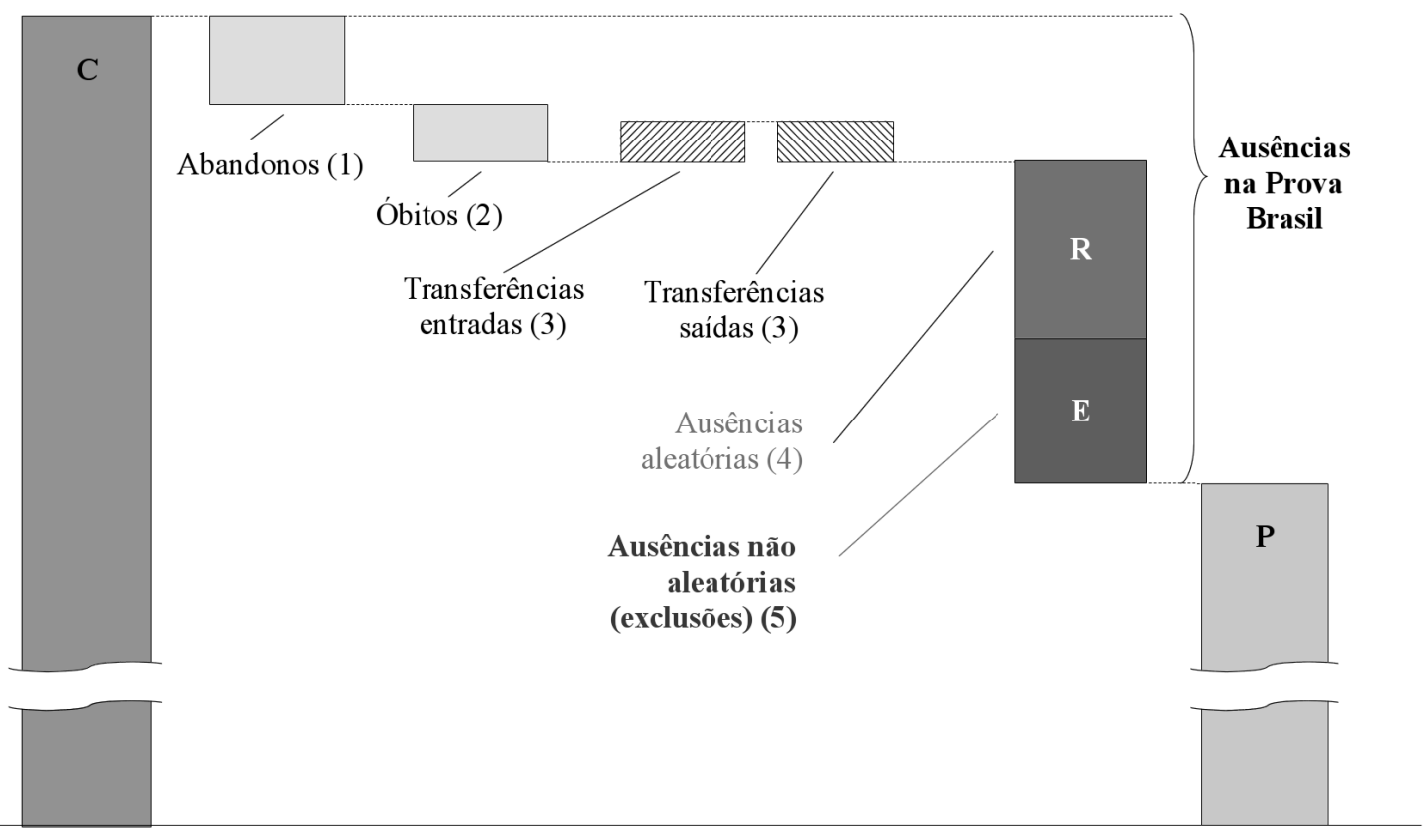

Alunos contados no Censo Escolar

$\sim 6$ meses

Fonte: Elaboração do autor.

\subsubsection{Identificação das ausências não aleatórias}

As proficiências dos alunos aferidas nas avaliações do Saeb são estimadas usando um modelo da Teoria de Resposta ao Item logístico de três parâmetros. Estes modelos, explicados em Rodrigues (2006, p. 55) e Klein (2013, p. 107-108), estimam proficiências cuja distribuição toma a forma de uma curva normal por meio de um fator de escala ${ }^{12}$.

Estas proficiências são distribuídas ao longo de um contínuo, das mais baixas às mais altas, com distribuição normal, em forma de um sino ou ogiva, com uma cauda à esquerda com os escores mais baixos, um bojo central perto da média e uma cauda à direita com os escores mais altos. Distorções ou assimetrias nas formas destas curvas podem indicar ausências seletivas ou não aleatórias e é com base nessas distorções que a abordagem proposta se fundamenta.

$\overline{12}$ O fator $D=1,7$ afetando a exponenciação no denominador da equação característica da TRI de três parâmetros leva aos resultados virtualmente normais (ANDRADE; TAVARES; VALLE, 2000, p. 9-10). 
Figura 16 - Ausências aleatórias e não aleatórias na distribuição de proficiências

Efeitos das ausências aleatórias na distribuição de proficiências

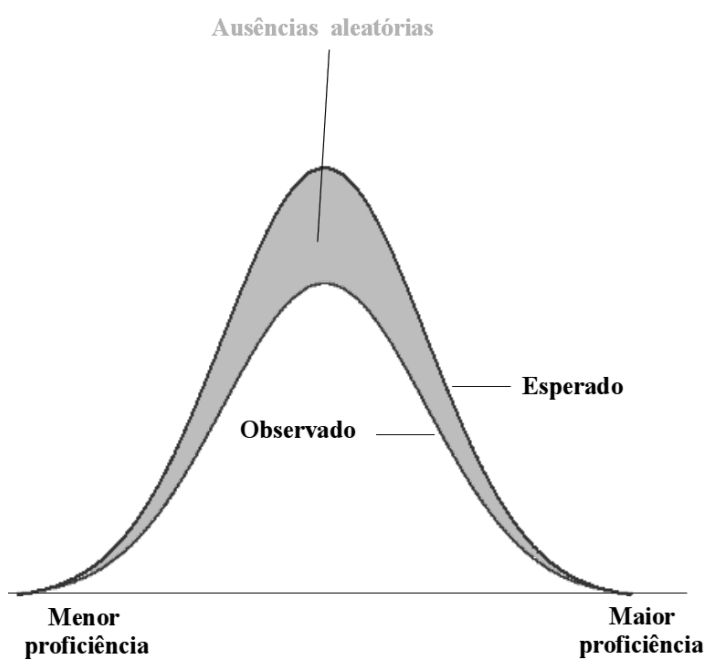

Efeitos das ausências não aleatórias na distribuição de proficiências

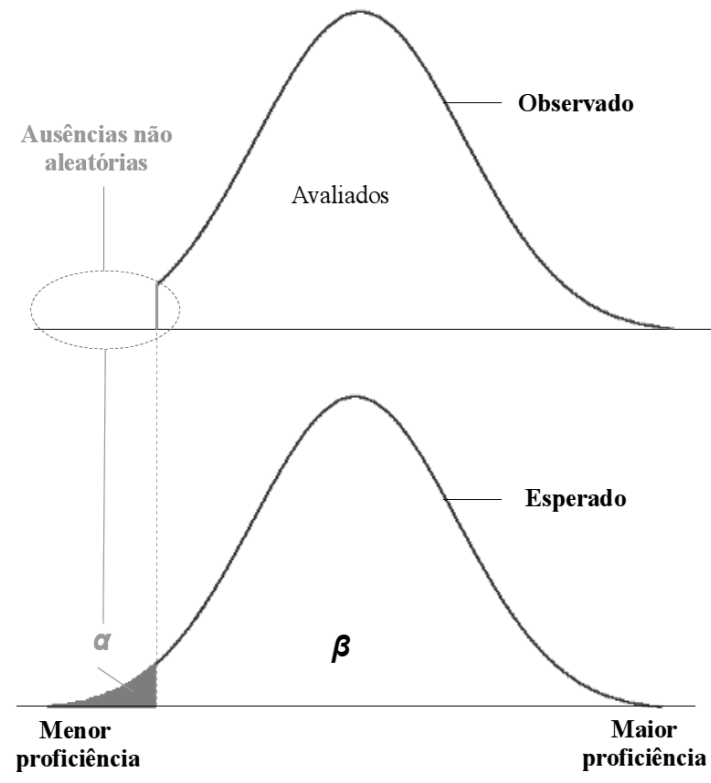

A+B

Fonte: Elaboração do autor.

A Figura 16 exemplifica graficamente a diferença entre ausências aleatórias e as não aleatórias nas curvas de distribuição de proficiências. As aleatórias não geram assimetrias em torno da média, tal como ilustrado no lado esquerdo da figura. Já as ausências não aleatórias, que seletivamente excluem os alunos de baixa proficiência, criam uma assimetria ilustrada na metade direita da figura, marcadamente na região destacada $\alpha$.

A área sob a curva normal de proficiências pode ser partida em duas regiões, $\alpha$ e $\beta$, sendo a fronteira entre elas determinada pelo ponto de divisão $z_{c}$ no eixo horizontal. $\mathrm{O}$ valor $z_{c}$ representa o ponto de corte na proficiência abaixo do qual os valores são censurados ou excluídos. O valor de $\alpha$ representa a proporção de casos que se encaixam nesta exclusão ou censura. $\mathrm{O}$ valor de $\beta$ representa a proporção de casos não censurados, acima de $z_{c}$.

Chamando de $P$ o número de alunos avaliados de fato no agrupamento escolhido (proporcional à contagem com truncamento) e $F$ a representar o número de alunos que teriam sido avaliados, caso não houvesse incidência de faltas não aleatórias (proporcional à contagem total de participantes, sem truncagem), então, por regra de três:

$$
\frac{F}{\alpha+\beta}=\frac{P}{\beta}
$$

Lembrando que a área sob a curva normal vale 1 , e portanto $\beta=1-\alpha$, tem-se por substituição:

$$
F=\frac{P}{1-\alpha}
$$


Este trabalho propõe uma medida da distorção representada pela área $\alpha$, com a criação de uma "impressão digital", identificadora de casos de exclusão de alunos de baixa proficiência. Para tanto, é empregado o artifício de simular amostragens de uma distribuição normal padronizada, com média zero e desvio padrão igual a um. Estas amostragens são truncadas na cauda esquerda, de maneira a simular a exclusão de percentagens $p$ crescentes de alunos de baixa proficiência.

Exemplos destas simulações podem ser vistos na Figura 17, que apresenta à esquerda as funções densidade de probabilidade truncadas, em histogramas. À direita, os gráficos quantil-quantil (Q-Q) comparam a normal truncada simulada (eixo vertical) com a normal de referência completa (eixo horizontal), evidenciando o descolamento entre as distribuições normais completas e aquelas truncadas por simulação.

Um polinômio interpolador foi construído, para este fim, de maneira a inferir uma fração $\alpha$ de exclusão para uma dada distribuição normalizada de proficiências $p_{i}$, com base na mediana observada ${ }^{13}$. A mediana é zero se não há assimetria na distribuição simulada. Na medida em que frações crescentes são excluídas à esquerda, mais negativa a mediana observada associada se torna e maior o $\alpha$ resultante.

13 Ver apêndice à página 203 para os detalhes da construção do polinômio. Optou-se por usar um polinômio interpolador e simulações de truncamento por ser uma abordagem mais facilmente tratável que desenvolver analiticamente o raciocínio por meio do Inverse Mills Ratio, aplicável à análise de distribuições normais truncadas. Isto exigiria a solução de equações não lineares resultantes da expansão por séries infinitas de uma aproximação deste ratio, usando médias e desvios medidos por agrupamento como parâmetros. Os cálculos do Inverse Mills Ratio também trariam dificuldades ao agrupamento de escolas, pois exigem como insumo a média e desvio padrão observados, e estes se reduzem a zero e um respectivamente, com a etapa de padronização adotada ao agrupar os dados. 
Figura 17 - Simulações de truncamentos à esquerda

\section{Simulação de Truncamento}

\section{Corte dos . $1 \%$ menos proficientes}
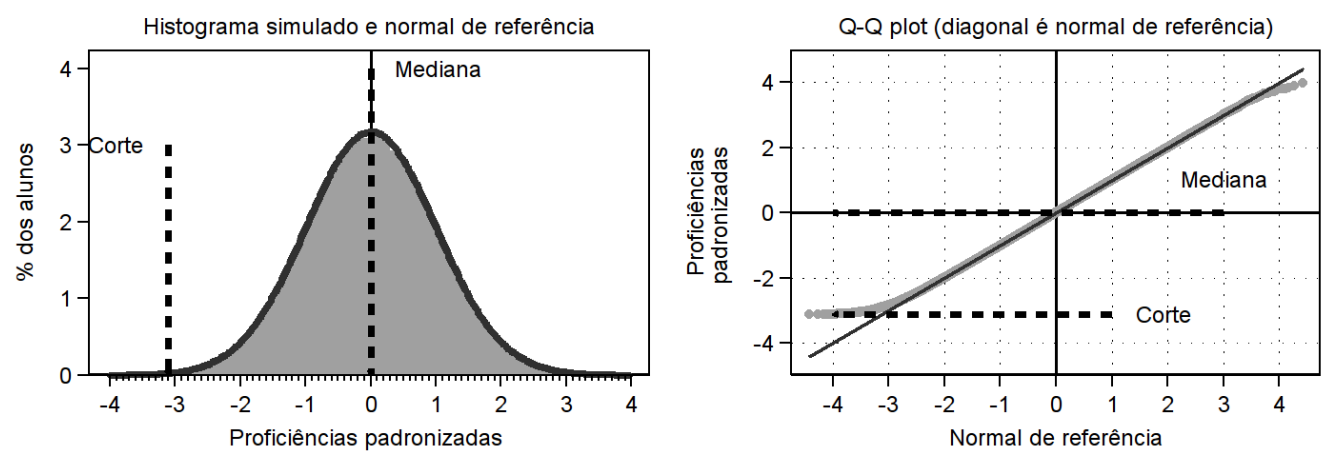

\section{Corte dos $5 \%$ menos proficientes}
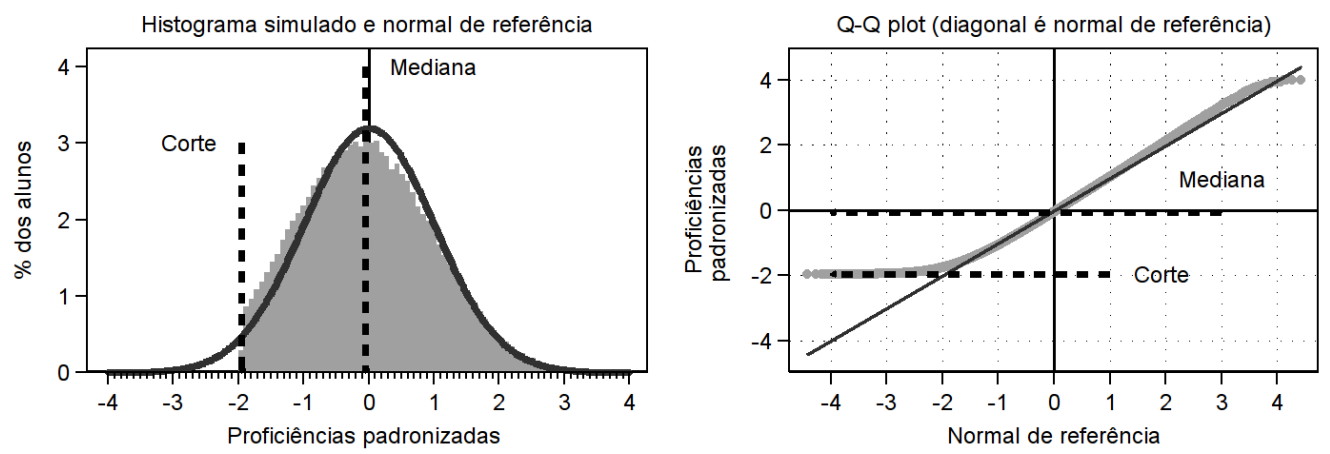

Corte dos $20 \%$ menos proficientes
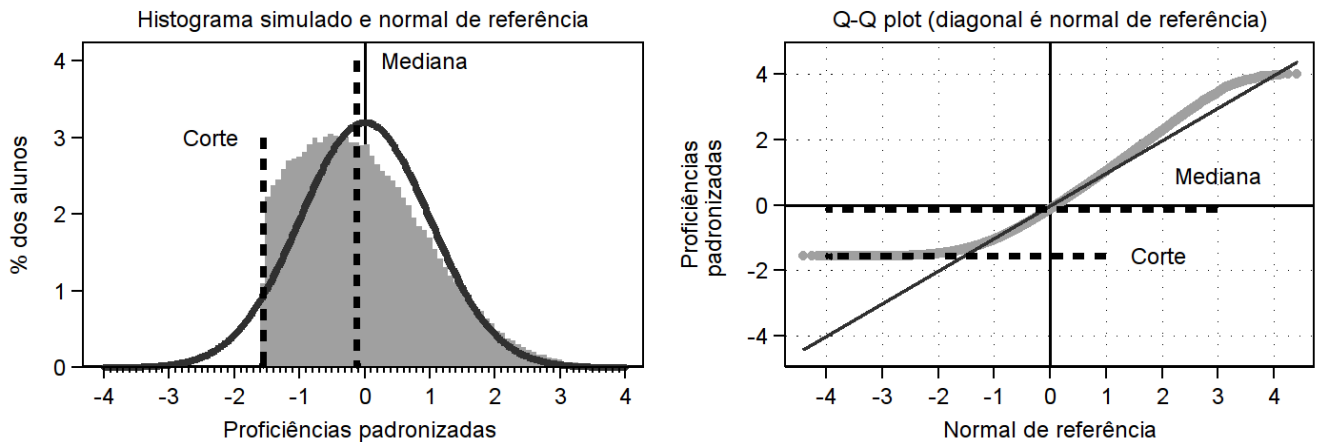

skinner_truncamentos

Fonte: Elaboração do autor.

É importante determinar os agrupamentos de interesse para os quais se deseja realizar as análises. Três fatores determinantes guiam a escolha dos agrupamentos: primeiro, a disponibilidade de dados com granularidade suficiente para segregar os grupos. Uma segunda condição de ordem prática se apresenta quanto ao tratamento dos resultados: se o 
número de agrupamentos for muito grande, a apresentação dos resultados será demasiado complexa. Esta condição inviabiliza, por exemplo, mostrar os resultados individualizados por escolas, pois são dezenas de milhares no âmbito da Prova Brasil.

Uma terceira e importante condição envolve a premissa de normalidade na distribuição de proficiências no agrupamento. Por exemplo, um agrupamento com poucos alunos pode não ter a representatividade necessária para reconstruir a curva normal de proficiências. Agrupamentos com alunos de características heterogêneas demais podem ter distribuições de proficiências com característica multimodal.

Para avaliar a normalidade das distribuições nos agrupamentos, duas abordagens complementares foram testadas neste trabalho:

a) estimativa do teste $W^{\prime}$ de Shapiro-Francia para normalidade (ROYSTON, 1991), cujo p-valor associado $W_{p}$, quando pequeno o suficiente, pode ser usado para selecionar agrupamentos de maneira programática nas análises, evitando usar distribuições que não sejam "suficientemente normais" na inferência de conclusões;

b) inspeção visual das distribuições em gráficos de diagnóstico, histogramas e gráficos quantil-quantil ( $Q$ - $Q$ plots), construídos por meio do pacote estatístico (exemplificado na Figura 18).

O arranjo da Figura 18 é simples, sem escalas, rótulos ou eixos, para facilitar a avaliação visual tanto do histograma quanto do $Q-Q$ plot produzido por agrupamento e suas respectivas referências normais. No exemplo da Figura 18, a escolha dos agrupamentos não é ideal, pois há grupos com multimodalidade e grupos pequenos com ogivas malformadas. O critério de agrupamento nela exemplificado leva em conta a rede administrativa das escolas (estadual ou municipal), localização (urbana ou rural) e seu nível socioeconômico, para o estado do Ceará. Sobre cada par de histogramas e $Q$ - $Q$ plots, é informado o qualificador do grupo, conforme indicado acima, o número de alunos nele representado $N$ e o p-valor $W_{p}$ associado à estatística de Shapiro-Francia $W^{\prime}{ }^{14}$

Um exemplo de uma distribuição adequadamente normal sem indícios de exclusão de alunos de baixa proficiência está representado na Figura 19. Nela está representada a proficiência dos alunos do $5^{\circ}$ ano de Santa Catarina, na avaliação de Matemática de 2013. É visível a aderência à curva normal, ao longo de todas as proficiências e, em particular, no lado esquerdo da figura, indicando baixa ou nula exclusão dos alunos menos proficientes.

14 Este mapeamento visual foi usado no processo preliminar de exploração de agrupamentos. Para os agrupamentos finais analíticos por FLAGs, usados para suportar as regressões, os gráficos não foram usados, pois o número de grupos excedia o prático. 


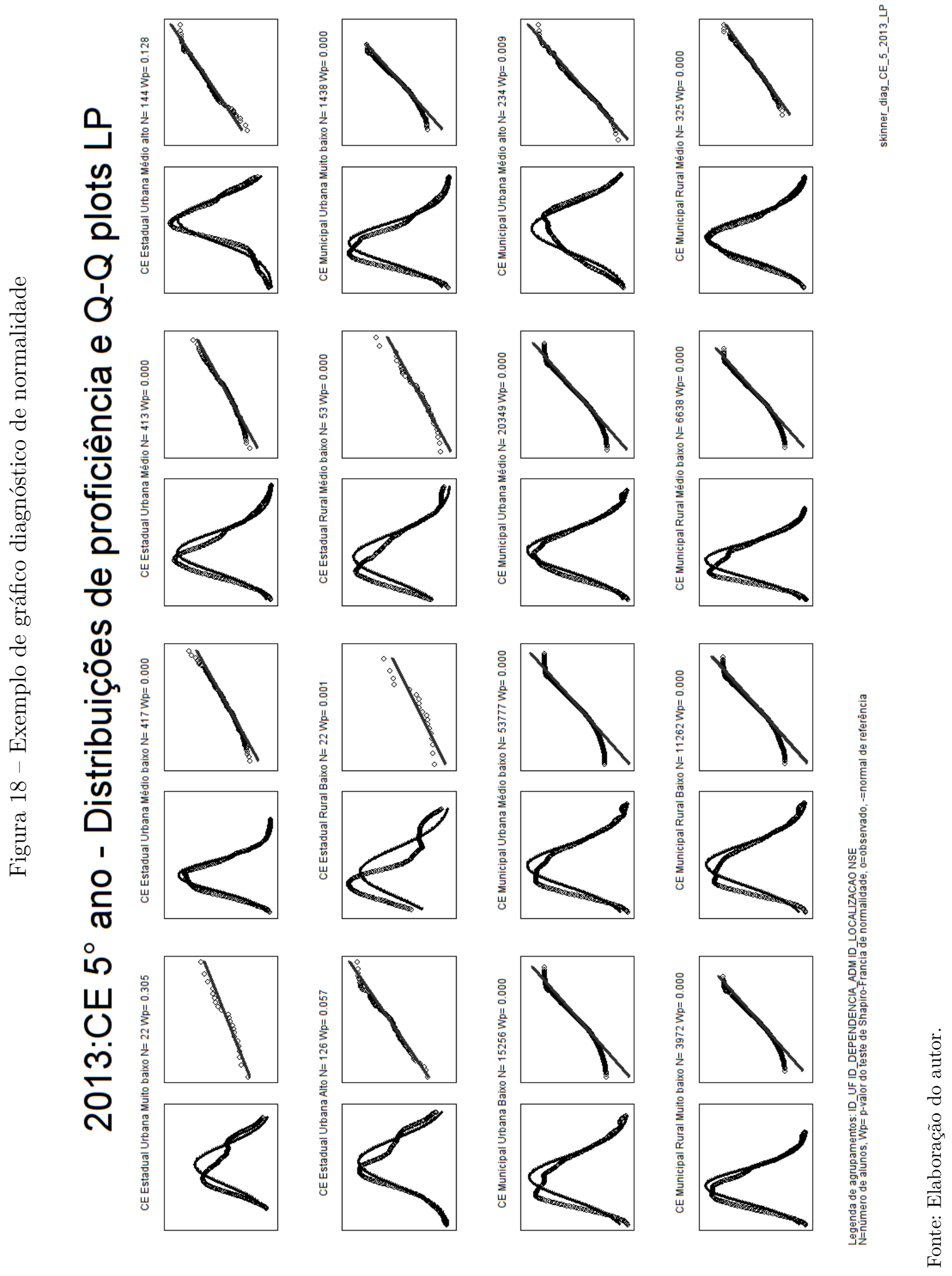


Figura 19 - Exemplo de histograma de proficiências com baixa exclusão

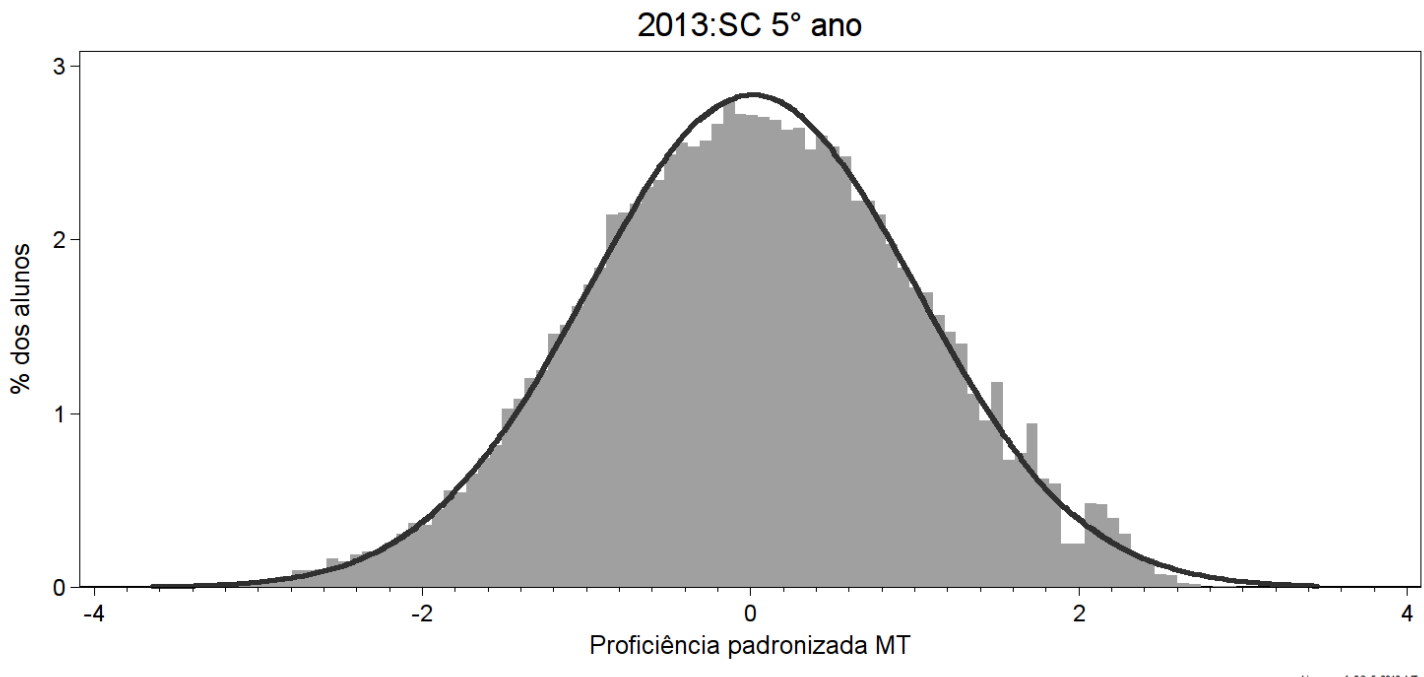

Fonte: Elaboração do autor, 5 ano da Prova Brasil MT 2013 Santa Catarina.

Figura 20 - Exemplo de histograma de proficiências com alta exclusão

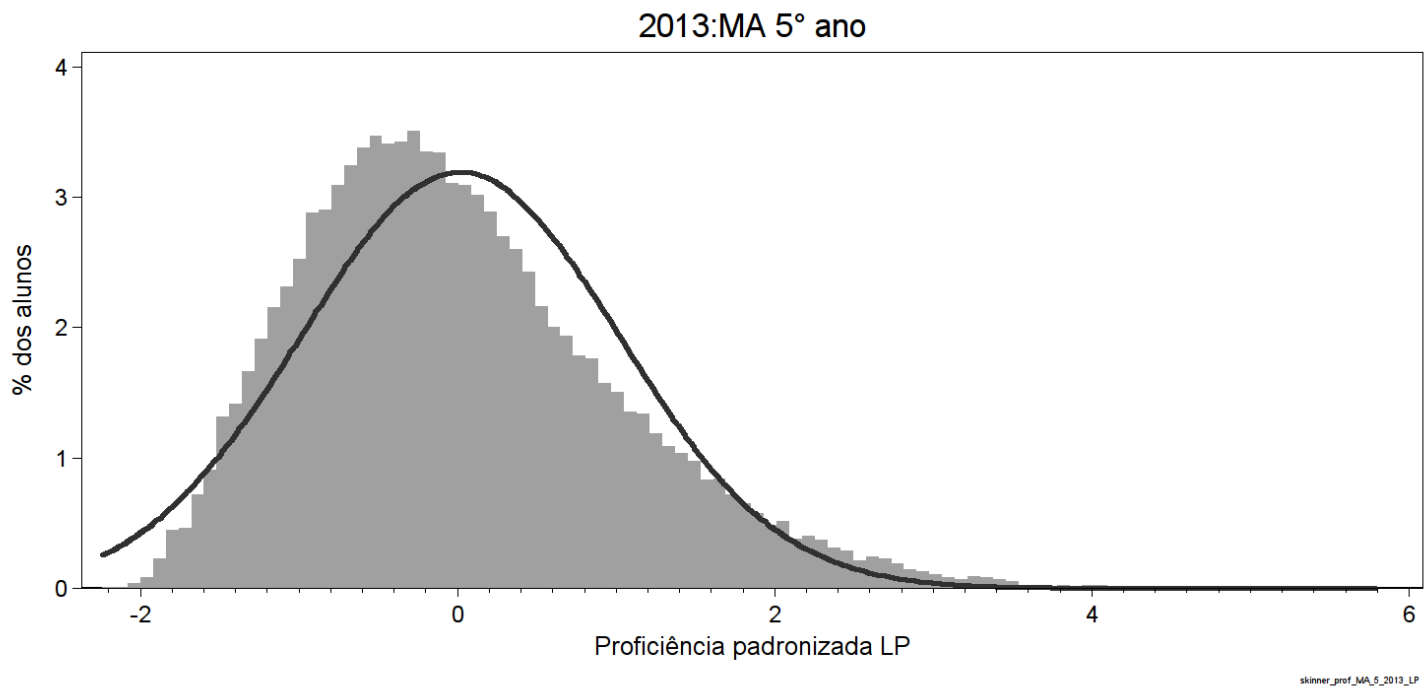

Fonte: Elaboração do autor, $5^{\circ}$ ano da Prova Brasil LP 2013 Maranhão.

Em contraste, os dados do Maranhão, quanto à avaliação de Língua Portuguesa, também do $5^{\circ}$ ano da Prova Brasil de 2013, representados na Figura 20, mostram elevadas taxas de exclusão. Um forte descolamento das proficiências observadas da distribuição normal esperada, na região de baixa proficiência, pode ser observado à esquerda do eixo horizontal.

Por meio de testes de agrupamento variados e o uso conjunto das duas abordagens, a análise dos gráficos de diagnóstico e a estatística de Shapiro-Francia, chegou-se a um agrupamento razoável, cobrindo UFs, NSE e FLAGs. A eleição feita envolve ter 
agrupamentos numerosos o bastante para observar diferenças entre eles quanto às exclusões, sem sacrificar a normalidade das distribuições de proficiência.

Para exemplificar a consequência desta eleição, temos que agrupando somente por 27 Unidades da Federação, 100\% dos casos têm p-valor praticamente nulo. Para um agrupamento por município, que resulta em cerca de 5400 grupos por ano avaliado, apenas $36 \%$ dos casos têm p-valor $W p \leq 0,10$. Para a análise, mostram-se úteis os agrupamentos que geram algumas centenas de casos. Por exemplo, para o agrupamento por fatores ligados ao gaming (FLAGs), 88\% dos casos têm $W p \leq 0,10$ e há casos suficientes para cobrir o espaço das variações destes FLAGs para as análises posteriores ${ }^{15}$.

Uma vez estabelecidos os agrupamentos, as ausências na Prova Brasil em suas componentes, explicadas a seguir, lembrando que o objetivo é isolar as ausências não aleatórias no dia da avaliação. Para um dado agrupamento $G$, são conhecidos, diretamente dos dados do Inep:

a) $C$ : número de alunos contados no Censo Escolar;

b) P: número de alunos avaliados na Prova Brasil;

c) as proficiências $p_{i}$ para uma dada disciplina, na escala Saeb, para os $P$ alunos $i$, tais quais reportadas pelo Inep nos microdados do Saeb;

d) $D$ : número de abandonos tabulados, no fim do ano letivo.

As ausências totais no dia da avaliação, num dado grupo, $A$, são obtidas por diferença simples:

$$
A=C-P
$$

O que leva à taxa de ausências:

$$
t_{A}=\frac{C-P}{C}
$$

Para alunos de um grupo de interesse na análise, a média e desvio padrão para as proficiências $p_{i}$ são $\mu$ e $\sigma$, respectivamente. As proficiências padronizadas são dadas por $z_{i}=\left(p_{i}-\mu\right) / \sigma$, as quais têm média $\mu_{z}=0$ e desvio padrão $\sigma_{z}=1$. As medianas resultam negativas, quando a distribuição de proficiências apresenta um truncamento ou censura à esquerda, nas proficiências mais baixas.

\footnotetext{
15 O critério de agrupamento escolhido para a preparação dos dados para análises de regressão usou as variáveis ID_UF, TIPO, NSE, PROF_BASED, BASE_AVAL_PROP, BASE_IDEB_PB, QUEDA_RANK, QUEDA_IDEB, ABAIXO_META, RURAL e ESTADUAL. Estas variáveis são explicadas adiante, à página 116, ao serem apresentados os modelos de regressão multinível. Gráficos foram gerados com base em agrupamentos definidos pelas variáveis NSE, ID_UF, TIPO, QUINTIL_DELTA, QUINTIL_GAP, QUINTIL_IDEB, QUINTIL_RANK e IDEB_NAO_REPORTADO. Aqui o uso de quintis ajudou a organizar visualmente as distribuições das variáveis contínuas FLAG.
} 
A análise da distribuição das proficiências padronizadas e a mediana resultante permitem estimar a fração de alunos $(\alpha)$ ausentes de maneira não aleatória na avaliação. Pela equação 2.5, determina-se o número $F$ estimado de alunos de baixa proficiência que fariam a prova caso não fossem excluídos de maneira seletiva. A estimativa de $\alpha$ para o grupo é obtida pelo polinômio interpolador descrito pela equação B.6 apresentada em apêndice à página 204. Restringindo a estimativa $F$ a não ultrapassar o total recenseado $C$ tem-se:

$$
F=\min \left\{C, \frac{P}{1-\alpha}\right\}
$$

Quando um aluno abandona as aulas, entre as datas do Censo e da Prova Brasil, ele não estará presente na turma para ser sujeitado a uma exclusão. Por outro lado, um aluno de baixa proficiência que esteja regularmente frequentando suas aulas, pode ser excluído pelos mecanismos de seleção já descritos. Não parece ser razoável que os alunos em abandono estejam distribuídos ao longo de toda a gama de proficiências. Possivelmente alunos de baixa proficiência estejam em maior número entre os abandonos. Por conseguinte, há uma parcela de ausências nas baixas proficiências, inferida pela assimetria da normal truncada, que não é fruto de exclusão deliberada e sim consequência de outros mecanismos associados ao abandono.

A componente de ausências de baixa proficiência representada no abandono precisa ser estimada e com ela, inferir por diferenças as exclusões deliberadas no dia da prova, fruto do gaming. Para desmembrar os efeitos do abandono das ausências ocorridas no dia da prova, conta-se com a equação 2.6, rearranjada na equação 2.7. Ambas decompõem as ausências em suas componentes.

$$
\begin{gathered}
A=\underbrace{R_{x}+R_{D}}_{\text {Parte aleatória }}+\underbrace{E_{x}+E_{D}}_{\text {Parte não aleatória }} \\
A=\underbrace{R_{x}+E_{x}}_{\text {Pontuais, no dia da prova }}+\underbrace{R_{D}+E_{D}}_{\text {Abandono anterior à prova }}
\end{gathered}
$$

Os subíndices ${ }_{x}$ indicam as ausências no dia da avaliação, tanto aleatórias $\left(R_{x}\right)$ quanto as concentradas nos alunos de baixa proficiência $\left(E_{x}\right)$. Os subíndices ${ }_{D}$ indicam as ausências originadas do abandono (dropouts) deflagradas entre a data do Censo e a da Prova Brasil.

$$
\begin{aligned}
& E=E_{D}+E_{x}=F-P \\
& R=R_{D}+R_{x}=C-F
\end{aligned}
$$

A Figura 21 resume os movimentos e suas contribuições na abordagem para estimar as ausências não aleatórias e as puramente aleatórias, conforme descrito. Óbitos são 
desconsiderados por serem numericamente inexpressivos. Transferências são assumidas neutras com entradas igualando saídas do grupo, além de terem baixa expressividade conforme a Tabela 3, portanto desprezadas na análise.

As taxas de ausências de cada uma das componentes de ausência são tomadas em relação ao número de alunos contados no Censo $(C)$. Por exemplo:

$$
t_{E_{x}}=\frac{E_{x}}{C}=\text { taxa de exclusões não aleatórias no dia da prova }
$$

O objetivo final é estimar $t_{E_{x}}$, a taxa de exclusão de alunos de baixa proficiência no dia da avaliação, que pode ser estimada pela equação 2.11, decorrente da divisão de todas as parcelas da equação 2.6 pelo número de alunos recenseados $C$ do grupo:

$$
t_{E_{x}}=t_{A}-t_{R_{x}}-t_{E_{D}}-t_{R_{D}}
$$

A taxa de ausências $t_{A}$ vem diretamente dos dados do Inep (equação 2.4). As componentes $t_{R_{x}}, t_{E_{D}}$ e $t_{R_{D}}$ são estimadas conforme passos descritos a seguir.

Os abandonos reportados pelo Inep para um dado grupo, designados por $D$, incluem todos os casos ocorridos entre a data da Prova Brasil e o encerramento do ano letivo, os quais não devem ser considerados na sua totalidade nas análises de ausência no dia da prova. A fração $d$ representa a parte do abandono que compete ao período entre o Censo Escolar e a Prova Brasil, conforme a equação 2.12.

$$
D=\underbrace{d \cdot D}_{\text {Entre Censo e Prova Brasil }}+\underbrace{(1-d) \cdot D}_{\text {Após Prova Brasil }}
$$

Para separar o efeito do abandono sobre a assimetria da curva normal, recorre-se a regressões lineares simples para casos de grupos com baixíssima incidência de exclusão $\left(t_{E}\right.$ muito próximas de zero $\left.{ }^{16}\right)$, como ilustrado na Figura 22. Da equação 2.6, no caso de agrupamentos com pouquíssima assimetria e, portanto, sem exclusões substanciais, decorrem:

$$
\begin{gathered}
A=R_{D}+R_{x}, \text { para } t_{E}=0 \\
t_{A}=t_{R_{D}}+t_{R_{x}}, \text { para } t_{E}=0
\end{gathered}
$$

Regredindo $t_{A}$ contra $t_{D}$ nestes grupos com $t_{E} \approx 0$ :

$$
t_{A}=\beta_{0}+\beta_{1} \cdot t_{D}+\text { resíduo }
$$

16 Usou-se $t_{E} \leq 0,01$ como critério para inclusão na regressão 2.15 . 


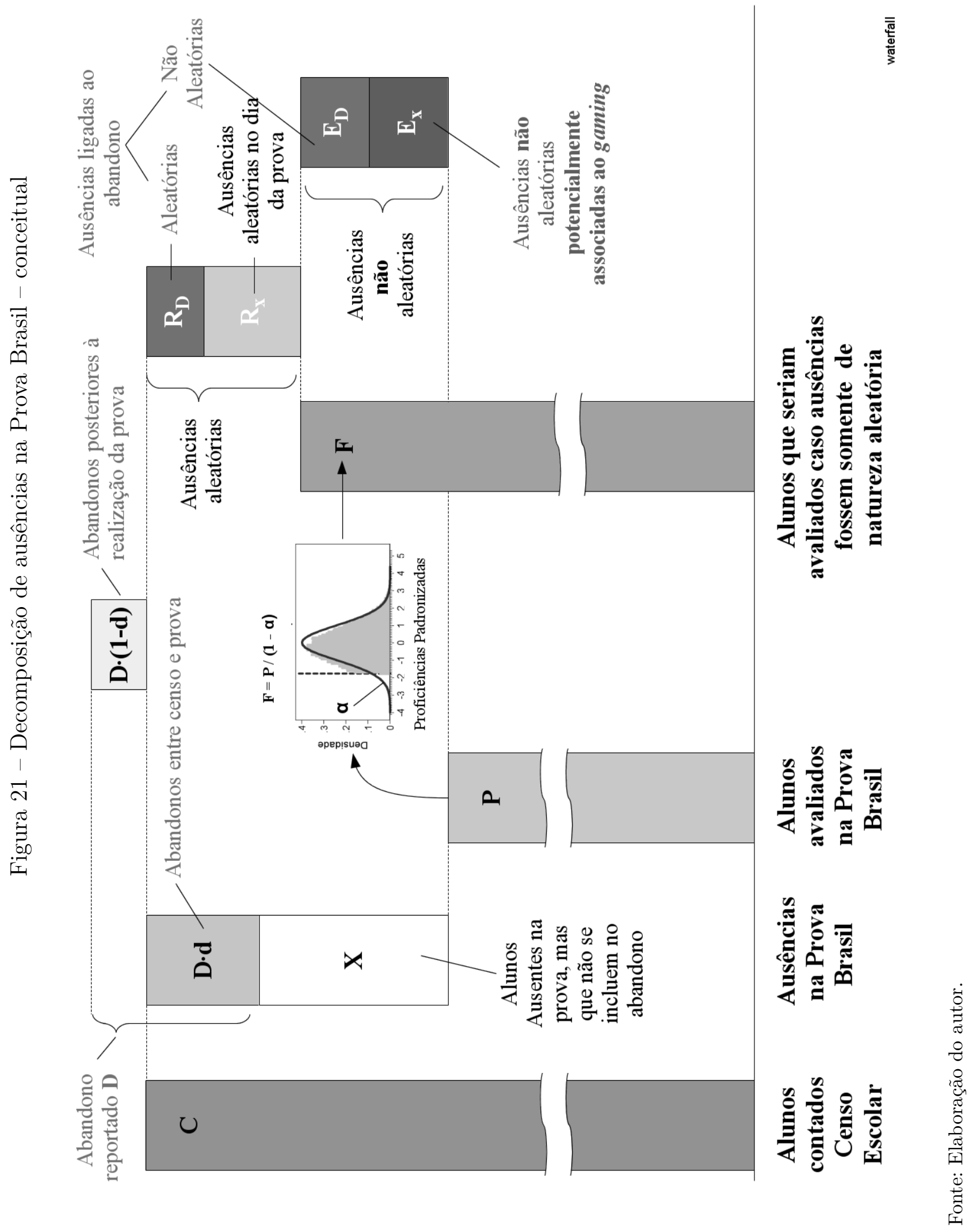




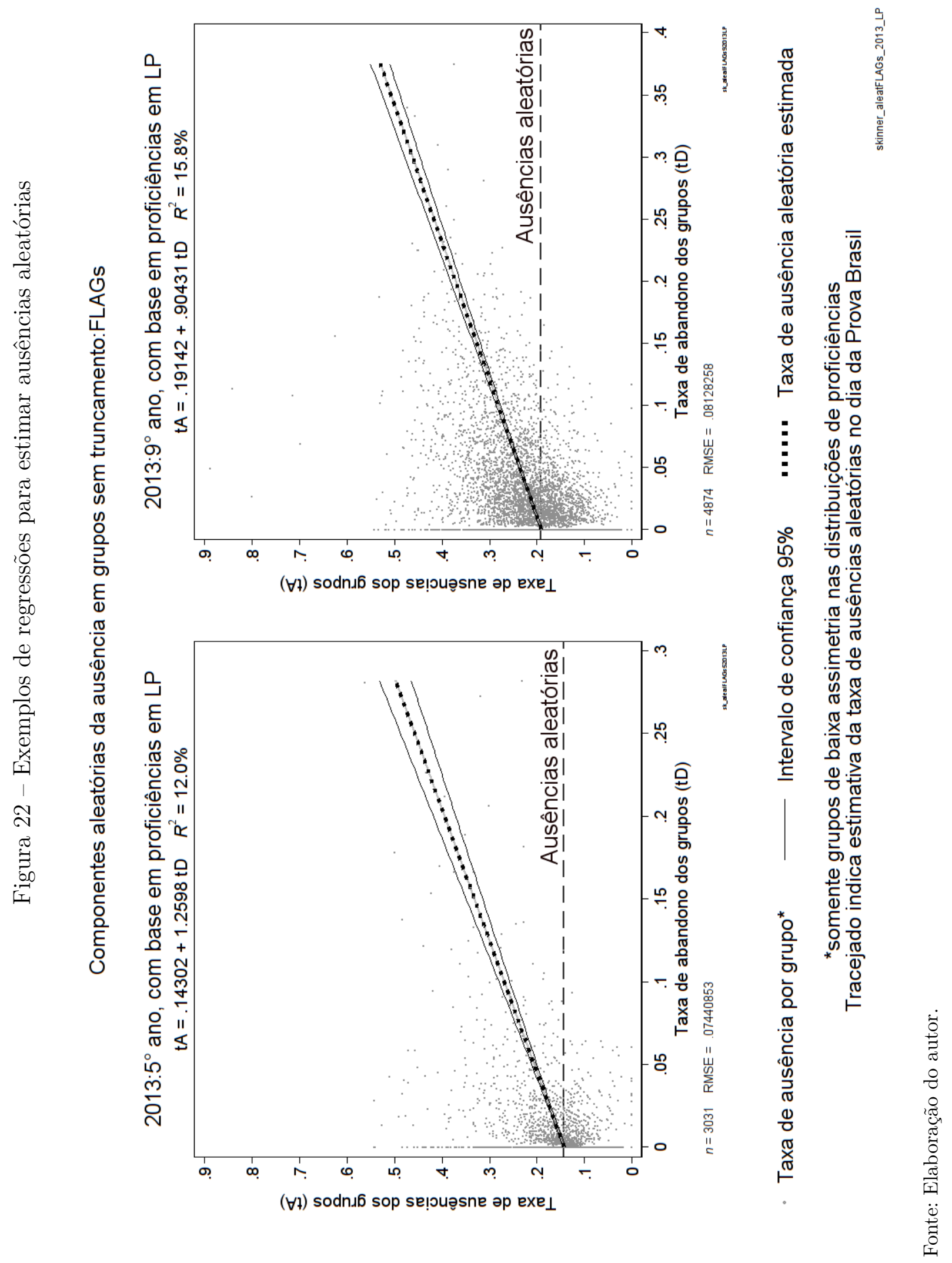


O intercepto $\beta_{0}$ convenientemente estima $t_{R_{x}}$, a taxa de faltas puramente aleatórias no dia da prova, isento da influência do abandono, pois o intercepto é onde a reta de regressão cruza o eixo vertical $t_{A}$, para taxa de abandono $t_{D}=0$.

$$
t_{R_{x}}=\max \left\{0, \beta_{0}\right\}, \operatorname{com} \beta_{0} \text { estimado na equação } 2.15 \text {. }
$$

O coeficiente linear $\beta_{1}$ estimado na equação 2.15 acomoda também convenientemente o parâmetro $d$ apresentado na equação 2.12. Na Figura 22, as linhas tracejadas horizontais indicam as taxas aleatórias de faltas no dia da prova: perto de $15 \%$ para o $5^{\circ}$ ano e perto de $20 \%$ para o $9^{\circ}$ ano. No processamento, força-se $0 \leq t_{R_{x}} \leq t_{R}$, sendo a componente $t_{R_{D}}$ estimada por:

$$
t_{R_{D}}=\max \left\{0, t_{R}-t_{R_{x}}\right\}=\max \left\{0, \frac{C-F}{C}-t_{R_{x}}\right\}
$$

Computadas as taxas $t_{R_{x}}$ e $t_{R_{D}}$, por multiplicação por $C$, chega-se a $R_{x}$ e $R_{D}$ : as ausências aleatórias em números absolutos de alunos no dia da prova e as ausências aleatórias decorrentes do abandono, respectivamente, em número de alunos. Uma regressão adicional (equação 2.18) de $t_{A}-t_{R_{x}}$ contra $t_{D}$ estima o coeficiente angular $\gamma_{1}$, o qual acomoda $d$ :

$$
\begin{gathered}
\left(t_{A}-t_{R_{x}}\right)=\gamma_{0}+\gamma_{1} \cdot t_{D}+\text { resíduo } \\
t_{E_{D}}+t_{R_{D}}=d \cdot t_{D}=\max \left\{0, \gamma_{1}\right\} \cdot t_{D}
\end{gathered}
$$

Rearranjando a equação 2.11 e usando os resultados das equações 2.4, 2.16 e 2.19:

$$
t_{E_{x}}=\left(t_{A}-t_{R_{x}}\right)-\left(t_{E_{D}}+t_{R_{D}}\right)
$$

E, finalmente, para $t_{E_{x}}$, a taxa de exclusão de alunos de baixa proficiência no dia da avaliação (o resultado de interesse), pode ser estimada pela equação 2.20, repetida abaixo incluindo a condição prática de não negatividade de $t_{E_{x}}$ :

$$
t_{E_{x}}=\max \left\{0,\left(t_{A}-t_{R_{x}}\right)-\left(t_{E_{D}}+t_{R_{D}}\right)\right\}
$$

A equação 2.21 é o ponto de chegada do processo proposto, quantificando a taxa de exclusão de alunos de baixa proficiência no dia da Prova Brasil, acomodando os resultados aleatórios e não aleatórios de abandono e as ausências puramente aleatórias no dia da avaliação.

A Prova Brasil provê duas proficiências avaliadas, Matemática (MT) e Língua Portuguesa (LP). O algoritmo proposto acima foi aplicado para ambas, de maneira independente. Os resultados são próximos, mas não idênticos. Não há um racional claro para que se prefira utilizar uma em detrimento da outra. Preferiu-se manter as medidas 
em separado, baseadas nas proficiências de cada disciplina, apresentando-as lado a lado nos resultados a seguir, com indicação do ponto médio. Um fluxograma descritivo resume o processo de cálculo proposto acima, na Figura 58, em apêndice, à página 206.

Para associar as ausências não aleatórias com os fatores de pressão descritos em literatura, a variável $t_{E_{x}}$ acima foi correlacionada com os indicadores FLAGs descritos neste capítulo, tanto graficamente quanto por meio de regressões hierárquicas lineares.

\subsubsection{Limitações da abordagem na identificação de ausências não aleató- rias}

Uma premissa desta abordagem é o conhecimento prévio da proficiência dos alunos, via avaliação interna, por parte do professor ou diretor, de maneira a escolher os "excluíveis". Esta é uma premissa básica para o gaming em geral e não particular da abordagem.

A dependência da escolha de critérios de agrupamento adequados é um complicador nesta abordagem. Esta escolha é trabalhosa e exige iteradas tentativas e erros. Esta dependência pode vir a dificultar a replicação imediata da abordagem para outras avaliações, como as estaduais ou municipais, por exemplo. Apesar do uso do teste de Shapiro-Francia ${ }^{17}$ e da inspeção visual dos gráficos de diagnóstico ajudarem na escolha de agrupamentos, não há garantia plena de serem todos "normais o suficiente". Testes alternativos de normalidade foram empregados, skewness e de simetria, mas resultaram menos precisos e muito mais intensos do ponto de vista computacional. A solução mais pragmática adotada foi o uso do teste estatístico e da análise visual dos gráficos de diagnóstico, em conjunto, para a escolha dos critérios de agrupamento.

Uma premissa da abordagem é a confiança nos números de alunos matriculados indicados pelo Censo Escolar. Se o número reportado para uma dada escola no Censo for inflado, de maneira a incluir alunos inexistentes, a parcela de alunos ausentes aferida na avaliação será anormalmente alta. A avaliação externa seria, portanto, uma proxy para uma lista de chamada para salientar casos que mereceriam uma auditoria específica. Apesar de não ter sido explorado analiticamente neste trabalho, não é de todo descabido usar resultados anormalmente altos de $t_{A}$ como indicadores de potenciais "alunos fantasmas"18.

\subsection{A análise das fraudes ou colas na Prova Brasil}

A abordagem descrita a seguir busca determinar se há padrões de respostas improváveis, num dado agrupamento de análise, indicativos de fraudes ou colas "ingênuas". Estes padrões são "ingênuos", pois capturam o efeito de respostas serem compartilhadas

17 Este teste perde seu poder explicativo para mais do que 5 mil casos.

18 Especialmente se forem correlacionados a incentivos associados ao registro inflado de alunos no Censo, para fins de financiamentos e transferências de recursos. 
sem levar em conta a diferença entre as questões de prova, decorrentes da existência de cadernos de prova distintos.

É importante salientar que o que se discute é a identificação, com base em estatísticas, de possíveis indicadores de comportamento fraudulento e não fraudes formalmente comprovadas. Os resultados apontados pelos indicadores não concluem a ocorrência segura de fraude, que só pode ser imputada por flagrante ou por confissão. Dada esta condição "indicativa", o que se propõe não pode ser usado como base para sanções ou punições. Exemplos de usos adequados são o ajuste dos protocolos de aplicação das avaliações, mudanças nos treinamentos dados aos aplicadores ou na divulgação de instruções para alunos, comentados no capítulo final.

Comportamentos que levam aos registros "ingênuos" descritos acima são, por exemplo:

a) um ou mais alunos avaliados copiam respostas de uma aluna de alta proficiência, com ou sem a anuência do aplicador da prova, na esperança de serem bem avaliados no exame, sem levar em conta que têm entre eles cadernos de prova diferentes;

b) um aplicador do exame interfere na aplicação, compartilhando respostas com alunos, na expectativa de aumentar suas pontuações, sem levar em conta a existência de cadernos diferentes para as provas. A Figura 23, oriunda do episódio de The Simpsons, comentado na Introdução deste trabalho, ilustra fantasiosamente este aspecto;

c) um aplicador manipula a distribuição de cadernos de resposta entre os alunos avaliados, favorecendo um determinado caderno, na expectativa de poder influenciar as respostas de maneira menos ingênua que nos dois casos anteriores.

Os protocolos de aplicação da Prova Brasil são construídos para evitar fraudes, vazamento de questões e interferências dos professores, com o emprego de aplicadores externos ${ }^{19}$.

Para os agentes diretos do processo educacional, professores, coordenadores, diretores e secretários, a fraude leva a descrédito e, como ilustrado na Introdução, até a sanções criminais.

Para o avaliador, as fraudes prejudicam a qualidade da proficiência medida. As fraudes "ingênuas" levam a proficiências medidas menores que as potencialmente aferidas sem fraude. Isto se dá pois as respostas divulgadas ingenuamente acabam por não coincidir com o gabarito correto e as pontuações resultantes acabam sendo menores.

\footnotetext{
19 Um exemplo de protocolo está no apêndice deste trabalho, como referência, à página 191.
} 
Figura 23 - Exemplo de fraude docente "ingênua" em The Simpsons

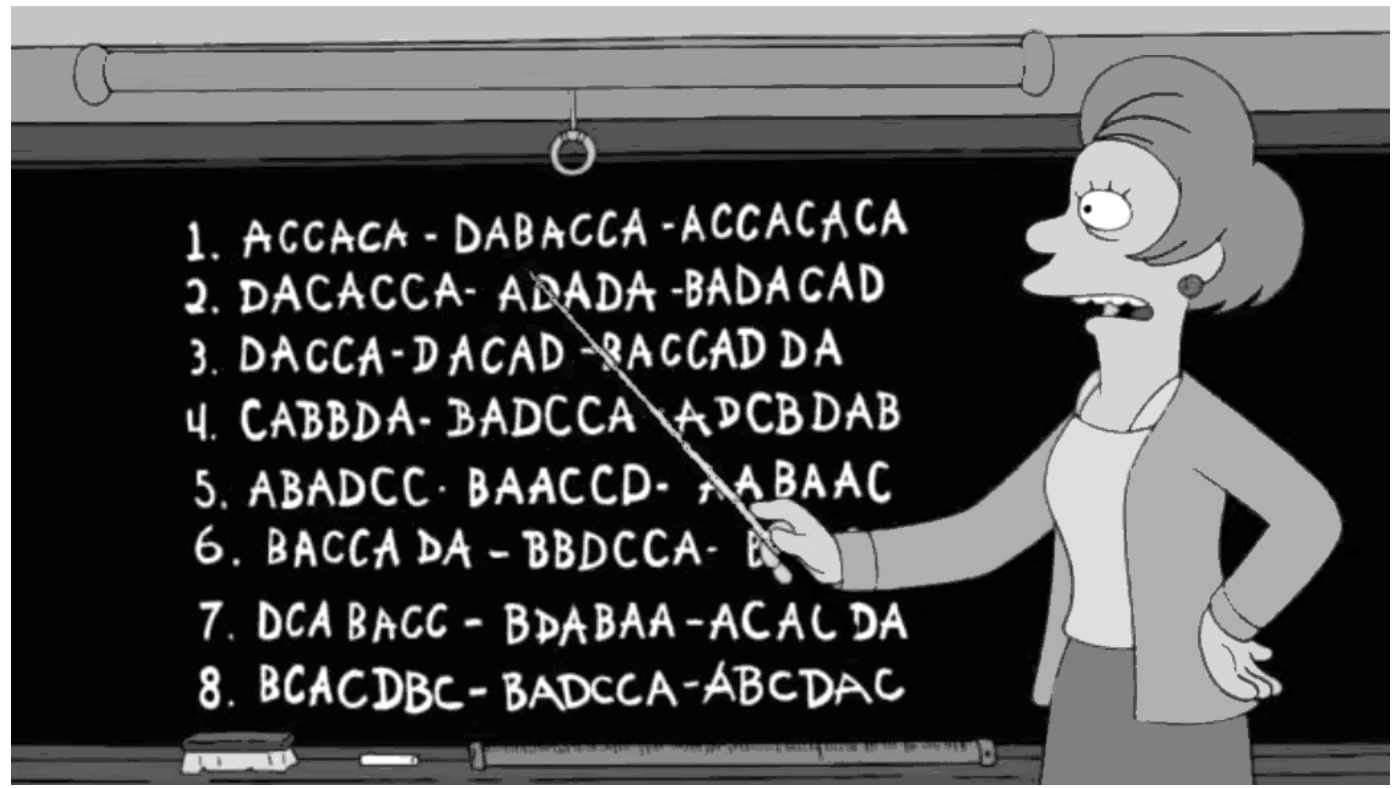

Fonte: 20th Century Fox, The Simpsons, How the Test was Won (KRAMER, 2009).

As fraudes mais sofisticadas envolvem dividir com o avaliado a resposta correta levando em conta a exata pergunta feita e, por isso, podem elevar artificialmente a proficiência medida versus a real. Estas fraudes sofisticadas têm sua detecção dependente de um acompanhamento longitudinal dos avaliados, em que crescimentos e decaimentos inexplicados de proficiência ao longo do tempo são um dos indicadores, como proposto por Jacob e Levitt (2003a, 2003b, 2004) ${ }^{20}$. Os microdados públicos da Prova Brasil não permitem este estudo longitudinal, dadas as considerações de sigilo e não-identificação pública dos participantes, mas se prestam a serem estudados quanto às fraudes ingênuas ${ }^{21}$, como descrito adiante.

\subsubsection{Descrição da abordagem para fraudes}

Suponha-se que para avaliar o domínio de um determinado currículo sejam necessárias 180 questões, cada uma exigindo dois minutos para ser respondida. A avaliação teria seis horas de duração, sendo demasiadamente longa. Se as 180 questões forem distribuídas entre seis cadernos de 30 itens e a cada aluno avaliado for designado um único caderno a responder, a duração da prova cai para uma hora, o que seria mais compatível com a rotina escolar. Um agregado de alunos terá seu domínio do currículo avaliado se a distribuição de cadernos e itens for homogênea entre eles ${ }^{22}$. Esta metodologia é conhecida por Blocos

20 Ver apêndice à página 201 para o detalhamento da metodologia usada por estes autores.

21 Aqui, a fraude ingênua é aquela praticada sem ter ciência das diferenças entre os cadernos de provas e de seus respectivos gabaritos de correção.

22 Os alunos individualmente não terão sido cobrados por todo o conteúdo, mas a proficiência da escola ou rede ao qual pertencem pode ser avaliada desta maneira. 
Incompletos Balanceados (BIB). Uma introdução à construção e aplicação de BIBs pode ser encontrada no trabalho de Roberto Bekman (2001) e seu emprego no Saeb e Prova Brasil é documentado pelo Inep (2015c, p. 7).

A Prova Brasil lança mão dos Blocos Incompletos Balanceados para distribuir itens entre seus avaliados: para cada disciplina das provas regulares, há 21 cadernos de prova distintos, cada um com dois blocos. Cada bloco é escolhido entre sete tipos de blocos possíveis, com seu conjunto de itens (questões) e respectivas respostas (gabaritos). A Tabela 4 mostra a composição de tipos de blocos, por caderno de prova, das provas regulares da Prova Brasil de 2013. A estrutura de blocos por caderno é repetida igualmente para cada disciplina, Língua Portuguesa (LP) e Matemática (MT).

Tabela 4 - Composição Cadernos por Blocos no Saeb 2013

\begin{tabular}{|c|c|c|}
\hline \multirow{2}{*}{ Caderno } & \multicolumn{2}{|c|}{ Tipo } \\
\hline & $1^{\circ}$ bloco & $2^{\circ}$ bloco \\
\hline 1 & 1 & 2 \\
\hline 2 & 2 & 3 \\
\hline 3 & 3 & 4 \\
\hline 4 & 4 & 5 \\
\hline 5 & 5 & 6 \\
\hline 6 & 6 & 7 \\
\hline 7 & 7 & 1 \\
\hline
\end{tabular}

\begin{tabular}{ccc}
\hline \multirow{2}{*}{ Caderno } & \multicolumn{2}{c}{ Tipo } \\
\cline { 2 - 3 } & $\mathbf{1}^{\circ}$ bloco & $\mathbf{2}^{\circ}$ bloco \\
\hline 8 & 1 & 3 \\
9 & 2 & 4 \\
10 & 3 & 5 \\
11 & 4 & 6 \\
12 & 5 & 7 \\
13 & 6 & 1 \\
14 & 7 & 2
\end{tabular}

\begin{tabular}{|c|c|c|}
\hline \multirow{2}{*}{ Caderno } & \multicolumn{2}{|c|}{ Tipo } \\
\hline & $1^{\circ}$ bloco & $2^{\circ}$ bloco \\
\hline 15 & 1 & 4 \\
\hline 16 & 2 & 5 \\
\hline 17 & 3 & 6 \\
\hline 18 & 4 & 7 \\
\hline 19 & 5 & 1 \\
\hline 20 & 6 & 2 \\
\hline 21 & 7 & 3 \\
\hline
\end{tabular}

Fonte: Elaboração do autor.

Cada bloco, por sua vez, é composto por itens de múltipla escolha, com gabaritos de resposta que podem assumir valores A, B, C ou D. Para alunos do $5^{\circ}$ ano, são 11 itens por bloco. Para alunos do $9^{\circ}$ ano e $3^{\circ}$ ano do ensino médio, são 13 itens por bloco. Exemplificando, um aluno do $5^{\circ}$ ano responderá 22 itens de Língua Portuguesa e 22 itens de Matemática, perguntados por meio de um caderno "próprio" pré-designado pelo Inep. Alunos do $9^{\circ}$ ano respondem a 26 itens de cada disciplina. Alunos a quem tenham sido designados cadernos diferentes enfrentarão perguntas diferentes com gabaritos distintos, de maneira a cobrirem, no agregado, itens suficientes para avaliar o domínio do currículo testado.

Para a Prova Brasil, os gabaritos de cada bloco, disciplina e ano avaliado são divulgados pelo Inep nos microdados ${ }^{23}$. Estes microdados trazem também a atribuição, por aluno, do seu respectivo caderno de provas próprio e o registro de resposta por bloco, item e disciplina. Respostas em branco e anuladas (ilegíveis ou com mais de uma marcação) são identificadas pelos caracteres "." e "*”, respectivamente.

23 Os gabaritos de correção dos itens de de Língua Portuguesa e Matemática, por item, bloco, série e caderno vêm do arquivo TS_ITEM.csv, integrante dos microdados públicos divulgados pelo Inep e já descritos. 
$\mathrm{Na}$ abordagem proposta, as provas de um determinado aluno são corrigidas usando todos os gabaritos possíveis, na expectativa de encontrar algum gabarito impróprio que maximize o número de acertos verificado (fraude ingênua). Especificamente, usando a notação a seguir, um acerto $h$ de um item $i$ do bloco $b$ da disciplina $d$, corrigido pelo gabarito $c$, para um dado aluno, é computado por:

$$
h_{d, b, c, i}= \begin{cases}1, & \text { se } r_{b, i}=g_{c, i} \text { um acerto de item } \\ 0, & \text { se } r_{b, i} \neq g_{c, i} \text { um erro de item, reposta em branco ou anulada }\end{cases}
$$

na qual $r_{b, i}$ é a resposta registrada pelo aluno, para o item $i$ do bloco $b$ e $g_{c, i}$ é a resposta correta do item $i$ segundo gabarito $c$.

Quando o gabarito usado na correção é o próprio do aluno, identificado pelo caderno de prova atribuído pelo Inep $(b=c)$, a correção estará de acordo com o gabarito do Saeb e as totalizações dos acertos terão forte correlação com o escore estimado e divulgado nos microdados.

As correções dos itens de uma disciplina por gabaritos impróprios, ou seja, os que não correspondam aos atribuídos ao aluno pelo Inep, caracterizados por $b \neq c$, também são consideradas na abordagem proposta.

Uma pontuação simples, para cada aluno é calculada, refletindo a percentagem de acertos. Este escore difere das respectivas pontuações na prova, por empregar a Teoria Clássica dos Testes (TCT) e não a Teoria de Resposta ao Item (TRI), por não considerar ponderações das dificuldades de itens e por não corrigir para acertos ao acaso ("chutes"). A equação 2.23 exemplifica a computação deste escore.

$$
T C T=\left(\text { Acertos } 1^{o} \text { bloco }\right)+\left(\text { Acertos } 2^{\circ} \text { bloco }\right)
$$

A Figura 24 exemplifica a forte correlação $\left(R^{2} \approx 95 \%\right)$ entre as proficiências Saeb obtidas pela TRI e a pontuação obtida pela equação 2.23 , no caso de uso dos gabaritos próprios ( $b=c$, gráfico da esquerda), e a fraquíssima correlação quando a correção é feita por blocos impróprios (gráfico à direita).

Um bloco $i$, próprio ou não, é designado maximizador se o gabarito a ele associado, quando comparado às respostas de um aluno, levar a uma pontuação de acertos que seja maior ou igual à obtida pelos demais blocos $j$ existentes, com $j \neq i$.

Normalmente, os maximizadores serão blocos próprios. Se o bloco maximizador for impróprio em numerosos casos numa dada escola, com uma frequência anormalmente alta, é caracterizada a fraude ingênua. 
Figura 24 - Correlações na proficiência com uso de blocos próprios ou impróprios

Correlações de correção TCT LP $9^{\circ}$ ano 2013

Correção com blocos próprios (Conforme gabaritos designados pelo Inep)

PROFICIENCIA $=120.04+8.5543$ TCT $\quad R^{2}=95.2 \%$

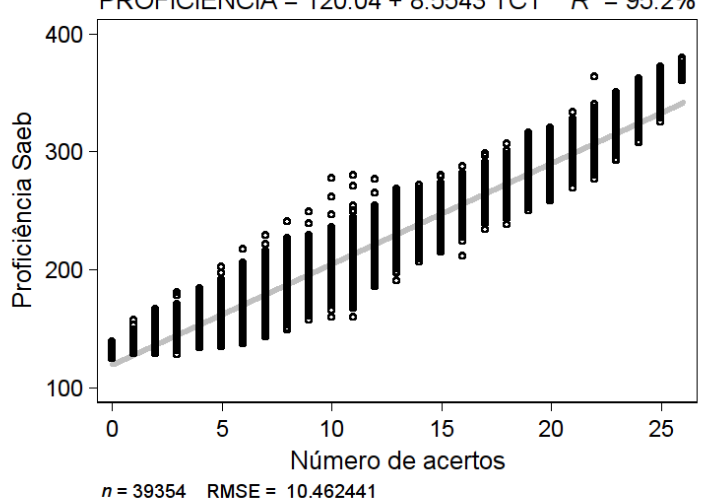

Correção com blocos impróprios

(Blocos $1 / 2$ corrigidos como se fossem $6 / 7$ )

PROFICIENCIA $=239.53+.17111$ TCTimprop $R^{2}=0.0 \%$

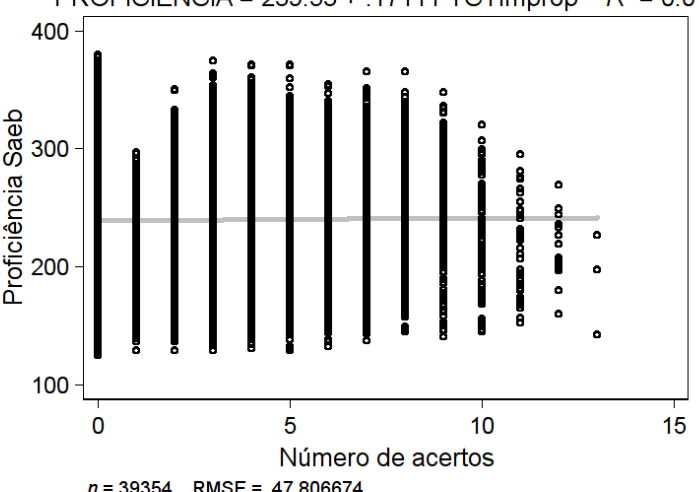

Fonte: Elaboração do autor.

Em resumo: os blocos das disciplinas são corrigidos conforme cada um dos sete gabaritos possíveis para cada um, aluno a aluno. Um destes sete gabaritos é o próprio, os seis demais são impróprios. Os escores de cada correção são tabulados e comparados. Os blocos que maximizarem os escores são identificados e contados, podendo ser mais de um único, se houver empate entre escores maximizados.

A Figura 25 exemplifica as frequências dos blocos maximizadores $M_{i}$ para cada bloco próprio $P_{i}$ nas respostas das provas de Língua Portuguesa do $5^{\circ}$ ano de 2013.

Será que o bloco de tipo 5 (M5) aparece com uma frequência anormalmente alta na correção dos blocos próprios P6 e P7? Caso afirmativo, pode ser a indicação da ocorrência de fraude ingênua. Para responder a esta pergunta, é empregado o teste ${ }^{24}$ de $\chi^{2}$.

24 Este teste, também conhecido por Chi quadrado ou Qui quadrado, de aderência avalia a hipótese nula que afirma que as distribuições observadas são iguais às esperadas, levando em conta o número de graus de liberdade e nível de ruído aleatório implícito na amostra estudada. O p-valor resultante do teste diz com qual probabilidade pode-se rejeitar a hipótese nula e afirmar que as distribuições têm ao menos uma componente com frequência de incidência diferente da esperada. 
Figura 25 - Exemplo de blocos maximizadores

Blocos LP $5^{\circ}$ ano 2013

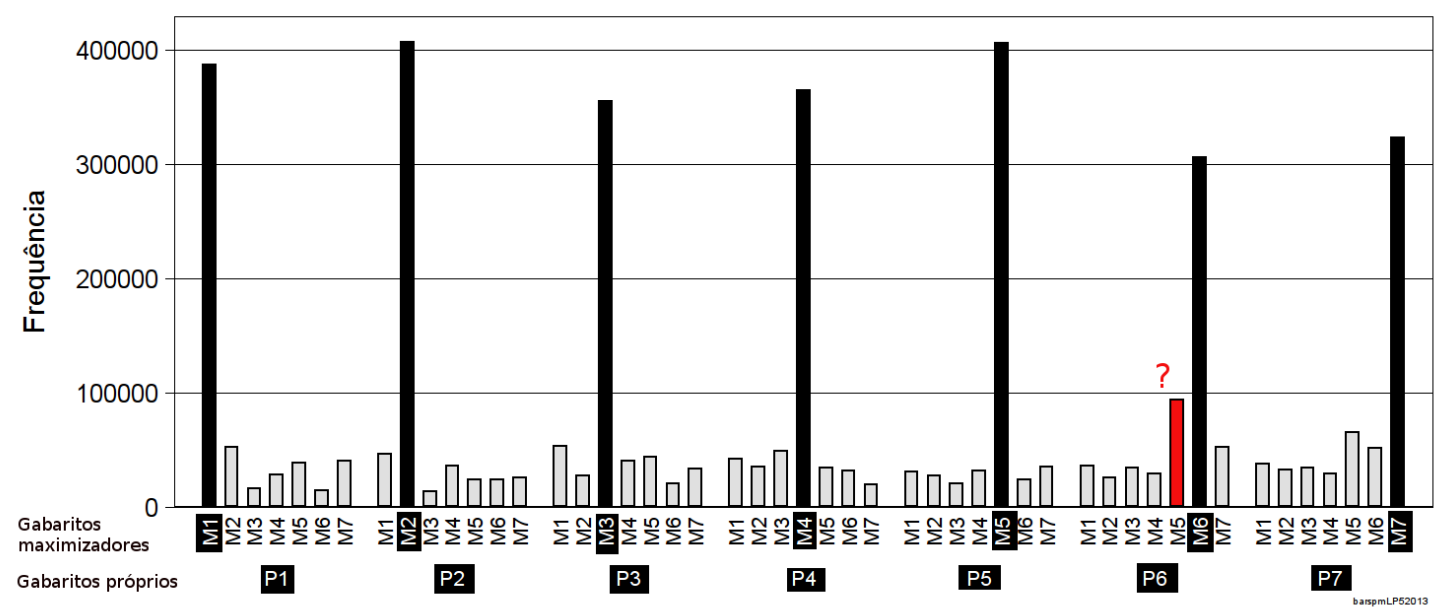

Fonte: Elaboração do autor.

As Figuras 26 e 27 ilustram as frequências dos blocos maximizadores aplicados aos alunos avaliados pelas Provas Brasil de 2013 e 2015, por série e disciplina. A estatística $\chi^{2}$ é obtida por meio da fórmula 2.24:

$$
\chi^{2}=\sum_{i=1}^{n_{b}}\left[\frac{\left(O b s_{i}-E s p_{i}\right)^{2}}{E s p_{i}}\right]
$$

$O b s_{i}$ é a contagem observada de vezes em que o bloco tipo $i$ maximizou o número de acertos de alunos, para cada um dos $n_{b}=7$ tipos de blocos possíveis, um dos quais é o próprio e os demais são impróprios. $E s p_{i}$ é a contagem esperada, correspondente aos cadernos próprios designados pelo Inep. Como são $n_{b}=7$ tipos de blocos para cada disciplina e série avaliada, as contagens esperadas relativas são muito próximas de um sétimo $^{25}$.

Cada escola participante da Prova Brasil, das redes estaduais e municipais, tem calculados os p-valores associados aos testes de $\chi^{2}$ de aderência ${ }^{26}$, para as disciplinas de Matemática e Língua Portuguesa, para o $5^{\circ}$ e $9^{\circ}$ anos do $\mathrm{EF}^{27}$.

Os resultados dos p-valores dos testes de $\chi^{2}$, por disciplina e série, uma vez estimados para cada escola, podem ser aglomerados em agrupamentos maiores, como redes, municípios ou unidades da federação. As contagens de indicadores de fraude (escola a escola) são

$\overline{25}$ Não são precisamente um sétimo dada a aleatoriedade na atribuição dos gabaritos próprios e nas eventuais ausências de alunos nas provas.

26 Estes p-valores são estimados pelo pacote estatístico, usando $n_{b}-1=6$ graus de liberdade.

27 Quanto menor for o p-valor (que varia entre zero e um) encontrado para cada caso acima, maior é a certeza de se poder afirmar que há frequências irregulares nas ocorrências dos gabaritos maximizadores, e portanto, indicação de fraude ingênua. 

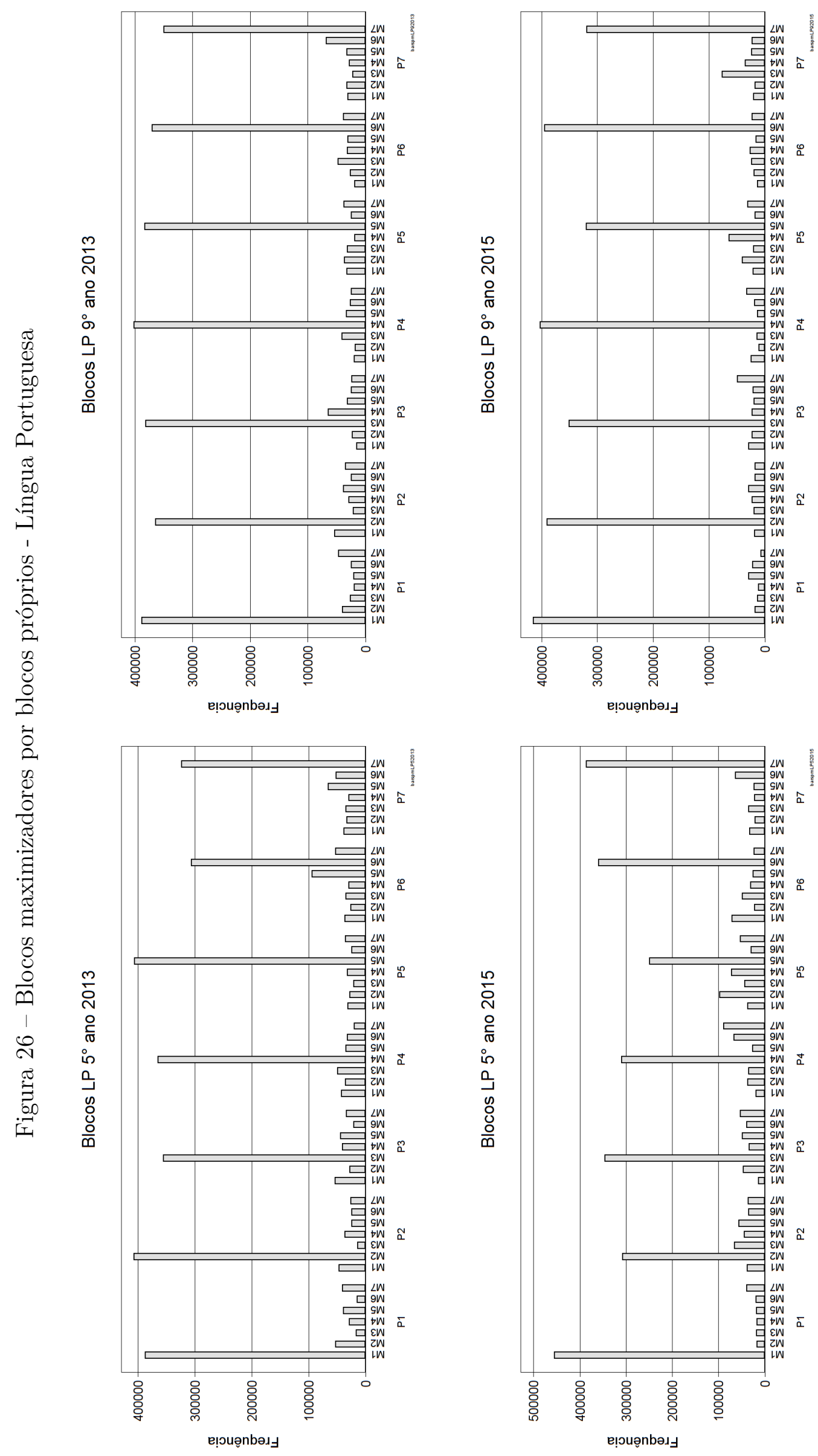

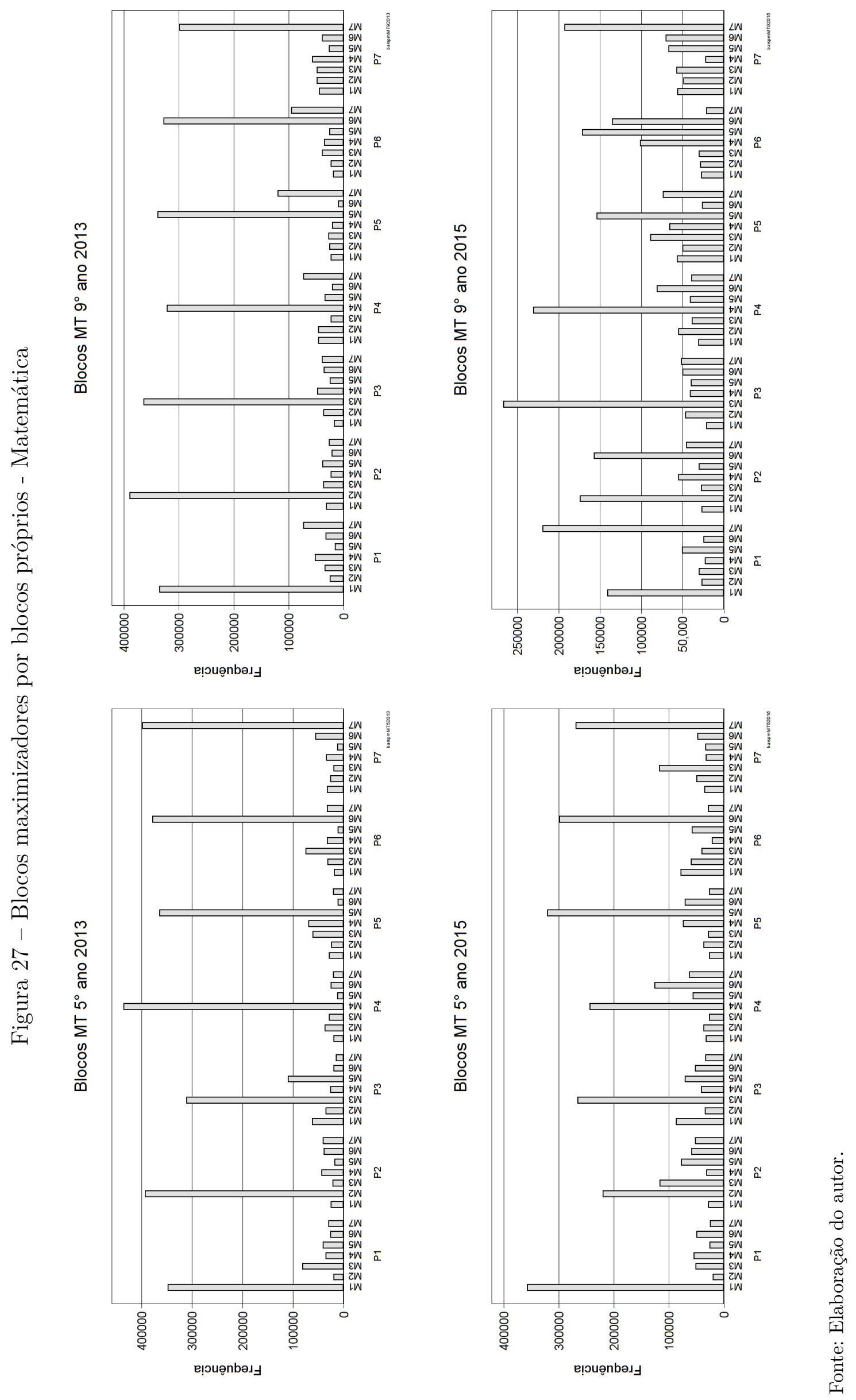
confrontados com os FLAGs já descritos, para verificar a associação de possíveis fraudes com os mecanismos de pressão de responsabilização.

A Figura 28 apresenta a distribuição dos p-valores para a análise das provas de Língua Portuguesa do $5^{\circ}$ ano em 2013. A linha vertical tracejada indica o $\alpha_{\text {crit }}$ crítico de 0,05, associado a um nível de confiança de $95 \%$. As contagens à esquerda desta linha ( -valores $\leq 0,05$ ) indicam os casos com blocos maximizadores impróprios observados com frequências anormalmente altas, comparado ao esperado. A Figura 29 apresenta os mesmos dados da Figura 28, só que acumulados em ordem crescente de p-valor. O eixo vertical indica a porcentagem de escolas com resultados suspeitos.

Figura 28 - Exemplo distribuição de p-valores indicativos de fraudes

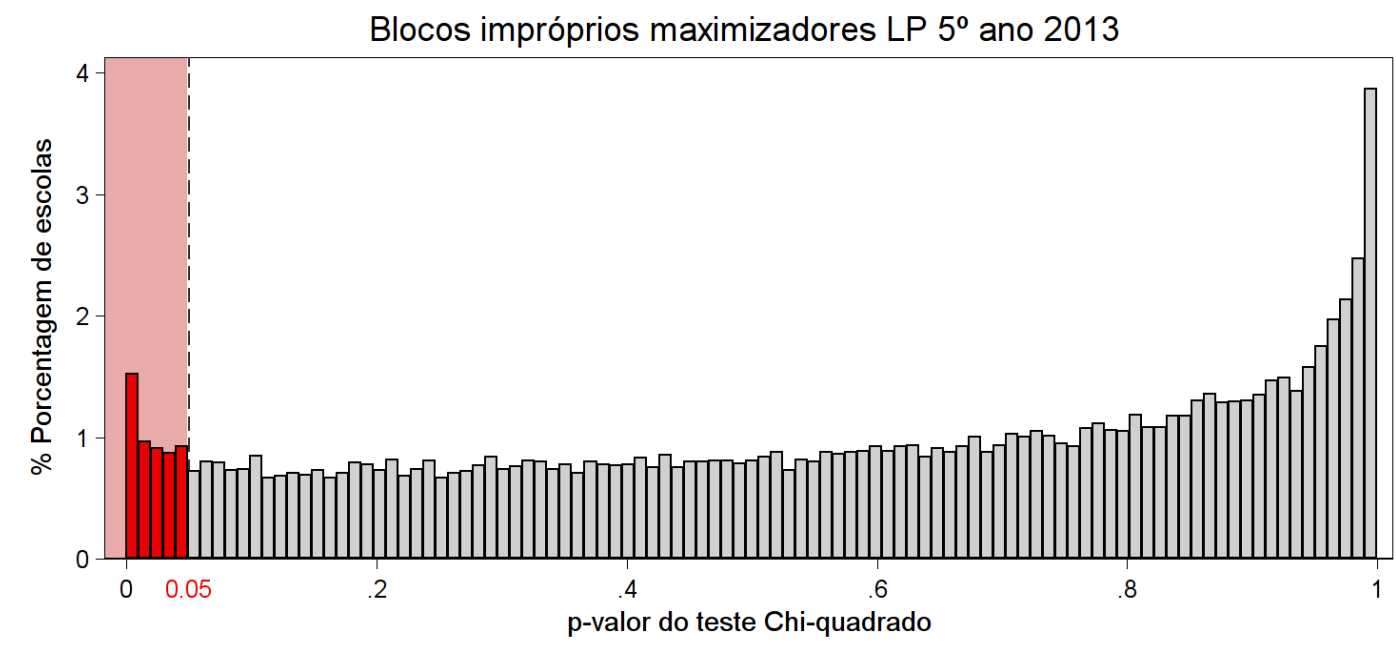

Fonte: Elaboração do autor. 
Figura 29 - Exemplo distribuição acumulada de p-valores indicativos de fraudes

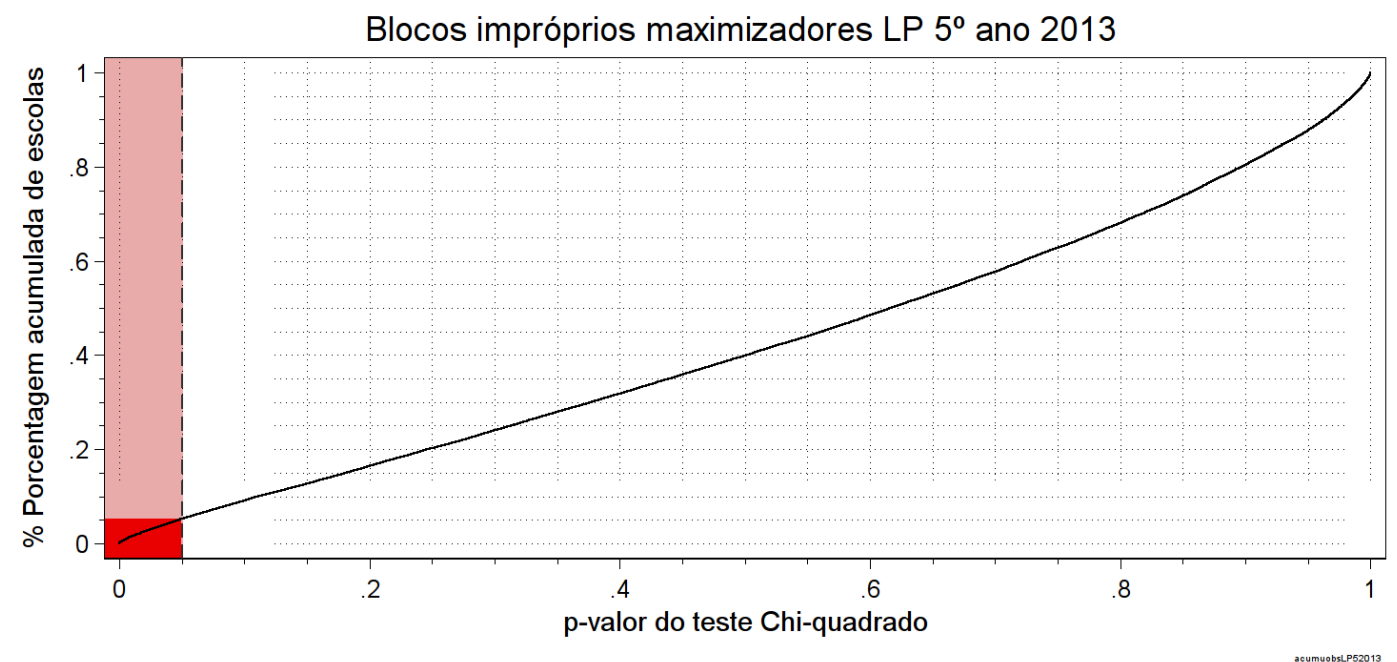

Fonte: Elaboração do autor.

Como ilustrado na Figura 29, a indicação da incidência de fraudes depende do $\alpha$ associado ao nível de confiança escolhido. Qual nível de confiança usar para caracterizar a fraude? Quão baixo tem que ser o p-valor crítico do teste de $\chi^{2}$ ? Um $\alpha_{\text {crit }}=0,05=$ $\frac{1}{20}$ significa que a chance de se atribuir erroneamente uma indicação de fraude é de uma em vinte. Quanto maior o nível de confiança arbitrário usado e, por conseguinte, menor o $\alpha_{\text {crit }}$ crítico, menor a leitura final da quantidade de ocorrências de fraudes, mas com maior certeza de não se cometer uma injustiça ao apontá-las.

As escolas analisadas têm dois p-valores estimados para cada série/ano avaliado, um para Matemática e outro para Língua Portuguesa. Algumas escolas têm só o $5^{\circ}$ ano avaliado, outras só o $9^{\circ}$ ano avaliado, enquanto outras têm ambos os anos avaliados. Um indicador "fraco" conta quantas escolas têm pelo menos um dos p-valores mencionados acima significantes. Um indicador "forte" conta as escolas que têm todos seus p-valores possíveis significantes simultaneamente, sugerindo que há algo sistêmico ocorrendo na escola, afetando disciplinas e séries distintas.

A Figura 30 ilustra o efeito da escolha arbitrária do nível de confiança na contagem de fraudes para a Prova Brasil de 2013. 
Figura 30 - Indicações de fraudes e níveis de confiança - 2013

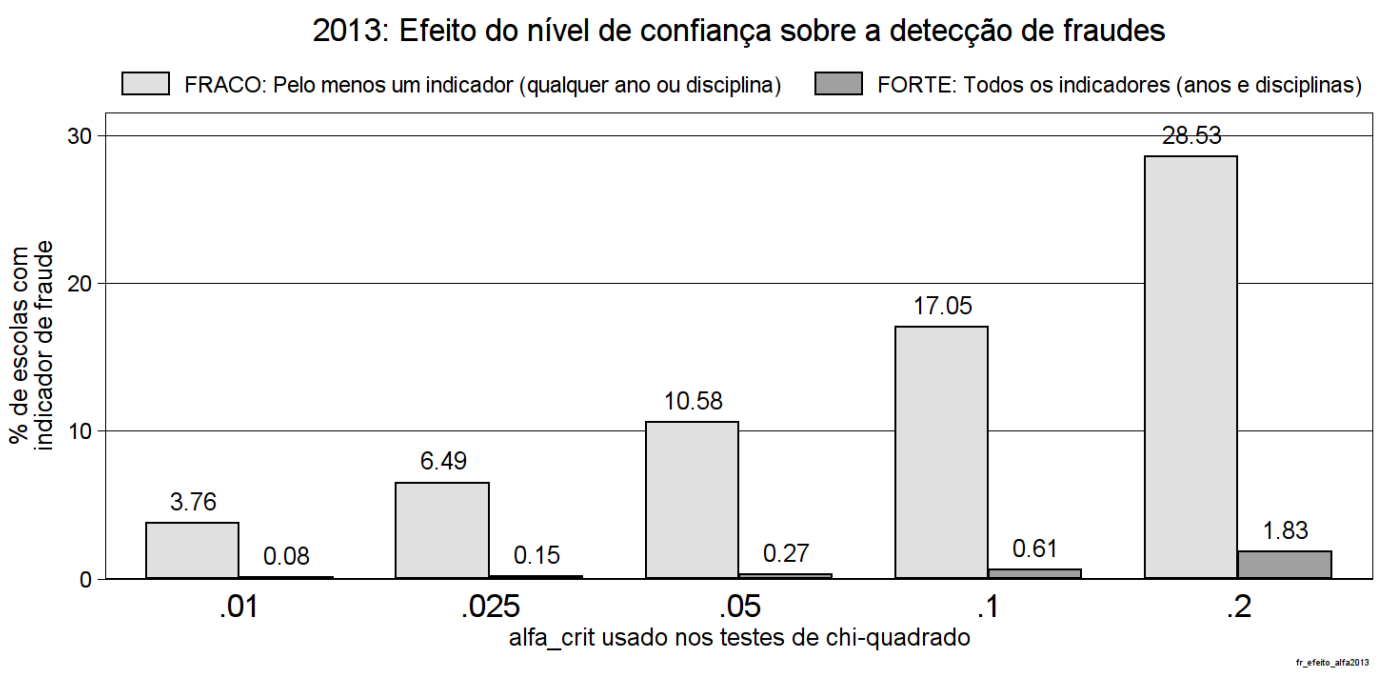

Fonte: Elaboração do autor.

Como esperado, contando com níveis de confiança maiores e, portanto $\alpha_{\text {crit }}$ menores, a frequência de identificações de fraudes é menor e mais sólida é a sugestão de sua ocorrência. A diferença nos indicadores forte e fraco evidencia a possível característica sistêmica ou isolada, num ano ou disciplina, das indicações de fraude. Nos resultados apresentados no próximo capítulo, adotou-se o nível de confiança de $95 \%$ com o $\alpha_{\text {crit }}=0,05$ decorrente.

As Figuras 31 e 32 mostram as frequências acumuladas dos p-valores obtidos dos testes de $\chi^{2}$, com as linhas tracejadas verticais assinalando $\alpha_{\text {crit }}=0,05$. A leitura na escala vertical, da intersecção das curvas com o tracejado, indica a fração de escolas com um nível estatisticamente significante, a 95\%, de gabaritos impróprios maximizadores em frequência diferente que a esperada.

Um fluxograma resumido do processo de construção dos indicadores de fraudes pode ser encontrado na Figura 59, em apêndice, à página 207.

\subsubsection{Limitações da abordagem na identificação de fraudes}

A dependência da abordagem na escolha de um nível de confiança adequado para se contar as incidências de fraude não pode ser subestimada. Isto desqualifica reportes sensacionalistas em que se leiam "Fraude assola 10\% das escolas na Prova Brasil!", por duas razões. Primeiro, as fraudes não foram constatadas formalmente, apenas indicadas por meio de uma estatística. Segundo, a arbitrariedade na escolha do nível de confiança pode incluir mais ou menos escolas na lista das "ofensoras", refletindo esta arbitrariedade. Contudo, apesar da dependência na escolha de um $\alpha_{\text {crit }}$ a usar, uma vez escolhido, as análises resultantes permitem comparar as incidências relativas de fraudes ao longo de categorias de escolas ou em agrupamentos que reflitam os FLAGs. 

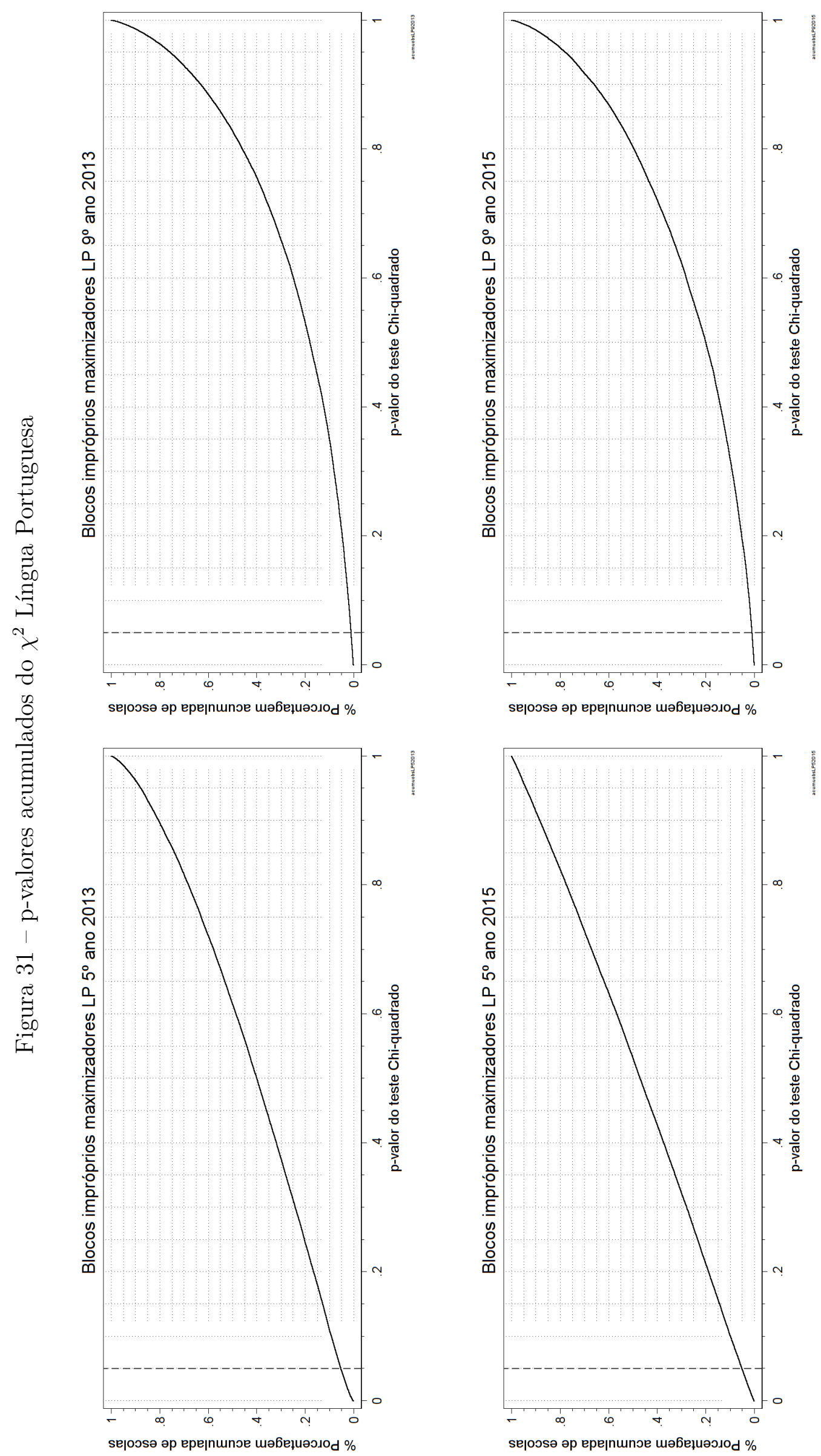

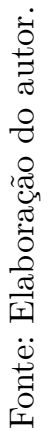



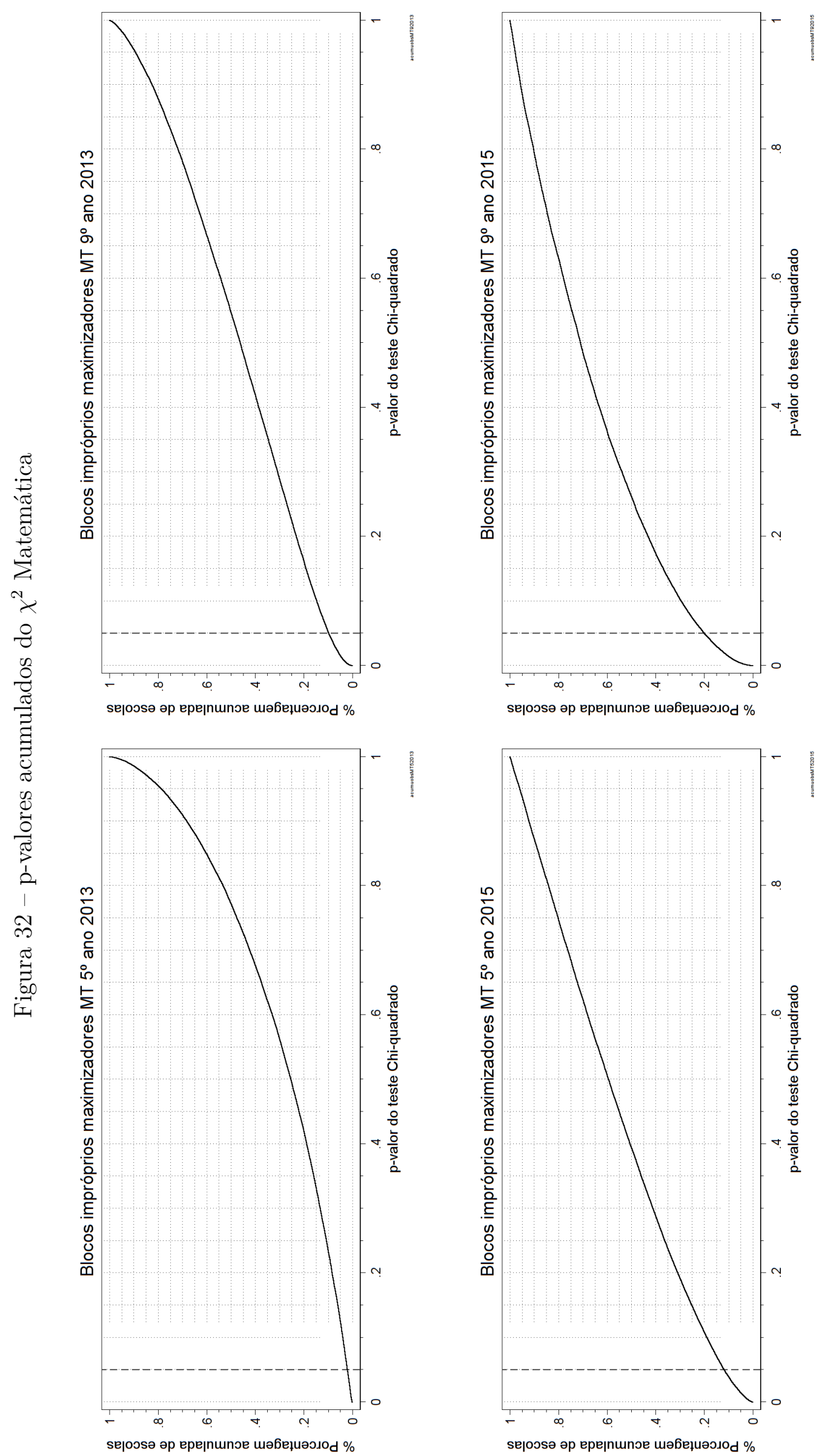

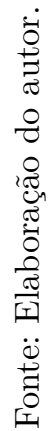


O poder da abordagem identificar respostas suspeitas é fortemente dependente da diferença entre padrões de respostas corretas entre os sete tipos de blocos possíveis para cada posição. Caso os gabaritos corretos para uma dada posição fossem iguais entre si, seria perdida a capacidade discriminatória da abordagem em atribuir acertos por blocos próprios e impróprios.

Tomando emprestada a expressão "entropia da informação" introduzida por Claude Shannon (1948) para designar a quantidade útil de informação nestes gabaritos, pode-se avaliar quanto as coincidências de respostas prejudicam a capacidade de discriminação.

Para ilustrar, tomem-se três tipos de gabarito hipotéticos, denominados $G_{1}, G_{2}$ e $G_{3}$, para avaliar cinco questões. O primeiro e segundo gabaritos têm respostas cujas letras são idênticas:

$$
\begin{aligned}
& G_{1}=\{A, A, B, B, C\} \\
& G_{2}=\{A, A, B, B, C\} \\
& G_{3}=\{D, D, A, A, B\}
\end{aligned}
$$

Como $G_{1}$ e $G_{2}$ são idênticos, se $G_{1}$ for próprio, um gabarito $G_{2}$ impróprio não permitirá discriminar uma indicação de fraude, dada a total coincidência nas letras de resposta (baixa entropia entre os gabaritos). Por outro lado, o gabarito $G_{3}$, por não ter nenhuma coincidência com as respostas de $G_{1}$ e $G_{2}$, permite a maior discriminação possível ao ser confrontado com os demais (alta entropia).

A Tabela 5, construída com os gabaritos das provas regulares do Saeb 2013, indica que a entropia não é perfeita. Por exemplo, considerando os gabaritos de Matemática do $5^{\circ}$ ano, vemos que o bloco tipo 7 corrigido como se fosse o tipo 2 leva a zero coincidências (alta entropia), o que é o caso perfeito. Contudo, o gabarito do bloco tipo 5, quando corrigido pelo tipo 1, leva a 5 respostas coincidentes (baixa entropia), o que enfraquece a capacidade de identificar respostas suspeitas para esta combinação particular de bloco próprio tipo 1 e impróprio tipo 5 e vice-versa. 
Tabela 5 - Coincidências de respostas em gabaritos - Prova Brasil 2013

\begin{tabular}{|c|c|c|c|c|c|c|c|c|c|}
\hline \multirow{2}{*}{ Ano/Série } & \multirow{2}{*}{ Disciplina } & \multirow{2}{*}{ Gabarito Próprio... } & \multicolumn{7}{|c|}{...corrigido como se fosse } \\
\hline & & & 1 & 2 & 3 & 4 & 5 & 6 & 7 \\
\hline \multirow{14}{*}{$5^{\circ}$ Ano } & \multirow{7}{*}{ LP } & 1 & 11 & 3 & 1 & 3 & 3 & 2 & 2 \\
\hline & & 2 & 3 & 11 & 2 & 2 & 2 & 5 & 1 \\
\hline & & 3 & 1 & 2 & 11 & 4 & 2 & 4 & 5 \\
\hline & & 4 & 3 & 2 & 4 & 11 & 1 & 3 & 3 \\
\hline & & 5 & 3 & 2 & 2 & 1 & 11 & 5 & 2 \\
\hline & & 6 & 2 & 5 & 4 & 3 & 5 & 11 & 4 \\
\hline & & 7 & 2 & 1 & 5 & 3 & 2 & 4 & 11 \\
\hline & \multirow{7}{*}{ MT } & 1 & 11 & 4 & 4 & 2 & 6 & 3 & 2 \\
\hline & & 2 & 4 & 11 & 1 & 4 & 4 & 4 & 0 \\
\hline & & 3 & 4 & 1 & 11 & 6 & 6 & 2 & 3 \\
\hline & & 4 & 2 & 4 & 6 & 11 & 5 & 2 & 3 \\
\hline & & 5 & 6 & 4 & 6 & 5 & 11 & 3 & 2 \\
\hline & & 6 & 3 & 4 & 2 & 2 & 3 & 11 & 2 \\
\hline & & 7 & 2 & 0 & 3 & 3 & 2 & 2 & 11 \\
\hline \multirow{14}{*}{$9^{\circ}$ Ano } & \multirow{7}{*}{ LP } & 1 & 13 & 7 & 1 & 3 & 4 & 4 & 5 \\
\hline & & 2 & 7 & 13 & 3 & 4 & 3 & 3 & 3 \\
\hline & & 3 & 1 & 3 & 13 & 5 & 3 & 3 & 4 \\
\hline & & 4 & 3 & 4 & 5 & 13 & 1 & 4 & 2 \\
\hline & & 5 & 4 & 3 & 3 & 1 & 13 & 1 & 3 \\
\hline & & 6 & 4 & 3 & 3 & 4 & 1 & 13 & 7 \\
\hline & & 7 & 5 & 3 & 4 & 2 & 3 & 7 & 13 \\
\hline & \multirow{7}{*}{ MT } & 1 & 13 & 2 & 3 & 3 & 4 & 2 & 2 \\
\hline & & 2 & 2 & 13 & 3 & 2 & 4 & 2 & 1 \\
\hline & & 3 & 3 & 3 & 13 & 6 & 2 & 4 & 4 \\
\hline & & 4 & 3 & 2 & 6 & 13 & 1 & 4 & 7 \\
\hline & & 5 & 4 & 4 & 2 & 1 & 13 & 5 & 3 \\
\hline & & 6 & 2 & 2 & 4 & 4 & 5 & 13 & 6 \\
\hline & & 7 & 2 & 1 & 4 & 7 & 3 & 6 & 13 \\
\hline
\end{tabular}

Fonte: Elaboração do autor.

A Tabela 6 apresenta as ocorrências de coincidências de respostas nos gabaritos da Prova Brasil de 2013 e 2015. Quanto menor a percentagem, maior a entropia por serem menores as coincidências, melhorando o poder discriminatório da abordagem ${ }^{28}$. $\mathrm{O}$ melhor caso é o da Prova Brasil 2015, Língua Portuguesa do $5^{\circ}$ ano, com apenas 22,9\% de coincidências.

28 Para melhorar a entropia entre gabaritos das provas, visando a refinar a capacidade de identificar potenciais fraudes ingênuas, não seria necessária a criação de novos itens, o que é custoso. Bastaria alguma etapa intermediária na composição dos cadernos para reordenar os itens em seus blocos, na construção das provas, visando a aumentar a entropia. Obviamente, esta etapa só teria utilidade se a abordagem proposta neste trabalho for ser usada pelos avaliadores na aferição de potenciais indicações de fraudes. 
Tabela 6 - Entropia dos gabaritos da Prova Brasil

\begin{tabular}{llll}
\hline \multicolumn{2}{c}{ Anos e disciplinas avaliados nas Prova Brasil de... } & $\ldots 2013$ & $\ldots 2015$ \\
\hline \multirow{2}{*}{$5^{\circ}$ ano } & LP & $25,5 \%$ & $22,9 \%$ \\
& MT & $29,4 \%$ & $26,0 \%$ \\
\hline \multirow{2}{*}{$9^{\circ}$ ano } & LP & $26,7 \%$ & $25,3 \%$ \\
& MT & $25,6 \%$ & $26,0 \%$ \\
\hline
\end{tabular}

Fonte: Elaboração do autor.

Uma melhoria possível na abordagem consiste na atribuição de ponderações para os itens, ao serem corrigidos pela TCT, de maneira a emular o parâmetro de dificuldade do item na TRI. Este cuidado diminuiria a dispersão em torno da reta de previsão representada no gráfico à esquerda da Figura 24 (página 105). Esta abordagem não foi seguida nesta análise por não se dispor de meios para determinar as dificuldades relativas dos itens, sem prejuízo dos resultados apresentados no capítulo a seguir.

\subsection{Modelos hierárquicos}

Dois modelos hierárquicos lineares (MHL) de dois níveis são construídos para analisar associações plausíveis dos FLAGs com os efeitos medidos, por meio dos coeficientes das variáveis independentes, quanto às suas magnitudes e significância.

A escolha de modelos hierárquicos se faz para não subestimar os erros padrão associados a aninhamentos nos dados estudados e evitar conclusões equivocadas sobre seus reais efeitos nas modelagens. A característica de aninhamento é comum em dados educacionais, com hierarquias naturais nas estruturas de dados: alunos em turmas, turmas em séries, séries em escolas, que por sua vez fazem parte de redes maiores. ${ }^{29}$

O nível 2 é caracterizado pela UF, por meio da variável ID_UF e afetado pelos FLAGs dummies seguintes:

a) PROF_BASED, que determina se há bonificação baseada em proficiência de alunos na UF;

b) BASE_AVAL_PROP, que determina se há avaliação própria como insumo para bonificação na UF;

29 A referência para estes conceitos é o trabalho de Raudenbush e Bryk (1986, 2001), com extensões práticas em texto moderno de Snijders e Bosker (2011). Em português, existe o livro de Maria Eugénia Ferrão (2003) e seu artigo em parceria com Cristiano Fernandes (2000). Um acessível resumo em Alkharusi (2011) didaticamente resume os conceitos principais da modelagem multinível, também conhecida por mista ou hierárquica. 
c) $B A S E \_I D E B \_P B$, que determina se a Prova Brasil e Ideb são insumos para bonificação na UF.

Estes três FLAGs dummies reconstituem os cinco tipos ${ }^{30}$ apresentados no Quadro 5. Cabe esclarecer que o nível 2 é idêntico para ambos os modelos analisados, de exclusão e de fraudes.

Para o modelo de exclusão associada à manipulação da base de alunos, o nível 1 é constituído pelos agrupamentos de escolas, subordinados à hierarquia da UF e, portanto à política de bonificação conhecida, existente ou não. É neste nível em que se avalia a variável dependente, a taxa de exclusão de alunos de baixa proficiência no dia da Prova Brasil $\left(t_{E_{x}}\right)$. Neste nível subordinado são usadas as seguintes covariantes dummies e contínuas:

a) $R U R A L$, que assume valor 1, caso o agrupamento ou escola seja rural e zero para escolas urbanas;

b) ESTADUAL, que assume valor 1, caso o agrupamento ou escola seja da rede estadual e zero caso seja municipal;

c) $A B A I X O \_M E T A$, que indica 1 para agrupamentos ou escolas que estejam abaixo das metas do Ideb na avaliação anterior;

d) QUEDA_IDEB, que indica 1 para agrupamentos ou escolas que tenham apresentado queda no Ideb da penúltima para a última avaliação;

e) QUEDA_RANK, que indica 1 para agrupamentos ou escolas que tenham apresentado queda no ranking em suas redes no município, da penúltima para a última avaliação, sumarizando binariamente a variável

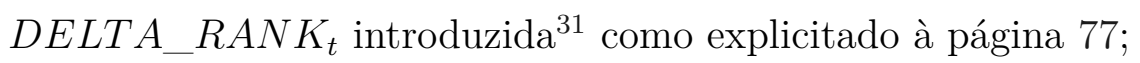

f) DOSE, que mede a duração em anos da vigência de eventual política de bonificação, para a UF, na data da realização da prova (2013 ou 2015), sendo que DOSE é zero caso não haja bonificação estadual;

g) $I D E B$, valor médio do Ideb para o agrupamento ou escola ${ }^{32}$;

h) DELT A, variação média do Ideb nas avaliações anteriores da Prova Brasil, tal qual descrito para a variável DELTA_IDEB $B_{t}$ conforme a página 75;

30 Tipo 1 = ausência de políticas estaduais de bonificação; Tipo 2 = políticas estaduais de bonificação não embasadas na medida da proficiência dos alunos; Tipo 3 = políticas estaduais de bonificação embasadas na medida da proficiência aferida por avaliação estadual própria; Tipo $4=$ políticas estaduais de bonificação embasadas na medida da proficiência aferida conjuntamente pela Prova Brasil e avaliação própria; Tipo $5=$ políticas estaduais de bonificação embasadas unicamente na proficiência aferida pela Prova Brasil.

31 A variável $D E L T A \_R A N K_{t}$, removida do modelo por não ajudar na análise, dada a proporção grande (25\%-30\%) de escolas que não mudaram de posição.

32 A variável $N S E$, baseada no Inse médio para o agrupamento, foi removida da modelagem dada sua multicolinearidade com a variável $I D E B, \rho \approx 0,9$ 
i) GAP, distância média do Ideb à meta na avaliação anterior da Prova Brasil.

Quatro instâncias de modelos são consideradas: uma para cada ano avaliado $\left(5^{\circ} \mathrm{ou}\right.$ $9^{\circ}$ do EF) e para cada aplicação da Prova Brasil (2013 e 2015), apresentados nas Tabelas 8 e 9, nas páginas 153 e 155, respectivamente ${ }^{33}$.

Para analisar as incidências de fraudes são empregados dois modelos lineares hierárquicos de dois níveis com covariantes independentes, similares aos modelos de exclusão já propostos. Nestes modelos para fraudes, o nível 1 representa escolas individuais, subordinadas a uma UF (nível 2, igual ao descrito para exclusões). A variável independente, tomada no nível 1, no primeiro tipo de modelo é o indicador FRACO de fraudes. No segundo conjunto de modelos, a variável independente é o indicador FORTE ${ }^{34}$.

Também aqui quatro instâncias destes modelos são consideradas: uma para cada ano/série avaliado e para cada aplicação da Prova Brasil. Os modelos lineares hierárquicos para o indicador FRACO estão nas Tabelas 10 e 11, nas páginas 156 e 158, respectivamente. Para o indicador FORTE, ver Tabelas13 e 14, às páginas 159 e 160, respectivamente.

Os modelos multinível foram computados usando o pacote estatístico Stata ${ }^{35}$ (StataCorp, 2013).

\subsection{Fontes de dados}

Os dados provêm dos microdados do Saeb de 2013 e 2015, disponibilizados pelo Inep $^{36}$, incluindo os resultados da Prova Brasil. São usados os dados dos arquivos de alunos

33 Idealmente, para estimar variáveis dependentes fracionárias, como a taxa de alunos excluídos $t_{E_{x}}$, modelos de regressão logística seriam indicados. O uso da regressão logística tem o benefício de predizer as taxas percentuais dependentes mais adequadamente, mas além da complexidade computacional adicional, apresenta um desafio maior na interpretação dos coeficientes das variáveis independentes. Como o intuito desta modelagem é entender a associação dos efeitos colaterais com os FLAGs, foi adotado um modelo hierárquico linear no qual a interpretação dos coeficientes resultantes é mais direta.

$34 \mathrm{O}$ indicador $F R A C O$, por escola, assume valor 1, caso pelo menos uma das séries ou disciplinas avaliadas na escola apresentarem indicação de fraude e valor zero, caso contrário. O indicador FORTE assume 1 se todas as séries e disciplinas avaliadas apresentarem simultaneamente indicação de fraude e zero caso contrário. Idealmente, para modelar uma variável dependente binária, seria indicado o uso de um modelo de regressões multinível do tipo probit, mas estas têm a interpretação complexa dos coeficientes, sendo portanto substituídas por regressões hierárquicas lineares.

35 Por meio da função - mixed-, com constantes suprimidas tanto na equação de efeitos fixos quanto para os efeitos aleatórios (opção noconstant), e com estimativas de variância-covariância da parte aleatória estimadas de maneira completa (opção covariance(unstructured)). As regressões logísticas e probit foram testadas por meio das funções -melogit-e -meprobit-mas não foram incluídas nos resultados finais

36 Disponíveis no repositório do Inep em ftp://ftp.inep.gov.br/microdados/microdados - acompanhados das suas documentações de suporte (BRASIL. Ministério da Educação. Instituto Nacional de Estudos e Pesquisas Educacionais Anísio Teixeira, 2014b; BRASIL. Ministério da Educação. Instituto Nacional de Estudos e Pesquisas Educacionais Anísio Teixeira, 2015c). 
do $5^{\circ}$ e $9^{\circ}$ anos, com os resultados de proficiência de Matemática e Língua Portuguesa e respostas dos questionários contextuais, por aluno.

Foram usadas apenas as provas regulares, ou seja, foram desconsideradas as "provas especiais", oferecidas para cobrir necessidades especiais de alguns alunos (impressão com caracteres ampliados (macro tipo 18), auxílio ledor, linguagem Libras, por exemplo). Estas provas especiais têm identificação por meio de tipos de caderno com numeração acima de 21 e foram desconsideradas nas análises para diminuir a influência de fatores exógenos não controlados. Apenas 0,15\% das provas de 2013 no $5^{\circ}$ ano e $0,04 \%$ no $9^{\circ}$ ano são de tipos especiais. Foram incluídas nas análises as escolas públicas estaduais e municipais, participantes da Prova Brasil ${ }^{37}$.

Nos microdados públicos, há identificadores de escolas ou municípios que passaram por um processo de mascaramento, usualmente para atender a um pedido de veto ao reporte, feito por escolas ou secretarias de educação locais. Estes $\operatorname{casos}^{38}$ não permitem a associação dos resultados aos FLAGs e, por isso, foram desconsiderados nas análises. A Figura 33 ilustra a inclusão de alunos nas análises, a remoção pelos fatores elencados acima (fora de escopo) e as ausências no dia da avaliação.

Resultados e metas do Ideb são disponibilizados pelo Inep (2015a) e empregados na construção dos FLAGs. Dados de abandono por escola e série (2010), usados na estimativa de faltas não aleatórias, são obtidos do sítio do Inep, identificados por código da escola.

Para medidas do nível socioeconômico (NSE) usado como proxy para o capital social, estimado para escolas, foi empregado o Indicador de Nível Socioeconômico das Escolas de Educação Básica (Inse) criado pelo Inep (2014a). Este indicador, gerado com base nos questionários contextuais preenchidos pelos alunos avaliados, classifica cada escola participante da Prova Brasil em um de sete grupos: o Grupo 1 corresponde ao NSE "muito baixo" e Grupo 7 ao NSE "muito alto".

A Figura 34 torna evidente a associação forte do NSE com as proficiências avaliadas, daí a sua inclusão nas análises deste trabalho. Contudo, nas modelagens de regressão, a variável $N S E$ foi omitida por ser fortemente colinear com a variável $I D E B$.

$\overline{37}$ Escolas federais também são avaliadas na Prova Brasil, mas foram excluídas por representarem menos de $0,2 \%$ dos alunos, não serem expostas às políticas estaduais de bonificação estudadas e representarem um desafio adicional no reporte de resultados.

38 Mascaramento indicado pelo dígito mais significativo do identificador fixado em 6 . 
Figura 33 - Mapa de alunos considerados nas análises

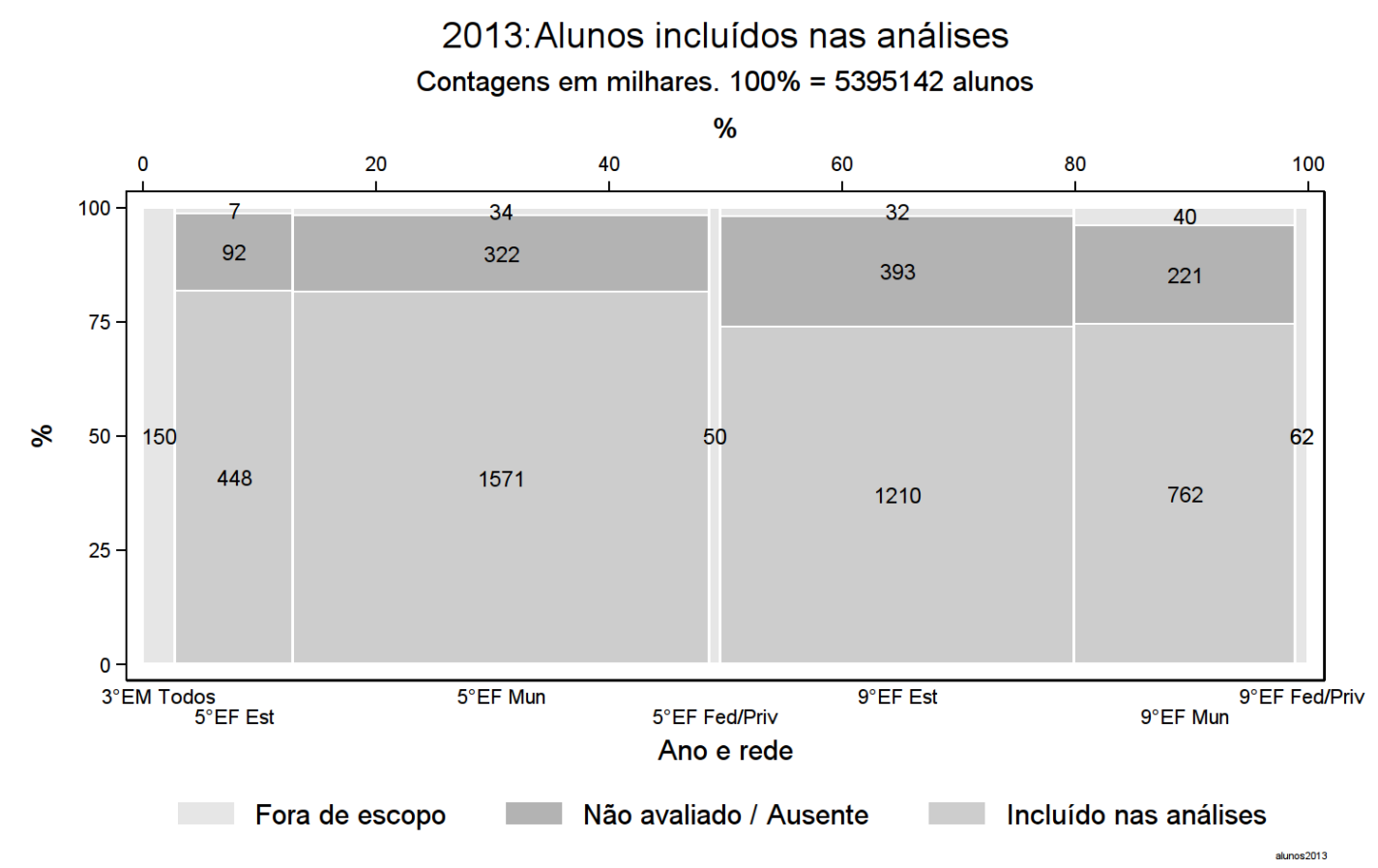

2015: Alunos incluídos nas análises

Contagens em milhares. $100 \%=5031032$ alunos

$\%$

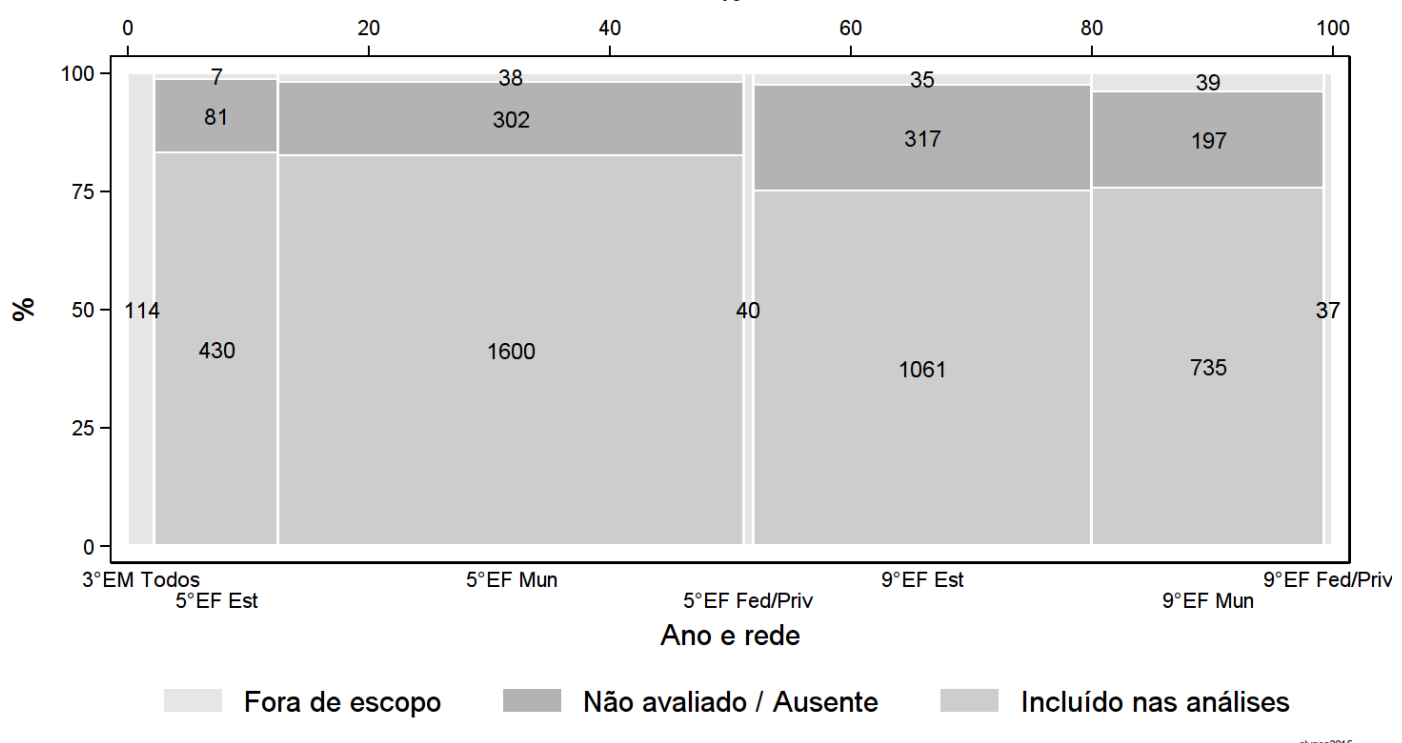

Fonte: Elaboração do autor. 
Figura 34 - Distribuições de proficiência por Inse, Matemática $5^{\circ}$ ano
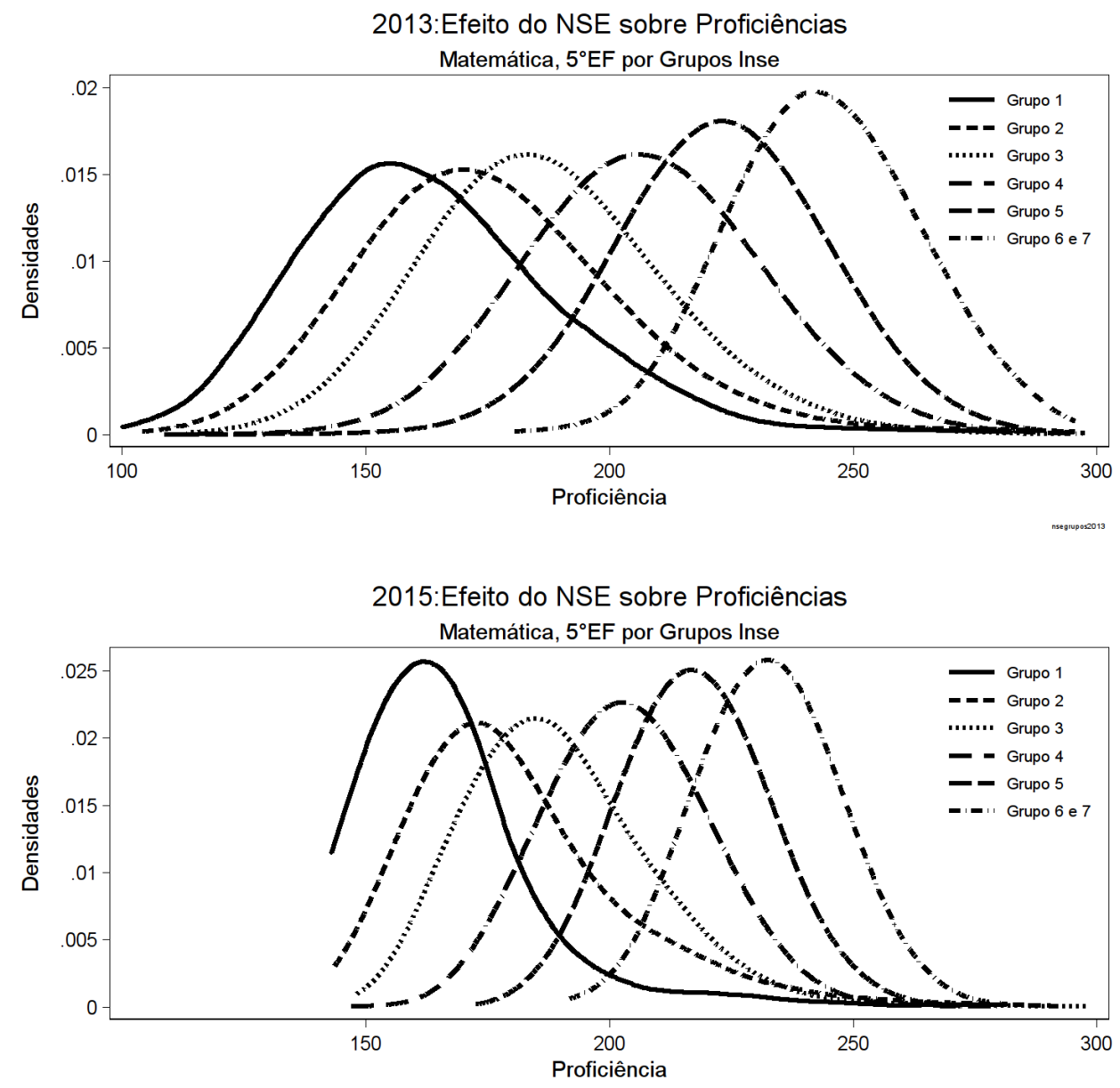

Fonte: Elaboração do autor.

A Figura 34 mostra, também, uma "compressão" na classificação do Inse entre 2013 e 2015. A documentação técnica de suporte ao Inse foi publicada por ocasião da divulgação dos resultados de 2013, não tendo sido atualizada para os dados de 2015, até o momento de conclusão deste trabalho. O Critério Brasil ${ }^{39}$ de pontuação no nível socioeconômico (ABEP, 2013), que é usado como base para as perguntas relacionadas ao NSE nos questionários contextuais dos alunos no Saeb, é atualizado anualmente, para refletir diferenças nos padrões de consumo, itens e serviços utilizados pelas famílias. É uma hipótese que os resultados do Inse publicados para 2015 não tenham sido atualizados para refletir as mudanças estruturais de NSE para o biênio 2013-2015.

A Figura 60, em apêndice, à página 208, resume os fluxos de dados, suas fontes e relacionamentos nesta dissertação. 



\title{
3 Resultados e suas interpretações
}

\author{
"Correlação não implica causalidade, \\ mas ela mexe as sobrancelhas, sugestivamente, \\ de modo furtivo gesticulando \\ enquanto sussurra 'dê uma olhadinha ali'." \\ Randall Munroe (2009), tradução nossa.
}

Neste capítulo são apresentados os resultados para as abordagens de exclusão não aleatória de alunos de baixa proficiência e de fraudes ingênuas, conforme abordagens propostas no capítulo anterior. Estes resultados são comentados em função de sua aderência ou não ao esperado, à luz das pressões de gaming elencadas pelos FLAGs.

A Tabela 7 apresenta alguns resultados importantes para a exclusão. As exclusões não aleatórias de alunos de baixa proficiência na Prova Brasil são mais substantivas em UFs que usam esta avaliação no pagamento de bonificações. Estas exclusões também são mais severas nos agrupamentos de escolas que tiveram Ideb baixo na avaliação anterior, sugerindo que o fenômeno pode estar ligado à pressão resultante do acompanhamento deste indicador.

Tabela 7 - Resultados resumidos da exclusão 2013-2015

\begin{tabular}{|c|c|c|c|c|c|c|c|c|}
\hline \multirow[b]{4}{*}{ Tipo de bonificação docente na UF } & \multicolumn{4}{|c|}{2013} & \multicolumn{4}{|c|}{2015} \\
\hline & \multicolumn{2}{|c|}{$5^{\mathrm{o}}$} & \multicolumn{2}{|c|}{$9^{\mathrm{o}}$} & \multicolumn{2}{|c|}{$5^{\mathrm{o}}$} & \multicolumn{2}{|c|}{$9^{\mathrm{o}}$} \\
\hline & MT & LP & MT & LP & MT & LP & MT & LP \\
\hline & & & & & & & & \\
\hline 1-Sem bonificação & $3,9 \%$ & $7,6 \%$ & $2,1 \%$ & $2,9 \%$ & $6,5 \%$ & $6,5 \%$ & $4,5 \%$ & $1,5 \%$ \\
\hline 2-Não baseada em proficiência de alunos & $4,3 \%$ & $4,7 \%$ & $1,4 \%$ & $1,6 \%$ & $6,9 \%$ & $4,2 \%$ & $3,9 \%$ & $0,9 \%$ \\
\hline 3-Baseada em avaliação estadual própria & $2,4 \%$ & $4,7 \%$ & $1,0 \%$ & $1,8 \%$ & $3,7 \%$ & $2,4 \%$ & $3,1 \%$ & $0,6 \%$ \\
\hline 4-Baseada na Prova Brasil e avaliação própria & $5,3 \%$ & $7,0 \%$ & $3,4 \%$ & $2,8 \%$ & $7,3 \%$ & $5,0 \%$ & $4,8 \%$ & $1,5 \%$ \\
\hline 5 -Prova Brasil como insumo & $5,5 \%$ & $9,5 \%$ & $3,4 \%$ & $4,5 \%$ & $7,9 \%$ & $8,3 \%$ & $5,6 \%$ & $2,2 \%$ \\
\hline Total Brasil & $3,3 \%$ & $6,1 \%$ & $1,6 \%$ & $2,3 \%$ & $5,2 \%$ & $4,5 \%$ & $3,7 \%$ & $1,0 \%$ \\
\hline \multicolumn{9}{|l|}{ Quintil do Ideb anterior } \\
\hline Mais baixo & $5,4 \%$ & $11,8 \%$ & $2,9 \%$ & $4,9 \%$ & $9,5 \%$ & $10,7 \%$ & $5,8 \%$ & $2,0 \%$ \\
\hline Baixo & $4,7 \%$ & $9,6 \%$ & $2,7 \%$ & $3,9 \%$ & $7,8 \%$ & $6,3 \%$ & $5,0 \%$ & $1,5 \%$ \\
\hline Médio & $3,8 \%$ & $6,6 \%$ & $1,4 \%$ & $2,0 \%$ & $5,6 \%$ & $3,6 \%$ & $4,3 \%$ & $0,9 \%$ \\
\hline Alto & $2,5 \%$ & $3,6 \%$ & $0,8 \%$ & $1,1 \%$ & $3,5 \%$ & $2,3 \%$ & $2,9 \%$ & $0,5 \%$ \\
\hline Mais alto & $0,9 \%$ & $1,0 \%$ & $0,4 \%$ & $0,4 \%$ & $1,1 \%$ & $1,0 \%$ & $1,1 \%$ & $0,2 \%$ \\
\hline Total Brasil & $3,3 \%$ & $6,1 \%$ & $1,6 \%$ & $2,3 \%$ & $5,2 \%$ & $4,5 \%$ & $3,7 \%$ & $1,0 \%$ \\
\hline
\end{tabular}

Fonte: Elaboração do autor.

A variação das exclusões aferidas, de 2013 para 2015, ilustra uma das limitações da abordagem. Usando a curva de distribuição de proficiências em Matemática como insumo 
de cálculo, há um aumento na exclusão agregada no período analisado. Por outro lado, ao se usar as proficiências em Língua Portuguesa, a tendência é de queda. Estes padrões são consistentes para os anos/séries avaliados e se mantêm nos sub-agrupamentos usados nas análises, conforme detalhado na Tabela 7 .

Nas análises apresentadas neste capítulo, são indicadas as exclusões para cada uma das disciplinas usadas como insumo, Matemática e Língua Portuguesa, com a identificação da média aritmética simples entre os valores obtidos. Os resultados apresentados a seguir resultam da agregação dos casos obtidos por agrupamento dos FLAGs de nível socioeconômico, UF, tipo de bonificação docente estadual, variação do Ideb nos anos anteriores, distância à meta no ano anterior, variação do ranking da escola na sua rede e município no ano anterior e a variável dummy não preditiva indicando se a escola teve ou não seu Ideb reportado.

Em geral, a abordagem proposta revelou uma porcentagem maior de exclusões de alunos de baixa proficiência no $5^{\circ}$ ano comparado ao $9^{\circ}$ ano. Não se encontrou evidência documental que explicasse com evidências esta diferença no perfil de ausências. Estas ausências deliberadas são consistentes ao longo das Provas de 2013 e 2015, e por disciplinas.

Quanto aos resultados dos indicadores de fraudes ingênuas, aparecem dois resultados salientes. Em geral, as incidências verificadas em 2015 são muito maiores que as de 2013, para virtualmente todos os agrupamentos e categorias de análise usados. A variação destes indicadores com relação aos FLAGs é, em geral, consistente com o previsto, sugerindo o vínculo entre a ocorrência do fenômeno com mecanismos de pressão.

A análise da Figura 35 mostra um crescimento do nível percebido de fraudes ingênuas. Para um dado nível de confiança escolhido, o número de indicações de fraude dobra, grosso modo, de 2013 para 2015. Este aumento pode ter origem na pressão criada pela participação mínima de $80 \%$, necessária e divulgada na época da realização da Prova Brasil 2015. À luz desta diretriz, escolas que tenham diminuído sua exclusão deliberada de alunos de baixa proficiência podem ter aumentado sua incidência de fraudes, para tentar compensar um resultado pior previsto.

Uma comparação direta no nível das unidades escolares, para testar esta hipótese não é possível com as abordagens propostas, pois a análise de exclusão usa agrupamentos que consolidam múltiplas escolas, para não abusar da não-normalidade. No final deste capítulo, há análise combinada dos dois efeitos estudados, por UF. 
Figura 35 - Indicação de fraudes em função dos níveis de confiança 2013-2015
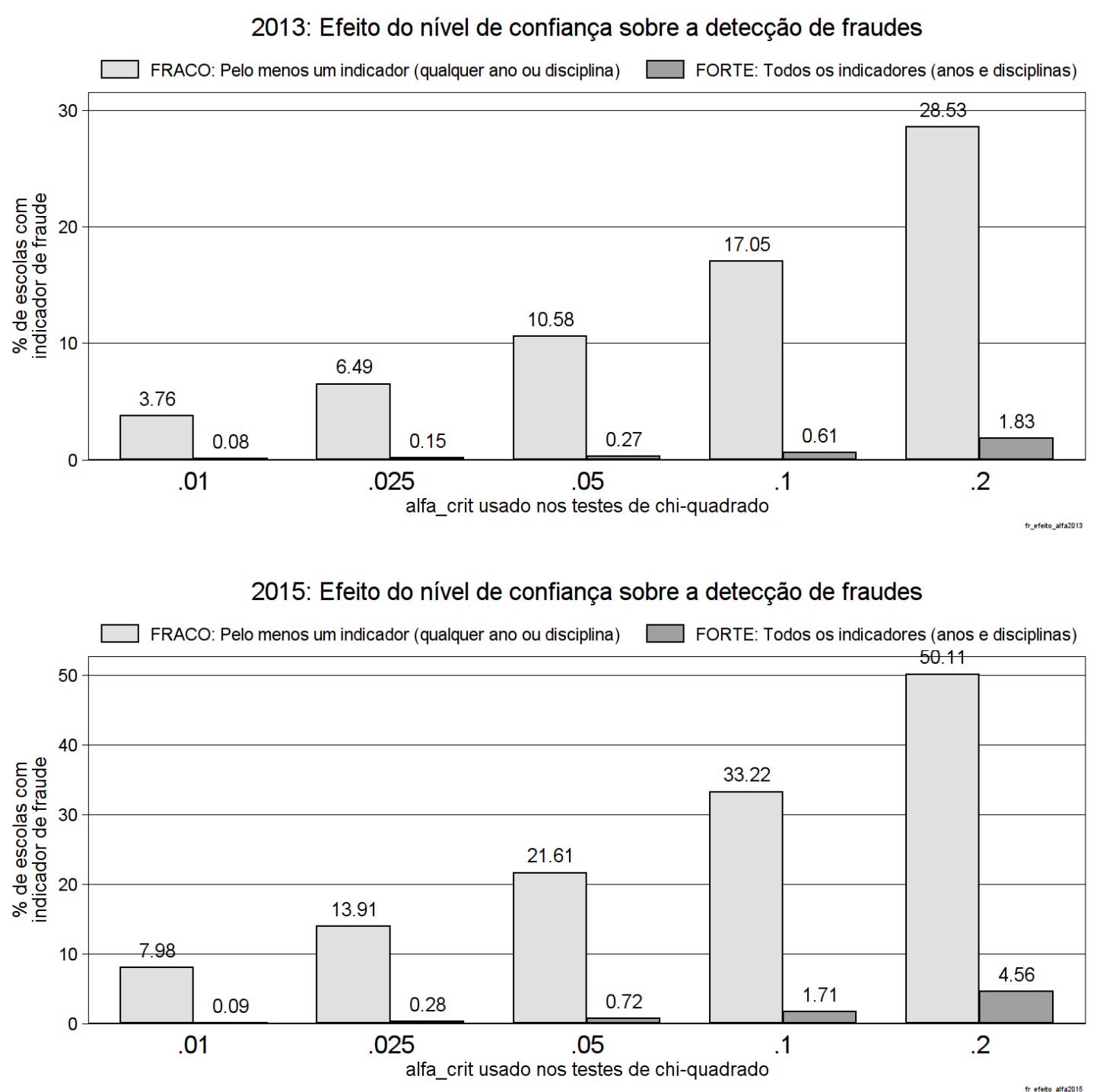

Fonte: Elaboração do autor.

Nas figuras relativas aos indicadores de fraudes, apresentadas a seguir, há duas grandezas reportadas: um indicador "forte" e outro "fraco". O "forte" indica que as análises de fraude apontaram frequências anormais de blocos impróprios maximizadores em todas as séries e disciplinas testadas de uma escola. O indicador "fraco" aponta estas frequências anormais em pelo menos uma das séries ou disciplinas testadas de uma escola.

É importante lembrar que a escolha do nível de confiança é arbitrário, e que claramente mais "falsos positivos" podem ser registrados à medida em que a confiança decresce. A construção dos indicadores FRACO e FORTE foram criados usando um nível de confiança de $95 \%$ e seu $\alpha_{\text {crit }}=0,05$ para o teste de $\chi^{2}$, e desta maneira aparecem nos gráficos e modelos de regressão deste capítulo. 


\subsection{Efeitos medidos por Unidade da Federação}

A Figura 36 apresenta as estimativas da taxa de exclusão, por UF, dos alunos menos proficientes no dia da Prova Brasil ${ }^{1}$.

Todos os estados da Região Sul, MG e SP, apresentam baixos níveis de exclusão para as edições da Prova Brasil analisadas e séries avaliadas. Não há mudança substantiva nas posições relativas das UF de 2013 para 2015. Entretanto, há indicação de estados que excluem mais de $10 \%$ dos seus alunos menos proficientes de $5^{\circ}$ ano, como por exemplo AL, AP, MA, PE, RN e RR.

Não há uma justificativa clara para realizar a análise com base numa disciplina ou em outra, como discutido ao apresentar as limitações da abordagem. Em dados de 2013, o uso das proficiências em Língua Portuguesa como subsídio para estimativas indica uma exclusão mais alta que a obtida por meio da Matemática. Para a edição de 2015, o comportamento é invertido, ou seja, a análise pela Matemática leva a uma medida de exclusão maior que a aferida pela Língua Portuguesa.

Os gráficos deixam claro esta alternância. Contudo, indicam que numa dada combinação Prova Brasil $(2013,2015)$ / Ano avaliado (5 e $9^{\circ}$ ano EF) as tendências são consistentes. Uma hipótese para explicar estas alternâncias pode ser a dificuldade relativa dos itens de prova, mas o entendimento deste comportamento exige uma análise mais profunda das características TRI dos itens que compõem as provas.

Um aspecto notável que se vê a seguir é que as exclusões têm variações consistentes ao longo das categorias das varáveis explicativas empregadas, qualquer que seja a disciplina usada como insumo de cálculo. Por exemplo, se as exclusões estimadas com base em Matemática caem com o crescimento do Ideb, assim também ocorre com as exclusões estimadas com base em Língua Portuguesa.

A Figura 37 demonstra a ampla variação dos indicadores de fraudes por UF. Em particular, fica evidente, em 2015, um aumento no nível de fraudes detectado no Distrito Federal.

1 As estimativas vêm da aplicação idêntica do algoritmo de estimação com base nas proficiências de Língua Portuguesa e de Matemática, representados pelos pontos extremos dos segmentos verticais. Os pontos médios destes segmentos são rotulados e ligados entre os casos para indicar a tendência geral de comportamento de exclusão, para as categorias do eixo horizontal. 

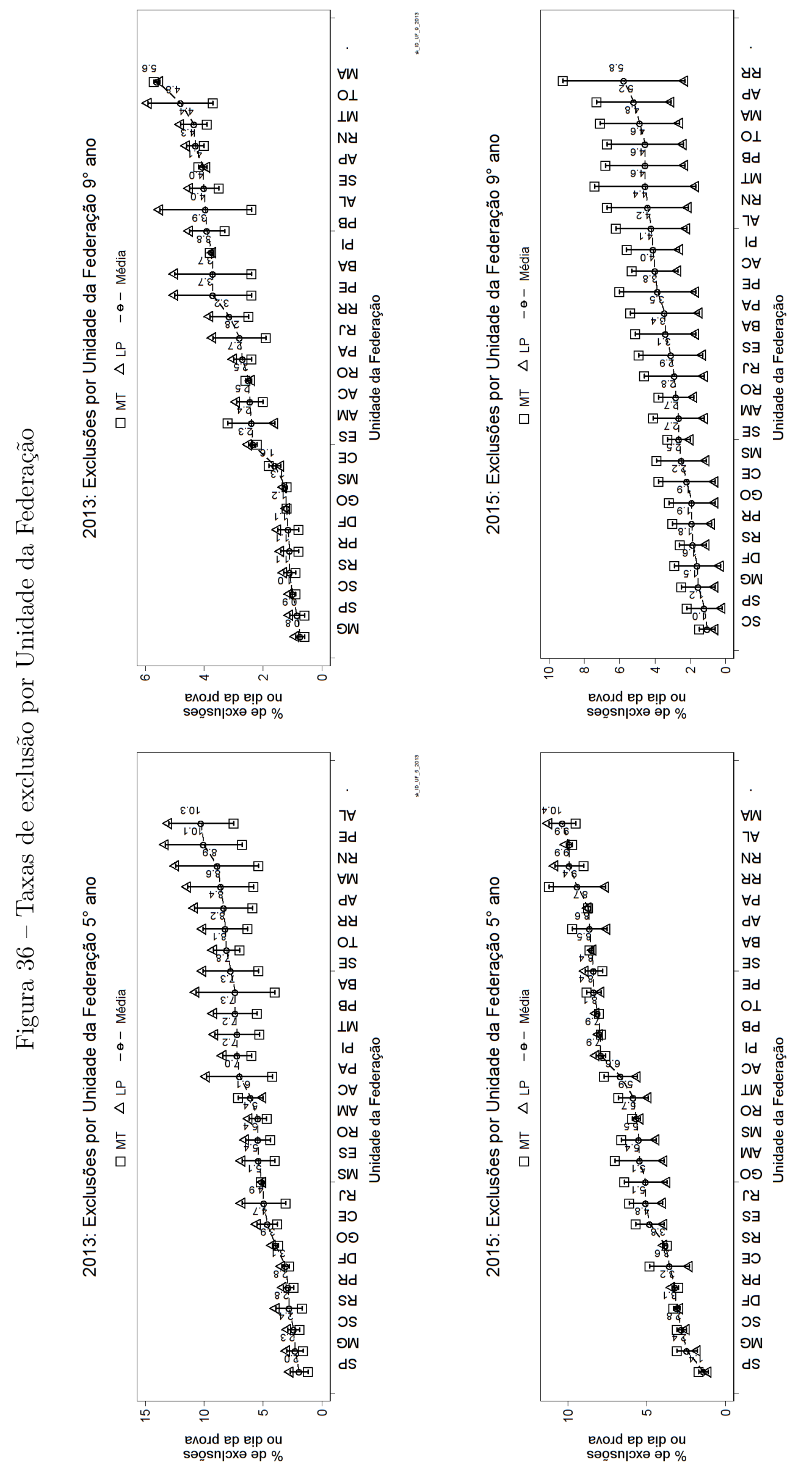

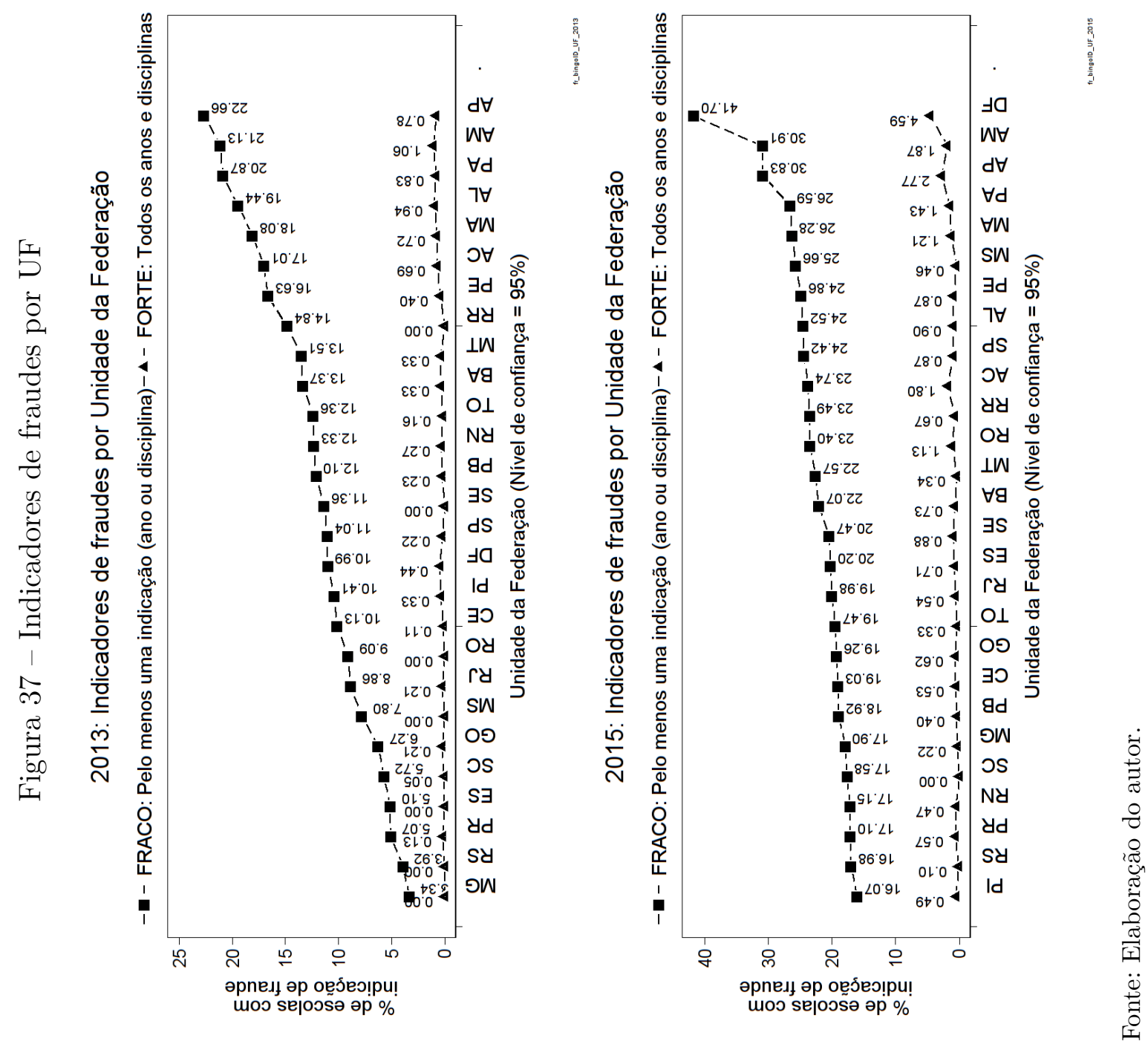


\subsection{Efeitos medidos por tipo de bonificação}

A Figura 38 apresenta os resultados para os primeiros FLAGs associados ao gaming. Recordando as convenções adotadas no Quadro 5, vê-se que a exclusão é maior nos estados que usam a Prova Brasil em alguma capacidade como insumo para a bonificação, confirmando a hipótese de trabalho².

Os estados que usam a Prova Brasil como insumo para a definição do bônus, seja isoladamente (Tipo 5) ou de maneira combinada com avaliações próprias (Tipo 4), apresentam maiores taxas de exclusão, indicando o possível intento estratégico de excluir alunos de baixa proficiência para inflar proficiências médias e com isso, maximizar o bônus médio esperado.

Os estados que não dependem de proficiência medida de alunos como insumo à bonificação (Tipo 2) têm baixas taxas de exclusão, ainda que estas sejam maiores que as taxas dos estados que contam com avaliações próprias para base da bonificação (Tipo 3).

É importante contextualizar o observado para as UFs de Tipo 3: a Prova Brasil é low-stakes nestas UFs. Se este estudo fosse realizado com as avaliações estaduais ${ }^{3}$ que de fato contam na bonificação, os resultados plausivelmente seriam diferentes, possivelmente concordando com o encontrado aqui para os Tipos 4 e 5 . Contudo, os dados destas avaliações não são públicos, o que dificulta a pronta análise.

Os estados que não possuem nenhuma política de bonificação (Tipo 1) têm um comportamento errático. O que se vê, possivelmente, é a influência de outros mecanismos de incentivo, como o de programas municipais, PARs, ou mesmo de programas estaduais que, sem registro formal, não foram incluídos adequadamente na classificação do Quadro 5.

A Figura 39 mostra um comportamento de fraudes consistente com o verificado para exclusões. O Tipo 4 apresenta maior incidência dos indicadores fortes e fracos. Em 2013, as indicações de fraudes se apresentam conforme o esperado, sendo mais altas nos casos em que a Prova Brasil se presta a bonificar. Em 2015, contudo, as indicações de fraudes se mostram mais homogêneas entre os tipos, ainda que com uma leve alta nos estados que usam uma combinação de avaliação própria e a Prova Brasil na bonificação.

2 Tipos listados aqui para conveniência, Tipo 1: AL, AP, BA, DF, MA, MS, MT, PA, PI, PR, RN, RO, RS, SC; Tipo 2: AC, GO, RR; Tipo 3: ES, RJ, CE, SP, MG, PE; Tipo 4: TO, AM; Tipo 5: SE, PB, conforme Quadro 5 da página 80

3 Simave (MG), Saresp (SP), Saerj (RJ), Spaece (CE), Saepe (PE) e Paebes (ES) 


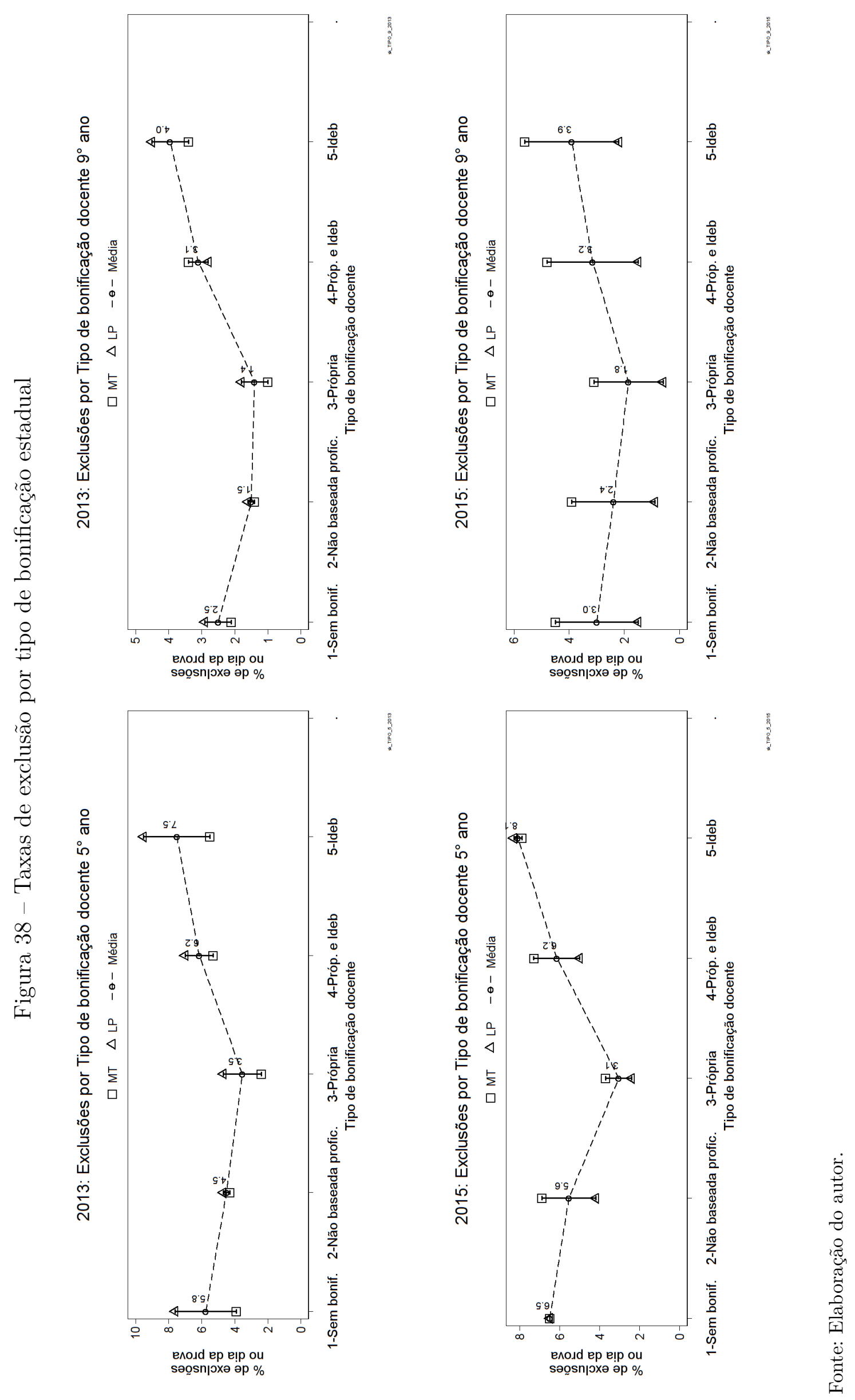



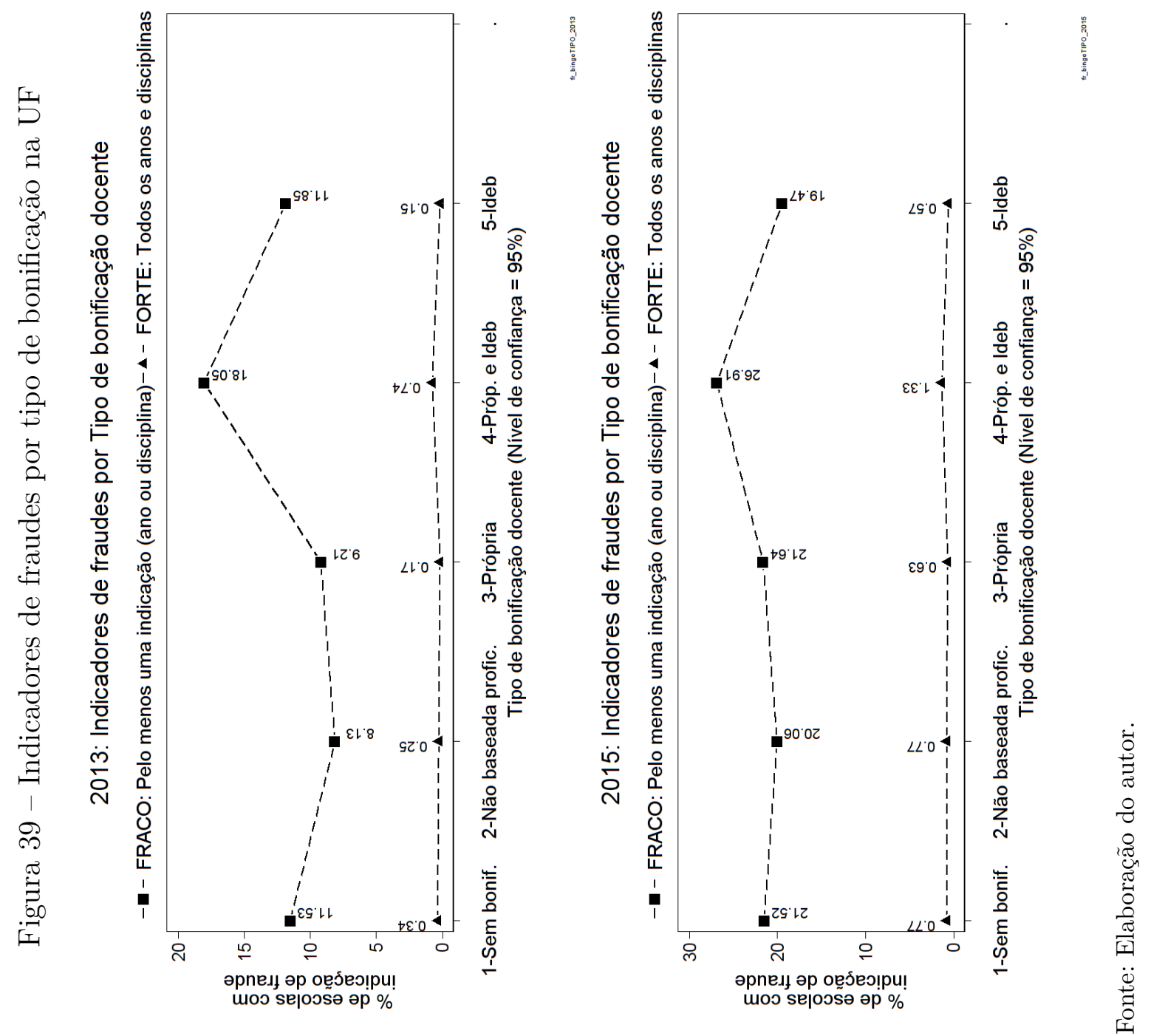


\subsection{Efeitos medidos por Ideb absoluto}

Segundo os resultados obtidos, quanto menor o Ideb, em termos absolutos, obtido na avaliação anterior, maior é a medida de exclusão de alunos de baixa proficiência. Este padrão, claramente identificado na Figura 40, apresenta forte correlação negativa. A força desta correlação vem da simplicidade e da disponibilidade do indicador, pois o Ideb absoluto divulgado é comparável ao da escola vizinha ou à média da rede, de maneira direta.

A Figura 41 mostra um comportamento de fraudes consistente ao reportado para exclusões. Escolas com Ideb alto aferido em 2013 têm indicações de fraudes menores quando confrontadas com grupos similares em 2015. Este padrão de generalização das fraudes se dá, também, nas análises seguintes. Seria esta alteração um reflexo da pressão criada pelo novo patamar mínimo de participação, de $80 \%$, imputado pelo Inep em 2015 ?

O uso de uma métrica simples, o nível absoluto do Ideb, parece ter forte influência no gaming, indicando que este não é de natureza sofisticada. A informação usada na tomada de decisão para engajar no gaming não envolve necessariamente históricos nem comparações às metas, mas ela pode ser simplesmente o Ideb aferido na avaliação anterior, amplamente conhecido por diretores, conforme análise de questionários contextuais.

A Figura 42 apresenta a tabulação por tipo de bonificação docente da UF como categorização. Seria de se esperar que diretores cuja bonificação dependesse do Ideb seguissem este indicador. No entanto, diretores cujas UFs têm bonificação baseada somente em resultados da Prova Brasil alegam conhecer seus resultados anteriores com frequência menor do que aqueles de outras UFs. 


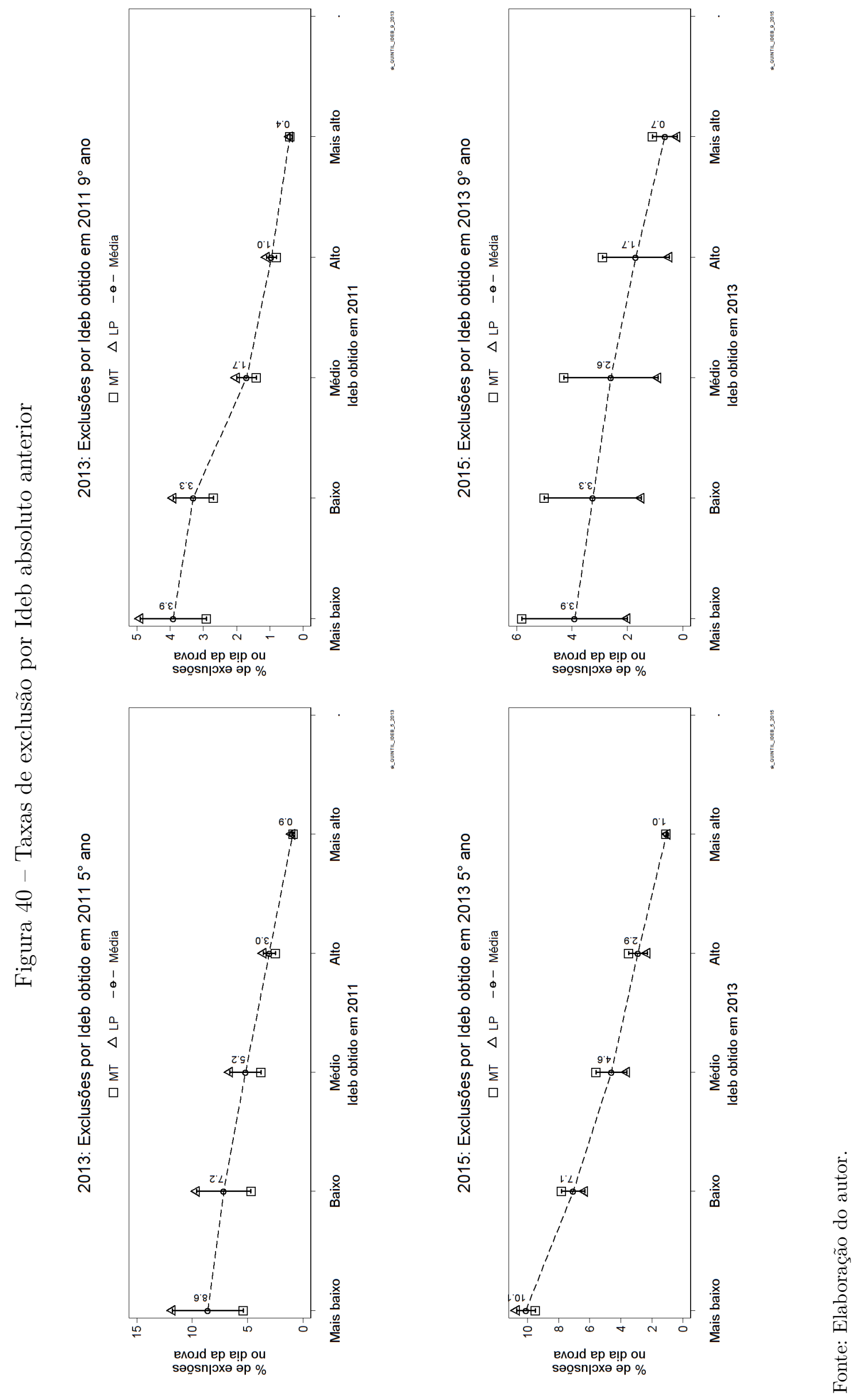



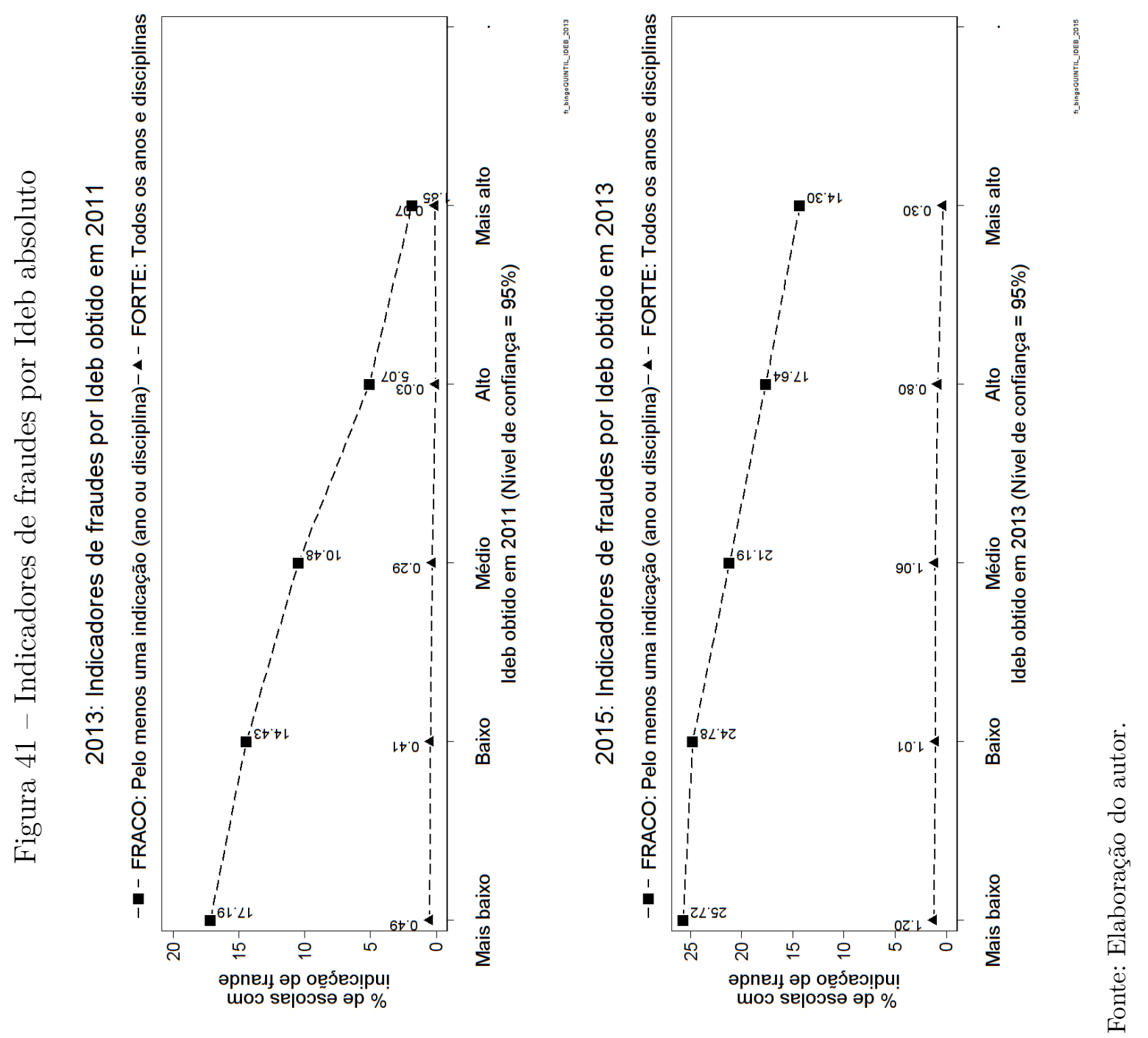


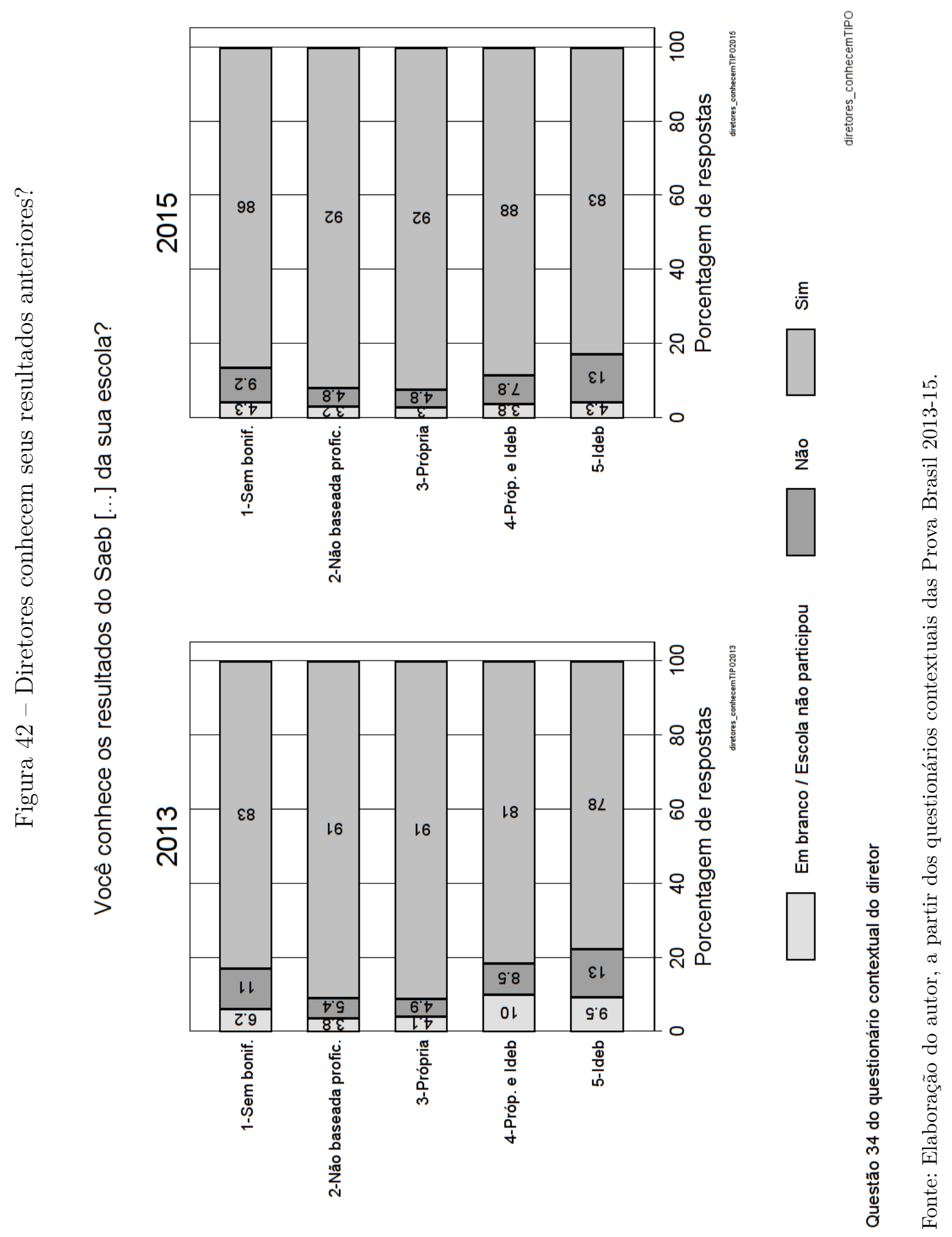




\subsection{Efeitos medidos por nível socioeconômico}

De acordo com os resultados da Figura 43, o nível socioeconômico das escolas é um bom preditor da taxa de exclusão, tal qual o é o Ideb absoluto. Escolas com NSE mais baixo apresentam taxas maiores de exclusão, quando comparadas às escolas de NSE mais alto.

Os alunos do $5^{\circ}$ ano são os mais atingidos pela exclusão, quando comparados aos seus colegas do $9^{\circ}$ ano, do mesmo NSE. Os mais novos mantêm taxas de exclusão similares desde o NSE "muito baixo" até o "médio baixo", para só então cair para patamares mais baixos de exclusão nos níveis de NSE mais altos. Esta não linearidade pode indicar que outros aspectos podem estar influindo na exclusão dos alunos do $5^{\circ}$ ano.

Para o $9^{\circ}$ ano, a exclusão diminui regular e consistentemente à medida em que o NSE aumenta. Esta regularidade não é observada no $5^{\circ}$ ano, pois há uma persistência de alta exclusão mesmo em níveis médios de NSE.

No que concerne as indicações de fraudes, para a Prova Brasil 2013, estas eram mais frequentes nas escolas com nível socioeconômico menor que o médio, tal qual se vê para as exclusões, como indicado na Figura 44. Para os resultados de 2015, contudo, os indicadores de fraudes são homogeneamente distribuídos entre os grupos de NSE.

O NSE e Ideb absoluto têm, em geral, efeitos muito similares, nos padrões de exclusão e de fraudes, como visto. Em função desta correlação, o NSE foi excluído das modelagens hierárquicas lineares, apresentadas adiante. 

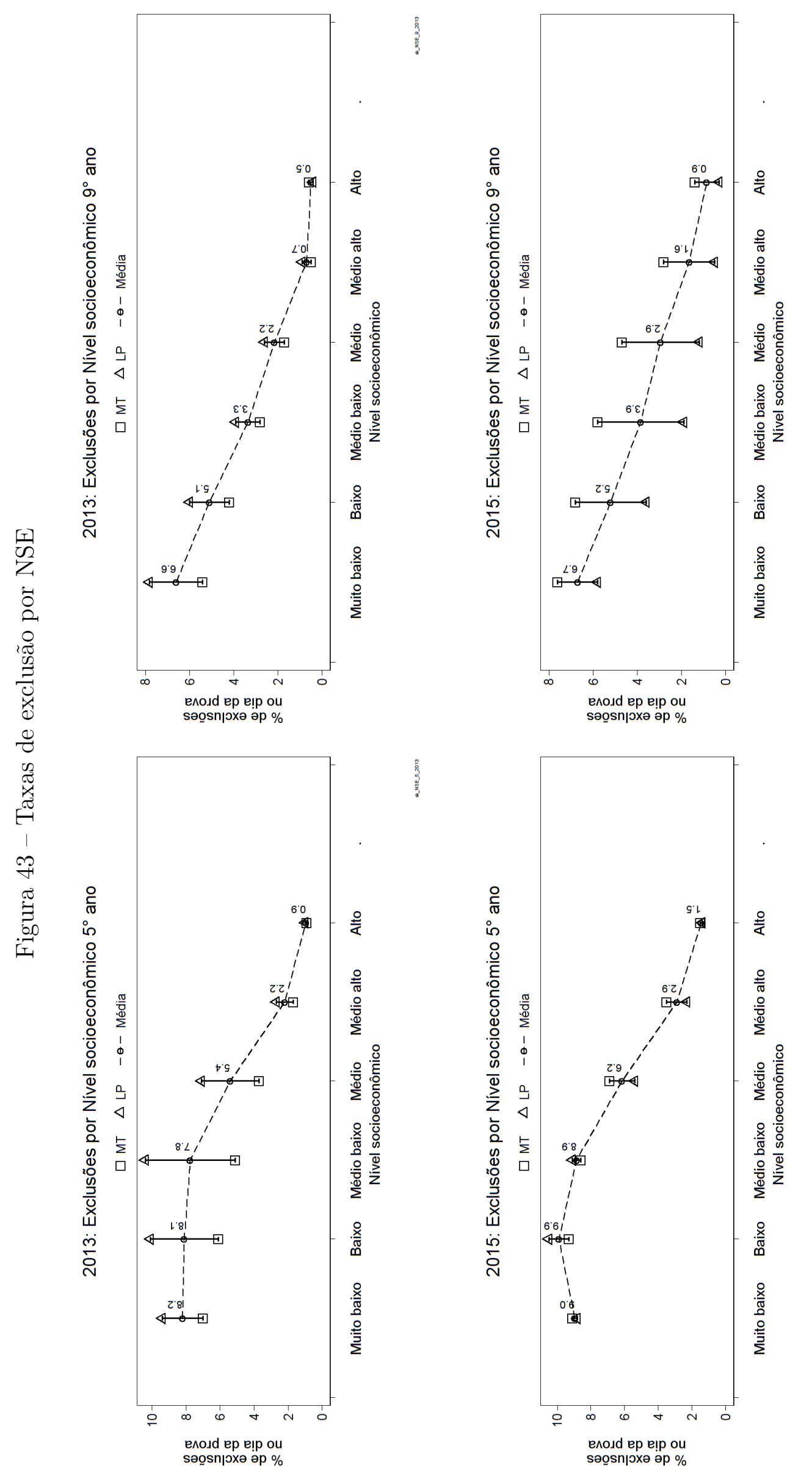

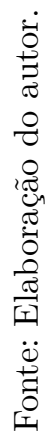



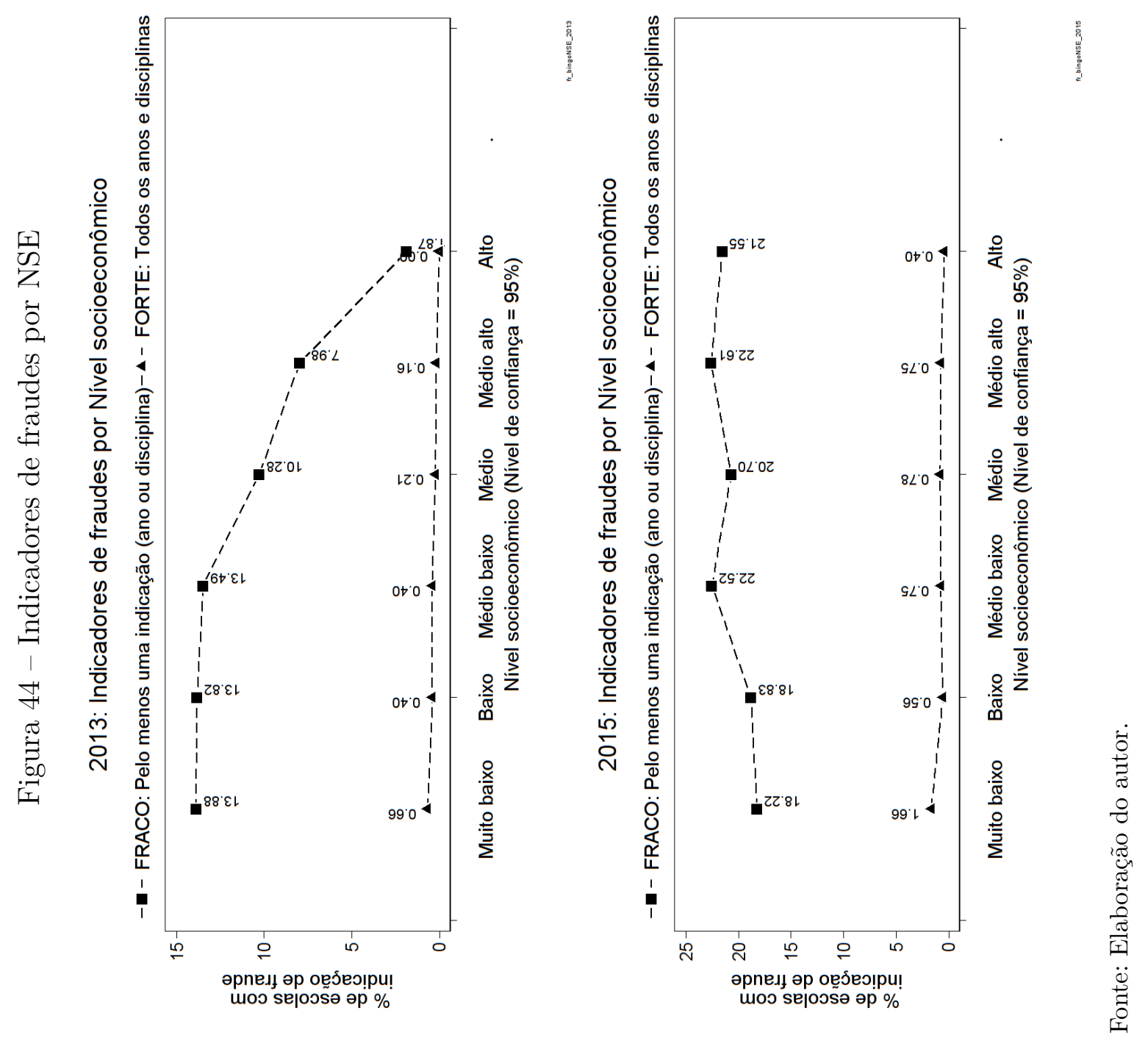


\subsection{Efeitos medidos por variação do Ideb}

A Figura 46 mostra o efeito da variação do Ideb dos anos anteriores, nas taxas de exclusão, por quintil. Visualmente, pela análise dos gráficos, a associação é tênue, exceto no caso do $5^{\circ}$ ano em 2015. O FLAG usado para esta análise depende de um histórico que talvez não tenha deixado registro com os agentes, pois usa a variação no tempo do Ideb de quatro e dois anos-calendário anteriores à prova.

Uma segunda causa plausível para a associação tênue pode ter sua origem na natureza dos dados faltantes. A existência de um valor para este FLAG no ano $t$ é dependente da existência de dados de Ideb para os anos $t_{-1}$ e $t_{-2}$. Basta que um destes últimos seja faltante, ou não reportado, para que o FLAG em $t$ seja faltante também.

Uma terceira explicação pode estar na composição do Ideb, nos casos das escolas que mostrem crescimento estagnado deste indicador. Na medida em que o modelo de crescimento do Ideb com base na correção do fluxo se exaure ${ }^{4}$, só resta crescer na proficiência, que se apresenta como um desafio respeitável.

A Figura 45 mostra que o aumento do fluxo (fator $P$ ) tem mostrado sinais de saturação (à esquerda do gráfico), colocando sobre o fator cognitivo ( $N$, no centro do gráfico) a responsabilidade pelo aumento do Ideb (à direita). Sem melhorias do aspecto cognitivo, as variações positivas de uma aferição para a outra, tendem a diminuir, restringindo a variabilidade deste FLAG e sua capacidade de resolver diferenças na exclusão.

A Figura 47 mostra um comportamento de fraudes similar ao reportado para exclusões, com pouca diferenciação entre intensidades das variações no Ideb. Isto sugere a baixa influência deste fator na construção da resposta estratégica dos agentes.

4 Lembrando que $I d e b=N \cdot P$, onde $P$ é um fator associado ao fluxo escolar e $N$ é o fator associado à proficiência. Ver Fernandes (2007). 


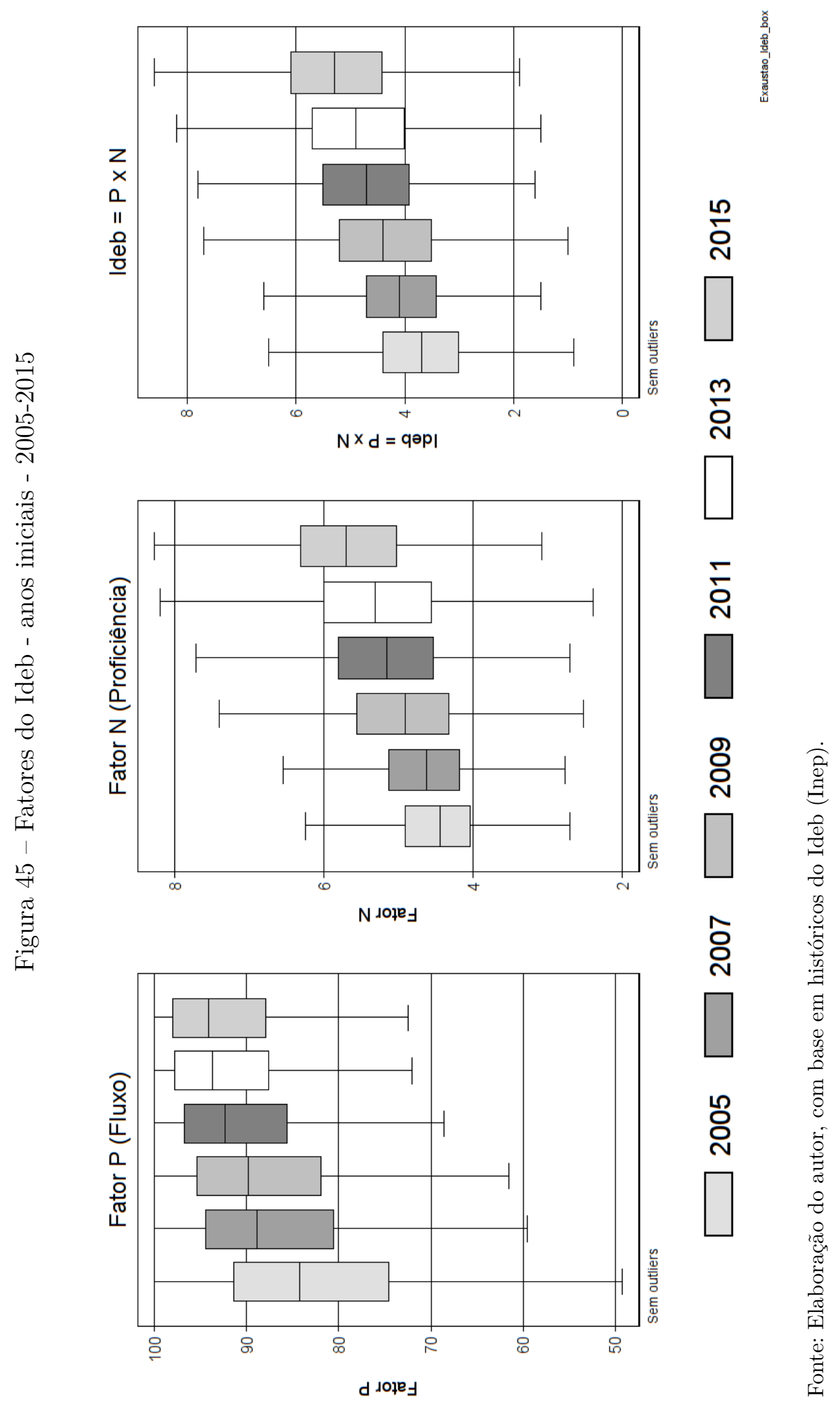




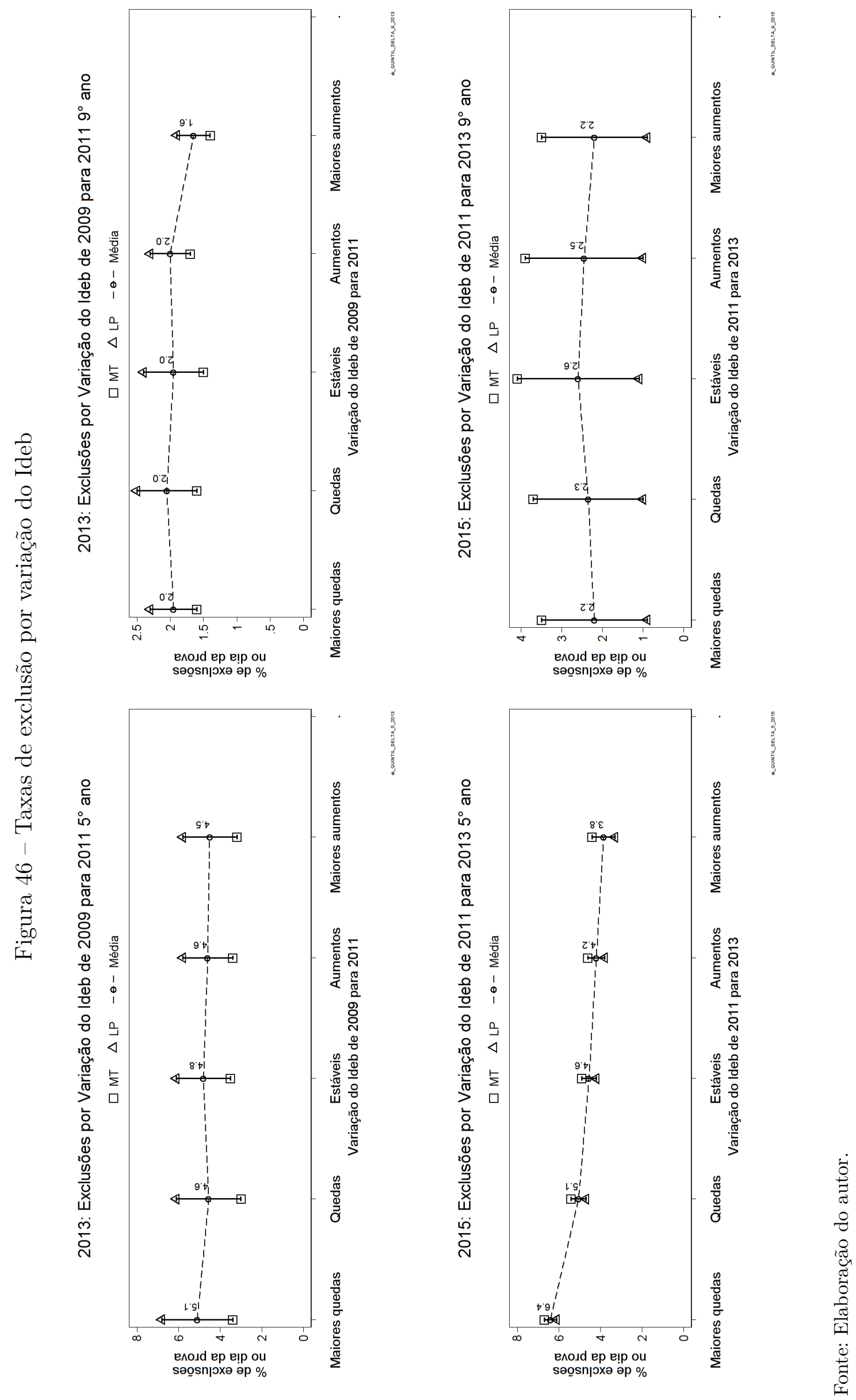



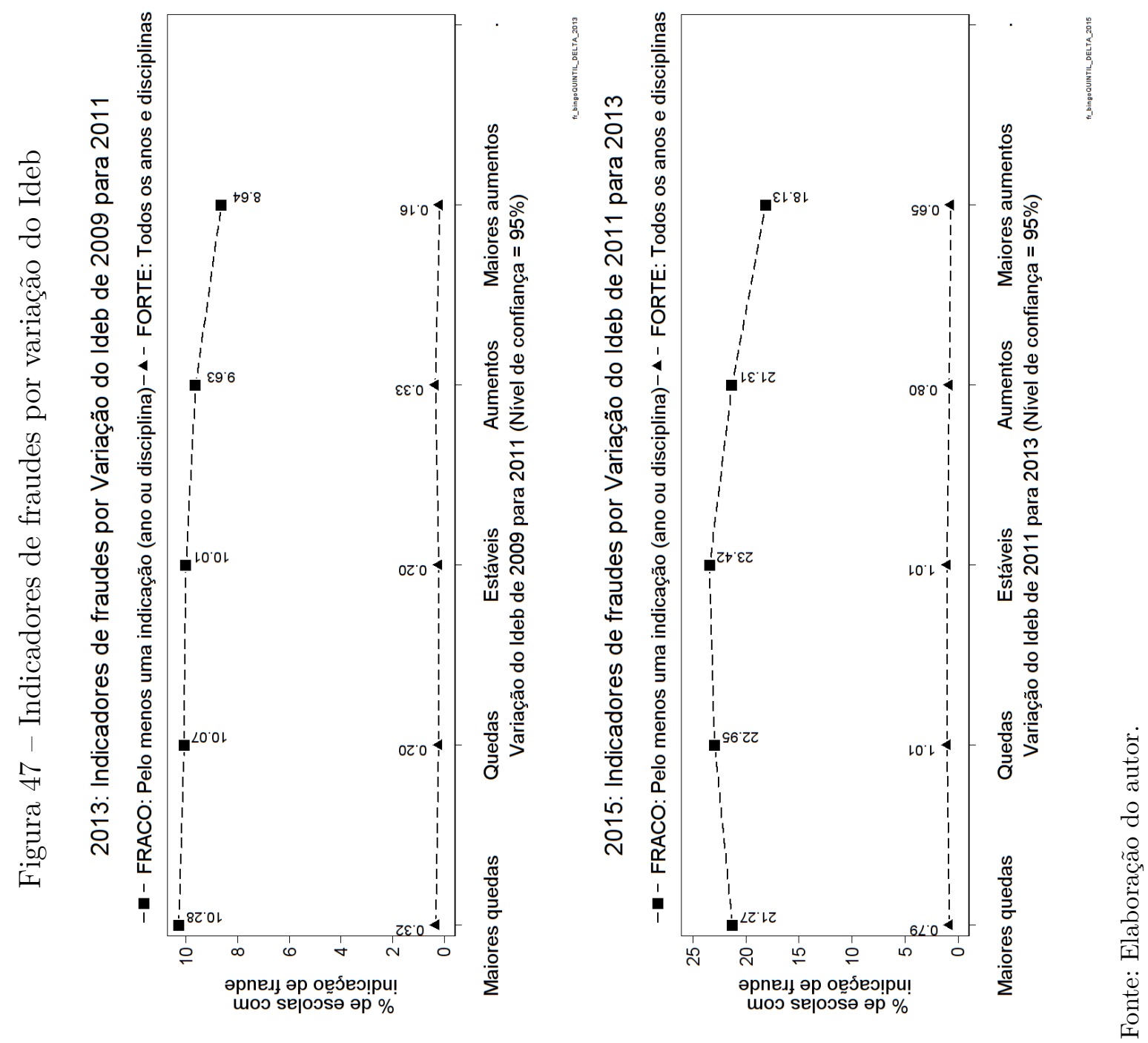


\subsection{Efeitos medidos por distância à meta Ideb}

A pressão induzida pela comparação dos resultados do ano anterior com suas metas está ilustrada na Figura 48. Quanto mais o Ideb aferido na avaliação anterior superar a meta associada, menor resulta a taxa de exclusão na avaliação seguinte, conforme o previsto.

Estes resultados sugerem uma pressão indutora de gaming quando a meta é usada como referência de desempenho, especialmente para o $5^{\circ}$ ano. O efeito no $9^{\circ}$ ano em 2015 , contudo, é menos pronunciado, com exclusões menores que a metade das verificadas para o $5^{\circ}$ ano. ainda que indique exclusões reduzidas no quintil mais alto de superação da meta.

Para este FLAG, como nos casos anteriores, as fraudes seguem o perfil apresentado para as exclusões. A Figura 49 confirma a pouca diferenciação entre intensidades dos gaps, especialmente em 2015. Os declives verificados, ainda que tênues, sugerem que a comparação à meta é mais indutora que a variação histórica do Ideb. 


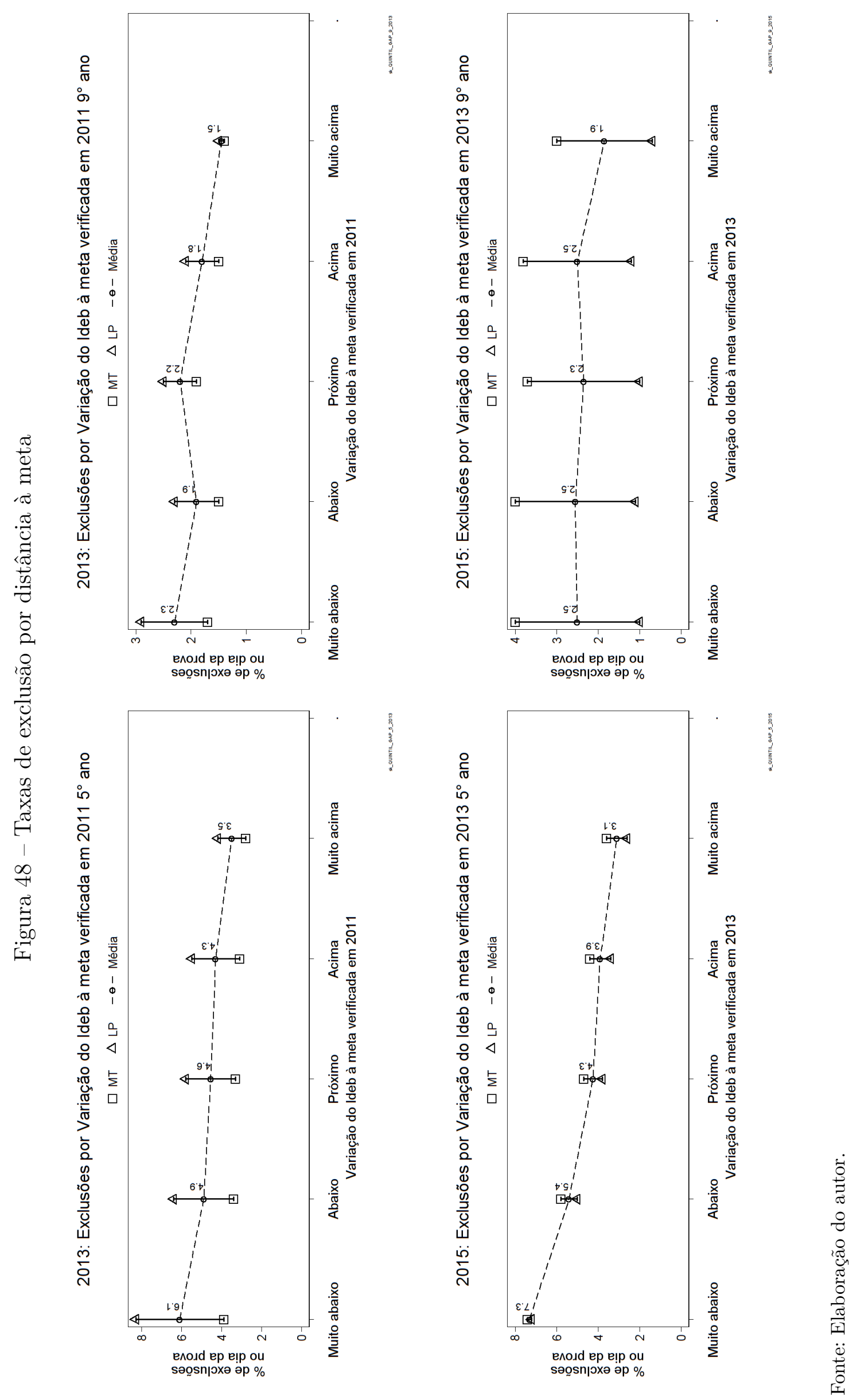



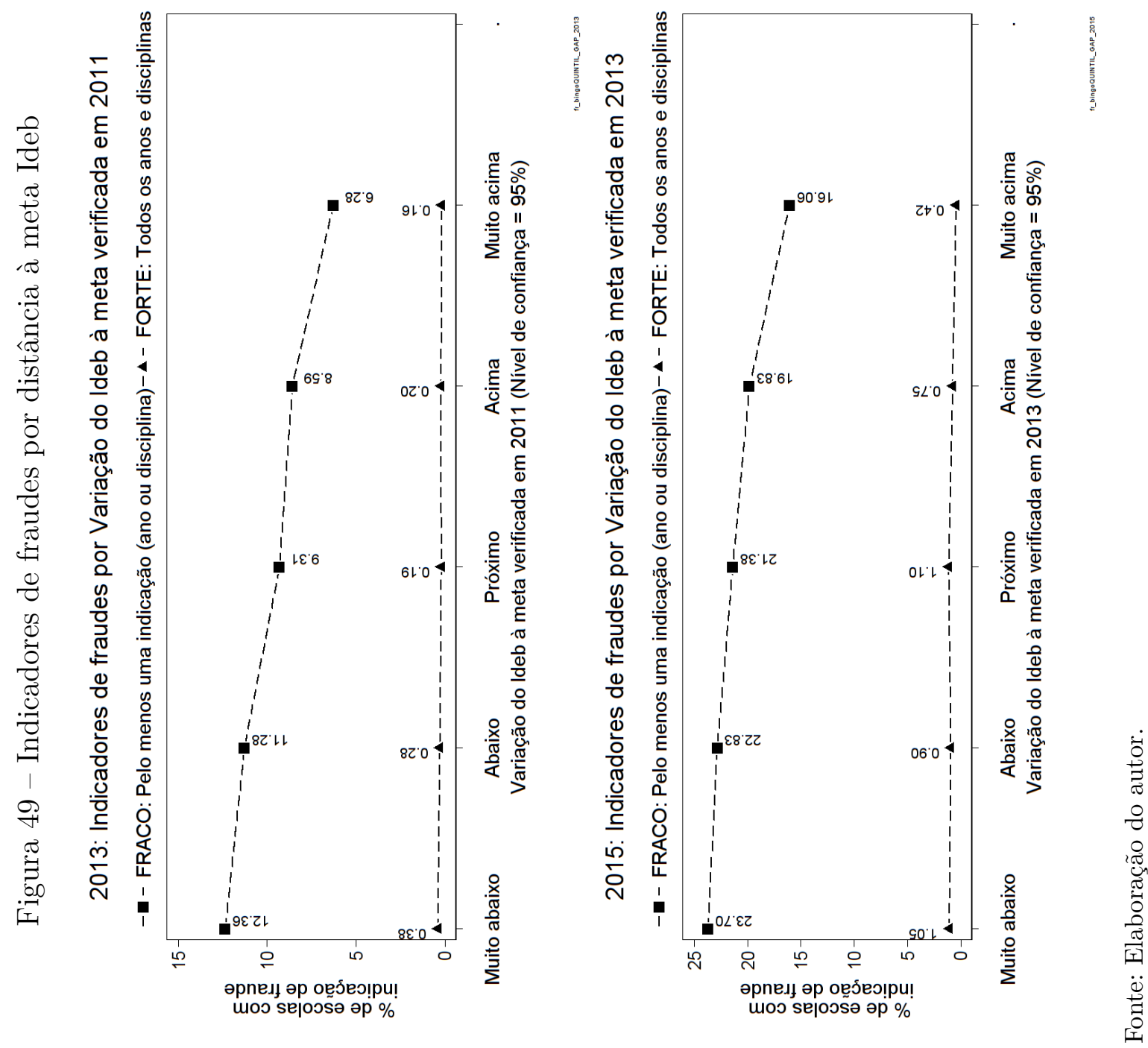


\subsection{Efeitos medidos pela variação no ranking na rede e muni- cípio}

Os resultados para a variação de ranking mostram uma correlação mais fraca com a exclusão, o que é de certa forma esperado em função da construção do FLAG. A informação necessária para a elaboração da variável é mais convoluída, tanto na formulação quanto no dia a dia das escolas. A menos que o ranking seja explicitamente fornecido pelas secretarias locais, sua derivação requer acesso a dados e processamento de outra forma estranhos aos agentes. A Figura 50 registra os resultados das exclusões para variações de ranking na rede e no município.

As variações nas posições dos rankings não parecem ter associações com as exclusões. A fraca influência da variação no ranking nas taxas de exclusão suporta a hipótese de se ter, em geral, gaming não sofisticado: a resposta para o gaming vem de insumos baseados em dados simples, como o Ideb absoluto ou variações contra um histórico ou uma meta.

A Figura 51 mostra um comportamento de fraudes similar ao encontrado para exclusões. Aqui, também, não parece haver indicação de pressão de indução. 


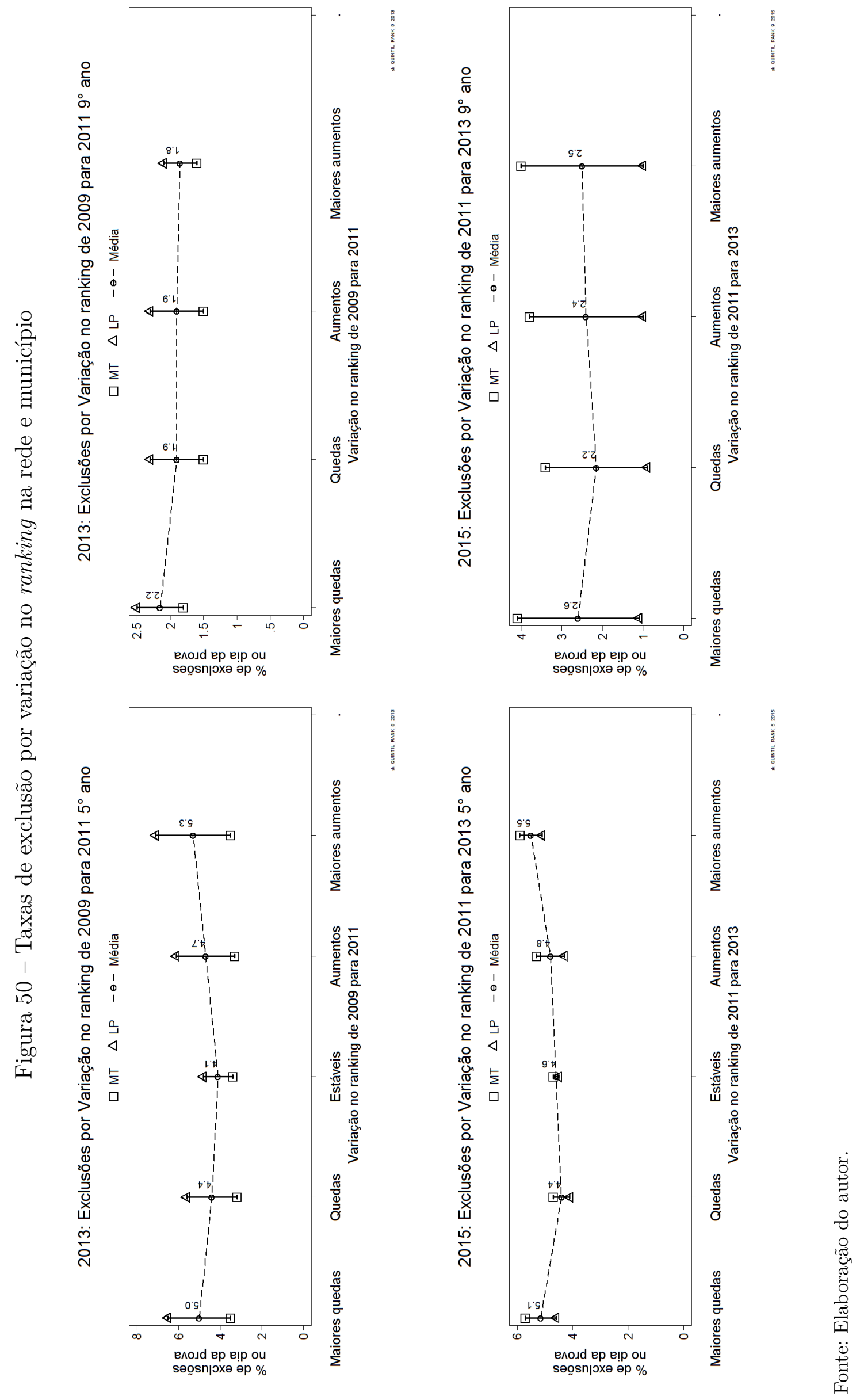



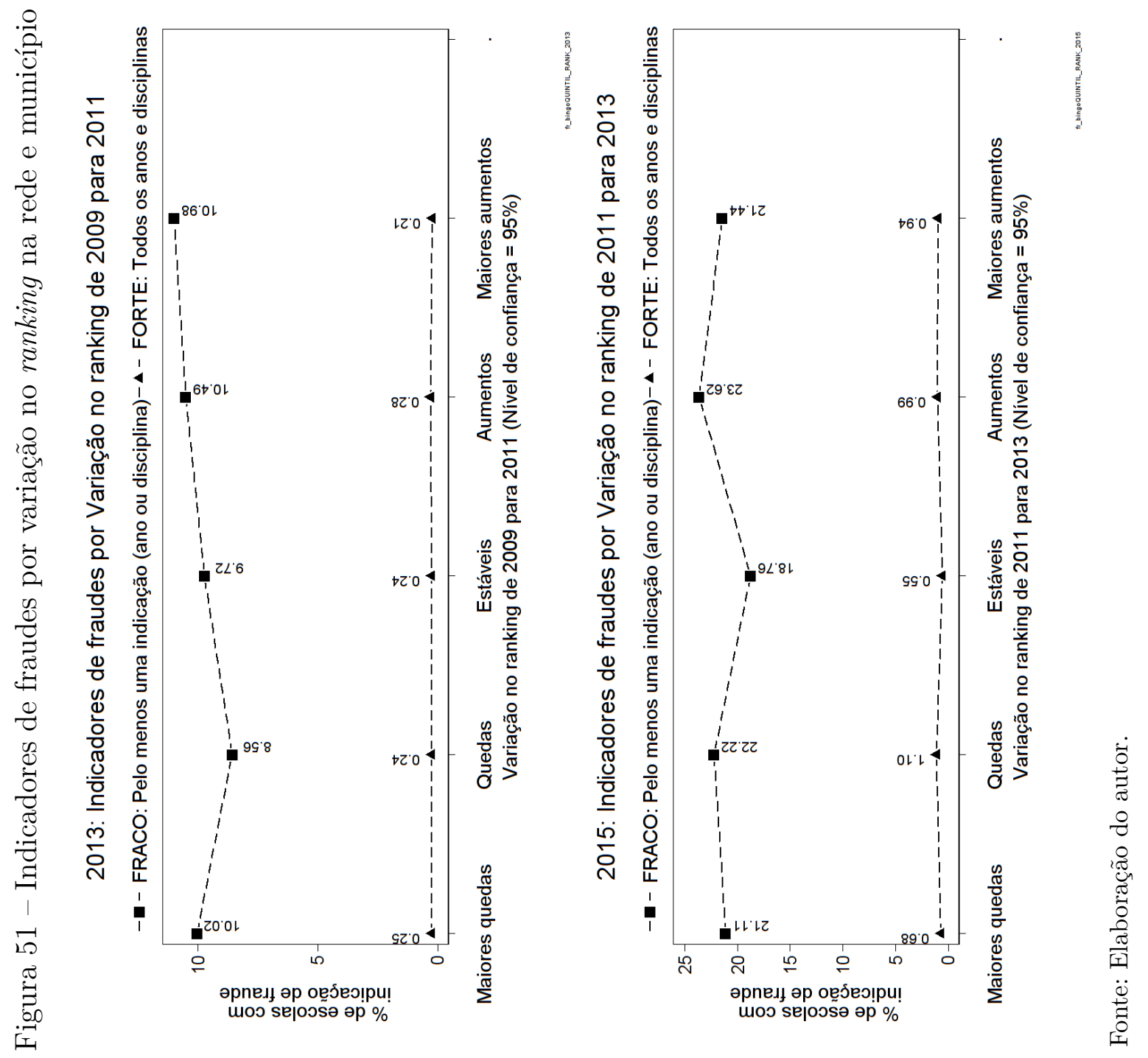


\subsection{Efeitos medidos por reporte ou não do Ideb}

Este FLAG não tem poder de explicação das pressões de indução a priori, pois é calculado com base no resultado publicado do Ideb, posterior à avaliação. Porém, é um sinalizador interessante, dada a facilidade de sua construção e das consequências práticas que podem originar de sua análise.

Escolas sem reporte de Ideb num dado ano apresentam taxas maiores de exclusão neste mesmo ano. Um pedido de "não reporte" requerido por uma secretaria ou escola, ao ser atendido pelo Inep, deveria ser, idealmente, seguido por um questionamento que abordasse fenômenos como os indicados na Figura 52, especialmente nos casos de baixa participação na avaliação ou com indicações de exclusão não aleatória dos alunos de baixa proficiência.

A Figura 53 mostra os indicadores "fracos" e "fortes", com comportamento consistente com o encontrado para exclusões: ambos os efeitos estudados resultam mais intensos nas escolas que não têm o Ideb reportado. É importante lembrar que este indicador não tem poder de previsão, pois associa, aqui, indícios de fraudes ingênuas com o não-reporte do Ideb depois de realizada a prova e avaliados os alunos. 


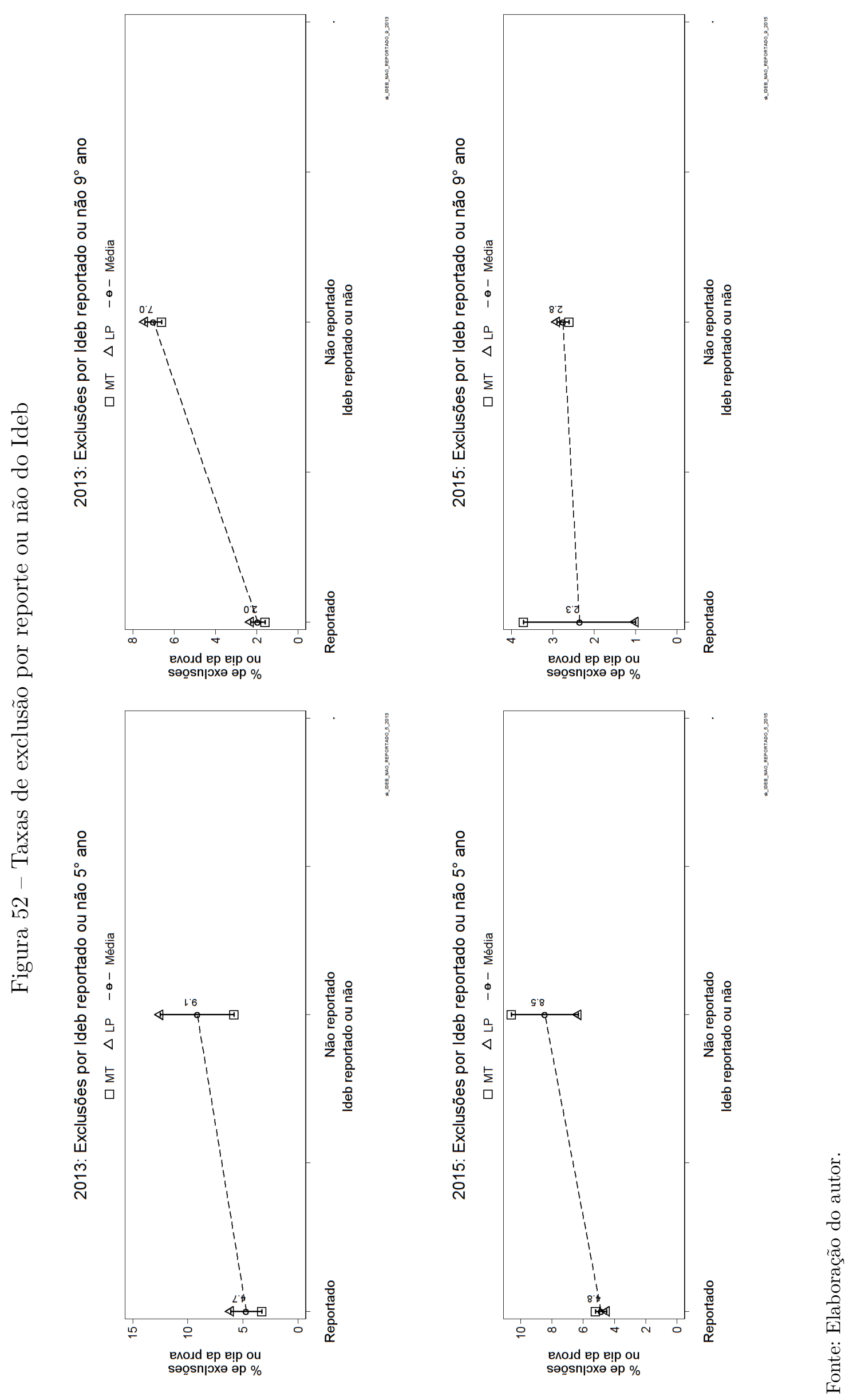



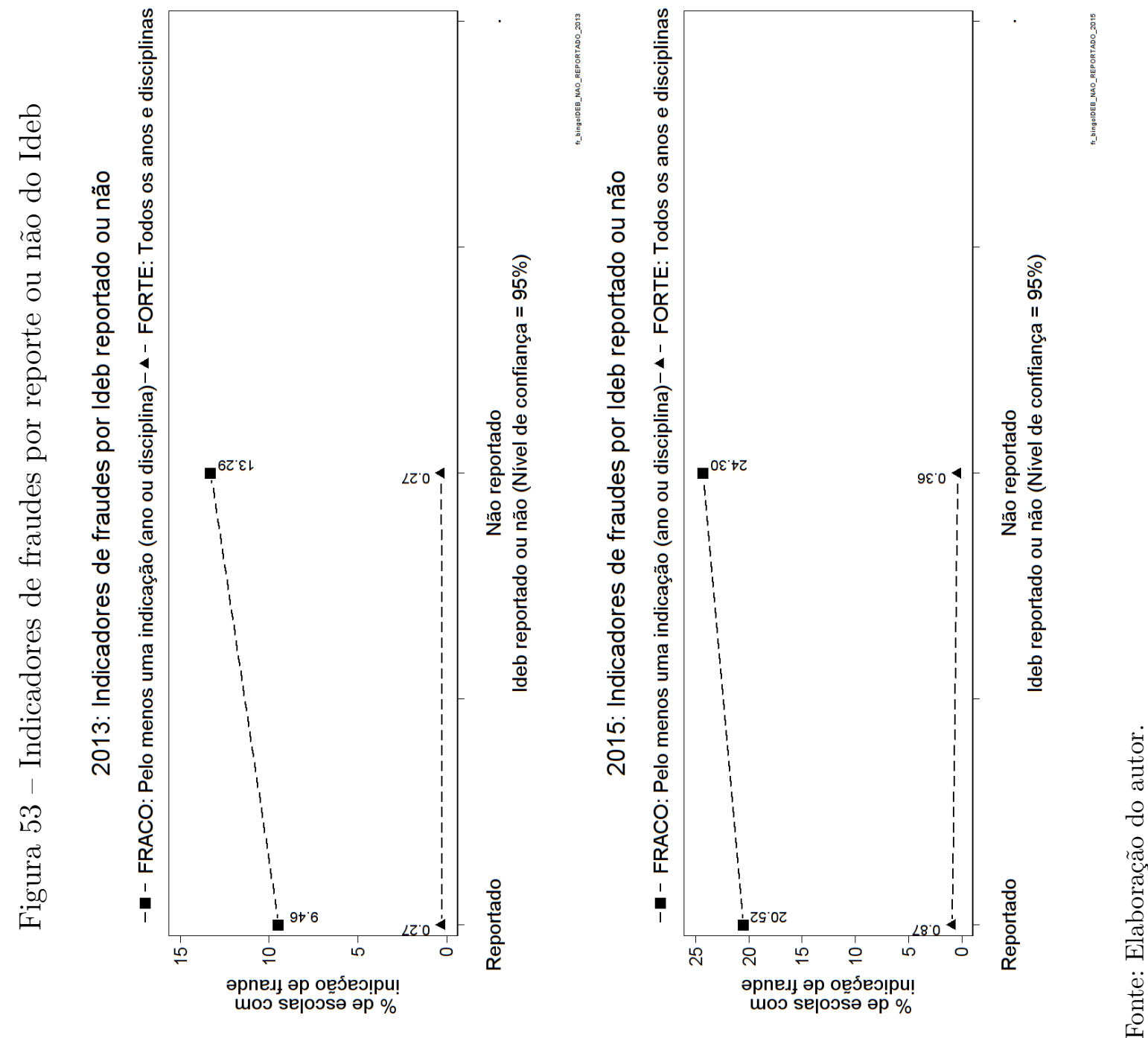


\subsection{Indicadores de fraudes por rede e localização}

As análises indicaram que a localização e a rede administrativa das escolas têm baixa influência nos efeitos medidos. Uma notável exceção é o efeito em fraudes, em 2015, da localização urbana ou rural das escolas. As urbanas, neste ano, tiveram uma incidência relativa de fraudes visivelmente maior que suas contrapartes rurais, como indica a Figura 54. Sem dados mais abrangentes, só é possível conjecturar sobre este efeito.

Figura 54 - Indicadores de fraudes por rede e localização

2013: Indicadores de fraudes por Rede e localização

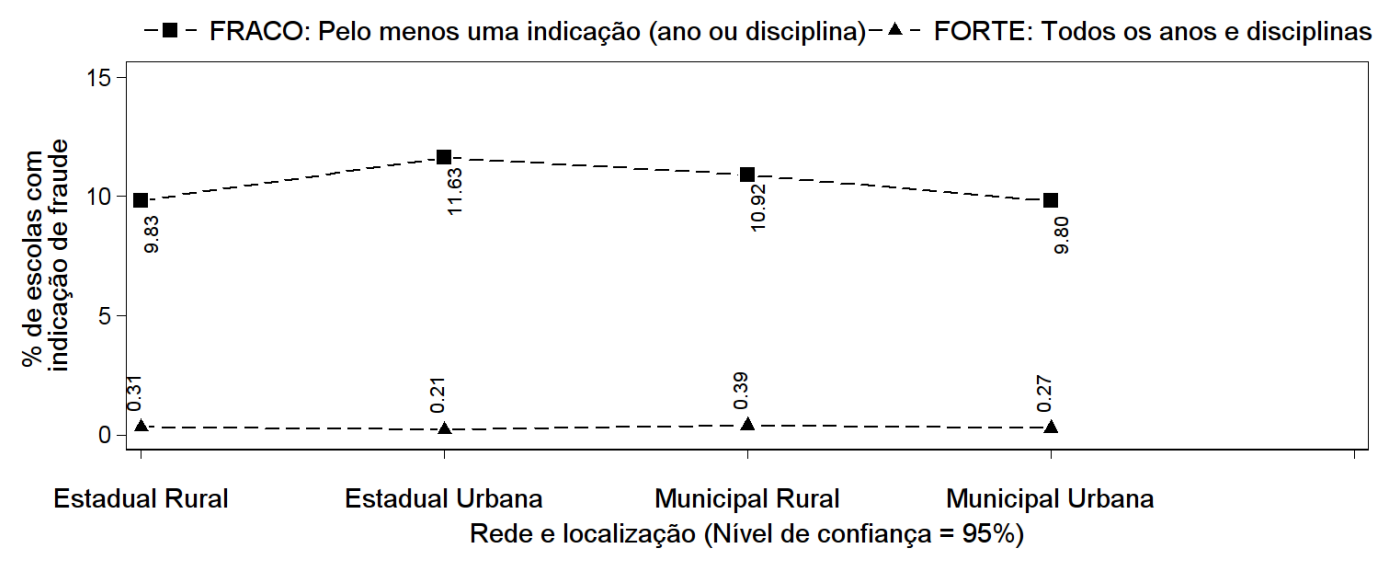

2015: Indicadores de fraudes por Rede e localização

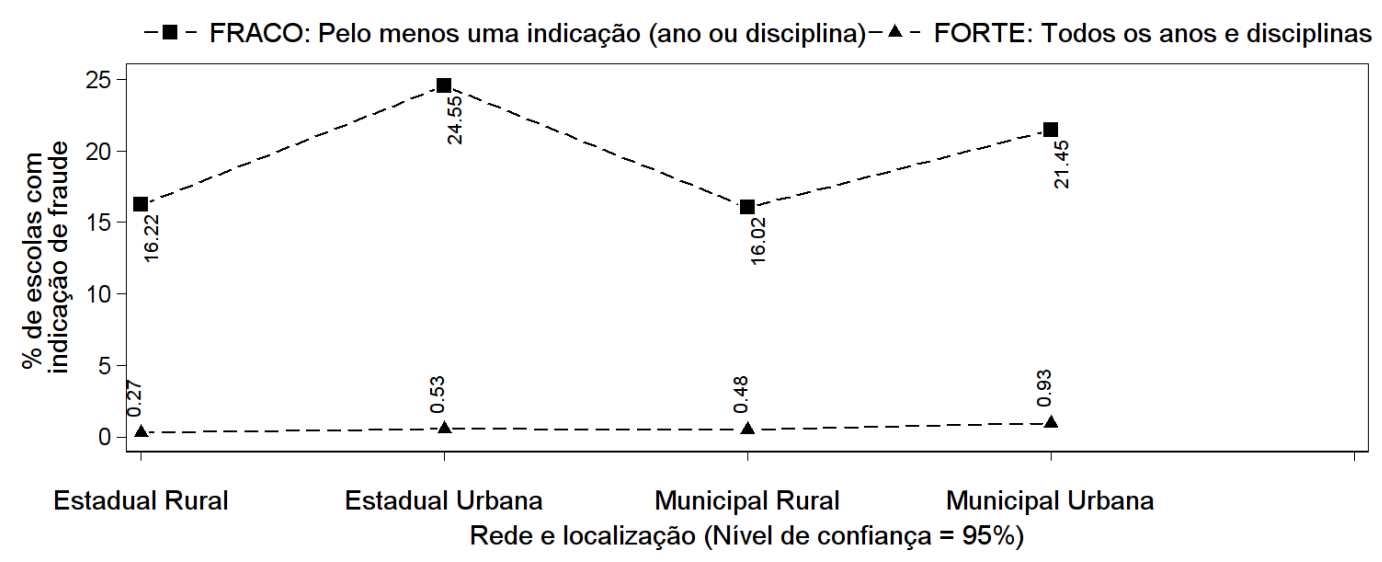

Fonte: Elaboração do autor. 


\subsection{Resultados das modelagens de regressão}

Modelos hierárquicos de regressão linear usados na explicação da associação dos fatores ligados ao gaming às taxas de exclusão de alunos de baixa proficiência estão sintetizados nas Tabelas 8 e 9. Estas tabelas apresentam os coeficientes lineares das componentes fixas e seus p-valores entre parênteses, além das métricas descritivas das regressões ${ }^{5}$. Para os modelos do $5^{\circ}$ ano, as correlações intraclasse (ICC) são da ordem de $80 \%$, indicando que as características hierárquicas do nível 2 (UFs) explicam substancialmente a variabilidade nas taxas de exclusão. Nos modelos do $9^{\circ}$ ano, as ICCs são menores, 32 a 41\%, ainda justificando o uso de modelos hierárquicos, mas indicando que o poder explicativo das diferenças entre UFs é menor na fase final do ensino fundamental.

Tabela 8 - Modelagem hierárquica para exclusão de alunos - $5^{\circ}$ ano

\begin{tabular}{|c|c|c|c|c|}
\hline & \multicolumn{2}{|c|}{$5^{\circ}$ ano 2013} & \multicolumn{2}{|c|}{$5^{\circ}$ ano 2015} \\
\hline \multicolumn{5}{|l|}{$\mathrm{tEx}$} \\
\hline RURAL & 0.0132 & $(0.000)^{* * *}$ & 0.00711 & $(0.003)^{* *}$ \\
\hline ESTADUAL & 0.000955 & $(0.687)$ & -0.00785 & $(0.001)^{* *}$ \\
\hline DOSE & 0.0304 & $(0.000)^{* * *}$ & 0.0269 & $(0.000)^{* * *}$ \\
\hline IDEB & -0.0179 & $(0.000)^{* * *}$ & -0.0240 & $(0.000)^{* * *}$ \\
\hline DELTA & 0.00773 & $(0.071)$ & 0.0125 & $(0.007)^{* *}$ \\
\hline GAP & 0.00596 & $(0.162)$ & 0.00771 & $(0.079)$ \\
\hline ABAIXO_META & 0.00370 & $(0.354)$ & -0.000342 & $(0.936)$ \\
\hline QUEDA_IDEB & 0.00393 & $(0.290)$ & 0.00129 & $(0.740)$ \\
\hline QUEDA_RANK & -0.000777 & $(0.762)$ & -0.00280 & $(0.265)$ \\
\hline Correl. Intraclasse & 0.78 & & 0.87 & \\
\hline$-2^{*} \log *$ verossim & 4511.6 & & 4563.9 & \\
\hline AIC & -9005.2 & & -9097.8 & \\
\hline $\mathrm{BIC}$ & -8949.9 & & -9005.7 & \\
\hline Graus de liberdade & 9 & & 9 & \\
\hline Número de agrupamentos & 3454 & & 3426 & \\
\hline UFs & 27 & & 27 & \\
\hline Mínimo de agrupamentos por UF & 46 & & 56 & \\
\hline Agrupamentos médios por UF & 127.9 & & 126.9 & \\
\hline Máximo de agrupamentos por UF & 226 & & 198 & \\
\hline Convergiu & 1 & & 1 & \\
\hline
\end{tabular}

p-valores entre parênteses: ${ }^{*} \mathrm{p}<0.05^{* *} \mathrm{p}<0.01 * * * \mathrm{p}<0.001$

Fonte: Elaboração do autor.

$\overline{5}$ O Akaike information criterion (AIC) e o Bayesian information criterion (BIC) permitem comparar numericamente a qualidade dos modelos entre si, sendo o valor maior o melhor. A variável Convergiu $=1$ indica que o algoritmo do Stata chegou a um resultado dentro dos limites de convergência. 
Escolas rurais têm taxas de exclusão maiores que suas contrapartes estaduais em todos os modelos, dado o sinal e significância do coeficiente de $R U R A L$. Escolas estaduais não têm exclusão diferente de suas contrapartes municipais, com coeficientes de EST ADU AL não significativos a $95 \%$ de confiança, exceto no modelo do $5^{\circ}$ ano em 2015 , em que a diferença é muito pequena, mas significativa.

Tanto DOSE quanto IDEB resultam significativos e com sinais consistentes com o esperado, para todos os modelos estudados. Quanto maior o tempo de vigência das políticas de bonificação, maiores são as taxas de exclusão. Quanto maior o Ideb absoluto aferido na avaliação anterior, menores são as taxas de exclusão.

Este resultado é importante pois reforça que um mecanismo simples de indução, com base no conhecimento do Ideb anterior, pode estar relacionado à exclusão de alunos de baixa proficiência. A regressão não implica causalidade, mas mostra que há uma correlação forte entre o tipo de política existente na UF, bem como sua longevidade, e um indicador de fácil interpretação, o próprio Ideb.

As variáveis contínuas DELTA e GAP não se mostraram, em geral, significativas nos modelos. A exceção se dá para o $9^{\circ}$ ano em 2015, mas os coeficientes, apesar de significativos, têm sinais contrários ao esperado ${ }^{6}$.

As variáveis dummy $A B A I X O \_M E T A, Q U E D A \_I D E B$ e $Q U E D A \_R A N K$ não são significativas para os modelos do $5^{\circ}$ ano. Isto sugere que nesta etapa o gaming não se dá com a sofisticação, que exigiria o cômputo de variações do Ideb contra históricos ou metas, nem tampouco com considerações de mudanças de rankings.

Para os modelos do $9^{\circ}$ ano, contudo, quedas no Ideb histórico parecem ter influência nas taxas de exclusão, de maneira significativa e consistente com o esperado. Estar abaixo da meta também teve sua influência predita com o sinal correto, ainda que de maneira significativa apenas em 2015. Em outras palavras, uma indicação de existência de pressão indutora leva a um aumento na exclusão medida. Quedas na posição de ranking só se mostraram significativas em 2013. As variáveis dummy ABAIXO_META, $Q U E D A \_I D E B$ e $Q U E D A \_R A N K$ para o $9^{\circ}$ ano, em geral, são significativas mas têm baixa substancialidade ${ }^{7}$, contribuindo com cerca de metade do efeito da variável $R U R A L$.

Ainda que de maneira não contundente, o gaming ocorrido em torno dos alunos do $9^{\circ}$ ano do EF parece ser marginalmente mais sofisticado que aquele associado ao $5^{\circ}$ ano, pela maior sensibilidade a insumos históricos, comparativos a metas e rankings.

6 O esperado é que variações negativas em DELT A e GAP levassem a um aumento no gaming percebido.

7 As substancialidades, ou as forças relativas das variáveis no modelo, podem ser diretamente comparadas, no caso das dummies, devido à natureza binária destas variáveis (0 ou 1). 
Tabela 9 - Modelagem hierárquica para exclusão de alunos - $9^{\circ}$ ano

\begin{tabular}{|c|c|c|c|c|}
\hline \multirow{2}{*}{ tEx } & \multicolumn{2}{|c|}{$9^{\circ}$ ano 2013} & \multicolumn{2}{|c|}{$9^{\circ}$ ano 2015} \\
\hline & & & & \\
\hline RURAL & 0.0257 & $(0.000)^{* * *}$ & 0.0201 & $(0.000)^{* * *}$ \\
\hline ESTADUAL & 0.000150 & $(0.940)$ & -0.00153 & $(0.464)$ \\
\hline DOSE & 0.00693 & $(0.000)^{* * *}$ & 0.00812 & $(0.000)^{* * *}$ \\
\hline IDEB & -0.00717 & $(0.000)^{* * *}$ & -0.00932 & $(0.000)^{* * *}$ \\
\hline DELTA & 0.000836 & $(0.850)$ & 0.0126 & $(0.004)^{* *}$ \\
\hline GAP & -0.00124 & $(0.774)$ & 0.0111 & $(0.006)^{* *}$ \\
\hline ABAIXO_META & 0.00174 & $(0.627)$ & 0.0114 & $(0.004)^{* *}$ \\
\hline QUEDA_IDEB & 0.00876 & $(0.009)^{* *}$ & 0.0114 & $(0.001)^{* *}$ \\
\hline QUEDA_RANK & 0.0125 & $(0.000)^{* * *}$ & 0.000406 & $(0.860)$ \\
\hline Correl. Intraclasse & 0.32 & & 0.41 & \\
\hline$-2^{*} \log *$ verossim & 5005.6 & & 4919.6 & \\
\hline AIC & -9993.2 & & -9805.1 & \\
\hline $\mathrm{BIC}$ & -9937.8 & & -9700.4 & \\
\hline Graus de liberdade & 9 & & 9 & \\
\hline Número de agrupamentos & 3480 & & 3502 & \\
\hline UFs & 27 & & 27 & \\
\hline Mínimo de agrupamentos por UF & 42 & & 44 & \\
\hline Agrupamentos médios por UF & 128.9 & & 129.7 & \\
\hline Máximo de agrupamentos por UF & 228 & & 226 & \\
\hline Convergiu & 1 & & 1 & \\
\hline
\end{tabular}

p-valores entre parênteses: ${ }^{*} \mathrm{p}<0.05{ }^{* *} \mathrm{p}<0.01{ }^{* * *} \mathrm{p}<0.001$

Fonte: Elaboração do autor.

Os resultados dos modelos lineares hierárquicos usados para análise dos indicadores de fraudes estão representados nas Tabelas 10 e 11 para os indicadores "fracos" e 13 e 14 para os indicadores "fortes", em disposição semelhante ao apresentado para os modelos de exclusão já expostos. 
Tabela 10 - Modelagem hierárquica de fraudes pelo indicador FRACO $5^{\circ}$ ano

\begin{tabular}{|c|c|c|c|c|}
\hline \multirow{2}{*}{ FRACO } & \multicolumn{2}{|c|}{$5^{\circ}$ ano 2013} & \multicolumn{2}{|c|}{$5^{\circ}$ ano 2015} \\
\hline & & & & \\
\hline RURAL & -0.0345 & $(0.000)^{* * *}$ & -0.0724 & $(0.000)^{* * *}$ \\
\hline ESTADUAL & 0.0214 & $(0.000)^{* * *}$ & 0.0418 & $(0.000)^{* * *}$ \\
\hline DOSE & 0.0749 & $(0.000)^{* * *}$ & 0.0738 & $(0.000)^{* * *}$ \\
\hline IDEB & -0.0500 & $(0.000)^{* * *}$ & -0.0455 & $(0.000)^{* * *}$ \\
\hline DELTA & 0.0122 & $(0.009)^{* *}$ & -0.00100 & $(0.885)$ \\
\hline GAP & 0.00426 & $(0.317)$ & -0.0114 & $(0.055)$ \\
\hline ABAIXO_META & -0.00280 & $(0.588)$ & -0.0105 & $(0.154)$ \\
\hline QUEDA_IDEB & -0.00631 & $(0.238)$ & -0.0356 & $(0.000)^{* * *}$ \\
\hline QUEDA_RANK & 0.00232 & $(0.556)$ & 0.00387 & $(0.495)$ \\
\hline Correl. Intraclasse & 0.54 & & 0.53 & \\
\hline$-2^{*} \log *$ verossim & -5281.7 & & -15425.4 & \\
\hline AIC & 10595.4 & & 30868.8 & \\
\hline $\mathrm{BIC}$ & 10728.8 & & 30943.5 & \\
\hline Graus de liberdade & 9 & & 9 & \\
\hline Número de escolas & 30898 & & 29618 & \\
\hline UFs & 27 & & 27 & \\
\hline Mínimo de escolas por UF & 80 & & 66 & \\
\hline Escolas médias por UF & 1144.4 & & 1097.0 & \\
\hline Máximo de escolas por UF & 4531 & & 4584 & \\
\hline Convergiu & 1 & & 1 & \\
\hline
\end{tabular}

p-valores entre parênteses: ${ }^{*} \mathrm{p}<0.05^{* *} \mathrm{p}<0.01{ }^{* * *} \mathrm{p}<0.001$

Fonte: Elaboração do autor.

Os modelos da Tabela 10, para alunos do $5^{\circ}$ ano do EF, indicam que escolas rurais têm menos indicações de fraudes que suas contrapartes urbanas, dados os coeficientes negativos e significativos para a dummy $R U R A L$, possivelmente refletindo a presença constante do aplicador ao longo da duração da prova, dada a potencial dificuldade de locomoção entre escolas e impossibilidade de sobrecarregar aplicadores com múltiplos encargos. As escolas estaduais mostram uma maior incidência de fraude que suas contrapartes municipais, também significativas em 2013 e 2015.

A variável DOSE tem coeficiente positivo e significativo, conforme esperado, indicando que quanto mais tempo de exposição à política de bonificação as escolas tiverem, maior é a incidência das fraudes. Os coeficientes negativos e significativos para IDEB indicam que escolas com Idebs maiores têm menores indicadores de fraude. As variáveis $G A P$ e $D E L T A$, contínuas, têm sinais contrários ao esperado, mas em geral não atingem 
nível de confiança de $95 \%$. Isto pode significar que a natureza do gaming não é sofisticada e depende apenas da magnitude do Ideb conhecido e não de comparações históricas (DELTA) ou contra metas $(G A P)$.

Os coeficientes das variáveis dummy ABAIXO_META e QUEDA_IDEB corroboram o exposto acima. O esperado seria ter coeficientes positivos, mas eles aparecem como não significativos (exceto $Q U E D A \_I D E B$ para 2015, com sinal contrário ao esperado). A dummy $Q U E D A \_R A N K$, apesar de ter sinal consistente com o esperado, não resulta significativa, indicando que a sofisticação necessária para incluí-la no gaming é demasiada.

A Tabela 11 repete os modelos descritos acima para alunos do $9^{\circ}$ ano. Escolas rurais têm menos incidência de fraudes, congruente com o modelo para o $5^{\circ}$ ano. Escolas estaduais, por outro lado, mostram uma menor incidência que suas contrapartes no $5^{\circ}$ ano. Esta diferença não é de todo inesperada, por duas hipóteses. Primeiramente, a distribuição de escolas municipais que oferecem os anos finais do ensino fundamental difere das que oferecem os anos iniciais, como pode ser observado na Tabela 12. Portanto, a comparação de rede por série avaliada não se dá sobre bases iguais. Adicionalmente, as fraudes ingênuas refletem sobremaneira a capacidade do aplicador ou professor presente permitir ou induzir "colas". No caso do $9^{\circ}$ ano, o conteúdo avaliado pode, eventualmente, ser menos dominado pelo professor ou avaliador presentes. Desta forma, estes se sentiriam menos confiantes em oferecer respostas aos avaliados. 
Tabela 11 - Modelagem hierárquica de fraudes pelo indicador FRACO $9^{\circ}$ ano

\begin{tabular}{|c|c|c|c|c|}
\hline \multirow{2}{*}{ FRACO } & \multicolumn{2}{|c|}{$9^{\circ}$ ano 2013} & \multicolumn{2}{|c|}{$9^{\circ}$ ano 2015} \\
\hline & & & & \\
\hline RURAL & -0.0701 & $(0.000)^{* * *}$ & -0.108 & $(0.000)^{* * *}$ \\
\hline ESTADUAL & -0.0125 & $(0.009)^{* *}$ & -0.0366 & $(0.000)^{* * *}$ \\
\hline DOSE & 0.0961 & $(0.000)^{* * *}$ & 0.0542 & $(0.000) * * *$ \\
\hline IDEB & -0.0695 & $(0.000)^{* * *}$ & -0.00135 & $(0.773)$ \\
\hline DELTA & 0.00805 & $(0.206)$ & -0.0238 & $(0.006)^{* *}$ \\
\hline GAP & 0.0119 & $(0.053)$ & 0.00281 & $(0.724)$ \\
\hline ABAIXO_META & -0.0117 & $(0.071)$ & 0.0197 & $(0.026)^{*}$ \\
\hline QUEDA_IDEB & -0.00378 & $(0.562)$ & -0.00865 & $(0.326)$ \\
\hline QUEDA_RANK & 0.0133 & $(0.009)^{* *}$ & 0.0228 & $(0.001)^{* * *}$ \\
\hline Correl. Intraclasse & 0.59 & & 0.31 & \\
\hline$-2 * \log *$ verossim. & -7805.7 & & -14455.6 & \\
\hline AIC & 15629.5 & & 28929.1 & \\
\hline $\mathrm{BIC}$ & 15702.6 & & 29001.9 & \\
\hline Graus de liberdade & 9 & & 9 & \\
\hline Número de escolas & 25085 & & 23961 & \\
\hline UFs & 27 & & 27 & \\
\hline Mínimo de escolas por UF & 65 & & 61 & \\
\hline Escolas médias por UF & 929.1 & & 887.4 & \\
\hline Máximo de escolas por UF & 4703 & & 4690 & \\
\hline Convergiu & 1 & & 1 & \\
\hline
\end{tabular}

p-valores entre parênteses: ${ }^{*} \mathrm{p}<0.05^{* *} \mathrm{p}<0.01{ }^{* * *} \mathrm{p}<0.001$

Fonte: Elaboração do autor.

Tabela 12 - Oferta de ensino fundamental por rede administrativa em 2015

\begin{tabular}{lccc}
\hline \multirow{2}{*}{ Escolas (com oferta de...) em 2015 } & \multicolumn{3}{c}{ Rede administrativa } \\
\cline { 2 - 4 } & Estaduais & Municipais & Total \\
\hline ... só anos iniciais & $13,04 \%$ & $86,96 \%$ & $100 \%$ \\
... só anos finais & $75,12 \%$ & $24,88 \%$ & $100 \%$ \\
.. tanto anos iniciais quanto anos finais & $38,38 \%$ & $61,62 \%$ & $100 \%$ \\
\hline Total & $35,24 \%$ & $64,76 \%$ & $100 \%$
\end{tabular}

Fonte: Elaboração do autor. 
As Tabelas 13 e 14 mostram os resultados da modelagem para o indicador "forte", que sinaliza que todas as aplicações de uma dada escola, simultaneamente, acusaram frequências anormais nos blocos impróprios maximizadores.

O indicador "fraco" - aquele que identifica pelo menos uma indicação de fraude por escola - tem quase metade de sua variabilidade explicada pelo nível 2 do modelo: as UFs e suas características de bonificação, como indicado pelas respectivas correlações intraclasse. O indicador "forte", ao contrário, tem quase nenhuma variabilidade explicada pela hierarquia do nível 2 (ICCs nulas ou próximas de zero), indicando que o nível 2 (UFs) e suas variáveis dummy associadas explicam muito pouco da variação encontrada no indicador.

Tabela 13 - Modelagem hierárquica de fraudes pelo indicador FORTE $5^{\circ}$ ano

\begin{tabular}{lrlrl}
\hline \hline & \multicolumn{5}{c}{$5^{\circ}$ ano 2013} & \multicolumn{2}{c}{$5^{\circ}$ ano 2015} \\
\hline FORTE & & & & \\
RURAL & 0.000342 & $(0.704)$ & -0.00829 & $(0.000)^{* * *}$ \\
ESTADUAL & -0.000265 & $(0.713)$ & -0.00218 & $(0.133)$ \\
DOSE & 0.00000871 & $(0.976)$ & 0.00264 & $(0.003)^{* *}$ \\
IDEB & 0.000175 & $(0.388)$ & -0.000547 & $(0.402)$ \\
DELTA & 0.000525 & $(0.513)$ & -0.00142 & $(0.369)$ \\
GAP & 0.000195 & $(0.784)$ & -0.00229 & $(0.085)$ \\
ABAIXO_META & 0.00207 & $(0.018)^{*}$ & -0.000878 & $(0.600)$ \\
QUEDA_IDEB & 0.00103 & $(0.260)$ & -0.00243 & $(0.155)$ \\
QUEDA_RANK & 0.0000498 & $(0.941)$ & 0.00102 & $(0.430)$ \\
\hline Correl. Intraclasse & 0.00 & & 0.03 & \\
-2*log*verossim. & 49044.2 & & 28339.2 & \\
AIC & -98070.4 & & -56660.3 & \\
BIC & -97995.3 & & -56585.6 & \\
Graus de liberdade & 9 & & 9 & \\
Número de escolas & 30898 & & 29618 & \\
UFs & 27 & & 27 & \\
Mínimo de escolas por UF & 80 & & 66 & \\
Escolas médias por UF & 1144.4 & & 1097.0 & \\
Máximo de escolas por UF & 4531 & & 4584 & \\
Convergiu & 1 & & & \\
\hline \hline
\end{tabular}

p-valores entre parênteses: ${ }^{*} \mathrm{p}<0.05{ }^{* *} \mathrm{p}<0.01{ }^{* * *} \mathrm{p}<0.001$

Fonte: Elaboração do autor. 
Tabela 14 - Modelagem hierárquica de fraudes pelo indicador FORTE $9^{\circ}$ ano

\begin{tabular}{lrrrr}
\hline \hline & \multicolumn{3}{c}{$9^{\circ}$ ano 2013} & $9^{\circ}$ ano 2015 \\
\hline FORTE & & & & \\
RURAL & -0.0000666 & $(0.932)$ & -0.000452 & $(0.603)$ \\
ESTADUAL & 0.000830 & $(0.106)$ & 0.00173 & $(0.003)^{* *}$ \\
DOSE & 0.000220 & $(0.168)$ & -0.0000329 & $(0.768)$ \\
IDEB & -0.000148 & $(0.365)$ & -0.000266 & $(0.170)$ \\
DELTA & 0.00100 & $(0.170)$ & -0.00000486 & $(0.995)$ \\
GAP & -0.000357 & $(0.603)$ & 0.00156 & $(0.029)^{*}$ \\
ABAIXO_META & 0.000675 & $(0.358)$ & 0.00297 & $(0.000)^{* * *}$ \\
QUEDA_IDEB & 0.000789 & $(0.287)$ & 0.000444 & $(0.583)$ \\
QUEDA_RANK & 0.000678 & $(0.241)$ & 0.000877 & $(0.163)$ \\
\hline Correl. Intraclasse & 0.00 & & 0.00 & \\
-2*log*verossim. & 46200.1 & & 42355.8 & \\
AIC & -92382.2 & & -84683.6 & \\
BIC & -92309.0 & & -84570.4 & \\
Graus de liberdade & 9 & & 9 & \\
Número de escolas & 25085 & & 23961 & \\
UFs & 27 & & 27 & \\
Mínimo de escolas por UF & 65 & & 61 & \\
Escolas médias por UF & 929.1 & & 4690 & \\
Máximo de escolas por UF & 4703 & & & \\
Convergiu & 1 & & & \\
\hline \hline
\end{tabular}

p-valores entre parênteses: ${ }^{*} \mathrm{p}<0.05^{* *} \mathrm{p}<0.01{ }^{* * *} \mathrm{p}<0.001$

Fonte: Elaboração do autor.

O indicador forte não é bem predito por estes modelos. Os coeficientes das variáveis explicativas resultam não significativos ${ }^{8}$ e não terão seus coeficientes comentados.

8 Isto ocorre mesmo depois de serem testadas opções de rescaling de FORTE para diminuir erros de arredondamento e serem testadas tolerâncias e opções de estimativa de máxima verosimilhança diferentes. Por apresentarem problemas de convergência, as modelagens do indicador "forte" tiveram que ser realizadas usando a opção $\operatorname{cov}($ independent) do comando -mixed-. 


\subsection{Resultados combinados por Unidade da Federação}

Quando se combinam os efeitos indesejados estudados, no nível de UF, para as avaliações de 2013 e 2015 da Prova Brasil, o perfil emergente indica que todas as UFs aumentaram suas incidências de fraude, mas algumas reduziram suas exclusões.

Figura 55 - Variação dos efeitos indesejados por UF 2013-2015

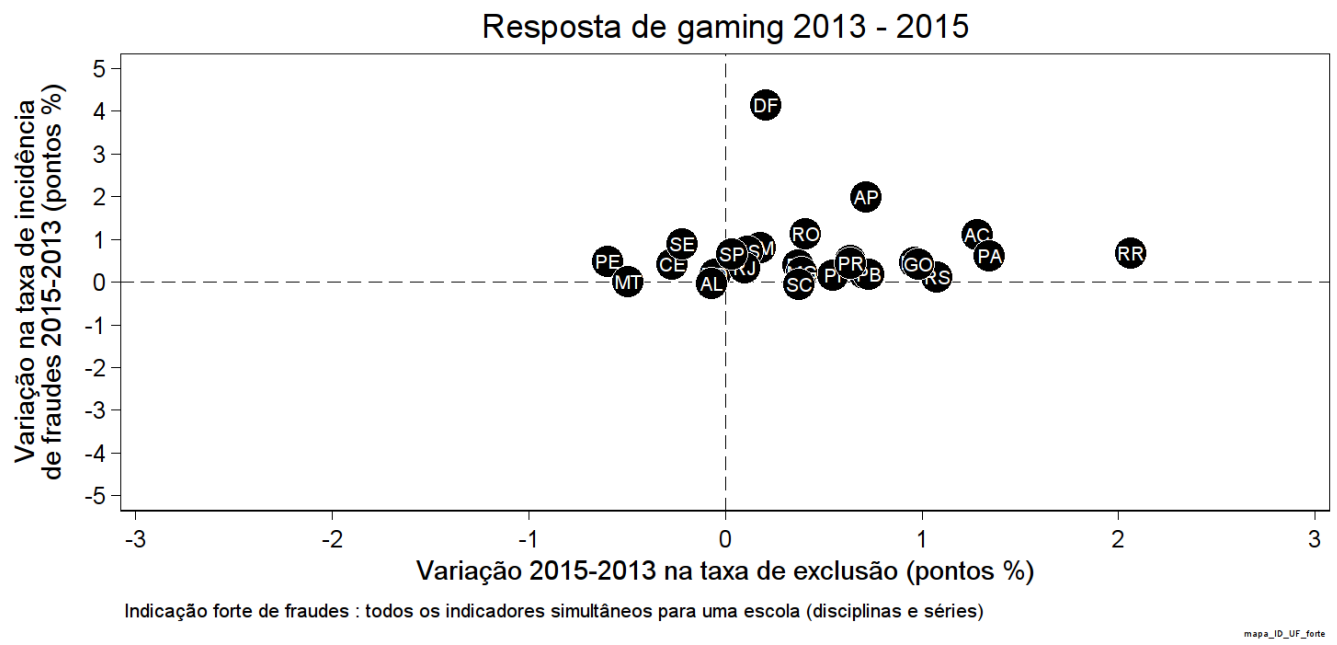

Fonte: Elaboração do autor.

O eixo horizontal da Figura 55 representa a variação de 2013 para 2015 em pontos percentuais na taxa de exclusão de alunos de baixa proficiência, sendo que um valor negativo indica uma redução em 2015 versus 2013. O eixo vertical representa a variação em pontos porcentuais nas frações de escolas que apresentaram fraudes "fortes": todas as variações são positivas, indicando um aumento generalizado deste fenômeno em 2015.

A resposta estratégica às mudanças nos patamares mínimos de participação na Prova Brasil, estado a estado, é consistente com o crescimento generalizado nas indicações de fraudes, com seis estados reduzindo suas taxas de exclusão de alunos de baixa proficiência.

A indicação de fraude ingênua, se constatada para uma dada turma avaliada, leva a um número menor de acertos computados. Isto ocorre porque as respostas marcadas nos cadernos de prova, registradas sob efeito da fraude ingênua, não geram acertos quando corrigidas pelos gabaritos próprios designados pelo Inep ${ }^{9}$. Estas fraudes ingênuas levam, portanto, a proficiências aferidas mais baixas: a turma sob efeito da fraude ingênua apresentará frequências maiores de alunos com baixa proficiência. Este aumento na frequência de baixos desempenhos pode ofuscar a distorção na curva de distribuição de proficiências usada para estimar exclusões. Em outras palavras, o efeito de exclusão pode ser subestimado, se a escola que exclui também pratica, simultaneamente, a fraude ingênua.

$\overline{9}$ A menos das coincidências resultantes da "baixa entropia" explicada à página 115. 



\title{
4 Conclusões: implicações para políticas públicas
}

\author{
"Não importa o quão bonita a sua teoria é, \\ não importa quanto você é inteligente, \\ se sua teoria não concordar com a experiência... está errada!" \\ Richard P. Feynman (1965), tradução nossa.
}

Aqui se retoma a questão de pesquisa. Há evidência empírica do emprego de estratagemas indesejados associados à accountability nas avaliações em larga escala no Brasil?

A resposta parece ser que essa evidência existe, de modo consistente com o indicado em literatura. Dois efeitos colaterais distintos e independentes, usualmente associados às pressões da responsabilização, puderam ser medidos e confrontados com variáveis associadas aos indicadores das pressões. As associações encontradas, evidenciadas tanto graficamente quanto por modelos de regressão, suportam as associações descritas na literatura dos efeitos peiragênicos, tais como descritas por Madaus e Russell (2010).

A partir dos resultados obtidos neste trabalho, pode-se afirmar que a exclusão de alunos de baixa proficiência ocorre, de fato, caracterizando a manipulação da base de estudantes testados na avaliação estudada, a Prova Brasil. Isto tem ressonância nos relatos encontrados na literatura nacional ${ }^{1}$. Sem mecanismos que coíbam a exclusão seletiva de alunos de baixa proficiência ou que compensem esta realidade, as proficiências aferidas sofrem inflação, como indicado por Madaus (1988a), Zlatos (1994) e Koretz (2009).

Para aqueles que conferem recompensas por mérito baseadas neste único resultado, a proficiência discente, emerge a certeza de recompensar sem justiça. Aos que confiam nos resultados de ganhos de proficiência, ou ausência destes, para dispensar políticas de melhoria, há a incerteza de que suas ações tenham focado nos objetivos corretos.

Os alunos excluídos, sujeitos à exclusão "subjetiva” que Freitas menciona (2002), não têm sua voz ouvida, suas necessidades consideradas, seu contexto mapeado. Cabe relembrar que as exclusões são tão mais frequentes quanto menor o nível socioeconômico médio das escolas, possivelmente pautando um caminho indesejado à evasão escolar.

Neste trabalho, as correlações com os fatores ligados ao gaming levam a crer que

1 Financiamento e Prova Brasil em (CAMARGO; PINTO; GUIMARÃES, 2008), Saresp em (ALVES, 2011), avaliações da rede municipal do Rio de Janeiro em (ROSISTOLATO; PRADO; FERNÁNDEZ, 2014; KOSLINSKI; CUNHA; ANDRADE, 2014). 
esta exclusão seja uma resposta das escolas na busca da maximização de suas pontuações no Ideb às custas do afastamento dos alunos mais frágeis e dependentes de políticas de intervenção. A causalidade entre a responsabilização e a exclusão verificada não pode ser atribuída apenas com base nas análises de correlação dos dados observacionais, mas as conclusões a seguir são sustentadas pelas análises ${ }^{2}$.

De acordo com as análises realizadas, a exclusão dos alunos menos proficientes causa uma inflação na proficiência medida. A magnitude desta inflação, medida em desvios padrão, foi estimada por simulação e é apresentada na Figura 56. Em resumo, uma taxa de exclusão de $10 \%$ equivale a uma inflação de 0,23 desvios padrão, correspondente a aproximadamente 10 pontos de acréscimo no escore Saeb, se os alunos forem do $5^{\circ}$ ano. Se os alunos excluídos forem do $9^{\circ}$ ano do EF, a exclusão dos $10 \%$ menos proficientes causa uma inflação de 11,5 pontos Saeb. Grosso modo, cada percentil de exclusão dos alunos menos proficientes leva a um aumento de um ponto na escala Saeb ${ }^{3}$, constituindo um estratagema de crescimento aparente de resultados de "fácil" implementação por parte das escolas, dentro da margem de manobra permitido pela norma da avaliação.

Seguindo este este raciocínio, ganhos reportados nos escores, se acompanhados por aumentos nas taxas de exclusão, são questionáveis dada a inflação potencialmente presente. Cabe um ajuste na proficiência reportada para acomodar este viés, ou a execução de medidas de inibição de ausências. Estas últimas já foram abordadas tanto na literatura quanto na prática. O Prêmio Escola Alfabetizadora do Ceará tinha participação mínima exigida de 98\%, como relatado pelo Inep (2005). Nesta linha, o PNE de 2014 estava correto ao firmar um patamar mínimo de $80 \%$ de participação. Nas análises desta dissertação, as taxas puramente aleatórias de ausência na Prova Brasil resultaram próximas de 85\% para o $5^{\circ}$ ano e de $80 \%$ para o $9^{\circ}$ ano $^{4}$.

Outro caminho já adotado para mitigar as exclusões foi a imputação de proficiências baixas nos casos de ausências elevadas. Conforme Fernandes e Gremaud, "[. . ] ]os programas devem procurar incluir formas de penalizar a exclusão de alunos com baixa proficiência" (2009, p. 224). O município de São Paulo já adotou esta medida para seu Índice de Qualidade da Educação (SERPA, 2011, p. 9), por exemplo. Medidas desta natureza, contudo, só têm efeito se forem vinculadas a ampla e tempestiva comunicação da imputação, constituindo ameaça crível e conhecida pelas escolas.

2 Lembrando que o âmbito deste estudo é a Prova Brasil. Esta avaliação é high-stakes para quatro estados e low-stakes para os demais, quanto à bonificação docente estadual.

3 O eixo vertical à direita está graduado em desvios padrão e os eixos paralelos à esquerda estão na escala de proficiências Saeb, com pontuações para o $5^{\circ}$ e $9^{\circ}$ anos. As escalas Saeb são diferentes para o $5^{\circ}$ e $9^{\circ}$ anos, com suas construções originais em 1997. O $9^{\circ}$ ano, usado como referência na construção original do Saeb em 1995, tem média 250 e desvio padrão 50. O $5^{\circ}$ ano tem média 190,8 e desvio padrão 44. O eixo horizontal é a taxa de exclusão não aleatória no dia da prova, de alunos menos proficientes, modeladas na simulação variando de $0 \%$ a $25 \%$ da turma.

4 As ausências aleatórias são ilustradas pelos tracejados horizontais da Figura 22 à página 98. 
Figura 56 - Inflação de escores causada pela exclusão

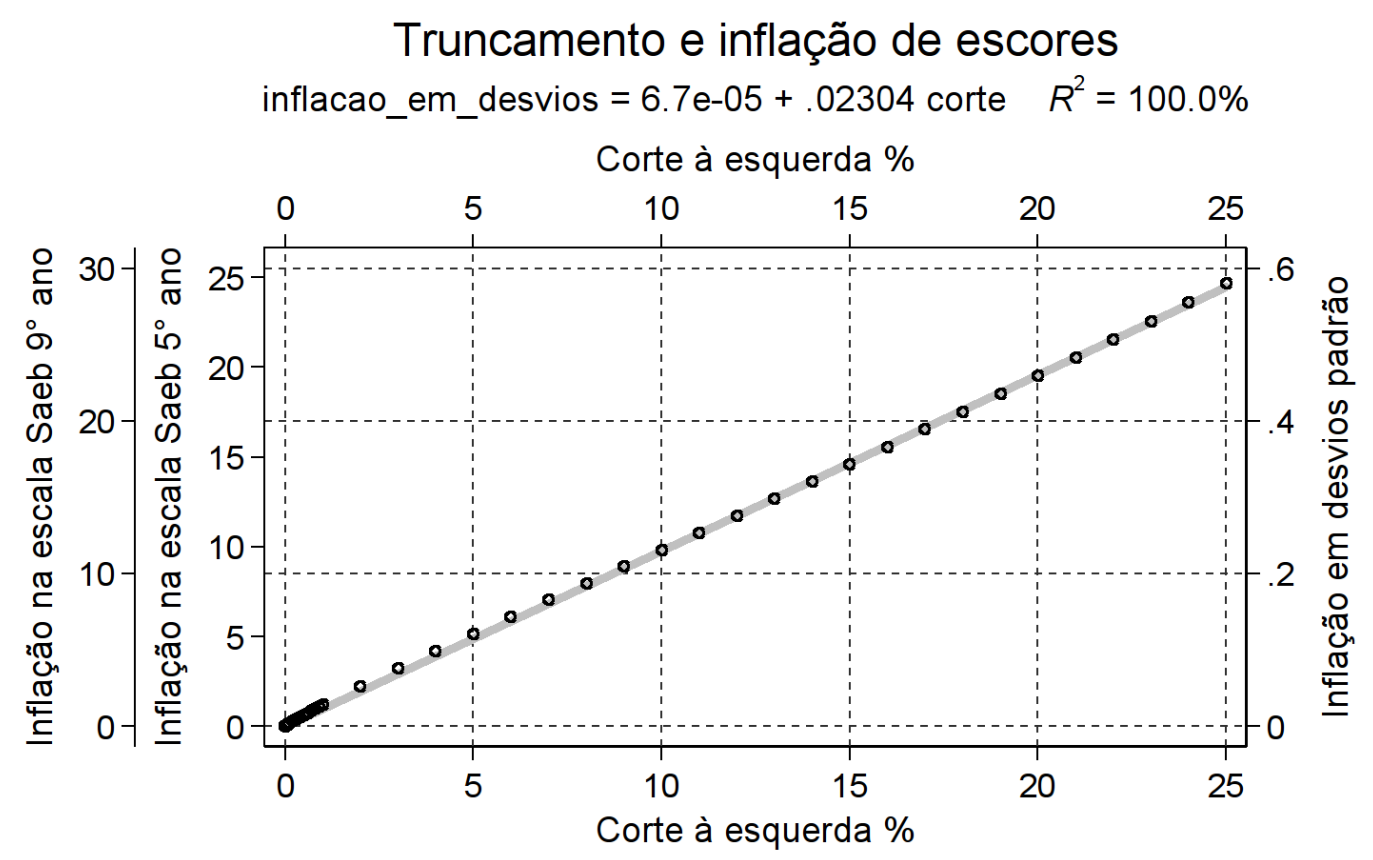

skinner_inflacao_por_corte

Fonte: Elaboração do autor.

A exclusão na Prova Brasil é maior em UFs em que há políticas de bonificação docente que usam esta avaliação como insumo para bonificação, como o Amazonas, Tocantins, Sergipe e Paraíba. A modelagem de regressão confirma que a exclusão nestes estados é tanto maior quanto mais longa for a vigência da política. Os modelos MHL obtidos indicam 2 a 3 pontos porcentuais de aumento da exclusão por ano de vigência para o $5^{\circ}$ ano e 1 a 2 pontos porcentuais para o $9^{\circ}$ ano.

Em contrapartida, a exclusão é menor em UFs em que há políticas de bonificação docente que usam somente avaliações estaduais próprias como insumo para bonificação. Isto leva a crer que a ausência de alunos de baixa proficiência é desincentivada na Prova Brasil. Seria a Prova Brasil (low-stakes no contexto) um treino para as avaliações próprias com high-stakes nestes estados? ${ }^{5}$

Estados que têm bonificações independentes de proficiência discente, como Acre, Goiás e Roraima, conforme classificação de Scorzafave, Ferreira e Dorigan (2014), tiveram medidas baixas para os efeitos colaterais estudados neste trabalho. Este resultado ressoa com a proposta de Berliner e Biddle (1995), que propõem políticas de incentivo que usem como insumo comportamentos registrados dos professores e diretores em vez de medidas de proficiência discente.

As bonificações docentes estaduais não são, aparentemente, as únicas fontes de

5 Ceará, Espírito Santo, Minas Gerais, Pernambuco, Rio de Janeiro e São Paulo. 
pressões indutoras. Mesmo em UFs que não têm estas políticas, encontrou-se exclusão de alta e baixa intensidade. Isto leva a crer que haja outros fatores influenciando os resultados, como por exemplo, incentivos municipais. Estaria o crescimento da exclusão de 2013 para 2015 nas UFs sem bonificação estadual e a diminuição na exclusão nas UFs do Tipo 3 associados à adoção crescente das avaliações municipais (BAUER et al., 2015) e políticas de incentivo a elas atreladas?

A pressão de indução resulta significativa para fenômenos simples como o observação do nível absoluto do Ideb, sob condições de responsabilização forte. Pressões indutoras mais complexas, que resultariam de comparações do Ideb obtido em avaliações anteriores com suas respectivas metas ou progressões históricas, parecem não afetar a exclusão de maneira significativa nem substancial, levando a crer que as respostas estratégicas não são sofisticadas.

O algoritmo proposto para sinalizar fraudes ingênuas, aplicado identicamente para dados de 2013 e 2015, indica um forte crescimento nos indicadores entre uma avaliação e a seguinte, crescendo em quase $100 \%$ em intensidade. Nos resultados de 2013, os indicadores mostram correlações fortes com os fatores empregados para caracterizar as pressões de accountability. Para 2015, a incidência estimada destas fraudes parece ser mais generalizada, afetando igualmente escolas com Ideb e NSE altos e baixos, de maneira menos dependente dos fatores ligados ao gaming escolhidos neste trabalho.

Estas indicações de fraudes ingênuas, obtidas à distância e sem confronto direto com as realidades locais, não podem ser usadas taxativamente em sanções, mas sugerem a necessidade de revisão dos protocolos de aplicação, dos modelos de seleção e alocação de aplicadores e melhor comunicação aos aplicadores e professores presentes sobre quais os comportamentos desejados no dia da avaliação. Se o "colar" for abordado na discussão da aplicação, inclusive com alunos, ressaltando que há múltiplos cadernos de respostas, esta burla poderá ser reduzida.

O aumento medido nas fraudes em 2015 exige alguma consideração adicional, ainda que seja no levantamento de hipóteses. É nesta linha, que se desdobra o raciocício a seguir. O Prova Brasil de 2013 teve um custo aproximado de $\mathrm{R} \$ 275$ milhões, de acordo com os $\operatorname{contratos}^{6}$ firmados entre o Inep e a Fundação Universidade de Brasília e a Moore Brasil. Naquele ano, quase 4,2 milhões de crianças e jovens foram avaliados pela Prova Brasil, a um custo médio por aluno de $\mathrm{R} \$ 65,50$ em valores da época. Este custo unitário, a valores de início de 2017, corrigido pelo Índice Nacional de Preços ao Consumidor Amplo (IPCA), é de $\mathrm{R} \$ 82,00$. Como a Prova Brasil é bianual, este custo resulta em $\mathrm{R} \$ 41,00$ por aluno por ano.

6 Mediante consulta à base de contratos e licitações do Inep (órgão 26290) feita em janeiro de 2017, através do sítio (BRASIL. Ministério da Transparência, Fiscalização e Controladoria-Geral da União, 2017), para licitações 1643236, 1642866 e contrato 246157. 
A Prova Brasil (Anresc) e a Aneb de 2015, licitadas ao consórcio composto pela Universidade Federal de Juiz de Fora, Fundação Cesgranrio e Centro Brasileiro de Pesquisa em Avaliação e Seleção e de Promoção de Eventos, constam como tendo sido valorizadas em $\mathrm{R} \$ 142$ milhões em moeda da época, ou aproximadamente $\mathrm{R} \$ 157$ milhões em valores de janeiro de 2017. Isto equivale a aproximadamente $\mathrm{R} \$ 38,00$ por aluno avaliado ou $\mathrm{R} \$ 19,00$ por aluno por ano. Salvo erro na interpretação destes registros, a aplicação de 2015 parece ter sido realizada com menos da metade do orçamento de 2013. Isto suscita uma dúvida: seria parte desta economia dada às custas de uma contratação insuficiente de aplicadores independentes? Não há, com os dados públicos disponíveis, meios de testar esta hipótese, que poderia ser também uma explicação plausível para o aumento medido nos indicadores de fraudes.

O investimento público direto em educação por estudante é de $\mathrm{R} \$ 6.925,00$ por aluno, conforme reportado pelo Inep (2017), médio para alunos do Ensino Fundamental, a valores de início de $2017^{7}$. Decorre, então, que o custo unitário da Prova Brasil, em geral, corresponde a menos de 0,6\% deste investimento. De qualquer forma, montante relativo não é exorbitante. Parece adequado e mesmo indispensável assegurar uma implementação segundo um protocolo seguro, para dar confiança aos resultados e proteger o investimento feito. Portanto, ter aplicadores capacitados e em número suficiente é fundamental. Em outras palavras, parece ser importante evitar o acúmulo de responsabilidades pelos aplicadores, mesmo que a um custo mais alto, para assegurar sua presença continuada e isenta durante as avaliações.

Este trabalho abordou exclusivamente dois efeitos indesejados das avaliações em larga escala e políticas de responsabilização na educação. Ao longo de sua realização, múltiplas questões sugiram, indicando um amplo campo de pesquisa ainda por ser explorado. Conclui-se com uma série de desdobramentos possíveis para esta investigação:

- Como medir e tratar o estreitamento curricular derivado do "ensinar para o teste" no Brasil?

- Como os efeitos colaterais influenciam a equidade? As políticas de responsabilização mais equitativas podem ser replicadas com sucesso e substituir as demais?

- Como preparar e prover aos professores condições para que se engajem nas três primeiras reações à realização sugeridas por Koretz (ensinar com mais eficácia, por mais tempo, com mais profundidade)?

- O que sente o aluno excluído, da avaliação e do processo escolar como um todo, e como coletar e registrar de maneira representativa este sentimento,

7 É debatível se outras componentes de custo devem ser agregadas, tais como o custo do Censo Escolar ou o custo acumulativo de se criar e manter uma base de itens de prova. 
posto que este aluno está ausente em pontos importantes de captura de informação? Quais tecnologias poderiam ajudar neste processo?

- Como trazer os resultados das avaliações externas para dentro das escolas avaliadas, tornando-os mais formativos que somativos?

As respostas a estas questões, sem dúvida, podem contribuir para que implicações indesejadas das avaliações de larga escala e políticas de responsabilização na educação sejam minimizadas e, em condições ideais, até mesmo eliminadas. 


\section{Referências}

ABEP. Critério de Classificação Econômica Brasil 2013. 2013. Disponível em: $<$ http://www.abep.org/criterio-brasil>. Acesso em: 25 jul. 2014. Citado 3 vezes nas páginas 121, 197 e 198.

ABRAMOWITZ, M.; STEGUN, I. (Ed.). Handbook of mathematical functions: with formulas, graphs, and mathematical tables. New York, NY: Dover Publications, 1964. v. 55. (Applied Mathematics Series, v. 55). ISBN 978-0-486-61272-0. Citado na página 203.

AFONSO, A. J. Para uma conceitualização alternativa de accountability em educação.

Educação \& Sociedade, v. 33, n. 119, p. 471-484, jun. 2012. Disponível em:

$<$ http://repositorium.sdum.uminho.pt/handle/1822/20710>. Acesso em: 30 nov. 2014. Citado 2 vezes nas páginas 40 e 50 .

AGÊNCIA ESTADO. Fraude no Saresp em Sorocaba causa revolta. O Estado de São Paulo, São Paulo, SP. 18 mai, 2012. Disponível em: < http://www.estadao.com.br/noticias/geral, fraude-no-saresp-em-sorocaba-causa-revolta,874635>. Acesso em: 14 mar. 2015. Citado na página 67.

AHN, T. The missing link: estimating the impact of incentives on teacher effort and instructional effectiveness using teacher accountability legislation data. Journal of Human Capital, v. 7, n. 3, p. 230-273, 2013. Disponível em: <http://www.jstor.org/stable/10.1086/673872>. Acesso em: 29 nov. 2014. Citado na página 61.

AHN, T.; VIGDOR, J. The impact of incentives on effort: teacher bonuses in North Carolina. In: Merit Pay: Will It Work? Is It Politically Viable? Cambridge, MA: Program on Education Policy and Governance, 2010. (Program on Education Policy and Governance Working Papers Series.). Disponível em: <http://eric.ed.gov/?q=impact+of+incentives+on+ effort\&id=ED513537>. Acesso em: 18 set. 2016. Citado na página 50.

ALAVARSE, O. M.; BRAVO, M. H.; MACHADO, C. Avaliação como diretriz das políticas educacionais dos governos federal, estaduais e municipais: o caso brasileiro. In: III Congresso Ibero Americano de Política e Administração da Educação. Zaragosa, Espanha: ANPAE, 2012. v. 14. Disponível em: <http://www.anpae.org.br/iberoamericano2012/Trabalhos/ OcimarM.Alavarse_res_int_GT3.pdf $>$. Acesso em: 12 mar. 2014. Citado na página 31.

ALEXANDRE, M. R.; LIMA, R. S. P. d.; WALTENBERG, F. D. Teoria econômica e problemas com remuneração de professores por resultados. Cadernos de Pesquisa, v. 44, n. 151, p. 36-61, mar. 2014. ISSN 0100-1574. Disponível em: <http://www.scielo.br/scielo.php?script= sci_arttext\&pid=S0100-15742014000100003\&lng=pt\&nrm=iso\&tlng=en $>$. Acesso em: 23 jul. 2014. Citado na página 41.

ALKHARUSI, H. Hierarchical linear models: Applications in educational assessment research. Educational Research Journal, v. 26, n. 1, p. 41, 2011. Disponível em: $<$ http://search.informit.com.au/documentSummary; $\mathrm{dn}=506085427767856$;res=IELHSS $>$. Acesso em: 3 abr. 2015. Citado na página 116.

ALVES, C. A. C. Táticas docentes frente aos efeitos do Saresp. Tese (Dissertação de Mestrado) - UNIFESP, Guarulhos, SP, 2011. Disponível em: <http://docs.academicoo.com/ user/caioaca/ALVES,\%20Caio.\%20T\%C3\%A1ticas\%20Docentes\%20frente\%20aos\%20Efeitos\% 
20do\%20SARESP.\%20UNIFESP,\%202011.pdf>. Acesso em: 29 nov. 2014. Citado 5 vezes nas páginas 59, 60, 63, 67 e 163.

AMERICAN INSTITUTE OF INDUSTRIAL ENGINEERS. 1975 Systems Engineering Conference Proceedings. Las Vegas, Nevada: American Institute of Industrial Engineers, 1975. Citado na página 49.

AMREIN, A. L.; BERLINER, D. C. An analysis of some unintended and negative consequences of high-stakes testing. Education Policy Research Unit, Education Policy Studies Laboratory, College of Education, Division of Educational Leadership and Policy Studies, Arizona State University, 2002. Disponível em: <http: //greatlakescenter.org/docs/early_research/pdf/H-S\%20Analysis\%20final.pdf $>$. Acesso em: 18 jun. 2015. Citado 3 vezes nas páginas 31, 39 e 61 .

AMREIN-BEARDSLEY, A.; BERLINER, D. C.; RIDEAU, S. Cheating in the first, second, and third degree: educators' responses to high-stakes testing. Education Policy Analysis Archives, v. 18, n. 14, p. 1-35, 2010. Disponível em: <http://eric.ed.gov/?id=EJ895618>. Acesso em: 29 nov. 2014. Citado 2 vezes nas páginas 51 e 61.

ANDRADE, D. F. d.; TAVARES, H. R.; VALLE, R. da C. Teoria da Resposta ao Item: conceitos e aplicações. São Paulo, SP: ABE, 2000. Citado na página 87.

ANDRADE, E. d. C. "School Accountability" no Brasil: experiências e dificuldades. Revista de Economia Política, v. 28, n. 3, p. 443-453, 2008. Disponível em: $<$ http://www.scielo.br/scielo.php?pid=S0101-31572008000300005\&script=sci_arttext $>$. Acesso em: 4 set. 2014. Citado 2 vezes nas páginas 30 e 31.

AQUINO, J. M. d. Uma ampliação da jornada escolar melhora o desempenho acadêmico dos estudantes? Uma avaliação do programa Escola de Tempo Integral da rede pública do estado de São Paulo. Tese (Doutorado) - Universidade de São Paulo, ago. 2011. Disponível em: <http://www.teses.usp.br/teses/disponiveis/11/11132/ tde-12092011-165425/>. Acesso em: 13 ago. 2014. Citado na página 53.

ARAUJO, L. C. abnTeX2. Brasília, DF: [s.n.], 2015. Disponível em: <http://www.abntex.net. br/>. Acesso em: 26 mar. 2017. Citado na página 209.

AU, W. High-Stakes Testing and Curricular Control: A Qualitative Metasynthesis.

Educational Researcher, v. 36, n. 5, p. 258-267, jan. 2007. ISSN 0013-189X. Disponível em: $<$ http://edr.sagepub.com/content/36/5/258>. Acesso em: 30 nov. 2014. Citado na página 50.

BALLOU, D.; SPRINGER, M. G. Using Student Test Scores to Measure Teacher Performance Some Problems in the Design and Implementation of Evaluation Systems. Educational Researcher, v. 44, n. 2, p. 77-86, 2015. Disponível em: <http://edr.sagepub.com/content/44/ 2/77.short>. Acesso em: 5 mai. 2015. Citado na página 67.

BARBOSA, M. E. F.; FERNANDES, C. Modelo multinível: uma aplicação a dados de avaliação educacional. Estudos em Avaliação Educacional, n. 22, p. 135-154, dez. 2000. ISSN 1984932X. Disponível em: <http://publicacoes.fcc.org.br/ojs/index.php/eae/article/view/2220>. Acesso em: 21 out. 2016. Citado na página 116.

BAUER, A. Usos dos resultados das avaliações de sistemas educacionais: iniciativas em curso em alguns países da América. Revista Brasileira de Estudos Pedagógicos, v. 91, n. 228, p. 315344, 2010. Disponível em: <http://www.rbep.inep.gov.br/index.php/RBEP/article/view/1690>. Acesso em: 25 jun. 2014. Citado 4 vezes nas páginas 28, 45, 46 e 190. 
BAUER, A.; GATTI, B. A. (Ed.). Vinte e cinco anos de avaliação de sistemas educacionais no Brasil - Implicações nas redes de ensino, no currículo e na formação de professores. V. 2. Florianópolis, SC: Editora Insular, 2013. v. 2. (Ciclo de Debates - FCC, v. 2). Disponível em: <http://www.fcc.org.br/institucional/2014/10/21/ ciclo-de-debates-\%E2\%80\%93-25-anos-de-avaliacao-de-sistemas-educacionais-no-brasil/>. Acesso em: 22 out. 2014. Citado na página 49.

BAUER, A. et al. Avaliação em larga escala em municípios brasileiros: o que dizem os números? Estudos em Avaliação Educacional, v. 26, n. 62, p. 326-352, out. 2015. ISSN 1984-932X. Disponível em: <http://publicacoes.fcc.org.br/ojs/index.php/eae/article/view/3207>. Acesso em: 5 nov. 2016. Citado 2 vezes nas páginas 81 e 166 .

BEKMAN, R. M. Aplicação dos Blocos Incompletos Balanceados na Teoria da Resposta ao Item. Estudos em Avaliação Educacional, v. 24, p. 119-137, 2001. Disponível em: $<$ http://www.fcc.org.br/pesquisa/publicacoes/eae/arquivos/990/990.pdf $>$. Acesso em: 7 mai. 2014. Citado na página 103.

BERLINER, D.; BIDDLE, B. The Manufactured Crisis: Myths, Fraud, and the Attack on America's Public Schools. Boston, MA: Addison-Wesley, 1995. ISBN 978-0-201-44196-3. Citado 4 vezes nas páginas 36, 45, 80 e 165 .

BIONDI, R. L. Avaliação econômica da olimpíada brasileira de matemática das escolas públicas (OBMEP). Rio de Janeiro, RJ: [s.n.], 2009. Disponível em: <http: //www.fundacaoitausocial.org.br/_arquivosestaticos/FIS/pdf/obmep_seminario_int.pdf>. Acesso em: 14 mar. 2014. Citado na página 53.

BLACK, S. E. Do Better Schools Matter? Parental Valuation of Elementary Education. The Quarterly Journal of Economics, v. 114, n. 2, p. 577-599, jan. 1999. ISSN 0033-5533, 1531-4650. Disponível em: <http://qje.oxfordjournals.org/content/114/2/577>. Acesso em: 6 set. 2016. Citado na página 46.

BLISS, T. J. Statistical Methods to Detect Cheating on Tests: A Review of the Literature. Tese (Ph.D.) - Brigham Young University, Provo, Utah, 2012. Disponível em: $<$ http://www.ncbex.org/assets/media_files/Research/2012Bliss.pdf > . Acesso em: 6 mar. 2015. Citado na página 60.

BONAMINO, A.; SOUSA, S. Z. Três gerações de avaliação da educação básica no Brasil: interfaces com o currículo da/na escola. Educação e pesquisa, v. 38, n. 2, p. 373-388, 2012. Disponível em: <http://www.scielo.br/pdf/ep/v38n2/aopep633.pdf>. Acesso em: 19 ago. 2014. Citado na página 31.

BOOHER-JENNINGS, J. Below the bubble: "Educational triage" and the Texas accountability system. American educational research journal, v. 42, n. 2, p. 231-268, 2005. Disponível em: < http://aer.sagepub.com/content/42/2/231.short $>$. Acesso em: 18 jun. 2015. Citado 2 vezes nas páginas 34 e 55 .

BORGES, E. M. Avaliações externas em larga escala no contexto escolar: percepção dos diretores escolares da rede estadual de ensino de Minas Gerais. Tese (Doutorado) — UFMG, Belo Horizonte, MG, 2016. Disponível em: $<$ http://www.gestrado.net.br/images/publicacoes/100/Tese_EdnaMartinsBorges.pdf $>$. Acesso em: 5 nov. 2016. Citado na página 35.

BOTELHO, F. B. et al. Sistemas de Accountability nas Escolas Públicas Brasileiras: Identificando a Eficácia das Diferentes Experiências. In: Políticas Públicas Educacionais e Desempenho Escolar dos Alunos da Rede Pública de Ensino. Ribeirão Preto, 
SP: FUNPEC Editora, BNDES, 2014. p. 59-80. ISBN 978-85-7747-087-7. Disponível em: $<$ http://www.bndes.gov.br/SiteBNDES/export/sites/default/bndes_pt/Galerias/Arquivos/ produtos/download/chamada_publica_FEP0410_topico3.pdf $>$. Acesso em: 5 set. 2014. Citado na página 57.

BRASIL. Ministério da Educação. Programa Novo Mais Educação. 2016. Disponível em: $<$ http://portal.mec.gov.br/programa-mais-educacao>. Acesso em: 11 mar. 2017. Citado na página 53.

BRASIL. Ministério da Educação. Instituto Nacional de Estudos e Pesquisas Educacionais Anísio Teixeira. Vencendo o desafio da aprendizagem nas séries iniciais: a experiência de Sobral/CE. Brasília, DF: INEP, Ministério da Educação, 2005. (Série Projeto Boas Práticas na Educação, 1). Citado 2 vezes nas páginas 62 e 164.

. Nota Técnica Indicadores Rendimento. Brasília, DF, 2010. Disponível em:

<http://download.inep.gov.br/download/censo/2010/nota_tecnica_indicadores_rendimento_ 2010.pdf $>$. Acesso em: 5 jan. 2016. Citado na página 119.

Instruções para Aplicação do SAEB 2013. Inep, MEC, 2013. Disponível em:

<http://download.inep.gov.br/educacao_basica/saeb/2013/cartilha_saeb_27set.pdf $>$. Acesso em: 14 mar. 2014. Citado na página 191.

. Portaria $\mathbf{N}^{\circ} 304$ de 21 de junho de 2013. 2013. Disponível em: <http:

//download.inep.gov.br/educacao_basica/prova_brasil_saeb/legislacao/2013/portaria_n304_ saeb_RevFC.pdf $>$. Acesso em: 23 fev. 2017. Citado na página 72.

. Indicador de Nível Socioeconômico das Escolas de Educação Básica (Inse). Brasília, DF, 2014. Disponível em: < http://download.inep.gov.br/mailing/2014/nota_tecnica_ INSE.pdf>. Acesso em: 4 dez. 2014. Citado na página 119.

Nota explicativa resultados Prova Brasil 2013. Brasília, DF, 2014. Disponível em: <http://download.inep.gov.br/mailing/2014/nota_explicativa_prova_brasil_2013.pdf $>$. Acesso em: 19 dez. 2014. Citado na página 118.

Estatísticas do Ideb 2013. 2015. Disponível em: < http://portal.inep.gov.br/web/ portal-ideb/planilhas-para-download $>$. Acesso em: 7 abr. 2015. Citado na página 119.

Instruções para aplicação do Sistema de Avaliação da Educação Básica. 2015. Disponível em: <http://download.inep.gov.br/imprensa/2015/cartilha_saeb2015.pdf > . Acesso em: 20 jan. 2017. Citado na página 191.

Microdados da Aneb e da Anresc (Prova Brasil) - Leia-me. 2015. Citado 2 vezes nas páginas 103 e 118.

Portaria $\mathbf{N}^{\circ} 174$ de 13 de maio de 2015. 2015. Disponível em: < http://download.inep. gov.br/educacao_basica/prova_brasil_saeb/legislacao/2015/portaria_n174_13052015.pdf $>$. Acesso em: 23 fev. 2017. Citado na página 72.

. Cartilha Módulo Situação do Aluno: Conceitos e Orientações. Brasília, DF: DEED/Inep, 2016. (EducaCenso). Disponível em: < http://download.inep.gov.br/educacao basica/educacenso/situacao_aluno/documentos/2015/cartilha_modulo_situacao_do_aluno_ educacenso.pdf $>$. Acesso em: 25 nov. 2016. Citado na página 83.

Resumo Técnico: Resultados do Índice de desenvolvimento da educação básica 2005-2015. Brasília, DF, 2016. Disponível em: <http://download.inep.gov.br/educacao_ basica/portal_ideb/planilhas_para_download/2015/resumo_tecnico_ideb_2005-2015.pdf $>$. Acesso em: 12 jan. 2017. Citado 2 vezes nas páginas 71 e 72. 
Retificação de 29 de julho de 2016, da Portaria $N^{\circ} 174$, de 13 de maio de 2015. 2016. 19 p. Disponível em: < http://pesquisa.in.gov.br/imprensa/servlet/INPDFViewer? jornal $=1 \&$ pagina $=19 \&$ data $=29 / 07 / 2016 \&$ captchafield $=$ firistAccess $>$. Acesso em: 23 fev. 2017. Citado na página 73.

Investimento público direto em educação por estudante em valores reais, por nível de ensino. 2017. Disponível em: $<$ http://portal.inep.gov.br/web/guest/indicadores-financeiros-educacionais/ investimento-publico-direto-em-educacao-por-estudante-em-valores-reais-por-nivel-de-ensino $>$. Acesso em: 4 jan. 2017. Citado na página 167.

BRASIL. Ministério da Transparência, Fiscalização e Controladoria-Geral da União. Transparência Pública. 2017. Disponível em: <http://www.transparencia.gov.br $>$. Acesso em: 20 fev. 2017. Citado na página 166.

BRASIL. Ministério do Planejamento, Orçamento e Gestão. Instituto Brasileiro de Geografia e Estatística IBGE. Tábuas Abreviadas de Mortalidade por Sexo e Idade - Brasil, Grandes Regiões e Unidades da Federação - 2010. Rio de Janeiro, RJ, 2013. Disponível em: < http://www.ibge.gov.br/home/estatistica/populacao/tabuas_abreviadas_mortalidade/ 2010/> . Acesso em: 25 set. 2014. Citado 2 vezes nas páginas 84 e 85.

BRASIL. Presidência da República. Lei № 13.005, de 25 de junho de 2014, Aprova o Plano Nacional de Educação - PNE e dá outras providências. 2014. Disponível em: < http://www.planalto.gov.br/CCIVIL_03/_Ato2011-2014/2014/Lei/L13005.htm>. Acesso em: 10 fev. 2015. Citado 2 vezes nas páginas 73 e 164.

BROOKE, N. O futuro das políticas de responsabilização educacional no Brasil. Cadernos de Pesquisa, v. 36, n. 128, p. 377-401, ago. 2006. ISSN 0100-1574. Disponível em: $<$ http://www.scielo.br/scielo.php?script=sci_abstract\&pid=S0100-15742006000200006\&lng= en\&nrm=iso\&tlng=pt>. Acesso em: 19 dez. 2014. Citado 2 vezes nas páginas 30 e 39.

Responsabilização educacional no Brasil. Revista Iberoamericana de Evaluación Educativa, v. 1, n. 1, p. 93-109, 2008. Disponível em: <http://rinace.net/riee/numeros/ vol1-num1/RIEE-Vol1Num1.pdf\#page $=102>$. Acesso em: 25 set. 2014. Citado 4 vezes nas páginas 27, 30, 34 e 39 .

Incentivos Salariais Baseados em Testes: uma avaliação. Fortaleza, CE: [s.n.], 2011. Disponível em: <http://www.abave.org.br/adm/pdf_upload/10OUTUBRO201110.54. 19380.pdf > . Acesso em: 18 set. 2014. Citado na página 39.

Controvérsias sobre políticas de alto impacto. Cadernos de Pesquisa, v. 43, n. 148, p. 336-347, 2013. Disponível em: <http://www.scielo.br/scielo.php?pid= S0100-15742013000100017\&script=sci_arttext>. Acesso em: 12 mar. 2014. Citado na página 39 .

Políticas estaduais de responsabilização: buscando o diálogo. In: Vinte e cinco anos de avaliação de sistemas educacionais no Brasil - Implicações nas redes de ensino, no currículo e na formação de professores. V. 2. Florianópolis, SC: Editora Insular, 2013. v. 2. Citado 2 vezes nas páginas 39 e 50.

Sobre a equidade e outros impactos dos incentivos monetários para professores. Estudos em Avaliação Educacional, v. 24, n. 55, p. 34-62, 2013. ISSN 0103-6831. Disponível em: $<$ http://publicacoes.fcc.org.br/ojs/index.php/eae/article/view/2719>. Acesso em: 5 nov. 2016. Citado na página 39. 
BROOKE, N.; CUNHA, M. A. A avaliação externa como instrumento da gestão educacional nos estados. Estudos \& Pesquisas Educacionais, v. 2, p. 17-79, 2011. Disponível em: $<$ http://www.educadores.diaadia.pr.gov.br/arquivos/File/pdf/avaliacao_externa_fvc.pdf $>$. Acesso em: 14 mar. 2014. Citado 4 vezes nas páginas 28, 39, 40 e 46.

BROOKE, N.; CUNHA, M. A. d. A.; FALEIROS, M. A avaliação externa como instrumento da gestão educacional nos estados. [S.l.], 2011. Acesso em: 14 mar. 2014. Citado 2 vezes nas páginas 28 e 39 .

BRUnS, B. et al. Paying Teachers to Perform: The Effects of Bonus Pay in Pernambuco, Brazil. Washington, D.C., 2011. Disponível em: < http://siteresources. worldbank.org/EDUCATION/Resources/ppt_paying_teachers_Dec.7.2011.pdf>. Acesso em: 4 set. 2014. Citado 2 vezes nas páginas 28 e 42 .

CALAMUR, K. Jail terms handed to most Atlanta teachers convicted in cheating scandal. NPR, Washington, D.C. 14 abr, 2015. Disponível em: <http://www.npr.org/sections/thetwo-way/ 2015/04/14/399543049/atlanta-teachers-convicted-in-cheating-scandal-await-sentencing > . Acesso em: 20 jul. 2015. Citado na página 37.

CALDERÓN, A. I.; RAQUEL, B. M. G.; CABRAL, E. S. O Prêmio Escola nota 10: meritocracia e cooperação para a melhoria do desempenho escolar. Revista Ensaio: Avaliação e Políticas Públicas em Educação, v. 23, n. 87, p. 517-540, 2015. Disponível em: $<$ http://revistas.cesgranrio.org.br/index.php/ensaio/article/view/743>. Acesso em: 19 jan. 2017. Citado na página 43.

CAMARGO, R. B. d.; PINTO, J. M. d. R.; GUIMARÃES, J. L. Sobre o financiamento no Plano de Desenvolvimento da Educação. Cadernos de pesquisa, v. 38, n. 135, p. 817-839, 2008. Disponível em: < http://www.scielo.br/pdf/cp/v38n135/v38n135a14.pdf>. Acesso em: 17 jul. 2015. Citado 2 vezes nas páginas 63 e 163.

CAMERON, W. B. Informal sociology: a casual introduction to sociological thinking. New York, NY: Random House, 1963. (Studies in Sociology, 21). Citado na página 9.

CAMPBELL, D. T. Assessing the Impact of Planned Social Change. [S.1.], 1976.

Disponível em: < https://www.globalhivmeinfo.org/CapacityBuilding/Occasional\%20Papers/ 08\%20Assessing\%20the\%20Impact\%20of\%20Planned\%20Social\%20Change.pdf $>$. Acesso em: 25 mai. 2015. Citado 2 vezes nas páginas 33 e 49.

CAMPOS, A. M. Accountability: quando poderemos traduzi-la para o português? Revista de Administração Pública, v. 24, n. 2, p. 30-50, abr. 1990. Disponível em: $<$ http://admsp20061. wikispaces.com/file/view/Accountability-+Quando+poderemos+ traduzi-la+par+o+portugu\%C3\%AAs+-+Anna+Maria+Campos.pdf $>$. Acesso em: 29 mar. 2015. Citado na página 40.

CANnelL, J. J. How Public Educators Cheat on Standardized Achievement Tests: The "Lake Wobegon"Report. Albuquerque, NM, 1989. Disponível em: $<$ http://eric.ed.gov/?id=ED314454>. Acesso em: 2 jul. 2016. Citado na página 33.

CARVAlhO, C. P. d.; OliveiRA, A. C. P. d.; LiMA, M. d. F. M. d. Avaliações externas: tensões e desafios para a gestão escolar. Estudos em Avaliação Educacional, v. 25, n. 59, p. 50-76, out. 2014. ISSN 1984-932X. Disponível em: < http://publicacoes.fcc.org.br/ojs/index. php/eae/article/view/2856>. Acesso em: 1 abr. 2015. Citado na página 34.

CASSETTARI, N. Principais modelos de remuneração por desempenho para professores no Brasil. In: Congresso ibero-americano de política e administração da educação. 
[s.n.], 2012. v. 3. Disponível em: <http://www.anpae.org.br/iberoamericano2012/Trabalhos/ NathaliaCassettari_res_int_GT2.pdf $>$. Acesso em: 1 abr. 2015. Citado 2 vezes nas páginas 79 e 80 .

CASTRO, M. H. G. A consolidação da política de avaliação da educação básica no Brasil. Revista Meta: Avaliação, v. 1, n. 3, p. 271-296, 2009. Disponível em: $<$ http://metaavaliacao.cesgranrio.org.br/index.php/metaavaliacao/article/viewArticle/51>. Acesso em: 30 nov. 2014. Citado na página 30.

CERDEIRA, D. G. d. S.; ALMEIDA, A. B. d.; COSTA, M. d. Indicadores e avaliação educacional: percepções e reações a políticas de responsabilização. Estudos em Avaliação Educacional, v. 25, n. 57, p. 198-255, jul. 2014. ISSN 1984-932X. Disponível em: <http://publicacoes.fcc.org. $\mathrm{br} / \mathrm{ojs} /$ index.php?journal $=$ eae\&page $=$ article\&op $=$ view $\&$ path $\% 5 \mathrm{~B} \% 5 \mathrm{D}=2845>$. Acesso em: 6 set. 2014. Citado 2 vezes nas páginas 30 e 59.

CHAKRABARTI, R.; SCHWARTZ, N. Unintended consequences of school accountability policies: evidence from Florida and implications for New York. Economic Policy Review, v. 19, n. 1, 2013. Disponível em: <http://www.ny.frb.org/research/epr/2013/0513chak.pdf>. Acesso em: 5 set. 2014. Citado na página 63.

Chico Buarque. Até o Fim. Rio de Janeiro, RJ: Polygram, 1978. Citado na página 39.

CIZEK, G. J. Cheating on tests: how to do it, detect it, and prevent it. Mahwah, New Jersey: Lawrence Erlbaum Associates, Inc., 1999. ISBN 0-8058-3145-2. Disponível em: $<$ http://eric.ed.gov/?id=ED435699>. Acesso em: 25 abr. 2015. Citado 2 vezes nas páginas 60 e 64 .

Cheating to the Test. Education Next, v. 1, n. 1, 2001. Disponível em: $<$ http://educationnext.org/cheatingtothetest/>. Acesso em: 13 jul. 2015. Citado 3 vezes nas páginas 49, 60 e 65 .

More unintended consequences of high-stakes testing. Educational Measurement: Issues and Practice, v. 20, n. 4, p. 19-27, dez. 2001. ISSN 1745-3992. Disponível em: $<$ http://onlinelibrary.wiley.com/doi/10.1111/j.1745-3992.2001.tb00072.x/abstract>. Acesso em: 11 mai. 2015. Citado na página 65.

COWEN, T.; TABARROK, A. Modern Principles of Economics. Third edition. New York, NY: Worth Publishers, 2014. ISBN 978-1-4292-7839-3. Citado na página 32.

CROCCO, M. S.; COSTIGAN, A. T. The Narrowing of Curriculum and Pedagogy in the Age of Accountability Urban Educators Speak Out. Urban Education, v. 42, n. 6, p. 512-535, nov. 2007. ISSN 0042-0859. Disponível em: <http://uex.sagepub.com/cgi/doi/10.1177/0042085907304964>. Acesso em: 6 mar. 2015. Citado na página 58.

CUllEN, J. B.; REBACK, R. Tinkering Toward Accolades: School Gaming Under a Performance Accountability System. [S.l.], 2006. Disponível em: < http: //www.nber.org/papers/w12286>. Acesso em: 11 set. 2014. Citado na página 62.

DARLING-HAMMOND, L. Standards, accountability, and school reform. The Teachers College Record, v. 106, n. 6, p. 1047-1085, 2004. Disponível em: <http: //www.tcrecord.org/Content.asp?ContentId=11566>. Acesso em: 2 nov. 2015. Citado na página 41.

DEE, T. S.; JACOB, B. The impact of No Child Left Behind on student achievement. Journal of Policy Analysis and Management, v. 30, n. 3, p. 418-446, 2011. Disponível em: 
<http://onlinelibrary.wiley.com/doi/10.1002/pam.20586/full>. Acesso em: 18 jun. 2016. Citado na página 55.

DEE, T. S.; JACOB, B. A. The impact of No Child Left Behind on students, teachers, and schools. Brookings Papers on Economic Activity, p. 149-207, 2010. Disponível em: <http://www.jstor.org/stable/41012846>. Acesso em: 18 jun. 2016. Citado na página 55.

DEE, T. S.; JACOB, B. A.; MCCRARY, J. Manipulation in the Grading of New York's Regents Examinations. 2011. Disponível em: <http://eml.berkeley.edu/ jmccrary/Dee Jacob_McCrary2011.pdf $>$. Acesso em: 5 set. 2014. Citado na página 66.

DEMATTHEWS, D. E. Looks like 10 miles of bad road cheating, gaming, mistrust, and an interim principal in an urban Texas high school. Journal of Cases in Educational Leadership, v. 17, n. 4, p. 19-33, 2014. Disponível em: < http://jel.sagepub.com/content/17/4/19.short>. Acesso em: 6 mar. 2015. Citado na página 55.

DOYLE, A. C. The Crime of the Congo. 4th. ed. London, UK: Hutchinson \& Co., 1909. Citado na página 32 .

EE SANTA TEREZINHA. Escola Estadual Santa Terezinha Lagoa Grande - MG: Fixação da Placa do IDEB. 12 feb. 2013. Disponível em: < http://eesantaterezinhalg. blogspot.com.br/2013/02/fixacao-da-placa-do-ideb.html>. Acesso em: 5 nov. 2016. Citado na página 29.

ELLIOTT, S. W.; HOUT, M. Incentives and test-based accountability in education. Washington, D.C.: National Academies Press, 2011. Citado 4 vezes nas páginas 28, 42,43 e 50.

ESPAÇO DO SERVIDOR. SAEB 2013. 2013. Disponível em: < https://www.youtube.com/ watch? $\mathrm{v}=\mathrm{yB} 6 \mathrm{p} 1 \mathrm{AYnmxs} \&$ feature=youtu.be $>$. Acesso em: 20 jan. 2017. Citado na página 191.

FAUSSET, R.; BLINDER, A. Atlanta school workers sentenced in test score cheating case. 15 abr. 2015. Disponível em: < http://www.nytimes.com/2015/04/15/us/ atlanta-school-workers-sentenced-in-test-score-cheating-case.html?nytmobile $=0>$. Acesso em: 18 jun. 2015. Citado na página 37.

FENSTERMACHER, G. D. Assessment Explained. Briefs. The Newsletter of the American Association of Colleges of Teacher Education, nov. 1991. Citado 2 vezes nas páginas 27 e 36 .

FERNANDES, R. Índice de desenvolvimento da educação básica (IDEB). Brasília, DF, 2007. 26 p. ISSN 1414-0640. Disponível em: <http://escoladegestores.mec.gov.br/site/6-sala topicos_especiais_pne/textos_links/ideb.pdf $>$. Acesso em: 16 jul. 2014. Citado 2 vezes nas páginas 31 e 139.

FERNANDES, R.; GREMAUD, A. P. Qualidade da educação básica: avaliação, indicadores e metas. In: VELOSO, F. (Ed.). Educação básica no Brasil: construindo o país do futuro. Rio de Janeiro: Elsevier, 2009. Disponível em: <http://www.cps.fgv.br/ibrecps/rede/seminario/ reynaldo_paper.pdf>. Acesso em: 20 jun. 2016. Citado 3 vezes nas páginas 40, 51 e 164 .

FERnANDES, R. et al. (Ed.). Políticas Públicas Educacionais e Desempenho Escolar dos Alunos da Rede Pública de Ensino. Ribeirão Preto, SP: FUNPEC Editora, BNDES, 2014. ISBN 978-85-7747-087-7. Disponível em: < http://www.bndes.gov.br/SiteBNDES/export/ sites/default/bndes_pt/Galerias/Arquivos/produtos/download/aep_fep/chamada_publica_ FEP0410_Politicas_Publicas_BNDES.pdf $>$. Acesso em: 7 jan. 2016. Citado na página 57. 
FERRÃO, M. E. Introdução aos modelos de regressão multinível em educação. Campinas, SP: Komedi, 2003. ISBN 978-85-7582-012-4. Citado na página 116.

FEYNMAN, R. P. The Character of Physical Law. Cornell University, NY: BBC, 1965. ISBN 0-679-60127-9. Citado na página 163.

FIGLIO, D. N. Testing, crime and punishment. Cambridge, MA, 2005. Disponível em: < http://www.nber.org/papers/w11194>. Acesso em: 17 jul. 2015 . Citado na página 62.

FIGLIO, D. N.; GETZLER, L. S. Accountability, ability and disability: Gaming the system. [S.l.], 2002. Disponível em: < http://www.nber.org/papers/w9307>. Acesso em: 5 set. 2014. Citado na página 62.

FIGLIO, D. N.; LOEB, S. School Accountability. In: HANUSHEK, E. A.; MACHIN, S.; WOESSMANN, L. (Ed.). Handbook of the economics of education. Vol. 3. 1. ed. ed. Amsterdam: North-Holland, 2011, (Handbooks in economics). ISBN 978-0-444-53429-3. Disponível em: < https://cepa.stanford.edu/sites/default/files/Accountability_Handbook.pdf > . Citado 2 vezes nas páginas 28 e 40.

FIGLIO, D. N.; LUCAS, M. E. What's in a grade? School report cards and the housing market. American Economic Review, v. 94, n. 3, p. 591-604, jun. 2004. ISSN 0002-8282. Disponível em: < https:/ www.aeaweb.org/articles?id=10.1257/0002828041464489>. Acesso em: 6 set. 2016. Citado na página 46.

FIRESTONE, W. A.; MAYROWETZ, D.; FAIRMAN, J. Performance-Based Assessment and Instructional Change: The Effects of Testing in Maine and Maryland. Educational Evaluation and Policy Analysis, v. 20, n. 2, p. 95-113, 1998. ISSN 0162-3737. Acesso em: 5 jan. 2016. Citado na página 46.

FREITAS, L. C. d. A internalização da exclusão. Educação \& Sociedade, v. 23, n. 80, p. 299 325, 2002. Disponível em: <http://www.scientificcircle.com/pt/89535/internalizacao-exclusao/>. Acesso em: 26 set. 2014. Citado 2 vezes nas páginas 64 e 163.

Apresentação. Educação \& Sociedade, v. 33, n. 119, jun. 2012. Citado na página 50.

Caminhos da Avaliação de Sistemas Educacionais no Brasil: o Embate entre a Cultura da Auditoria e a Cultura da Avaliação. In: Vinte e cinco anos de avaliação de sistemas educacionais no Brasil - Implicações nas redes de ensino, no currículo e na formação de professores. V. 2. Florianópolis, SC: Editora Insular, 2013. v. 2. Citado 2 vezes nas páginas 39 e 50.

Políticas de responsabilização: entre a falta de evidência e a ética. Cadernos de Pesquisa, v. 43, n. 148, p. 348-365, jun. 2013. ISSN 1980-5314. Disponível em: $<$ http://publicacoes.fcc.org.br/ojs/index.php?journal=cp\&page=article\&op=view\&path\%5B\% $5 \mathrm{D}=266>$. Acesso em: 17 set. 2014. Citado na página 44.

FUNDAÇÃO LEMANN; INSTITUTO PAULO MONTENEGRO. Conselho de Classe 2014. São Paulo, SP, 2015. Disponível em: <http://www.fundacaolemann.org.br/wp-content/uploads/ 2015/04/conselho_de_classe.pdf > C Citado na página 38.

GESQUI, L. C. O estreitamento curricular em função dos resultados das avaliações externas em larga escala. Práxis Educacional, v. 11, n. 20, p. 229-245, dez. 2015. Disponível em: $<$ http://periodicos.uesb.br/index.php/praxis/article/viewFile/5282/5063>. Acesso em: 7 jan. 2016. Citado na página 59. 
O Índice de Desenvolvimento da Educação do Estado de São Paulo (IDESP): Práticas Escolares Resultantes. Educação (UFSM), v. 40, n. 2, maio 2015. ISSN 1984-6444, 0101-9031. Disponível em: <http://cascavel.ufsm.br/revistas/ojs-2.2.2/index.php/reveducacao/article/view/ 9121>. Acesso em: 7 jan. 2016. Citado na página 59.

GOIÁS. SEDUC. Secretaria de Estado da Educação de Goiás. 2011. Disponível em: $<$ http://www.seduc.go.gov.br/imprensa/?Noticia=2914>. Acesso em: 5 nov. 2016. Citado na página 29.

GRAMLICH, E. M.; KOSHEL, P. P. Educational Performance Contracting. An Evaluation of an Experiment. Washington, D.C.: The Brookings Institute, 1975. (Brookings studies in social experimentation). ISBN 978-0-8157-3239-6. Citado na página 55.

HAGOPIAN, J. (Ed.). More than a score: the new uprising against standardised testing. Chicago, IL: Haymarket Books, 2014. ISBN 978-1-60846-436-4. Citado na página 37.

HAGOPIAN, J. Jesse Hagopian interviewed by the Santa Fe Radio Cafe. 2016.

Disponível em: < http://www.santaferadiocafe.org/sfradiocafe/2016/06/21/jesse-hagopian-2/>. Acesso em: 19 set. 2016. Citado na página 37.

. More than a Score: giving students a solid chance. Seattle, WA: [s.n.], 2016.

Disponível em: < https://www.youtube.com/watch?v=gL64chNiuJQ\&app=desktop $>$. Acesso em: 25 jul. 2016. Citado na página 37.

HAMILTON, L. S. (Ed.). Standards-based accountability under No Child Left Behind: experiences of teachers and administrators in three states. Santa Monica, CA: Rand Corporation, 2007. ISBN 978-0-8330-4149-4. Citado 3 vezes nas páginas 55, 57 e 58.

HAMILTON, L. S.; STECHER, B. M.; KLEIN, S. P. (Ed.). Making sense of test-based accountability in education. Santa Monica, CA: Rand, 2002. ISBN 0-8330-3161-9. Citado 3 vezes nas páginas 46,47 e 56 .

HANEY, W. The Myth of the Texas Miracle in Education. Education Policy Analysis Archives, v. 8, p. 41, ago. 2000. ISSN 1068-2341. Disponível em: < http: //epaa.asu.edu/ojs/article/view/432>. Acesso em: 5 jul. 2016. Citado na página 55.

HANNAWAY, J. Management Decentralization and Performance-Based Incentives: Theoretical Consideration for Schools. In: HANUSHEK, E. A.; JORGENSON, D. W. (Ed.). Improving America's schools the role of incentives. Washington, D.C.: National Academy Press, 1996. ISBN 0-585-02095-7 978-0-585-02095-2 0-309-52197-1 978-0-309-52197-0. Disponível em: < http://site.ebrary.com/id/10041154>. Acesso em: 19 jun. 2015. Citado 2 vezes nas páginas 34 e 55 .

HART, R. et al. Student Testing in America's Great City Schools: An Inventory and Preliminary Analysis. Washington, D.C, 2015. 164 p. Disponível em: <http://www.cgcs.org/cms/lib/DC00001581/Centricity/Domain/87/Testing\%20Report.pdf > . Acesso em: 24 jul. 2016. Citado na página 37.

HO, A. D. The Problem With "Proficiency": Limitations of Statistics and Policy Under No Child Left Behind. Educational Researcher, v. 37, n. 6, p. 351-360, ago. 2008. ISSN 0013-189X. Disponível em: <http://edr.sagepub.com/cgi/doi/10.3102/0013189X08323842>. Acesso em: 5 mai. 2015. Citado na página 55.

HORTA NETO, J. L. Avaliações educacionais e seus reflexos em ações federais e na mídia eletrônica. Estudos em Avaliação Educacional, v. 25, n. 59, p. 172-201, out. 2014. ISSN 1984932X. Disponível em: < http://publicacoes.fcc.org.br/ojs/index.php/eae/article/view/2770>. Acesso em: 1 abr. 2015. Citado 2 vezes nas páginas 30 e 31. 
HORTA NETO, J. L.; JUNQUEIRA, R. D.; OLIVEIRA, A. S. d. Do Saeb ao Sinaeb: prolongamentos críticos da avaliação da educação básica. Em Aberto, v. 29, n. 96, set. 2016. ISSN 21766673. Disponível em: <http://emaberto.inep.gov.br/index.php/emaberto/article/ view/2693>. Acesso em: 5 nov. 2016. Citado na página 30.

INSTITUTO BRASILEIRO DE GEOGRAFIA E ESTATÍSTICA (Ed.). Pesquisa nacional de saúde do escolar, 2015. Rio de Janeiro: IBGE, 2016. ISBN 978-85-240-4387-1. Citado na página 54.

Instituto Paulo Montenegro. Ser professor: uma pesquisa sobre o que pensa o docente das principais capitais brasileiras. In: Estudos \& Pesquisas Educacionais. São Paulo, SP: Fundação Victor Civita, 2010. v. 1. Citado na página 38.

JACOB, B. A.; LEVITT, S. D. Catching cheating teachers: the results of an unusual experiment in implementing theory. [S.l.], 2003. Disponível em: $<$ http://www.nber.org/papers/w9414>. Acesso em: 7 mar. 2015. Citado 2 vezes nas páginas 65 e 102.

Rotten Apples: An Investigation of the Prevalence and Predictors of Teacher Cheating. [S.l.], 2003. Disponível em: <http://www.nber.org/papers/w9413>. Acesso em: 19 jun. 2015. Citado 3 vezes nas páginas 65, 102 e 201.

JENNINGS, J.; SOHN, H. Measure for Measure: How Proficiency-based Accountability Systems Affect Inequality in Academic Achievement. Sociology of Education, v. 87, n. 2, p. 125-141, abr. 2014. ISSN 0038-0407, 1939-8573. Disponível em: < http://soe.sagepub.com/content/87/2/125>. Acesso em: 24 abr. 2015. Citado na página 55.

JENSEN, M. C. Paying people to lie: The truth about the budgeting process. European Financial Management, v. 9, n. 3, p. 379-406, 2003. Disponível em: $<$ http://onlinelibrary.wiley.com/doi/10.1111/1468-036X.00226/abstract>. Acesso em: 6 jan. 2016. Citado na página 49.

JENSEN, M. C.; MECKLING, W. H. A Theory of the Firm: Governance. Journal of Financial Economics, v. 3, n. 4, p. 305-360, 1976. Disponível em: <http: //www.sfu.ca/ wainwrig/Econ400/jensen-meckling.pdf>. Citado na página 40.

JONES, M. G. et al. The Impact of High-Stakes Testing on Teachers and Students in North Carolina. Phi Delta Kappan, v. 81, n. 3, p. 199-203, nov. 1999. ISSN 0031-7217. Disponível em: <http://www.jstor.org/stable/20439620>. Acesso em: 5 jan. 2016. Citado na página 46.

JORNAL DO COMÉRCIO. MEC adia regra que reduziria em até $35 \%$ número de escolas com Ideb. JORNAL DO COMÉRCIO, Porto Alegre, RS. 26 jul, 2016. Disponível em: <http://jcrs.uol.com.br/_conteudo/2016/07/geral/ 512300-mec-adia-regra-que-reduziria-em-ate-35-numero-de-escolas-com-ideb.html>. Acesso em: 10 fev. 2017. Citado na página 73.

KAMENETZ, A. When Teachers, Not Students, Do The Cheating. NPR.org, Washington, D.C. 29 set, 2014. Disponível em: < http://www.npr.org/sections/ed/2014/09/29/352494603/ when-teachers-not-students-do-the-cheating $>$. Acesso em: 18 jun. 2015. Citado na página 37.

KATZ, L. G. Academic Redshirting and Young Children. ERIC Digest, 2000. Disponível em: $<$ http://eric.ed.gov/?id=ED447951>. Acesso em: 20 jul. 2015. Citado na página 63.

KLEIN, R. Produção e utilização de indicadores educacionais: metodologia de cálculo de indicadores de fluxo escolar da educação básica. Revista Brasileira de Estudos 
Pedagógicos, v. 84, n. 206-208, p. 107-157, 2003. Disponível em: <http://rbep.inep.gov.br/ index.php/RBEP/article/view/107>. Acesso em: 17 dez. 2015. Citado na página 84.

Aspectos Metodológicos e Técnicos: Delineamentos Assumidos nas Avaliações, Limites e Perspectivas de Aprimoramento. In: Vinte e cinco anos de avaliação de sistemas educacionais no Brasil - Origens e pressupostos. V. 1. 1. ed. Florianópolis, SC: Editora Insular, 2013. v. 1. Citado na página 87.

KORETZ, D. Arriving in Lake Wobegon: Are Standardized Tests Exaggerating Achievement and Distorting Instruction? American Educator, v. 12, n. 2, p. 8-15, 1988. Citado na página 33.

Test-based educational accountability. Research evidence and implications.

Zeitschrift für Pädagogik, v. 54, n. 6, p. 777-790, 2008. Disponível em: <http: //www.pedocs.de/volltexte/2011/4376/>. Acesso em: 10 jul. 2015. Citado na página 51.

. Measuring Up: What Educational Testing Really Tells Us. Cambridge, Mass.: Harvard University Press, 2009. ISBN 978-0-674-03521-8. Citado 4 vezes nas páginas 52, 53, 54 e 163 .

KORETZ, D. M. Measuring Up: What Educational Testing Really Tells Us (article). American Educator, n. Fall, 2008. Citado na página 60.

KORETZ, D. M.; MCCAFFREY, D. F.; HAMILTON, L. S. Toward a framework for validating gains under high-stakes conditions. Los Angeles, CA, 2001. Citado 2 vezes nas páginas 52 e 53 .

KOSLINSKI, M. C.; CUNHA, C. P. d.; ANDRADE, F. M. d. Accountability escolar: um estudo exploratório do perfil das escolas premiadas. Estudos em Avaliação Educacional, v. 25, n. 59, 2014. Disponível em: < http://publicacoes.fcc.org.br/ojs/index.php/eae/article/view/2865>. Acesso em: 19 mar. 2015. Citado 2 vezes nas páginas 62 e 163.

KRAMER, L. Comedy, The Simpsons, episode 431 - How the Test Was Won. Gracie Films, 20th Century Fox Television, 2009. Disponível em: <http: //en.wikipedia.org/wiki/How_the_Test_Was_Won>. Acesso em: 5 set. 2014. Citado 2 vezes nas páginas 36 e 102 .

LADD, H. F.; ZELLI, A. School-Based Accountability in North Carolina: The Responses of School Principals. Educational Administration Quarterly, v. 38, n. 4, p. 494-529, out. 2002. ISSN 0013-161X. Disponível em: < http://eaq.sagepub.com/cgi/doi/10.1177/001316102237670>. Acesso em: 4 jul. 2016. Citado na página 41.

LAUEN, D. L.; GADDIS, S. M. Accountability Pressure, Academic Standards, and Educational Triage. Society for Research on Educational Effectiveness, 2012. Disponível em: $<$ http://eric.ed.gov/?id=ED530122>. Acesso em: 24 abr. 2015. Citado na página 55.

LEVITT, S. D.; JACOB, B. A. To Catch a Cheat. Education Next, v. 4, n. 1, 2004. Disponível em: <http://educationnext.org/files/ednext20041_68.pdf>. Acesso em: 9 nov. 2016. Citado na página 102.

LIBÂNEO, J. C.; OLIVEIRA, J. F. d.; TOSCHI, M. S. Educação escolar: políticas, estrutura e organização. 10. ed. São Paulo: Cortez Editora, 2012. (Docência em Formação: Saberes Pedagógicos). ISBN 978-85-249-1860-5. Citado na página 82.

MADAUS, G. F. The Distortion of Teaching and Testing: High-Stakes Testing and Instruction. Peabody Journal of Education, v. 65, n. 3, p. 29-46, 1988. ISSN 0161-956X. Disponível em: < http://jwilson.coe.uga.edu/EMAT7050/articles/Madaus.pdf>. Acesso em: 10 mar. 2015. Citado 4 vezes nas páginas 33, 35, 48 e 163. 
The influence of testing on the curriculum. In: TANNER, L. N.; REHAGE, K. J. (Ed.). Critical Issues in Curriculum. Chicago, IL: The University of Chicago Press, 1988. Part I, p. 83-121. Citado na página 44.

MADAUS, G. F.; RUSSELL, M. Paradoxes of High-Stakes Testing. The Journal of Education, v. 190, n. 1/2, p. 21-30, 2010. ISSN 00220574. Disponível em: $<$ http://www.jstor.org/stable/42744178>. Acesso em: 18 jun. 2015. Citado 3 vezes nas páginas 39,44 e 163.

MADAUS, G. F.; RUSSELL, M. K.; HIGGINS, J. The paradoxes of high stakes testing: how they affect students, their parents, teachers, principals, schools, and society. Charlotte, NC: Information Age Pub, 2009. ISBN 978-1-60752-028-3. Citado 2 vezes nas páginas 31 e 63.

MAIA, M. M. V. O índice de desenvolvimento da educação do Estado de São Paulo como indutor da qualidade da educação: potencialidades e contradições. Tese (Mestrado) - Universidade Cidade de São Paulo, São Paulo, SP, 2013. Citado na página 43.

MARSAGLIA, G. Evaluating the normal distribution. Journal of Statistical Software, v. 11, n. 4, p. 1-7, 2004. Disponível em: < https://core.ac.uk/download/files/153/6287966.pdf > . Acesso em: 14 jul. 2016. Citado na página 203.

MCCARTY, T. L. The impact of high-stakes accountability policies on Native American learners: evidence from research. Teaching Education, v. 20, n. 1, p. 7-29, 2009. Disponível em: <http://www.tandfonline.com/doi/abs/10.1080/10476210802681600>. Acesso em: 5 set. 2014. Citado na página 55.

MCNEIL, L. M. Contradictions of school reform: educational costs of standardized testing. New York: Routledge, 2000. (Critical social thought). ISBN 978-0-415-92074-2. Citado na página 55.

MINARECHOVÁ, M. Negative impacts of high-stakes testing. Journal of Pedagogy / Pedagogický casopis, v. 3, n. 1, jan. 2012. ISSN 1338-1563. Disponível em: <http://www. degruyter.com/view/j/jped.2012.3.issue-1/v10159-012-0004-x/v10159-012-0004-x.xml>. Acesso em: 18 jun. 2015. Citado na página 28.

MINAS GERAIS. Secretaria de Estado de Educação. Escolas estaduais do interior de Minas Gerais começam a receber placas com os resultados do Ideb. 2013. Disponível em: < https://www.educacao.mg.gov.br/leis/story/

4058-escolas-estaduais-do-interior-de-minas-gerais-comecam-a-receber-placas-com-os-resultados-do-ideb- $>$. Acesso em: 5 nov. 2016. Citado na página 29.

MONTEIRO, M. PROVA BRASIL: Treinamento de Aplicadores 2011. Brasília, DF: [s.n.], 2011. Disponível em: <https://www.youtube.com/watch?v=PzFQSTi0v6U>. Acesso em: 20 jan. 2017. Citado na página 191.

MORICONI, G. M.; BÉLANGER, J. Comportamento dos alunos e uso do tempo em sala de aula: evidências da Talis 2013 e de experiências internacionais. São Paulo, SP: Fundação Carlos Chagas, 2015. v. 45. (Textos FCC, v. 45). Citado na página 53.

MOVIMENTO Contra Testes de Alto Impacto em Educação. 2010. Disponível em: $<$ https://sites.google.com/site/movimentocontratestes/home/pagina-dos-professores $>$. Acesso em: 15 nov. 2014. Citado na página 37.

MUNROE, R. xkcd: Correlation. 2009. Disponível em: <https://xkcd.com/552/>. Acesso em: 21 fev. 2017. Citado na página 123. 
NEAL, D.; SCHANZENBACH, D. W. Left behind by design: Proficiency counts and test-based accountability. The Review of Economics and Statistics, v. 92, n. 2, p. 263-283, 2010. Disponível em: < http://www.mitpressjournals.org/doi/abs/10.1162/rest.2010.12318>. Acesso em: 30 nov. 2014. Citado na página 55.

NICHOLS, S. L.; BERLINER, D. C. The Inevitable Corruption of Indicators and Educators Through High-Stakes Testing. Tempe, AZ, 2005. Disponível em: < http://epsl.asu.edu/epru/documents/EPSL-0503-101-EPRU.pdf>. Acesso em: 10 mar. 2015. Citado 3 vezes nas páginas 54, 61 e 64 .

Collateral Damage: How High-Stakes Testing Corrupts America's Schools. Cambridge, Mass: Harvard Education Press, 2007. ISBN 978-1-891792-35-9. Citado 3 vezes nas páginas 39, 61 e 63.

NOGUEIRA, D. X. P.; JESUS, G. R. d.; CRUZ, S. P. d. S. Avaliação de desempenho docente no Brasil: desvelando concepções e tendências. Linhas Críticas, v. 19, n. 38, p. 13-32, 2013. ISSN 1981-0431. Disponível em: <http://periodicos.unb.br/index.php/linhascriticas/article/view/ 8917>. Acesso em: 6 mai. 2015. Citado na página 80.

O GLOBO. Escola denuncia fraude na aplicação da Prova Brasil em Cabaceiras, PB. G1, Rio de Janeiro, RJ. 14 nov, 2013. Disponível em: < http://g1.globo.com/pb/paraiba/noticia/2013/11/ escola-denuncia-fraude-na-aplicacao-da-prova-brasil-em-cabaceiras-pb.html $>$. Acesso em: 27 ago. 2016. Citado na página 67.

OLIVEIRA, R. P. d.; ARAÚJO, G. C. d. Qualidade do ensino: uma nova dimensão da luta pelo direito à educação. Revista Brasileira de Educação, n. 28, abr. 2005. Disponível em: $<$ http://www.scielo.br/pdf/rbedu/n28/a02n28>. Acesso em: 22 jul. 2014. Citado na página 31.

OLIVER, J. Standardized Testing. New York, NY: HBO, 2015. Disponível em: $<$ https://www.youtube.com/watch?v=J6lyURyVz7k>. Acesso em: 14 out. 2016. Citado na página 37 .

OSHIRO, C. H. Efeito do pagamento de bônus aos professores sobre a proficiência escolar. Tese (Mestrado) - Universidade de São Paulo, fev. 2012. Disponível em: < http://www.teses.usp.br/teses/disponiveis/96/96131/tde-17042012-161016/>. Acesso em: 16 jul. 2014. Citado na página 43.

OSHIRO, C. H.; SCORZAFAVE, L. G. Efeito do pagamento de bônus aos professores sobre a proficiência escolar no Estado de São Paulo. Encontro Nacional de Economia, v. 39, 2011. Disponível em: <http://anpec.org.br/encontro/2011/inscricao/arquivos/ 000-e95d077296d03faa27e429dc66192da8.pdf >. Acesso em: 1 abr. 2015. Citado na página 50.

PEDULLA, J. J. et al. Perceived Effects of State-Mandated Testing Programs on Teaching and Learning: Findings from a National Survey of Teachers. Boston, MA, 2003. Disponível em: < http://www.bc.edu/research/nbetpp/statements/nbr2.pdf > . Acesso em: 10 mar. 2015. Citado na página 56.

PESTANA, M. C. et al. Diretrizes para apresentação de dissertações e teses da USP: parte I (ABNT). 3a edição. ed. São Paulo, SP: SIBiUSP, 2016. v. 9. (Caderno de Estudos, v. 9). ISBN 978-85-7314-060-6. Disponível em: <http://www.livrosabertos.sibi.usp.br/ portaldelivrosUSP/catalog/view/111/95/491-1>. Acesso em: 6 jan. 2017. Citado na página 210.

RAPPLE, B. A. Payment by Educational Results: An Idea Whose Time Has Gone? Thirty-Five Years of Experimentation with Educational Efficiency in England (1862-1897). Chicago, IL, 1990. Disponível em: < http://eric.ed.gov/?id=ED324808>. Acesso em: 9 set. 2016. Citado 3 vezes nas páginas 28, 43 e 55 . 
RAUDENBUSH, S.; BRYK, A. S. A Hierarchical Model for Studying School Effects. Sociology of Education, v. 59, n. 1, p. 1, jan. 1986. ISSN 00380407. Disponível em: $<$ http://www.jstor.org/stable/2112482?origin=crossref $>$. Acesso em: 11 jul. 2015. Citado na página 116.

RAUDENBUSH, S. W.; BRYK, A. S. Hierarchical Linear Models: Applications and Data Analysis Methods. 2nd. ed. Thousand Oaks: SAGE Publications, Inc, 2001. ISBN 978-0-7619-1904-9. Citado na página 116.

RAVITCH, D. The death and life of the great American school system: how testing and choice are undermining education. New York: Basic Books, 2010. ISBN 978-0-465-01491-0. Citado na página 37.

Reign of Error: The Hoax of the Privatization Movement and the Danger to America's Public Schools. [S.l.]: Vintage, 2013. Citado na página 37.

REID, L. N. The Unintended Consequences of Narrowing Secondary Curriculum in Response to Low Standardized Test Scores. Tese (Doutorado) - University of Phoenix, Phoenix, AZ, 2012. Disponível em: <http://gradworks.umi.com/35/35/3535729.html>. Acesso em: 6 mar. 2015. Citado na página 55.

RICHARDSON, J. Accountability incentives and academic achievement: Distributional impacts of accountability when standards are set low. Economics of Education Review, v. 44, p. 1-16, fev. 2015. ISSN 02727757. Disponível em: < http://linkinghub.elsevier.com/retrieve/pii/ S0272775714000983>. Acesso em: 30 abr. 2015. Citado na página 62.

RODRIGUES, J. R. d. S. Resultados Escolares e Responsabilização no Rio de Janeiro. Tese (Mestrado) - PUC Rio, Rio de Janeiro, RJ, abr. 2007. Disponível em: $<$ http://livros01.livrosgratis.com.br/cp076429.pdf>. Acesso em: 13 mar. 2017. Citado na página 42 .

RODRIGUES, M. M. M. Proposta de análise de itens das provas do SAEB sob a perspectiva pedagógica e a psicométrica. Estudos em Avaliação Educacional, v. 17, n. 34, p. 43-78, ago. 2006. ISSN 1984-932X. Disponível em: < http://publicacoes.fcc.org.br/ojs/index.php/eae/article/ view/2117>. Acesso em: 5 jul. 2016. Citado na página 87.

ROSISTOLATO, R.; PRADO, A. P. d.; FERNÁNDEZ, S. J. Cobranças, estratégias e "jeitinhos": avaliações em larga escala no Rio de Janeiro. Estudos em Avaliação Educacional, v. 25, n. 59, p. 78-107, 2014. Disponível em: < http://publicacoes.fcc.org.br/ojs/index.php/eae/article/ view/2853>. Acesso em: 19 mar. 2015. Citado 2 vezes nas páginas 62 e 163.

ROYSTON, P. Estimating departure from normality. Statistics in Medicine, v. 10, n. 8, p. 12831293, 1991. Disponível em: <http://onlinelibrary.wiley.com/doi/10.1002/sim.4780100811/full>. Acesso em: 18 out. 2016. Citado na página 91.

RUSTIQUE-FORRESTER, E. Accountability and the pressures to exclude: A cautionary tale from England. Education Policy Analysis Archives, v. 13, n. 26, p. 1-41, 2005. Disponível em: < http://eric.ed.gov/?id=EJ846558>. Acesso em: 24 abr. 2015. Citado 2 vezes nas páginas 27 e 61.

RYAN, K. E.; SHEPARD, L. A. (Ed.). The future of test-based educational accountability. New York: Routledge, 2008. ISBN 978-0-8058-6470-0 0-8058-6470-9 978-0-203-89509-2 0-203-89509-6. Citado na página 31. 
RÁDIO CULTURA FOZ DO IGUAÇU. Mãe de aluno registra queixa de fraude na prova do Ideb. Rádio Cultura AM, Foz do Iguaçu, PR. 14 nov, 2013. Disponível em: <http://www. radioculturafoz.com.br/mae-de-aluno-registra-queixa-informando-fraude-na-prova-do-ideb/ $>$. Acesso em: 14 mar. 2015. Citado na página 67.

SCORZAFAVE, L. G.; DORIGAN, T. A.; FERREIRA, J. N. d. P. Efeito das políticas de bonificação aos professores sobre a desigualdade de proficiência no ensino fundamental. In: $\mathbf{4 3}^{\circ}$ Encontro Nacional de Economia. Florianópolis, SC: [s.n.], 2015. Disponível em: <http://www.anpec.org.br/encontro/2015/submissao/files_I/ i12-5c95bdc61a58e5fc76edb81db3ef5632.pdf > . Acesso em: 22 dez. 2015. Citado na página 80.

SCORZAFAVE, L. G.; FERREIRA, J. N. d. P.; DORIGAN, T. A. Efeito das políticas de bonificação aos professores sobre a desigualdade de proficiência no ensino fundamental (manuscrito). 2014. Disponível em: < http://eesp.fgv.br/sites/eesp.fgv.br/files/ file/Luiz\%20Scorzafave.pdf>. Acesso em: 6 mai. 2015. Citado 3 vezes nas páginas 30, 80 e 165 .

SERPA, D. Avaliações externas - como o país usa os resultados e dicas para evitar 8 mitos criados em torno deles. São Paulo, SP: Fundação Victor Civita, 2011. Disponível em: < http://www.fvc.org.br/pdf/avaliacaoexterna/especial-gestao-avaliacoes-externas.pdf $>$. Acesso em: 2 out. 2014. Citado na página 164.

SHANNON, C. E. A Mathematical Theory of Communication. Bell System Technical Journal, v. 27, n. 3, p. 379-423, jul. 1948. Disponível em: <http://archive.org/details/bstj27-3-379>. Acesso em: 15 jan. 2017. Citado na página 114.

SHEPARD, L. A.; DOUGHERTY, K. C. Effects of High-Stakes Testing on Instruction. In: Annual Meeting of the American Educational Research Association. Chicago, IL: [s.n.], 1991. Disponível em: <http://eric.ed.gov/?id=ED337468>. Acesso em: 20 dez. 2015. Citado na página 55.

SINGH, S. Os Segredos Matemáticos dos Simpsons. 1ª ed. Rio de Janeiro, RJ: Record, 2016. ISBN 978-85-01-10374-1. Citado na página 36.

SNIJDERS, T. A. B.; BOSKER, R. Multilevel Analysis: An Introduction to Basic and Advanced Multilevel Modeling. 2nd edition. ed. Los Angeles, Calif.: SAGE Publications Ltd, 2011. ISBN 978-1-84920-201-5. Citado na página 116.

SOUSA, B. J. R. d. O plano de ações articuladas (PAR) como instrumento de planejamento da educação: o que há de novo? In: Políticas Públicas e Gestão da Educação. São Paulo, SP: Biblioteca Anpae, 2011. (Cadernos, v. 11). Disponível em: <http://anpae.org.br/simposio2011/ cdrom2011/PDFs/trabalhosCompletos/comunicacoesRelatos/0079.pdf>. Acesso em: 9 mar. 2017. Citado na página 82.

SOUSA, S. M. Z. L.; MAIA, M. M. V. d.; HAAS, C. M. Avaliação, índices e bonificação: controvérsias suscitadas por dados da rede estadual paulista. Estudos em Avaliação Educacional, v. 25, n. 58, p. 188-209, ago. 2014. Disponível em: $<$ http://publicacoes.fcc.org.br/ojs/index.php/eae/article/download/2772/2779>. Acesso em: 5 nov. 2014. Citado na página 43.

SOUSA, S. M. Z. L.; OLIVEIRA, R. P. d. Políticas de avaliação da educação e quase mercado no Brasil. Educação \& Sociedade, v. 24, n. 84, p. 873-895, set. 2003. Disponível em: $<$ http://www.scielo.br/pdf/\%0D/es/v24n84/a07v2484.pdf>. Acesso em: 12 mar. 2014. Citado na página 35. 
Sistemas estaduais de avaliação: uso dos resultados, implicações e tendências.

Cadernos de Pesquisa, v. 40, n. 141, p. 793-822, 2010. Disponível em: <http:

//www.scielo.br/pdf/cp/v40n141/v40n141a07.pdf>. Acesso em: 12 mar. 2014. Citado 2 vezes nas páginas 48 e 54 .

SPRINGER, M. G. Accountability incentives: Do failing schools practice educational triage.

Education Next, v. 8, n. 1, p. 74-79, 2007. Disponível em: <http://media.hoover.org/sites/ default/files/documents/ednext_20081_Springer_unabridged.pdf $>$. Acesso em: 5 set. 2014. Citado na página 55 .

Accountability Incentives: Do schools practice educational triage? Education Next, dez. 2008. Disponível em: <http://educationnext.org/accountability-incentives/>. Acesso em: 30 abr. 2015. Citado na página 55.

Rethinking Teacher Compensation Policies: Why Now, Why Again? In: Performance incentives: Their growing impact on American K-12 education. [S.l.]: Brookings Institution Press, 2009. Acesso em: 30 nov. 2014. Citado na página 50.

StataCorp. Stata multilevel mixed-effects reference manual. [s.n.], 2013. Disponível em: $<$ http://www.stata.com/manuals14/me.pdf $>$. Acesso em: 22 jan. 2017. Citado na página 118.

STECHER, B. M. Consequences of large-scale, high-stakes testing on school and classroom practice. In: Making sense of test-based accountability in education. Santa Monica, CA: Rand, 2002. Citado na página 55.

STECHER, B. M. et al. The Effects of the Washington State Education Reform on Schools and Classrooms: Initial Findings. Santa Monica, CA: Rand Corporation, 2000. ISBN 978-0-8330-2898-3. Disponível em: < http://eric.ed.gov/?id=ED449577>. Acesso em: 20 dez. 2015. Citado na página 56.

SÃO PAULO (ESTADO). Secretaria Estadual de Educação. Manual do Aplicador: Treinamento dos Coordenadores de Polo para Aplicação do Saeb 2011. 2011. Disponível em: <http://slideplayer.com.br/slide/3221564/>. Acesso em: 17 jan. 2017. Citado na página 191.

SÃO PAULO (ESTADO). Secretaria Estadual de Educação. Diretoria Sul 3. Edital Prova Brasil 2015. 2015. Disponível em: <http://desul3.edunet.sp.gov.br/E_Assuntos\%20do\%20Site/ 01_temp/ese/Edital_prova_brasil_2015_revisado.pdf $>$. Acesso em: 22 dez. 2016. Citado na página 195.

TAlalAY, R. Hell Bent. Doctor Who. Ep. 12 series 9. London, UK: BBC One, 2015. Citado na página 71.

THIESSEN, B. A. Educator Cheating: Classification, Explanation, and Detection. Tese (Mestrado) - University of Iowa, Iowa City, Iowa, 2006. Disponível em: <http: //www.bradthiessen.com/html5/docs/cheating.pdf $>$. Acesso em: 25 abr. 2015. Citado na página 60.

TODOS PELA EDUCAÇÃO. Equidade entre as escolas das redes municipais: Uma análise com base nos dados de IDEB para municípios e escolas. 2010. Citado na página 31 .

TOLEDO, L. F. Alunos denunciam fraude no Saresp em escola de Osasco. O Estado de São Paulo, São Paulo, SP. 13 jan, 2015. Disponível em: <http://educacao.estadao.com.br/noticias/ geral, alunos-denunciam-fraude-no-saresp-em-escola-de-osasco,1619218>. Acesso em: 14 mar. 2015. Citado na página 67. 
US GOVERNMENT ACCOUNTABILITY OFFICE. GAO-13-495R Test Security Leading Practices. Washington, D.C., 2013. Disponível em: <http://www.gao.gov/assets/660/654721. pdf>. Acesso em: 3 nov. 2015. Citado na página 37.

VIANNA, H. M. Avaliações nacionais em largas escalas: análises e propostas. Textos FCC, v. 23, p. 41, 2003. Disponível em: < http://publicacoes.fcc.org.br/ojs/index.php/textosfcc/ article/view/2441>. Acesso em: 14 jun. 2017. Citado na página 35.

WANG, L. C. The Effect of High-Stakes Testing on Suicidal Ideation of Teenagers with Reference-Dependent Preferences. Available at SSRN 2189268, 2013. Disponível em: $<$ http://papers.ssrn.com/sol3/papers.cfm?abstract_id=2189268>. Acesso em: 18 jun. 2015. Citado na página 54 .

WEST, M. Testing, learning, and teaching: The effects of test-based accountability on student achievement and instructional time in core academic subjects. In: FINN JR., C. E.; RAVITCH, D. (Ed.). Beyond the Basics: Achieving a Liberal Education for All Children. Washington, D.C.: Thomas B. Fordham Institute, 2007. p. 45-61. Disponível em: $<$ http://www.citizensforpublicschools.org/wp-content/uploads/2009/08/beyond_the_basics_ final.pdf\#page $=49>$. Acesso em: 11 set. 2014. Citado na página 58.

WILSON, B. L.; CORBETT, H. D. Two State Minimum Competency Testing Programs and Their Effects on Curriculum and Instruction. Philadelphia, PA, 1991. Disponível em: <http://eric.ed.gov/?q=corbett+wilson\&pg=2\&id=ED377251>. Acesso em: 20 dez. 2015. Citado na página 55 .

XIMENES, S. B. Responsabilidade educacional: concepções diferentes e riscos iminentes ao direito à educação. Educação \& Sociedade, v. 33, n. 119, p. 353-377, jun. 2012. ISSN 0101-7330. Disponível em: <http://www.scielo.br/scielo.php?script=sci_abstract\&pid= S0101-73302012000200003\&lng=en\&nrm=iso\&tlng=pt $>$. Acesso em: 29 nov. 2014. Citado na página 50.

ZANE, R. L. The Impact of High Stakes Accountability Systems and the New Performance Demands on Special Education Teachers' Attitudes, Beliefs and Practice. Tese (Doutorado) - University of California at Berkeley, Berkeley, CA, 2012. Disponível em: <http://escholarship.org/uc/item/1kq8v187.pdf>. Acesso em: 5 set. 2014. Citado na página 55.

ZHAN, S. Detecting test cheating using a deterministic, gated item response theory model. Tese (Doutorado) - University of North Carolina at Greensboro, Greensboro, North Carolina, 2010. Disponível em: <http://libres.uncg.edu/ir/uncg/f/Shu_uncg_0154D_10504. pdf $>$. Acesso em: 25 abr. 2015. Citado na página 61.

ZLATOS, B. Don't Test, Don't Tell. American School Board Journal, v. 181, n. 11, p. 24-28, 1994. ISSN 0003-0953. Acesso em: 24 abr. 2015. Citado 2 vezes nas páginas 61 e 163. 
Anexos 



\section{ANEXO A - Usos de avaliações em países da América}




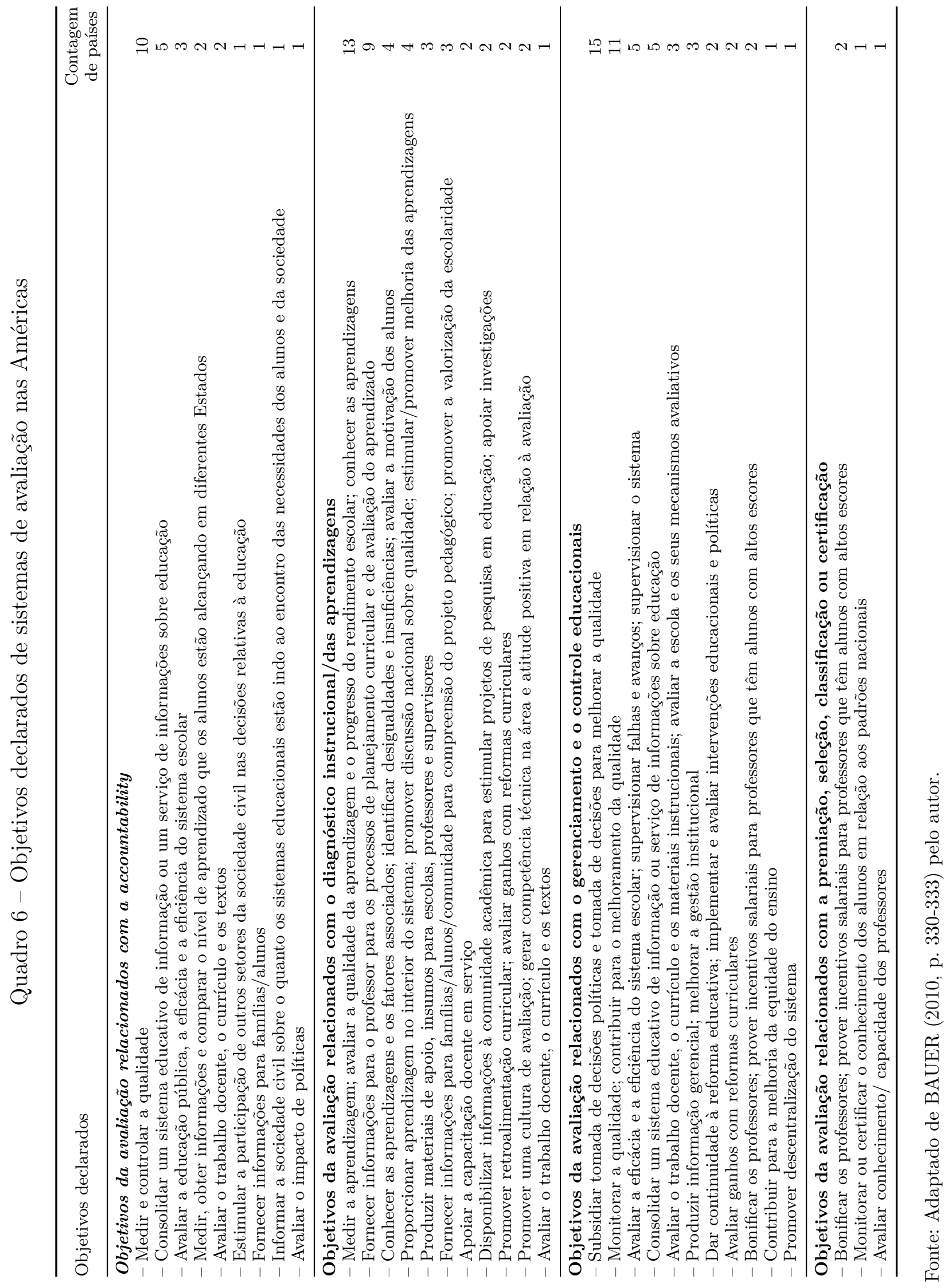




\section{ANEXO B - Protocolo da aplicação da Prova Brasil}

As cartilhas de preparação dos aplicadores da Prova Brasil de 2013 e 2015 resumem o protocolo de aplicação e podem ser consultadas em registros do Inep (2013a, 2015b).

Conteúdo multimídia usado para treinamento dos aplicadores está disponível em (MONTEIRO, 2011) para 2011 e em (ESPAÇO DO SERVIDOR, 2013) para 2013. O primeiro é curto, com 20 minutos de duração. O segundo, com mais de duas horas de duração traz também bastante conteúdo de contexto da Prova Brasil.

A seguir, apresenta-se a transcrição em texto de uma apresentação preparada pela Secretaria Estadual de Educação de São Paulo (SEE/SP), (2011), à guisa de exemplo de protocolo de aplicação da Prova Brasil ${ }^{1}$.

\section{MANUAL DO APLICADOR}

Treinamento dos Coordenadores de Polo para Aplicação do Saeb 2011 Rede Estadual de São Paulo, 18 e 19 de outubro de 2011

Antes da Aplicação

- Seleção:

- Quantidade: em média 10 aplicações por Aplicador.

- Exigência - Nível Médio Completo com comprovante de escolaridade e, preferencialmente, experiência em avaliações, ou concursos públicos ou vestibulares. (Nas turmas de $5^{\circ}$ ano, prioritariamente, aplicadores com experiência em magistério)

- Cadastramento: Todos os aplicadores devem se cadastrar no Sistema online e preencher a Ficha Cadastral com código.

- Capacitação Dos Aplicadores: Deve ocorrer no período de 31 de outubro a 6 de novembro de 2011, no Polo de Apoio e Treinamento com duração de $8 \mathrm{~h} 00$.

- Verificar agendamentos com o coordenador de polo

- Verificar o endereço e meio de transporte necessário para chegar em cada escola
- Buscar material de aplicação no polo de apoio e treinamento

- Sacola Envelope Plástico da Turma

- Provas

- Formulário de Controle da Aplicação

- Etiqueta Autoadesiva Envelope Pardo com os questionários (se for o caso)

\section{No dia da Aplicação}

- Levar além do material de aplicação: relógio, caneta, documento de identificação e carta de apresentação do Aplicador

- Chegar com uma hora de antecedência da aplicação.

- Dirigir-se a direção ou secretaria da escola com carta de apresentação e documento de identificação.

- Avisar ao diretor ou responsável pela escola, da necessidade de atestar a execução ao fim da aplicação.

- No caso de aplicação dos questionários: Entregue o questionário do diretor

- Entregue os questionários dos professores de língua portuguesa e matemática das séries e turmas designadas.

1 As durações da avaliação listados neste texto (25 minutos por bloco) fazem referência ao $5^{\circ}$ ano do EF. $\mathrm{O} 9^{\circ}$ ano do $\mathrm{EF}$ e $3^{\circ}$ ano do EM contam com 30 minutos por bloco. 
- Pedir ao diretor ou responsável que o acompanhe e apresente à turma.

- Solicitar a permanência em sala de aula, se possível, de um dos professores da turma, durante toda a aplicação.

- Cumprimentar o professor e os alunos.

- Solicitar que os alunos organizem as carteiras em fila.

- Explicar a importância da participação dos alunos na avaliação.

- Abrir o envelope plástico pelo picote.

- Retirar do envelope os cadernos de prova, o Formulário de Controle da Aplicação e a etiqueta autoadesiva.

- Marcar, no Formulário de Controle da Aplicação, o horário de abertura do envelope plástico.

- Conferir o número de alunos frequentes no diário de classe e anotar no item 12 do Formulário de Controle da Aplicação.

- Verificar o número de alunos presentes e anotar no item 13 do Formulário de Controle da Aplicação.

- E se a quantidade de provas for insuficiente para o número de alunos presentes?

- Se algum aluno presente ficou sem receber o caderno de prova, utilize os dois cadernos de reserva da turma. Caso não sejam suficientes, use caderno de alunos ausentes e preencha o campo 1 (Aluno ausente) da folha de respostas e, a seguir, complete as informações solicitadas.

- Distribuir os cadernos de prova chamando o aluno pelo nome, pedindo que ele levante a mão e dirigir-se à carteira do aluno.

- Pedir ao aluno que ele marque na folha de resposta o número do seu caderno e escreva o seu nome.

- Não será permitida a entrada de alunos na sala após iniciada a sessão de aplicação.

- Os alunos do $5^{\circ} \mathrm{EF}$ devem usar lápis preto e os demais alunos caneta de tinta azul ou preta

- Caso haja alunos com necessidades especiais assinale o campo ANE (3) e preencha os recursos existentes para atender aos alunos, ambos na folha de resposta.
- Caso a escola tenha um ledor para os alunos com deficiência visual poderá fazer a prova em outro local, acompanhado de outro Aplicador, permanecendo até o término da aplicação e trazendo a prova e as folhas de respostas para serem lacradas no envelope plástico da turma.

- Se o quantitativo de alunos for maior do que o $\mathrm{n}^{\circ}$ de cadernos reserva e dos alunos ausentes, solicitar que os alunos excedentes sejam encaminhados ao local da escola indicado pela direção.

- Nesse caso o Aplicador deve selecionar, utilizando a ordem alfabética, quais destes alunos farão as provas.

- Atenção! Em hipótese alguma os cadernos de provas poderão ser retirados da sala de aula, ou copiados por qualquer pessoa.

\section{Durante a Aplicação}

- Informar que cada prova é formada por duas partes, uma de Língua Portuguesa e outra de Matemática.

- Esclarecer que as provas são diferentes; algumas começam com questões de Língua Portuguesa e outras com questões de Matemática.

- Avisar que cada parte da prova possui dois blocos de questões.

- Comunicar que os alunos terão um tempo para responder às questões de cada bloco e que este tempo será indicado no decorrer da aplicação da prova.

- Pedir aos alunos que destaquem a folha de resposta do caderno de prova cuidadosamente, dobrando e passando a mão na linha pontilhada primeiro, antes de destacá-la pelo picote. O Aplicador deverá demonstrar várias vezes o procedimento e auxiliar os alunos que tenham dificuldade em realizá-lo.

- Treinar com os alunos do $5^{\circ}$ ano como marcar as respostas às questões no caderno de prova, usando os exemplos do verso da capa.

- Aplicação do $1^{\circ}$ Bloco de Questões

1. Avisar aos alunos que terão 25 minutos para responder ao $1^{\circ}$ bloco de questões.

2. Anotar o horário de início da aplicação do bloco.

3. Marcar o tempo. Após 20 minutos, avisar aos alunos que terão mais 5 minutos para concluir o $1^{\circ}$ bloco. 
4. Interromper após esse prazo.

5. Pedir aos alunos que aguardem autorização para começar o bloco seguinte, parando no aviso.

6. Anotar o horário de término da aplicação deste bloco no Formulário de Controle da Aplicação.

- Aplicação do $2^{\circ}$ Bloco de Questões (25 Minutos)

- Repetir os procedimentos do $1^{\circ}$ bloco.

- Enquanto os alunos estão fazendo a prova, o aplicador deverá continuar o preenchimento do Formulário de Controle da Aplicação.

- Após a conclusão de 2 blocos de uma disciplina, treine o preenchimento correto da folha de respostas conforme os exemplos dados no caderno de prova.

- Dê 10 minutos para que os alunos transfiram suas respostas do caderno de prova para a folha de respostas.

- Após a conclusão de 2 blocos de uma disciplina, treine o preenchimento correto da folha de respostas.

- Atenção ao preenchimento dos horários no formulário de controle da aplicação

- Duração:

- Tempo de duração: 2 horas e 30 minutos

- $1^{\circ}$ bloco de questões: 25 minutos ${ }^{2}$

- $2^{\circ}$ bloco de questões: 25 minutos

- Transcrever as respostas do $1^{\circ}$ e $2^{\circ}$ blocos: 10 minutos

- $3^{\circ}$ bloco de questões: 25 minutos

- $4^{\circ}$ bloco de questões: 25 minutos

- Transcrever as respostas do $3^{\circ}$ e $4^{\circ}$ blocos: 10 minutos

- Questionário do aluno na própria folha de resposta: 30 minutos

\section{Após a Aplicação}

- Completar o preenchimento do Formulário de Controle da Aplicação e assinar no espaço correspondente ao Aplicador.

- Recolher todos os cadernos de provas (UTILIZADOS e NÃO UTILIZADOS), todas as folhas de respostas e os Questionários do Aluno e colocar dentro do envelope plástico.

- Fechar o envelope plástico.

- Colar a etiqueta autoadesiva de segurança em cima da borda de fechamento e lacrar o envelope.

- Atenção! O Formulário de Controle da Aplicação não deve ser colocado dentro do envelope plástico.

- Ver com o Diretor da Escola se nessa turma teve troca de professores e preencher na Formulário de Controle da Aplicação o campo 8

- Solicitar ao Diretor que ateste a aplicação realizada no Formulário de Controle da Aplicação com carimbo e assinatura.

- Pegar a Carta de Apresentação do Aplicador com o Diretor e verificar se os campos foram preenchidos e se consta a assinatura do Diretor e o carimbo da escola.

- Colocar o Formulário de Controle da Aplicação e a Carta de Apresentação na sacola do Aplicador /envelope pardo.

- Recolher os Questionários do Diretor e dos Professores de Língua Portuguesa e Matemática, bem como as respectivas folhas de respostas e colocar no envelope pardo.

- Preencher o Questionário da Escola visitando a escola na companhia da pessoa designada pelo Diretor. Também coloque este questionário no envelope pardo. 



\section{ANEXO C - Edital de convocação de aplicadores da Prova Brasil 2015}

Um exemplo de edital de convocação de aplicadores para a Prova Brasil 2015, documento da Secretaria Estadual de Educação de São Paulo - Diretoria Sul 3 (2015), é apresentado neste apêndice.

A aplicação da Prova Brasil será na primeira quinzena de novembro. Para tanto faz-se necessária a contratação de aplicadores. O aplicador é responsável pela aplicação dos cadernos de provas e questionários, e se inscreverá em um único polo. Para fins deste Edital o termo polo define apenas um agrupamento de escolas e o aplicador deverá consultar o polo de seu interesse. Os polos (de 01 a 08 ) constam no corpo da publicação deste Edital, como Anexo I.

O remanejamento do aplicador será a critério da Coordenação em nível de Diretoria, e somente por necessidade dos polos. A alocação do aplicador em escola "x" ou "y" será a critério do coordenador do polo.

O aplicador deverá ter disponibilidade de dias e horários para atuar nos períodos manhã, tarde (vespertino) e noite e para fins de pagamento pelo serviço prestado deverá ser titular de conta corrente no Banco do Brasil ou Caixa Econômica Federal, e para conta conjunta somente se o aplicador for o primeiro titular, e há impedimento de pagamento em conta poupança e conta salário.

Os candidatos aplicadores deverão preencher uma ficha de pré-inscrição, disponível no link abaixo. É obrigatório a participação no evento de capacitação, previsto para o dia 27 de outubro, assim como no evento de alinhamento realizado a distancia via online. Na inscrição o candidato deverá apontar sua disponibilidade de horário. Serão permitidas apenas 220 inscrições no formulário online, o interessado inscrito deverá consultar lista de deferidos/convocados no site da Diretoria de Ensino sul três (http://desul3.edunet.sp.gov.br) a partir de 25 de outubro.

O candidato aplicador não poderá aplicar prova na escola a qual tem vínculo.

A inscrição no formulário (link no fim deste edital) assim como a participação na capacitação não garante que o aplicador será alocado.

\section{Da Qualificação}

Provas do $5^{\circ}$ e $9^{\circ}$ anos do Ensino Fundamental e $3^{\circ}$ ano do Ensino Médio: $\mathrm{I}-\mathrm{O}$ aplicador deve ter no mínimo o Ensino Médio completo; II - Experiência mínima de dois anos em avaliações externas; III - Residir no município.

Do Treinamento e da Ficha de Cadastro de Pessoa Física da Cesgranrio

- O cadastro no site da CESGRANRIO deverá ser feito antes da data de capacitação;

- O candidato deverá participar do evento de alinhamento, (curso online);

- No dia do capacitação/treinamento o Aplicador selecionado deverá trazer os seguintes documentos e informações em envelope pardo A-4: (cópias simples) RG, CPF, PIS, Comprovante de Escolaridade com Histórico Escolar (Declaração, Certificado e/ou Diploma);

- Comprovante de Endereço, Dados Bancários (comprovante da conta corrente do qual é titular, ex: extrato, cópia talão cheque ou cópia do cartão);

- e-mail pessoal, telefones para contato;

- Declaração de próprio punho comprovando experiência de no mínimo dois anos em avaliações externas;(modelo disponível no formulário online);

\section{Da Aplicação \\ O aplicador deverá:}

- Chegar uma hora antes da aplicação da prova na escola polo a ele direcionada;

- Participar do treinamento/capacitação de Aplicadores, em local a ser definido, previsto para o dia 27 de outubro;

- Verificar a data e o horário previstos de aplicação dos cadernos de provas com seu Coordenador de Polo; 
- Localizar cada escola e saber qual o meio de transporte necessário para chegar a ela;

- Ter relógio disponível, para utilizar durante a aplicação da prova;

- Entrar em contato com a escola um dia antes da aplicação a fim de confirmar com o diretor da U.E. a data e o horário da aplicação;

- Manter o aparelho celular e outros desligados durante a aplicação da prova;

- Retirar e entregar as avaliações na Diretoria de Ensino sul 3.

Do Pagamento a que fará jus

O Aplicador após o período de aplicação das provas fará jus aos seguintes valores, em conjunto:

- Uma Ajuda de Custo no valor de $\mathrm{R} \$ 30,00$ (trinta reais) referente ao dia da capacitação;

- $\mathrm{R} \$ 10,00$ (dez reais) por deslocamento a cada aplicação;

- Para cada aplicação será pago o valor de $\mathrm{R} \$$ 75,00, limitado a no máximo UMA turma por período (Matutino e Vespertino ou noturno);

- O pagamento das aplicações será realizado via depósito bancário na conta do aplicador (Banco do Brasil ou caixa econômica federal) pela empresa Cesgranrio.
Das Disposições Finais

- O candidato aplicador que porventura seja Profissional da Rede Estadual ou Municipal de Ensino não terá dispensa de ponto, nem do dia, nem do período, e deve agendar com o Diretor a natureza de sua falta nos termos da legislação vigente (TRE, abonada, justificada, injustificada);

- Por necessidade logística e técnica, o Aplicador poderá ser designado a aplicar provas em no mínimo dois períodos e em escolas diferentes (por exemplo: aplicar prova no período da manhã na escola X e no período da tarde na escola $\mathrm{Y}$, e vice versa).

Lembretes:

- O candidato aplicador deverá participar da capacitação em apenas um dos polos. Os candidatos que participarem de mais de um polo não farão jus a dois pagamentos de ajuda de custo;

- Não serão aceitos comprovantes de bancos que não sejam os especificados neste edital;

- Não serão disponibilizados envelopes pardos nem copias reprográficas;

- No local da capacitação não serão disponibilizados computadores para a realização de cadastros no site da Cesgranrio. 


\section{ANEXO D - O Critério Brasil de nível socioeconômico}

O Critério Brasil (CB) é um mecanismo de estimativa do nível socioeconômico (NSE) de domicílios, proposto e atualizado anualmente pela Associação Brasileira de Empresas de Pesquisa (ABEP).

Mediante questionário que afere a posse ou uso de serviços (Tabela 15), assim como o grau de instrução do chefe de família (Tabela 16), uma pontuação de 0 a 46 é atribuída ao respondente.

Tabela 15 - Pontuação por posse de itens e serviços - Critério Brasil 2013

\begin{tabular}{|c|c|c|c|c|c|}
\hline Número de itens ou serviços possuídos & 0 & 1 & 2 & 3 & $4 \mathrm{ou}+$ \\
\hline \multicolumn{6}{|l|}{ Pontos atribuídos } \\
\hline Televisão em cores & 0 & 1 & 2 & 3 & 4 \\
\hline Rádio & 0 & 1 & 2 & 3 & 4 \\
\hline Banheiro & 0 & 4 & 5 & 6 & 7 \\
\hline Automóvel & 0 & 4 & 7 & 9 & 9 \\
\hline Empregada mensalista & 0 & 3 & 4 & 4 & 4 \\
\hline Máquina de lavar & 0 & 2 & 2 & 2 & 2 \\
\hline Videocassete e/ou DVD & 0 & 2 & 2 & 2 & 2 \\
\hline Geladeira & 0 & 4 & 4 & 4 & 4 \\
\hline Freezer (independente ou parte da geladeira duplex) & 0 & 2 & 2 & 2 & 2 \\
\hline
\end{tabular}

Fonte: ABEP (2013).

Tabela 16 - Pontuação por instrução do chefe de família - Critério Brasil 2013

\begin{tabular}{lc}
\hline Instrução & Pontos \\
\hline Analfabeto/ Fundamental 1 Incompleto & 0 \\
Fundamental 1 Completo/ Fundamental 2 Incompleto & 1 \\
Fundamental 2 Completo/ Médio Incompleto & 2 \\
Médio Completo/ Superior Incompleto & 4 \\
Superior Completo & 8 \\
\hline
\end{tabular}

Fonte: ABEP (2013).

Em função desta pontuação, uma classificação agrupada em classes socioeconômicas é obtida (Tabela 17). 
Tabela 17 - Nível socioeconômico por pontuação - Critério Brasil 2013

\begin{tabular}{lc}
\hline Pontos atribuídos & Classe de NSE \\
\hline $42 \leq$ pontos $\leq 46$ & $\mathrm{~A} 1$ \\
$35 \leq$ pontos $\leq 41$ & $\mathrm{~A} 2$ \\
$29 \leq$ pontos $\leq 34$ & $\mathrm{~B} 1$ \\
$23 \leq$ pontos $\leq 28$ & $\mathrm{~B} 2$ \\
$18 \leq$ pontos $\leq 22$ & $\mathrm{C} 1$ \\
$14 \leq$ pontos $\leq 17$ & $\mathrm{C} 2$ \\
$8 \leq$ pontos $\leq 13$ & $\mathrm{D}$ \\
$0 \leq$ pontos $\leq 7$ & $\mathrm{E}$ \\
\hline
\end{tabular}

Fonte: ABEP (2013).

Os questionários contextuais usados no Saeb 2013 têm perguntas aderentes ao Critério Brasil 2013, o que torna a aplicação do critério direta ${ }^{1}$.

1 Isto nem sempre foi o caso. Os questionários do Saeb 2011 tinham diferenças na contagem de itens que descolavam do CB 2011. 
Apêndices 



\section{APÊNDICE A - Descrição da abordagem de Jacob e Levitt para análise de fraudes}

O modelo original proposto por Jacob e Levitt usou dois índices distintos para sinalizar a possibilidade de fraude docente. O primeiro índice reflete, para um ano $t$ de avaliação, resultados de proficiência sem sustentação: no ano $t$ há um expressivo ganho para uma dada classe avaliada quando comparado ao ano anterior $t-1$, havendo manutenção ou queda da proficiência no ano final $t+1$. Constrói-se:

$$
S C O R E=\left(\text { ganhorank }_{t}\right)^{2}+\left(1-\text { ganhorank }_{t+1}\right)^{2}
$$

onde ganhorank é a variação do percentil das proficiências médias de uma dada classe para uma dada disciplina de um ano para o ano seguinte.

No racional dos autores, quanto maior o SCORE resultar, para uma dada classe e disciplina avaliada, maior a probabilidade desta classe ter sido sujeita a fraude docente. Jacob e Levitt sugerem olhar com maior atenção as classes com o SCORE situado acima do percentil $95 \%$, lembrando que estar entre os $5 \%$ superiores não é garantia de ter ocorrido fraude. Na base de dados original usada pelos autores em seu estudo longitudinal, a progressão das classes no tempo era verificável pela identificação das turmas e classes, comparáveis ano a ano.

Um segundo índice, $A N S W E R S$, visa a identificar padrões improváveis de resposta e foi computado como a soma dos quadrados dos rankings percentuais de quatro medidas intermediárias, $M_{1}, M_{2}, M_{3}$ e $M_{4}$. Cada uma das medidas intermediárias busca identificar um aspecto específico da fraude docente, conforme descrito a seguir. As fórmulas para cômputo destas métricas estão descritas no apêndice do trabalho de Jacob e Levitt (2003b, p. $872-875)$.

- $M_{1}$ busca encontrar respostas improváveis ocorrendo em trechos contíguos nos vetores de resposta (os autores usaram a faixa de 3 a 7 itens). Quanto maior a incidência de respostas similares, ao longo de tanto mais posições, menor resulta $M_{1}$;

- $M_{2}$ mede a correlação em respostas ao longo da prova, especialmente para respostas inesperadas, dado que fraudes na aplicação levarão a uma maior correlação nas respostas de alunos;

- $M_{3}$ mede a variância no grau de correlação entre itens respondidos. $M_{2}$ pode acusar uma sinalização falsa, caso o professor tenha estressado um determinado aspecto 
do currículo, logo, $M_{3}$ visa a complementar o encontrado em $M_{2}$. Se um fraudador alterar um mesmo conjunto de respostas para um grupo de alunos em questões determinadas, a correlação na turma destas questões será altíssima, enquanto a correlação nas demais questões será típica;

- $M_{4}$ compara as respostas de alunos de uma turma contra os demais alunos de proficiência similar em toda a amostra. Esta métrica visa detectar alunos que tenham acertado questões difíceis e errado questões fáceis, indicando possível influência de um fraudador no registro das respostas.

Uma vez computados $M_{1}$ a $M_{4}$ e o índice $A N S W E R S$ resultante, em linha com o sugerido pelos autores, os casos acima do percentil 95\% são identificados como classes com possível fraude. Levitt e Jacob encontraram associação positiva entre a incidência de fraudes e desempenho fraco em avaliação anterior, com a existência de contextos high-stakes, com a proporção de alunos cuja nota contava para a média da escola (versus a proporção de alunos com necessidades especiais ou oficialmente não contados para fins de accountability).

Caso o Inep implemente data masking de identificadores ${ }^{1}$ de alunos e professores, nos seus microdados públicos, seria possível construir datasets sem revelar a identidade dos alunos. Isto abriria a possibilidade de realizar estudos longitudinais e em particular, suportar pesquisas como as realizadas por Jacob e Levitt para fraudes.

1 O data masking é um embaralhamento de um campo de uma base de dados que permite mascarar, de maneira consistente, seu valor, criptograficamente. Só quem conhece a chave usada na encriptação consegue associar o valor embaralhado ao seu estado original. O Inep conheceria esta chave, os pesquisadores, não. Estes últimos teriam um identificador consistente mas único para acompanhar a trajetória dos avaliados, entre escolas e anos. 


\section{APÊNDICE B - O polinômio interpolador}

A função densidade de probabilidade (FDP) da distribuição normal $(\Phi(t))$, acumulada de $-\infty$ até um dado $t$ é:

$$
\Phi(t)=\int_{-\infty}^{t} \frac{1}{\sigma \sqrt{2 \pi}} e^{-\frac{(z-\mu)^{2}}{2 \sigma^{2}}} d z
$$

Lembrando que

$$
\frac{F}{\alpha+\beta}=\frac{P}{\beta}
$$

e que

$$
F=\frac{P}{1-\alpha}
$$

pode-se definir $\alpha$ por meio da equação B.4, simplificando com o uso da distribuição normal padronizada, com a média $\mu=0$ e desvio padrão $\sigma=1$.

$$
\alpha=\int_{-\infty}^{z_{c}} \frac{1}{\sqrt{2 \pi}} e^{-\frac{z^{2}}{2}} d z
$$

Esta equação, com sua integral imprópria, não tem solução algébrica. O desafio de encontrar $\alpha$ é resolvido com auxílio de um polinômio interpolador, artifício que identifica caudas esquerdas sub-representadas nas distribuições de proficiência. A equação B.4 também poderia ser expandida por séries de Taylor como ilustram Abramowitz e Stegun (1964) ou com uma abordagem mais moderna proposta por George Marsaglia (2004), de trabalhosa manipulação, resolvendo a equação B.5.

$$
\Phi\left(z_{\text {trunc }}\right)=1-2 \cdot \Phi\left(m_{\text {trunc }}\right)
$$

em que $z_{\text {trunc }}$ é a localização do truncamento e $m_{\text {trunc }}$ é a mediana observada.

Em vez de resolver analiticamente as equações acima, simulações no pacote estatístico foram construídas, simulando truncamentos de porcentagens crescentes de alunos de baixa proficiência. Para cada uma das $M=5000$ simulações realizadas, uma amostra de $N=5 \cdot 10^{6}$ valores $x$ normalmente distribuídos foi truncada à esquerda excluindo os $N \cdot p_{i}$ valores mais baixos, onde $\epsilon \leq p_{i} \leq 1-\epsilon$, para $1 \leq i \leq M$ e $\epsilon$ arbitrariamente pequeno, adotado como $\epsilon=10^{-7}$.

Cada amostragem truncada resultante é padronizada por meio da transformação $x_{\text {trunc }}=(x-\mu) \div \sigma$, de maneira a assegurar que a média e desvio padrão pós-truncamento 
sejam $\mu_{\text {trunc }}=0$ e $\sigma_{\text {trunc }}=1$, respectivamente. Para a amostragem normalizada resultante, é estimada a mediana $m_{\text {trunc }}$, a qual resulta negativa, dado o truncamento à esquerda. Quanto mais negativa esta mediana for, nas observações padronizadas nos dados da Prova Brasil, maior terá sido a fração de alunos de baixa proficiência removidos, sendo os resultados da simulação prévia o mecanismo para estimar a exclusão ocorrida.

O polinômio obtido por regressão polinomial $^{1}$ no pacote estatístico STATA é:

$$
\begin{gathered}
\alpha=207671,3 m^{8}+198471,9 m^{7}+79086,79 m^{6}+17001,65 m^{5}+ \\
2217,049 m^{4}+169,0341 m^{3}+14,25438 m^{2}-0,4904603+\text { resíduo }
\end{gathered}
$$

onde $\alpha$ é a fração excluída de alunos de baixa proficiência e $m$ é a mediana das proficiências padronizadas observadas para um dado agrupamento de alunos.

A relação entre a fração de excluídos e a mediana da distribuição normal truncada está representada na Figura 57, assim como o comportamento dos resíduos de regressão. Os resíduos são normalmente distribuídos, têm média próxima de zero e são relativamente estáveis, com $\mid$ resíduo $\mid \leq 0,0001$, um centésimo de um ponto percentual. Este polinômio é usado para estimar a fração excluída $\alpha$ para cada grupo de interesse e sua mediana estimada.

Figura 57 - Polinômio interpolador e sua capacidade preditiva
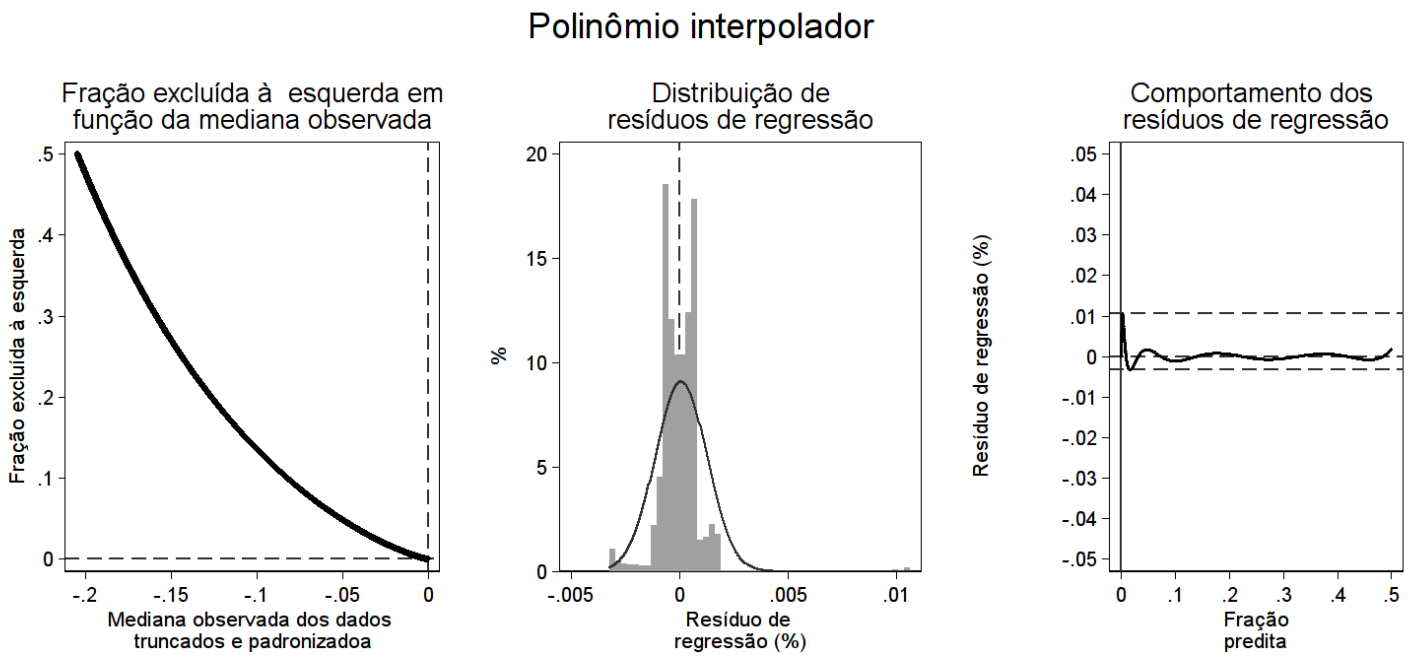

polinomio

Fonte: Elaboração do autor.

1 O coeficiente do termo em $m$ é nulo 


\section{APÊNDICE C - Fluxogramas descritivos}

A Figura 58 sintetiza a abordagem empregada para estimar as taxas de ausências não aleatórias na Prova Brasil. Como dados de entrada, são necessárias as proficiências LP e MT por aluno avaliado, as variáveis que caracterizam as escolas e os alunos quanto às suas participações ou ausências e os FLAGs usados para agrupamento. Os resultados decorrentes são as taxas de exclusão $t_{E_{x}}$ por agrupamento e as variáveis qualificadoras destes agrupamentos, para tratamento nos modelos hierárquicos e preparação de gráficos.

A Figura 59 sumariza a abordagem para estimar as incidências de fraudes ingênuas por escola, na Prova Brasil. Como insumos, são usados os gabaritos dos itens constantes nas provas e suas inclusões nos blocos, as marcações registradas nos cadernos de resposta, as tipificações destes cadernos designados a cada aluno, além das qualificações das escolas, como rede, município, localidade e FLAGs associados. Também é um insumo definido previamente o nível de confiança empregado para qualificar uma ocorrência anormal de frequência de blocos maximizadores impróprios como indicativa de fraude, adotado arbitrariamente como $95 \%\left(\alpha_{\text {crit }}=0,05\right)$.

Os resultados são as marcações, por escola, série/ano avaliado, disciplina e ano de aplicação da Prova Brasil, dos indicadores "fracos" e "fortes" de fraude, para a geração de gráficos e análise com modelos hierárquicos lineares.

A Figura 60 resume o relacionamento entre as fontes de dados empregadas e as análises propostas e descritas no capítulo Métodos e abordagens propostos à página 68 . À esquerda na figura, estão as fontes de dados usadas: microdados do Saeb (que incluem a Prova Brasil) de 2013 e 2015 e resultados históricos do Ideb, todos públicos e disponíveis no sítio do Inep.

Como etapas preparatórias estão a simulação de truncamentos, empregada para construir o polinômio de interpolação para estimar a taxa de excluídos em função da forma da curva de distribuição de proficiências (página 204) e a codificação das políticas estaduais de bonificação do Quadro 5 (página 80).

No centro da Figura 60, está representada a etapa de codificação dos FLAGs, que cria as covariantes explicativas para as duas análises principais e de agrupamento, de exclusão de alunos e de incidência de fraudes ingênuas. Os resultados da aplicação das abordagens, à direita, são usados para popular os modelos de regressão multinível e preparar gráficos descritivos. 


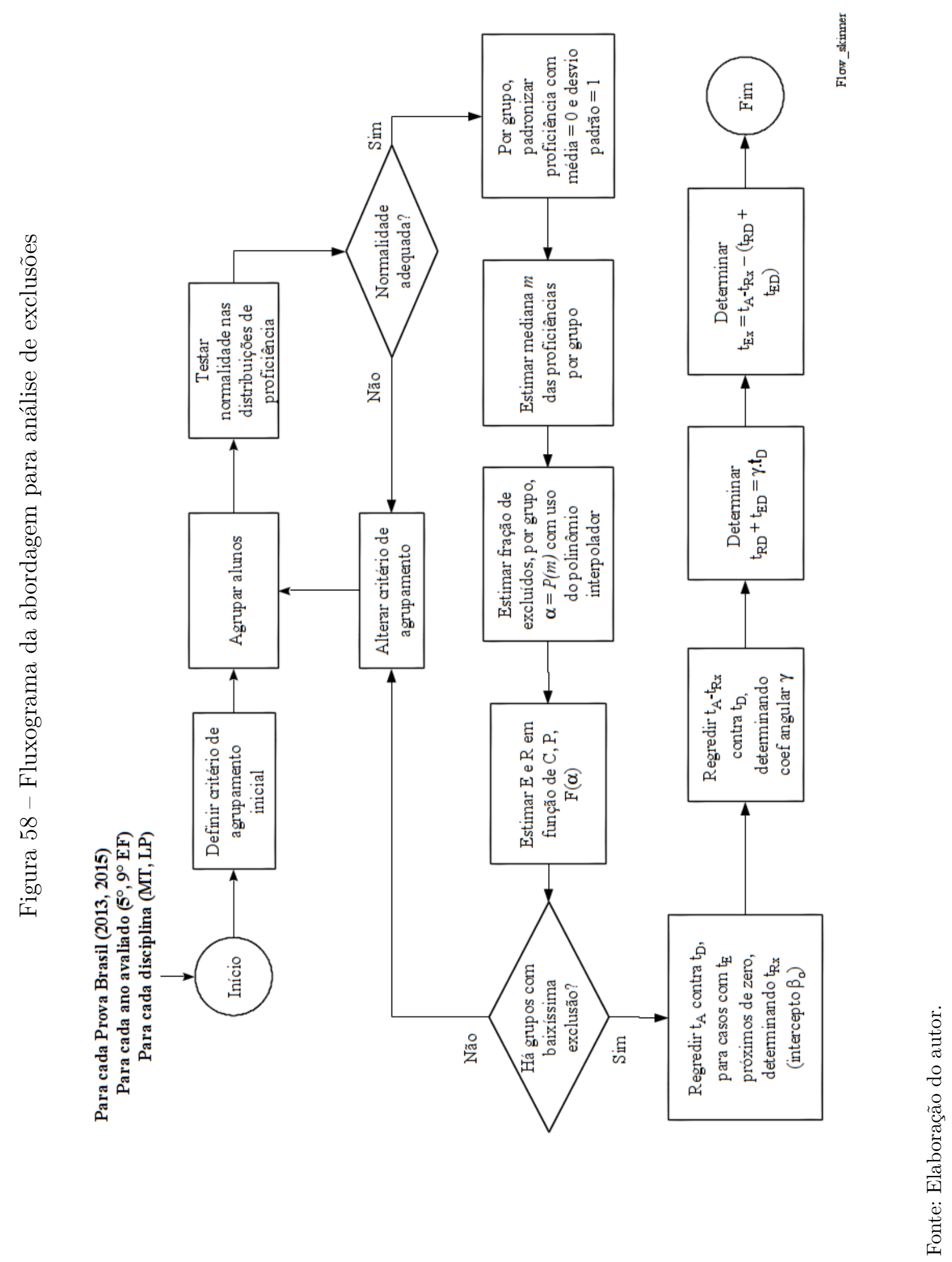




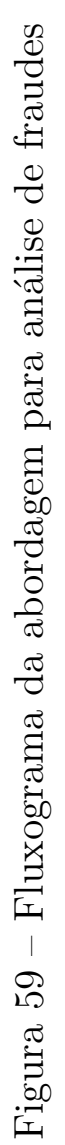

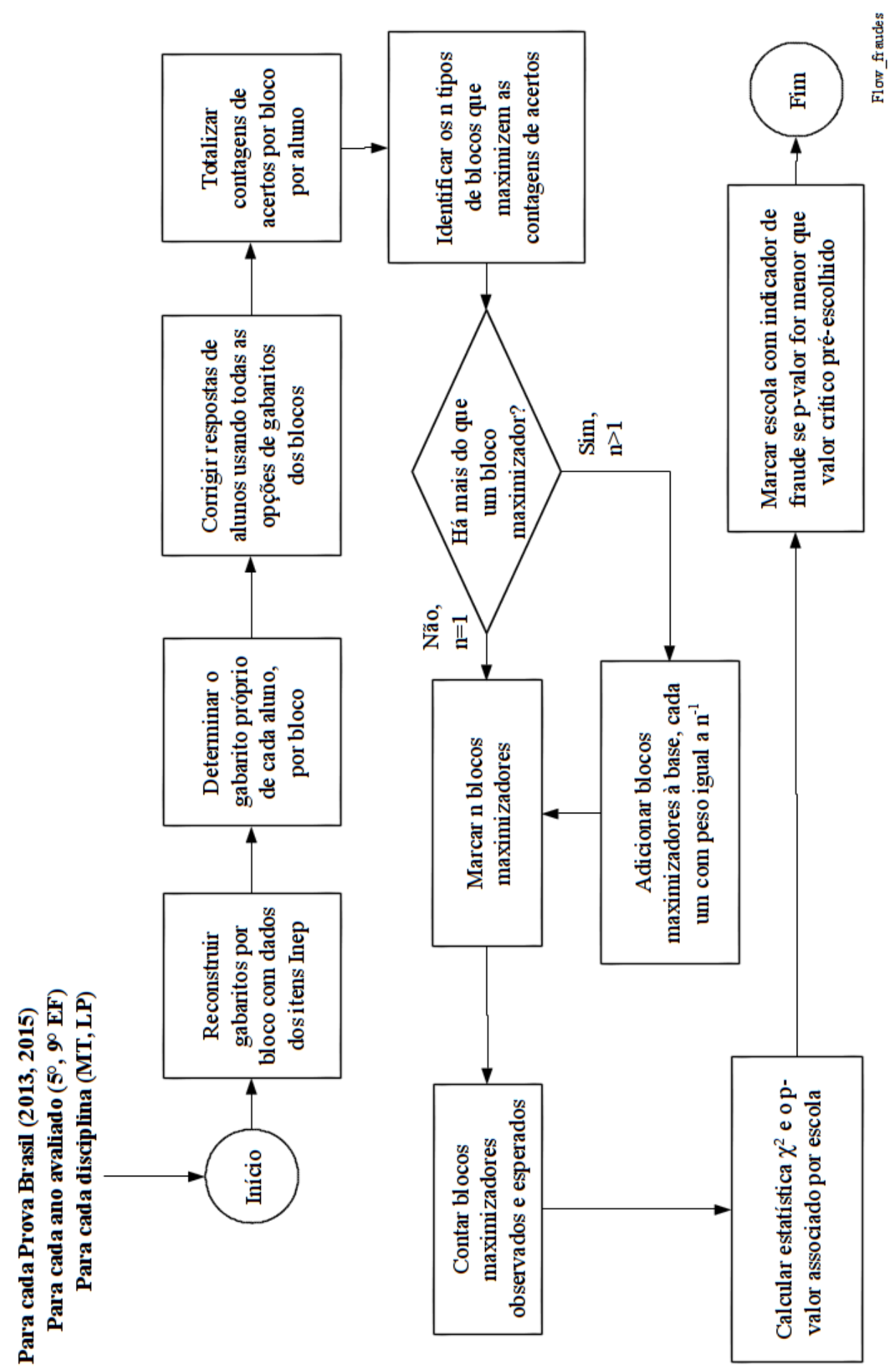




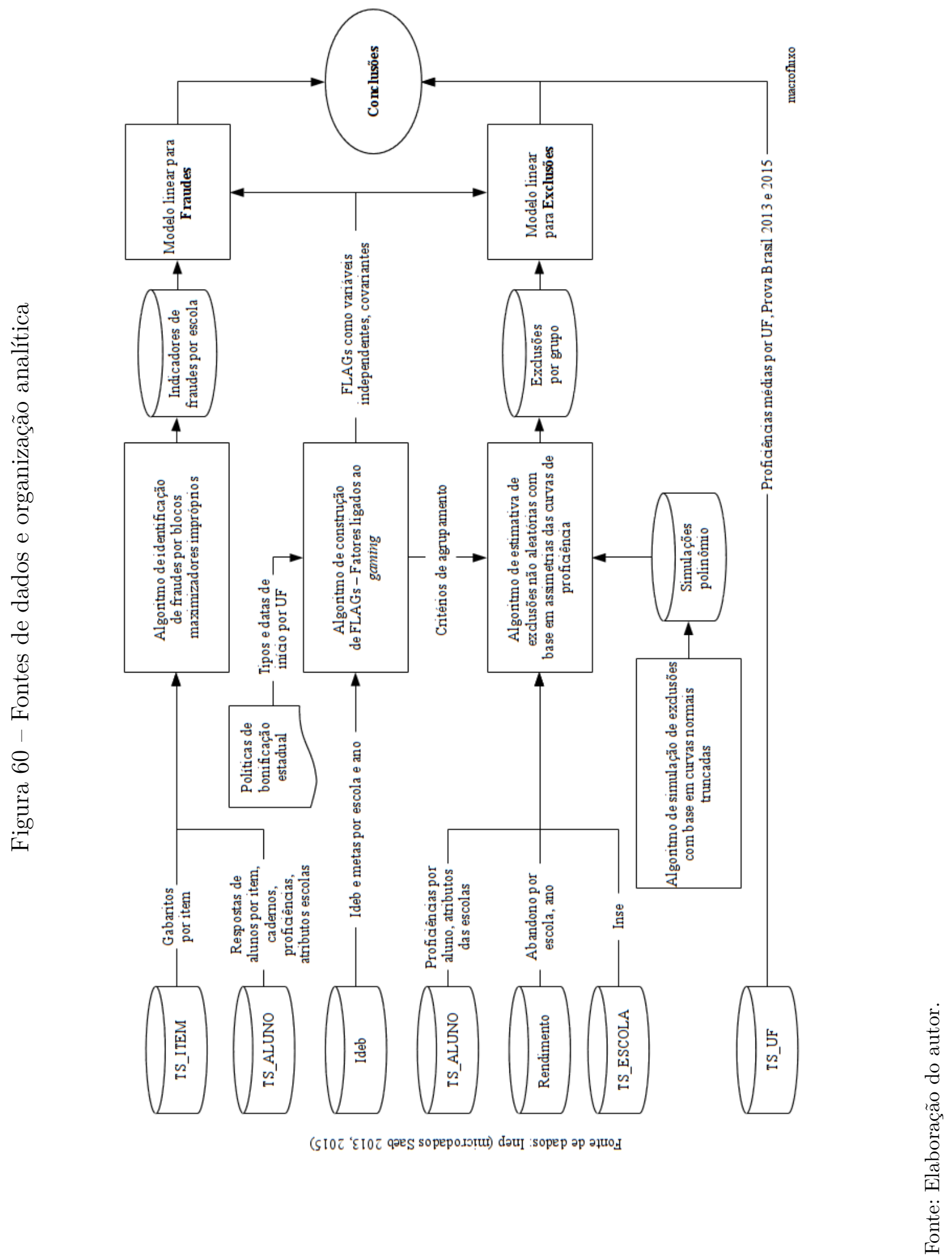




\section{APÊNDICE D - As tecnologias utilizadas neste estudo}

Este apêndice elenca as ferramentas informáticas usadas na captura, análise e triagem da bibliografia e dos dados, bem como na produção do documento final.

\section{Tratamento bibliográfico}

Para o levantamento bibliográfico, foi usada a ferramenta Zotero 4.0.29.10 ${ }^{1}$, da Universidade George Mason, um add-on do navegador Firefox ${ }^{2}$. Esta ferramenta livre permite tanto a captura automática de fontes online de textos quanto a inserção manual de dados bibliográficos de livros impressos consultados. Além de consolidar o corpo de literatura em ambiente protegido por backups, permite o acesso seguro a todo o corpo coletado a partir de qualquer estação de trabalho conectada à internet, mediante conta e senha. O Zotero permite a extração automatizada de metadados dos arquivos PDFs (desde que estes não sejam trancados por senhas), além da indexação de palavras e expressões dos textos, o "tagging" por identificadores e a inclusão de anotações em formato livre.

O fichamento dos textos se deu com o suporte do add-on livre ZotFile ${ }^{3}$ para Zotero, que permite extrair anotações e grifos associados aos arquivos PDF coletados, de maneira organizada. Para leitura e anotações, usou-se o visualizador de PDFs Okular ${ }^{4}$, livre, que se integra bem com as demais ferramentas.

O pós-processamento dos registros bibliográficos foi feito com o software livre JabRef $3.8 .2^{5}$, intermediado pelo exportador add-on Zotero Automatic Export ${ }^{6}$, para facilitar a integração com o $\mathbf{I}_{\mathbf{E}} \mathbf{X}$, descrito abaixo.

\section{Edição de textos}

O ambiente de type setting $\mathbf{H}_{\mathbf{E}} \mathbf{X}^{7}$, livre, pronunciado "latec", foi usado para a criação deste documento, com auxílio do pacote abnTeX2 1.9.6 (ARAUJO, 2015) ${ }^{8}$ com

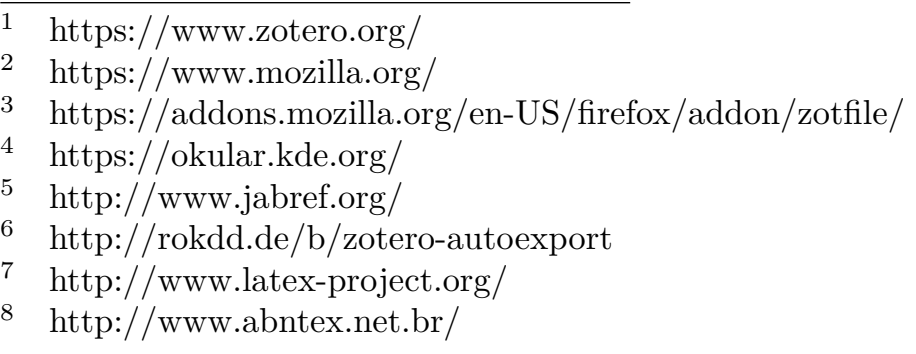


modificações para tornar o texto compatível com as diretrizes da Universidade de São Paulo, atualizadas em (PESTANA et al., 2016). Como ambiente integrado de desenvolvimento, usou-se o LaTeXila 2.10.1 para GNU/Linux ${ }^{9}$.

\section{Processamento dos dados}

Para o tratamento de dados foi usado o pacote estatístico STATA para Windows, único software não-livre usado neste trabalho ${ }^{10}$, nas suas versões 13 e 14, para processamento em até 8 CPUs simultâneas, em ambiente emulado Wine 1.6 de 64 bits $^{11}$, sobre o sistema operacional Linux Mint ${ }^{12}$, nas suas versões 17.3 "Rosa" e 18 "Sarah". A característica multi-CPU do STATA foi muito importante nas análises preliminares de seleção de modelos, pois permitiu executar em horas o que teria levado dias, na versão "single-core". Foram empregadas mais de cinco mil linhas de código fonte STATA, para tratamento dos dados brutos, processamento dos modelos de identificação, simulação, análise, geração de gráficos e de tabelas de suporte.

A adoção de um pacote estatístico programável permitiu documentar e replicar as análises, apesar de apresentar uma curva bastante íngreme de aprendizado. A escolha do STATA sobre o $\mathbf{R}^{13}$, software livre usado nas análises preliminares, se deu com o objetivo de ganhar proficiência para conclusão de uma das disciplinas cursadas para obtenção de créditos-aula ${ }^{14}$.

O ambiente de desenvolvimento computacional usado neste trabalho foi construído para permitir a integração dos resultados obtidos no processamento estatístico diretamente nos textos editáveis do documento final: tanto tabelas quanto figuras geradas no STATA foram incluídas automaticamente na compilação do ${ }^{A} \mathrm{~T}_{\mathrm{E}} \mathrm{X}$. Esta integração se deu com o compartilhamento em espaços virtuais de armazenamento de dados, DropBox ${ }^{15}$, permitindo a criação automática de backups e possibilitando que o trabalho fosse desenvolvido em computadores diferentes, sempre usando as versões mais atualizadas dos arquivos de trabalho.

\footnotetext{
9 https://wiki.gnome.org/Apps/LaTeXila

10 http://www.stata.com/

11 https://www.winehq.org/

12 https://www.linuxmint.com/

13 https://cran.r-project.org/

14 Pacotes - estout- e - esttab- disponíveis para o STATA foram usados para gerar código fonte $\mathbf{I A T}_{\mathbf{E}} \mathbf{X}$ diretamente a partir do pacote estatístico e incluídos no corpo da dissertação, evitando etapas de copiar e colar, usualmente sujeitas a erros e omissões. Os gráficos gerados em padrão PNG pelo STATA foram empregados com pouca ou nenhuma edição adicional diretamente no ambiente $\mathbf{I A T}_{\mathbf{E}} \mathbf{X}$.

15 https://www.dropbox.com
} 


\section{Outras ferramentas}

Para monitorar periodicamente o sítio de internet do Inep, visando obter notificações de atualização de microdados, foi usado o add-on Update Scanner ${ }^{16}$ para o Firefox.

Para criar cópias offline de sítios inteiros, para fins de coleta e extração de dados e documentação, foi usado o HTTrack ${ }^{17}$, que com moderação e sem abusos, permite pôr ordem em repositórios online com sérios problemas de curadoria ou organização de dados, sem infringir políticas de uso nem sobrecarregar conexões de acesso.

Para particionar arquivos de microdados gigantes em partes menores, para fins de pré-processamento e prototipagem, usou-se a linguagem $\mathbf{A} \mathbf{W} \mathbf{K}^{18}$. É uma ferramenta útil para pesquisadores interessados em tratar microdados extensos em equipamento com limitações de memória. Com quase 40 anos de vida, a linguagem AWK é antiga, mas está longe de ser obsoleta. Abaixo, está um exemplo de um programa AWK de poucas linhas usado para extrair dados referentes a um único município de um conjunto muito maior.

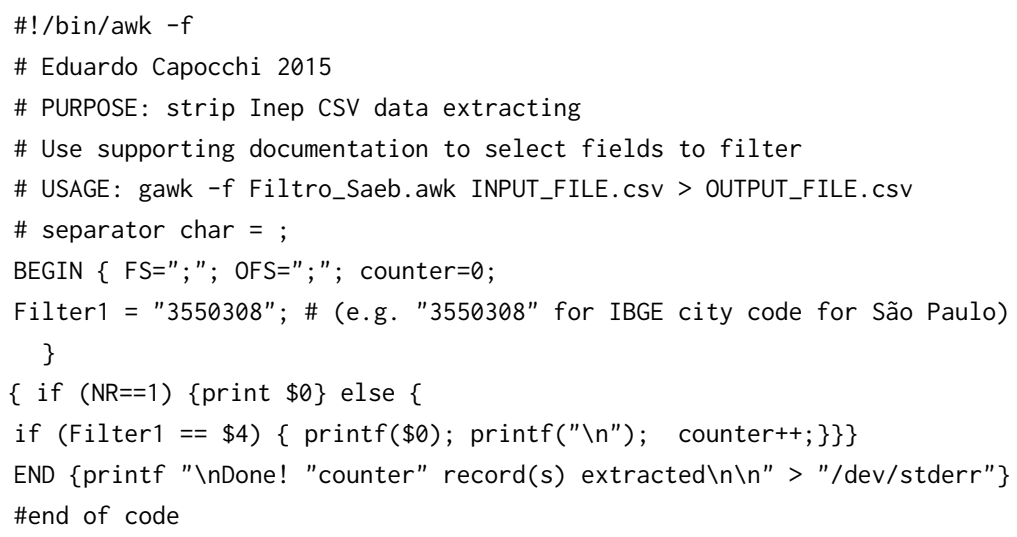

Um outro exemplo prático do uso do AWK está no script abaixo, que formata adequadamente as datas de acesso a URLs, conforme o requerido pela ABNT ("Acesso em: 2015-11-02" convertido para "Acesso em: 2 nov. 2015”). Infelizmente, há uma incompatibilidade entre a exportação do Zotero quanto à nomenclatura adotada pelo JabRef para designar os endereços de internet (URLs), também corrigido pelo script abaixo.

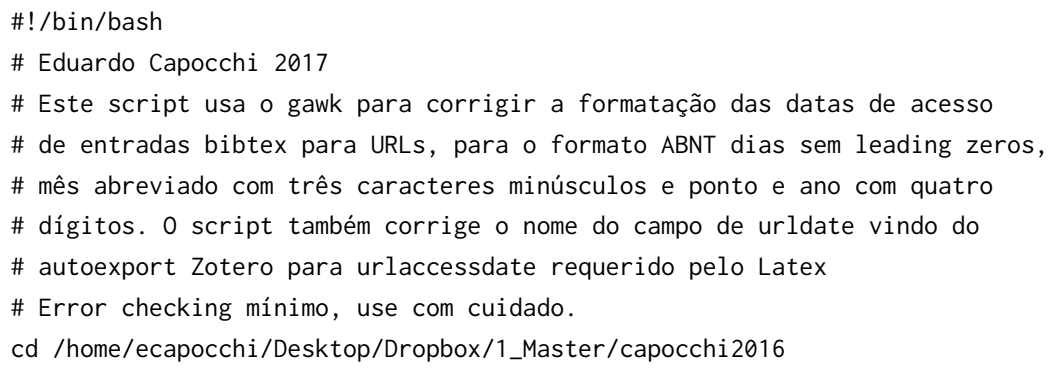

16 http://www.peteburgers.tk/updatescanner/

17 http://www.httrack.com/

18 http://www.cs.princeton.edu/ bwk/btl.mirror/ 
awk 'function $\operatorname{ltrim}(s)\left\{\operatorname{sub}\left(/^{\wedge}[\backslash t \backslash r \backslash n]+/, " n, s\right)\right.$; return $\left.s\right\}$

function $\operatorname{rtrim}(s)\{\operatorname{sub}(/[\backslash t \backslash r \backslash n]+\$ /, " n, s)$; return $s\}$

function $\operatorname{trim}(s)$ \{return $\operatorname{rtrim}(\operatorname{ltrim}(\mathrm{s})) ;\}$

BEGIN $\{$ FS $="="$; conta $=0 ;\}$

$\{$ linha $=\$ 0$;

if $(\operatorname{trim}(\$ 1)==$ "urlaccessdate" || $\operatorname{trim}(\$ 1)==$ "urldate" ) \{

data $=\operatorname{substr}(\operatorname{substr}(\operatorname{trim}(\$ 2), 0,11), 2,11)$;

separador $="-" ; n=$ split (data, array, separador);

if $(n !=3)$ \{ print "Erro:Datas no formato YYYY-MM-DD?" > "/dev/stderr"; exit; \}

ano $=\operatorname{trim}(\operatorname{array}[1])$;

if $\left(\operatorname{substr}(\operatorname{trim}(\operatorname{array}[3]), 1,1)==" 0^{\prime \prime}\right)\{$ dia $=\operatorname{substr}(\operatorname{trim}(\operatorname{array}[3]), 2,1) ;\}$

else $\{$ dia $=\operatorname{array}[3] ;\}$

mes $=$ "jan."

if $(\operatorname{trim}(\operatorname{array}[2])==" 01 ")\{$ mes $=$ "jan." $\}$

if $(\operatorname{trim}(\operatorname{array}[2])==" 02 ")\{$ mes $=$ "fev." $\}$

if $(\operatorname{trim}(\operatorname{array}[2])==" 03 ")\{$ mes $=$ "mar." $\}$

if $(\operatorname{trim}(\operatorname{array}[2])==" 04 ")\{$ mes $=$ "abr." $\}$

if $(\operatorname{trim}(\operatorname{array}[2])==" 05 ")\{$ mes = "mai." $\}$

if $(\operatorname{trim}(\operatorname{array}[2])==" 06 ")\{$ mes $=$ "jun." $\}$

if $(\operatorname{trim}(\operatorname{array}[2])==" 07 ")\{$ mes $="$ jul. $"$ \}

if $(\operatorname{trim}(\operatorname{array}[2])==" 08 ")\{$ mes = "ago." $\}$

if $(\operatorname{trim}(\operatorname{array}[2])==09 ")\{$ mes = "set." $\}$

if $(\operatorname{trim}(\operatorname{array}[2])==" 10 ")\{$ mes $=$ "out." $\}$

if $(\operatorname{trim}(\operatorname{array}[2])==" 11 ")\{$ mes $=$ "nov." $\}$

if $(\operatorname{trim}(\operatorname{array}[2])==" 12 ")\{$ mes $=$ "dez." \}

print "\turlaccessdate $=\{$ "dia" "mes" "ano" $\}$,"; conta++;

\} else \{print linha\}\}

END \{print conta" datas convertidas." > "/dev/stderr";\}' < capocchi2016.bib > output.bib cp output.bib capocchi2016.bib

rm output.bib 


\section{APÊNDICE E - Síntese das variáveis de modelagem linear}

As Tabelas 18 e 19 sintetizam. respectivamente, as variáveis dependentes e independentes usadas nos modelos hierárquicos lineares para análise das exclusões não aleatórias de alunos de baixa proficiência e de indicadores fortes e fracos de incidência de fraudes.

Tabela 18 - Resumo de variáveis de modelagem para a exclusão

\begin{tabular}{|c|c|c|c|c|c|c|c|c|c|c|}
\hline \multicolumn{11}{|l|}{ EXCLUSÕES } \\
\hline & \multicolumn{10}{|c|}{2013} \\
\hline & \multicolumn{5}{|c|}{$5^{\mathrm{o}}$ Ano } & \multicolumn{5}{|c|}{$9^{\mathrm{o}}$ Ano } \\
\hline & Obs & Média & $\mathrm{DP}$ & Min & Max & Obs & Média & DP & Min & Max \\
\hline tEx (Matemática) & 1790 & 0,053 & 0,065 & 0,000 & 0,413 & 1825 & 0,029 & 0,061 & 0,000 & 0,414 \\
\hline tEx (Língua Portuguesa) & 1790 & 0,081 & 0,071 & 0,000 & 0,377 & 1825 & 0,035 & 0,064 & 0,000 & 0,459 \\
\hline RURAL & 1790 & 0,335 & 0,472 & 0,000 & 1,000 & 1825 & 0,338 & 0,473 & 0,000 & 1,000 \\
\hline ESTADUAL & 1790 & 0,391 & 0,488 & 0,000 & 1,000 & 1825 & 0,501 & 0,500 & 0,000 & 1,000 \\
\hline PROF_BASED & 1790 & 0,412 & 0,492 & 0,000 & 1,000 & 1825 & 0,416 & 0,493 & 0,000 & 1,000 \\
\hline BASE_AVAL_PROP & 1790 & 0,336 & 0,472 & 0,000 & 1,000 & 1825 & 0,347 & 0,476 & 0,000 & 1,000 \\
\hline BASE_IDEB_PB & 1790 & 0,160 & 0,367 & 0,000 & 1,000 & 1825 & 0,142 & 0,350 & 0,000 & 1,000 \\
\hline DOSE & 1790 & 2,018 & 2,249 & 0,000 & 5,937 & 1825 & 1,978 & 2,227 & 0,000 & 5,937 \\
\hline ABAIXO_META & 1790 & 0,463 & 0,499 & 0,000 & 1,000 & 1825 & 0,476 & 0,500 & 0,000 & 1,000 \\
\hline QUEDA_IDEB & 1790 & 0,338 & 0,473 & 0,000 & 1,000 & 1825 & 0,366 & 0,482 & 0,000 & 1,000 \\
\hline QUEDA_RANK & 1790 & 0,370 & 0,483 & 0,000 & 1,000 & 1825 & 0,373 & 0,484 & 0,000 & 1,000 \\
\hline IDEB & 1761 & 4,324 & 0,954 & 1,400 & 7,309 & 1785 & 3,676 & 0,763 & 1,200 & 7,300 \\
\hline DELTA & 1727 & 0,163 & 0,510 & $-2,500$ & 3,100 & 1740 & 0,085 & 0,453 & $-1,700$ & 2,000 \\
\hline \multirow[t]{4}{*}{ GAP } & 1733 & 0,043 & 0,552 & $-2,135$ & 2,900 & 1754 & $-0,028$ & 0,502 & $-2,100$ & 2,000 \\
\hline & \multicolumn{10}{|c|}{2015} \\
\hline & \multicolumn{5}{|c|}{$5^{\mathrm{o}}$ Ano } & \multicolumn{5}{|c|}{$9^{\circ}$ Ano } \\
\hline & Obs & Média & DP & Min & $\operatorname{Max}$ & Obs & Média & DP & Min & Max \\
\hline tEx (Matemática) & 1826 & 0,077 & 0,070 & 0,000 & 0,383 & 1868 & 0,052 & 0,069 & 0,000 & 0,453 \\
\hline tEx (Língua Portuguesa)) & 1826 & 0,065 & 0,071 & 0,000 & 0,410 & 1868 & 0,020 & 0,050 & 0,000 & 0,423 \\
\hline RURAL & 1826 & 0,372 & 0,483 & 0,000 & 1,000 & 1868 & 0,372 & 0,483 & 0,000 & 1,000 \\
\hline ESTADUAL & 1826 & 0,358 & 0,480 & 0,000 & 1,000 & 1868 & 0,490 & 0,500 & 0,000 & 1,000 \\
\hline PROF_BASED & 1826 & 0,404 & 0,491 & 0,000 & 1,000 & 1868 & 0,435 & 0,496 & 0,000 & 1,000 \\
\hline BASE_AVAL_PROP & 1826 & 0,326 & 0,469 & 0,000 & 1,000 & 1868 & 0,358 & 0,480 & 0,000 & 1,000 \\
\hline BASE_IDEB_PB & 1826 & 0,166 & 0,372 & 0,000 & 1,000 & 1868 & 0,158 & 0,365 & 0,000 & 1,000 \\
\hline DOSE & 1826 & 2,853 & 3,131 & 0,000 & 7,921 & 1868 & 3,005 & 3,150 & 0,000 & 7,921 \\
\hline ABAIXO_META & 1826 & 0,465 & 0,499 & 0,000 & 1,000 & 1868 & 0,521 & 0,500 & 0,000 & 1,000 \\
\hline QUEDA_IDEB & 1826 & 0,380 & 0,485 & 0,000 & 1,000 & 1868 & 0,374 & 0,484 & 0,000 & 1,000 \\
\hline QUEDA_RANK & 1826 & 0,377 & 0,485 & 0,000 & 1,000 & 1868 & 0,398 & 0,490 & 0,000 & 1,000 \\
\hline IDEB & 1773 & 4,491 & 1,011 & 1,000 & 7,900 & 1831 & 3,820 & 0,779 & 1,400 & 7,000 \\
\hline DELTA & 1713 & 0,091 & 0,491 & $-2,600$ & 2,200 & 1751 & 0,085 & 0,463 & $-2,500$ & 2,300 \\
\hline GAP & 1749 & $-0,016$ & 0,581 & $-2,900$ & 2,200 & 1796 & $-0,169$ & 0,556 & $-2,000$ & 2,000 \\
\hline
\end{tabular}

Fonte: Elaboração do autor. 
Tabela 19 - Resumo de variáveis de modelagem para a fraudes

\begin{tabular}{|c|c|c|c|c|c|c|c|c|c|c|}
\hline \multicolumn{11}{|l|}{ FRAUDES } \\
\hline & \multicolumn{10}{|c|}{2013} \\
\hline & \multicolumn{5}{|c|}{$5^{\mathrm{o}}$ Ano } & \multicolumn{5}{|c|}{$9^{\mathrm{o}}$ Ano } \\
\hline & Obs & Média & DP & Min & Max & Obs & Média & $\mathrm{DP}$ & Min & Max \\
\hline FRACO & 38763 & 0,095 & 0,293 & 0,000 & 1,000 & 30874 & 0,131 & 0,338 & 0,000 & 1,000 \\
\hline FORTE & 38763 & 0,003 & 0,051 & 0,000 & 1,000 & 30874 & 0,001 & 0,038 & 0,000 & 1,000 \\
\hline RURAL & 38763 & 0,170 & 0,375 & 0,000 & 1,000 & 30874 & 0,157 & 0,364 & 0,000 & 1,000 \\
\hline ESTADUAL & 38763 & 0,223 & 0,416 & 0,000 & 1,000 & 30874 & 0,537 & 0,499 & 0,000 & 1,000 \\
\hline PROF_BASED & 38763 & 0,489 & 0,500 & 0,000 & 1,000 & 30874 & 0,514 & 0,500 & 0,000 & 1,000 \\
\hline BASE_AVAL_PROP & 38763 & 0,451 & 0,498 & 0,000 & 1,000 & 30874 & 0,480 & 0,500 & 0,000 & 1,000 \\
\hline BASE_IDEB_PB & 38763 & 0,072 & 0,259 & 0,000 & 1,000 & 30874 & 0,065 & 0,246 & 0,000 & 1,000 \\
\hline DOSE & 38763 & 2,334 & 2,350 & 0,000 & 5,937 & 30874 & 2,461 & 2,356 & 0,000 & 5,937 \\
\hline ABAIXO_META & 38763 & 0,216 & 0,412 & 0,000 & 1,000 & 30874 & 0,306 & 0,461 & 0,000 & 1,000 \\
\hline QUEDA_IDEB & 38763 & 0,163 & 0,370 & 0,000 & 1,000 & 30874 & 0,236 & 0,425 & 0,000 & 1,000 \\
\hline QUEDA_RANK & 38763 & 0,316 & 0,465 & 0,000 & 1,000 & 30874 & 0,297 & 0,457 & 0,000 & 1,000 \\
\hline IDEB & 33501 & 4,768 & 1,068 & 1,200 & 8,600 & 27167 & 3,898 & 0,855 & 0,100 & 7,800 \\
\hline DELTA & 30898 & 0,339 & 0,570 & $-4,700$ & 4,000 & 25085 & 0,184 & 0,542 & $-3,200$ & 3,800 \\
\hline \multirow[t]{4}{*}{ GAP } & 31749 & 0,293 & 0,652 & $-3,900$ & 3,900 & 25628 & 0,106 & 0,605 & $-3,500$ & 3,400 \\
\hline & \multicolumn{10}{|c|}{2015} \\
\hline & \multicolumn{5}{|c|}{$5^{\mathrm{o}}$ Ano } & \multicolumn{5}{|c|}{$9^{\mathrm{o}}$ Ano } \\
\hline & Obs & Média & DP & Min & $\operatorname{Max}$ & Obs & Média & DP & Min & $\operatorname{Max}$ \\
\hline FRACO & 38004 & 0,205 & 0,404 & 0,000 & 1,000 & 29455 & 0,264 & 0,441 & 0,000 & 1,000 \\
\hline FORTE & 38004 & 0,009 & 0,093 & 0,000 & 1,000 & 29455 & 0,002 & 0,044 & 0,000 & 1,000 \\
\hline RURAL & 38004 & 0,166 & 0,372 & 0,000 & 1,000 & 29455 & 0,156 & 0,363 & 0,000 & 1,000 \\
\hline ESTADUAL & 38004 & 0,205 & 0,404 & 0,000 & 1,000 & 29455 & 0,526 & 0,499 & 0,000 & 1,000 \\
\hline PROF_BASED & 38004 & 0,483 & 0,500 & 0,000 & 1,000 & 29455 & 0,523 & 0,499 & 0,000 & 1,000 \\
\hline BASE_AVAL_PROP & 38004 & 0,445 & 0,497 & 0,000 & 1,000 & 29455 & 0,488 & 0,500 & 0,000 & 1,000 \\
\hline BASE_IDEB_PB & 38004 & 0,072 & 0,259 & 0,000 & 1,000 & 29455 & 0,065 & 0,247 & 0,000 & 1,000 \\
\hline DOSE & 38004 & 3,350 & 3,302 & 0,000 & 7,921 & 29455 & 3,634 & 3,307 & 0,000 & 7,921 \\
\hline ABAIXO_META & 38004 & 0,286 & 0,452 & 0,000 & 1,000 & 29455 & 0,473 & 0,499 & 0,000 & 1,000 \\
\hline QUEDA_IDEB & 38004 & 0,223 & 0,416 & 0,000 & 1,000 & 29455 & 0,272 & 0,445 & 0,000 & 1,000 \\
\hline QUEDA_RANK & 38004 & 0,316 & 0,465 & 0,000 & 1,000 & 29455 & 0,308 & 0,462 & 0,000 & 1,000 \\
\hline IDEB & 33044 & 4,933 & 1,172 & 0,400 & 9,000 & 26307 & 3,971 & 0,868 & 0,300 & 7,900 \\
\hline DELTA & 29618 & 0,198 & 0,574 & $-3,800$ & 3,500 & 23961 & 0,126 & 0,551 & $-2,900$ & 3,500 \\
\hline GAP & 31765 & 0,181 & 0,716 & $-3,400$ & 5,100 & 25243 & $-0,164$ & 0,662 & $-3,700$ & 3,300 \\
\hline
\end{tabular}

Fonte: Elaboração do autor.

As colunas indicam os nomes das variáveis à esquerda, o número de observações (Obs), o valor médio da variável (Média), o desvio padrão (DP), o valor mínimo observado (Min) e o valor máximo observado (Max).

Para as exclusões, as observações da Tabela 18 correspondem a agrupamentos de análise escolhidos, com base na UF, rede, localização, características das dummies resultantes dos FLAGs, como descrito em rodapé à página 94. O número de observações se apresenta reduzido quando há Ideb ou metas associadas faltantes. Na Tabela 19, relativa à análise des fraudes, as observações se referem a escolas. Aqui também, números reduzidos de observações refletem lacunas nas variáveis de origem associadas ao Ideb. 